UNIVERSIDADE DE SÃO PAULO

FACULDADE DE ECONOMIA, ADMINISTRAÇÃO E CONTABILIDADE DEPARTAMENTO DE ECONOMIA PROGRAMA DE PÓS-GRADUAÇÃo EM ECONOMIA

ENSAIOS SOBRE A REDUÇÃO DA POBREZA NO BRASIL:

MENSURAÇÃO E DETERMINANTES

Henrique Eduardo Ferreira Vinhais

Orientador: Prof. Dr. André Portela Fernandes de Souza 
Profa. Dra. Suely Vilela

Reitora da Universidade de São Paulo

Prof. Dr. Carlos Roberto Azzoni

Diretor da Faculdade de Economia, Administração e Contabilidade

Prof. Dr. Joaquim José Martins Guilhoto

Chefe do Departamento de Economia

Prof. Dr. Dante Mendes Aldrighi

Coordenador do Programa de Pós-Graduação em Economia 
HENRIQUE EDUARDO FERREIRA VINHAIS

\section{ENSAIOS SOBRE A REDUÇÃO DA POBREZA NO BRASIL: MENSURAÇÃO E DETERMINANTES}

Dissertação apresentada ao Departamento de Economia da Faculdade de Economia, Administração e Contabilidade da Universidade de São Paulo como requisito para a obtenção do título de Mestre em Economia.

Orientador: Prof. Dr. André Portela Fernandes de Souza 
FICHA CATALOGRÁFICA

Elaborada pela Seção de Processamento Técnico do SBD/FEA/USP

Vinhais, Henrique Eduardo Ferreira

Ensaios sobre a redução da pobreza no Brasil: mensuração e

determinantes / Henrique Eduardo Ferreira Vinhais. -- São Paulo, 2006.

$158 \mathrm{p}$.

Dissertação (Mestrado) - Universidade de São Paulo, 2006

Bibliografia.

1. Pobreza - Brasil 2. Crescimento - Economia 3. Desigualdade de renda 4. Elasticidade I. Universidade de São Paulo. Faculdade de Economia, Administração e Contabilidade II. Título.

CDD - 339.460981 
Em memória ao meu pai, Manuel dos Santos Moura Vinhais. 


\section{AGRADECIMENTOS}

Primeiramente, ao meu orientador, Prof. Dr. André Portela Fernandes de Souza, por todo seu apoio e paciência, e por seus ensinamentos ao longo da realização deste trabalho.

À minha mãe e ao meu irmão, que tanto me ajudaram nos momentos difíceis.

A todos os professores do departamento de Economia da Universidade de São Paulo, com os quais tive contato ao longo dos últimos anos.

Aos professores Naércio Aquino Menezes Filho e Paulo Picchetti, pelas críticas e sugestões oferecidas na qualificação deste trabalho.

A todos os meus colegas de turma do mestrado, pela amizade e convivência ao longo do curso.

A todos que, direta ou indiretamente, colaboraram para a realização deste trabalho.

E, por fim, agradeço a Deus por me possibilitar cursar o mestrado e por sempre iluminar o meu caminho ao longo desta vida. 


\section{RESUMO}

Este trabalho analisa a pobreza no Brasil a partir dos micro-dados dos censos demográficos do IBGE dos períodos de 1991 e 2000. Na primeira parte, investiga a construção de uma Linha Híbrida de Pobreza para o Brasil, partindo da estimação empírica da elasticidade-renda da linha de pobreza. A criação desta linha permite contemplar os diferentes aspectos das linhas de pobreza absoluta e relativa, através de uma ponderação entre elas, onde os pesos relativos de cada uma dependem da elasticidade-renda estimada. Com as linhas absoluta e híbrida de pobreza, este trabalho verifica a alteração da incidência da pobreza no período analisado e, em seguida, a mudança dos determinantes desta incidência através de um modelo probit que considera os atributos determinantes da probabilidade de um indivíduo ser pobre. Na segunda parte, este trabalho examina de forma empírica a relação entre crescimento econômico, alteração na distribuição de renda e redução da incidência da pobreza. Além disto, assumindo a hipótese de log-normalidade da distribuição de renda no Brasil, calcula as elasticidades da incidência da pobreza com relação à renda e desigualdade. Por fim, estuda o efeito de variações na renda sobre a pobreza mensurada a partir de uma linha híbrida. Entre os principais resultados, constata-se que a elasticidade-renda da linha de pobreza é próxima de 0,60 e 0,70 para os anos 1991 e 2000, respectivamente. Verifica-se que o quadro de pobreza no Brasil apresenta uma redução tanto com a linha absoluta quanto com a híbrida. Contudo, com esta última, a redução da pobreza é menor. Destaca-se também o fato de que a diminuição da desigualdade de renda contribui para a redução da pobreza, assim como o crescimento da renda familiar per capita. Observa-se que municípios com baixo nível inicial de desenvolvimento e elevada desigualdade inicial de renda apresentam uma maior dificuldade para reduzir a pobreza. Há indícios de que a hipótese de distribuição log-normal da renda não é significante para o Brasil. Por fim, considerando a linha híbrida de pobreza, podemos constatar que um aumento na renda tem seu efeito sobre a mudança da pobreza reduzido pela metade, uma vez que também provoca um aumento desta linha. 


\begin{abstract}
This work analyzes the poverty in Brazil using the Brazilian 1991 and 2000 Census microdata. In the first part, it investigates the construction of a Hybrid Poverty Line for Brazil, from the empirical estimation of the income-elasticity of the poverty line. A hybrid poverty line permits us to take into consideration the different aspects of the absolute and relative poverty lines because it is a weighted average between them, where the weights depend on the incomeelasticity. With the absolute and hybrid poverty lines, this work verifies the variation of the poverty incidence between 1991 and 2000 and the change of the incidence determinants with a probit model. It considers the attributes that determines the individual's probability to be poor. In the second part, this work examines in an empiric way the relationship among economical growth, change in income distribution and reduction of poverty incidence. Besides, assuming the hypothesis of log-normality of the income distribution in Brazil, it calculates the income-elasticity and inequality-elasticity of the poverty incidence. Finally, it studies the effect of changes in the income on the poverty measured from a hybrid line. Among the main results, it is verified that the income-elasticity of the poverty line is close to 0.60 and 0.70 for the years 1991 and 2000, respectively. The poverty in Brazil presents reduction with the absolute and hybrid lines. However with the hybrid line, the reduction of poverty incidence is smaller. It is detached the fact that the decrease of the income inequality, as well as the growth of the family income per capita, contributes to the reduction of the poverty. It is observed that municipal districts with low initial level of development and high initial income inequality present a larger difficulty to reduce the poverty. There are indications that the hypothesis of log-normal income distribution is not significant to Brazil. Finally, considering the hybrid poverty line, the change of the poverty is reduced by the half when there is an increase in the income, because it also provokes an increase of this line.
\end{abstract}




\section{SUMÁRIO}

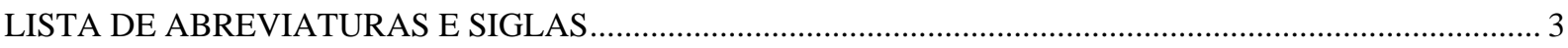

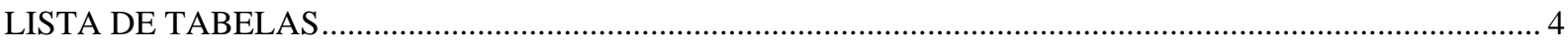

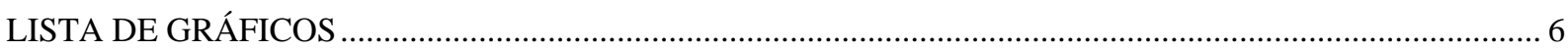

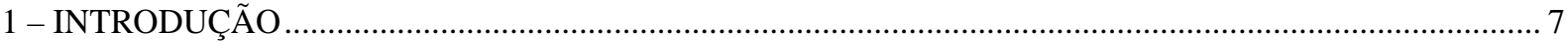

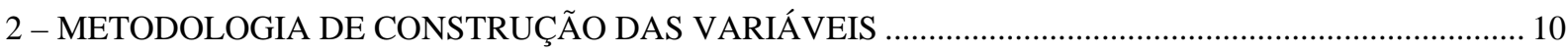

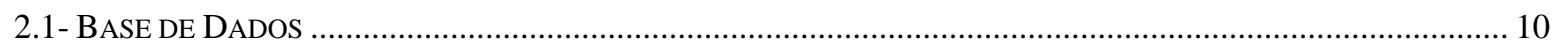

2.2- Definição e Metodologia de ConstruÇão das Principais VARIÁVEIS ............................................. 11

2.2.1 - Renda Familiar per Capita …………....................................................................................... 11

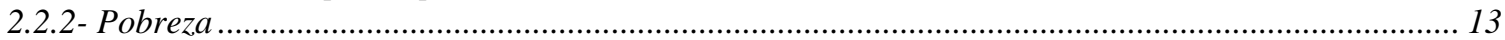

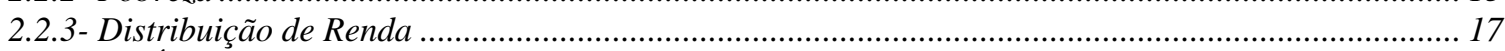

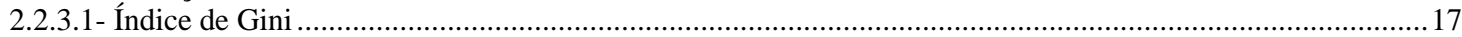

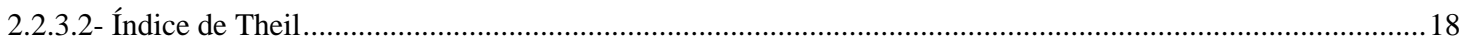

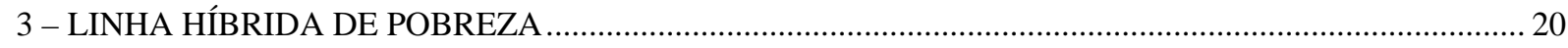

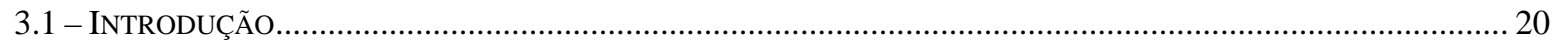

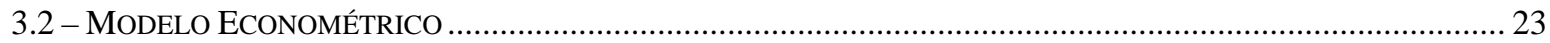

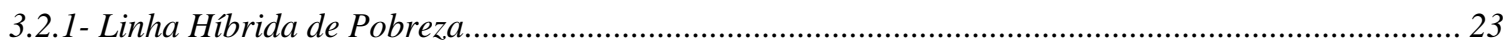

3.2.2- Determinantes da Probabilidade do Indivíduo Ser Pobre ………………….................................. 25

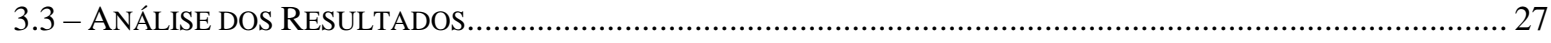

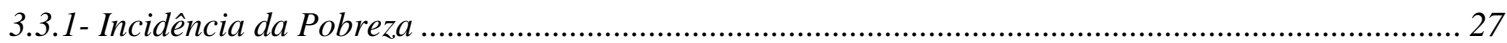

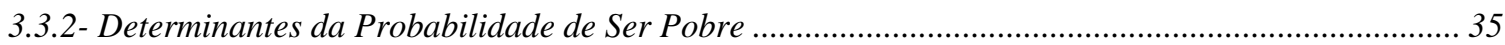

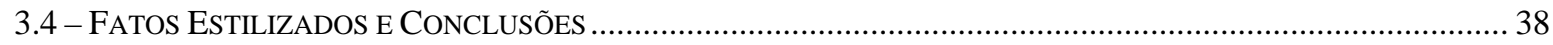

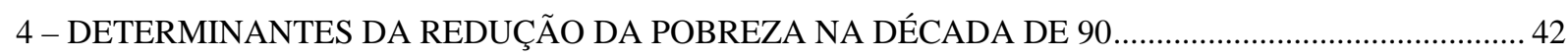

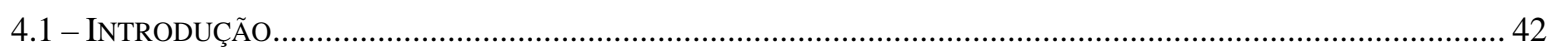

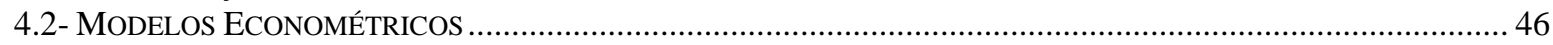

4.2.1 - Modelo baseado em Ravallion e Datt (1992)............................................................................ 46

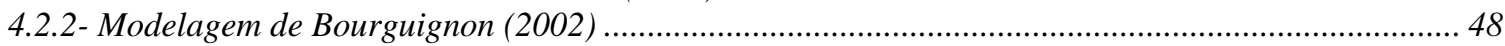

4.2.3- Elasticidades pela Log-Normalidade......................................................................................... 48

4.2.4- Modelo considerando uma Linha Híbrida de Pobreza ……………………................................... 51

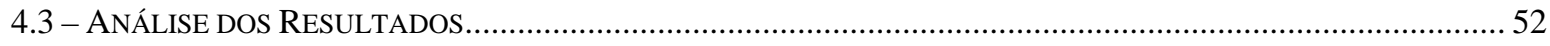

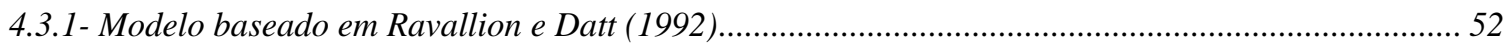

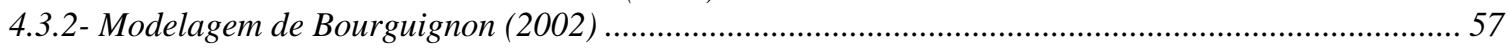

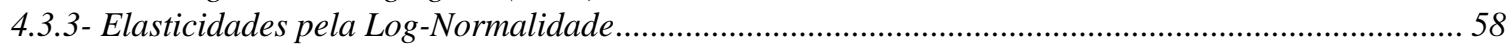

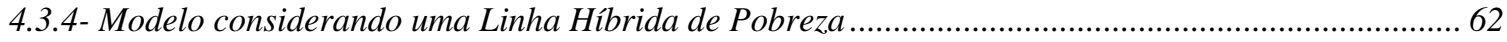

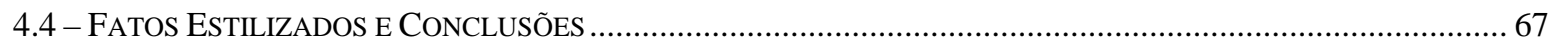

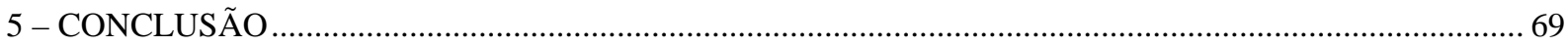

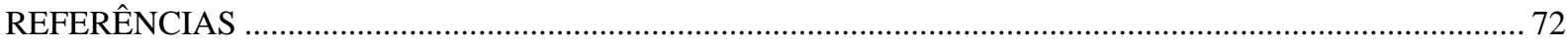

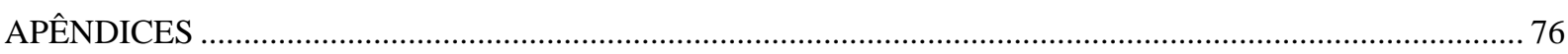

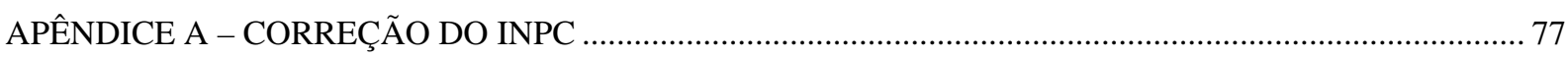

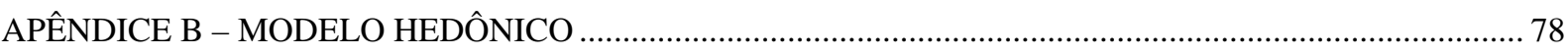

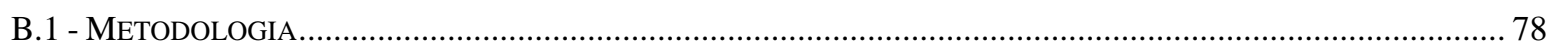

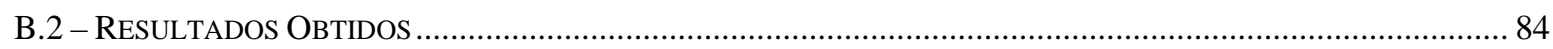

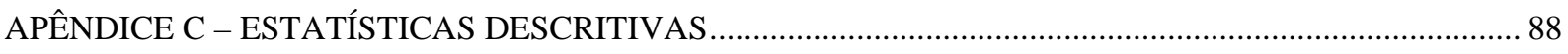

APÊNDICE D - POSSIBILIDADES DE CONSTRUÇÃO DA RENDA PER CAPITA........................................ 89

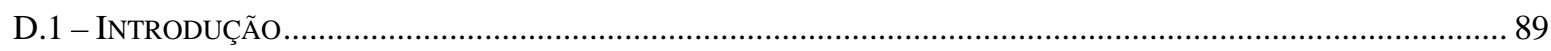

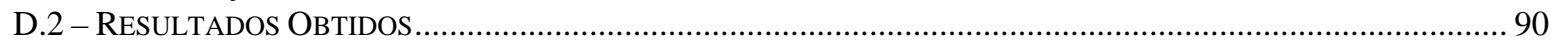

D.2.1 - Utilização Somente do Censo de 1991 .................................................................................... 90

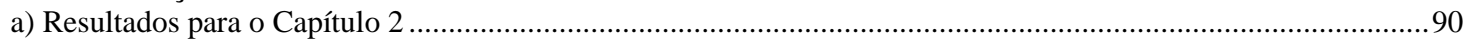




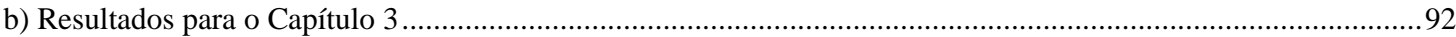

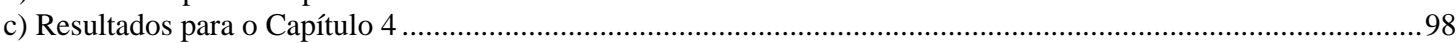

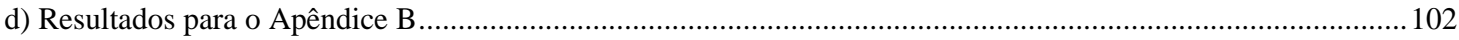

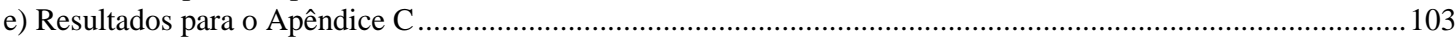

D.2.2 - Utilização das PNAD's de 1990, 1992, 1999 e 2001 .......................................................... 104

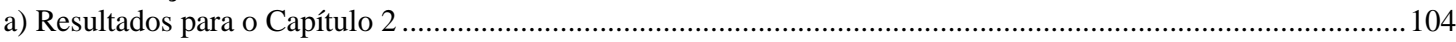

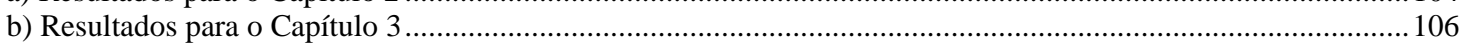

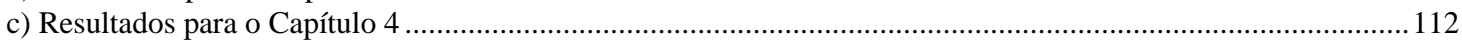

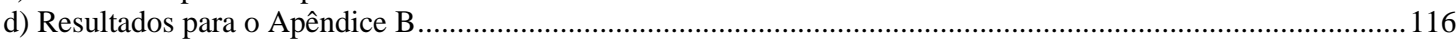

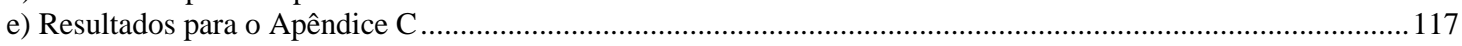

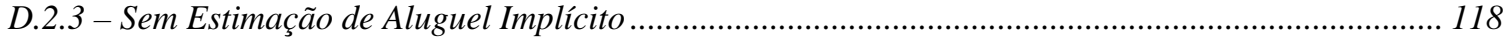

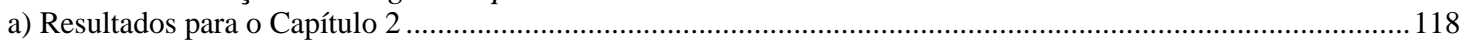

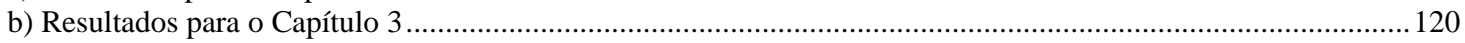

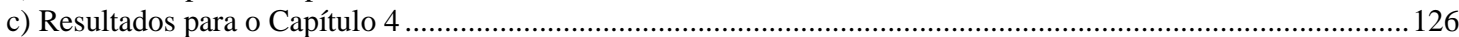

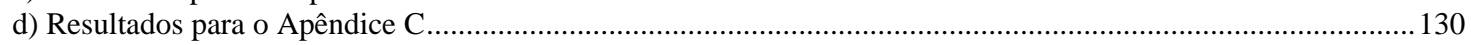

D.3 - CONSIDERAÇÕES SOBRE OS RESULTADOS APRESENTADOS …...................................................... 130

APÊNDICE E - COMPATIBILIZAÇÃO ENTRE MUNICÍPIOS DE 1991 E 2000 ........................................ 132

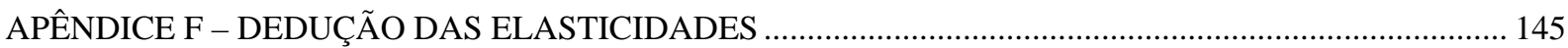

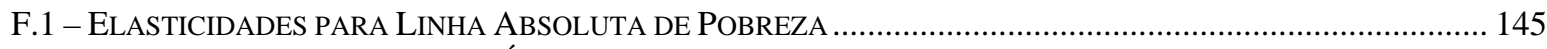

F.1.1- Elasticidades a partir do Índice de Gini .................................................................................... 146

F.1.2- Elasticidades a partir do Índice de Theil................................................................................... 147

F.2 - ESTIMAÇÃo DA ELASTICIDADE-RENDA COM LINHA HÍBRIDA DE POBREZA........................................ 148 


\section{LISTA DE ABREVIATURAS E SIGLAS}

CR\$: Cruzeiro Real

Cr\$: Cruzeiros

IBGE: Instituto Brasileiro de Geografia e Estatística

INPC: Índice Nacional de Preços ao Consumidor

MQO: Mínimos Quadrados Ordinários com todos os anos

MQVD: Mínimos Quadrados com Variáveis Dummy considerando todos os anos

NAS: National Academy of Science

ONU: Organização das Nações Unidas

PNAD: Pesquisa Nacional por Amostra de Domicílios

POF: Pesquisa de Orçamentos Familiares

PPP: Paridade do poder de compra

PPV: Pesquisa sobre Padrões de Vida

$\mathrm{R} \$$ : Reais

RMQR: Raiz quadrada da Média dos Quadrados dos Resíduos

URV: Unidade Real de Valor 


\section{LISTA DE TABELAS}

Tabela 1 - Estatísticas Básicas da Variável Renda Familiar per Capita ..................................................... 13

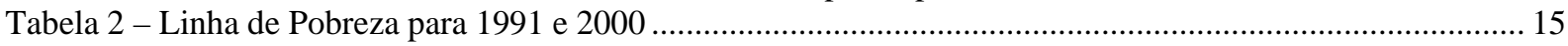

Tabela 3 - Estatísticas Básicas do Número de Pobres ..................................................................................... 16

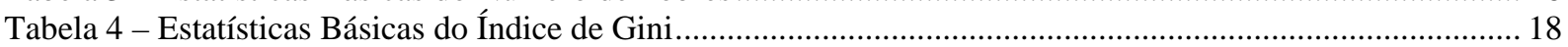

Tabela 5 - Estatísticas Básicas do Índice de Theil ......................................................................................... 19

Tabela 6 - Regressão em Logaritmo da Linha de Pobreza na Renda ..........................................................2 27

Tabela 7 - Regressão em Logaritmo da Linha de Pobreza com os Anos de 1991 e 2000 ...................................22

Tabela 8 - Linha Híbrida de Pobreza com Renda Média por Estrato e Nacional ...................................................30

Tabela 9 - Incidência da Pobreza com Renda Média por Estrato ........................................................... 31

Tabela 10 - Incidência da Pobreza com Renda Média Nacional ................................................................ 33

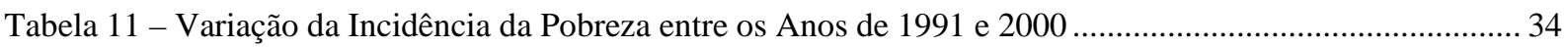

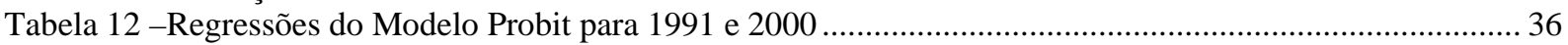

Tabela 13 - Resultados do Modelo Probit de Ferreira, Lanjouw e Neri (2000) ................................................ 40

Tabela 14 - Estimações de Logaritmo da Incidência da Pobreza em Logaritmos da Renda e Desigualdade........ 53

Tabela 15 - Testes de Verificação dos Métodos Aplicados..........................................................................5 54

Tabela 16 - Estimações em Logaritmo da Incidência da Pobreza em Renda e Desigualdade por MQVD com Peso

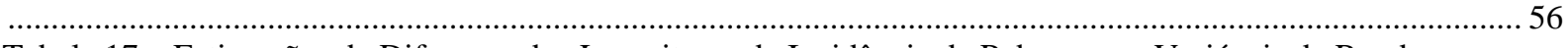

Tabela 17 - Estimações da Diferença dos Logaritmos da Incidência da Pobreza nas Variáveis de Renda e

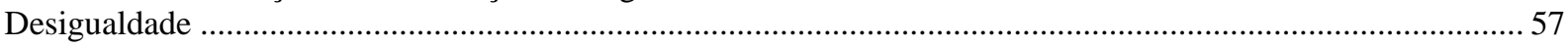

Tabela 18 - Comparativo entre as Elasticidades-Renda $\left(\varepsilon_{\mathrm{y}}\right.$ e $\left.\varepsilon_{\mathrm{m}}\right)$ e Elasticidades-Desigualdade $\left(\varepsilon_{\mathrm{G}}\right) \ldots \ldots \ldots \ldots \ldots \ldots . . . . . . .59$

Tabela 19 - Resultados do Teste Log-Normal com base em Bourguignon (2002) .......................................61

Tabela 20 - Teste dos Coeficientes dos Termos das Elasticidades.................................................................62

Tabela 21 - Estimações em Logaritmo da Incidência da Pobreza em Renda, Desigualdade e Linha Híbrida ....... 63

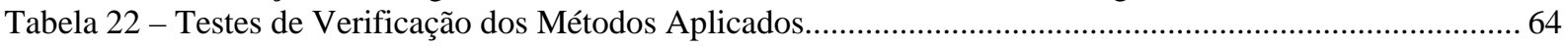

Tabela 23 - Estimações em Logaritmo da Incidência da Pobreza em Renda, Desigualdade e Linha Híbrida por

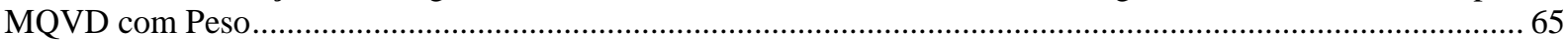

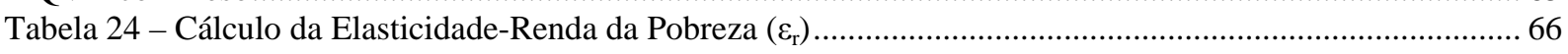

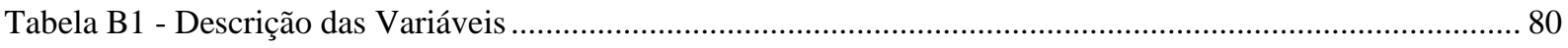

Tabela B2 - Tipos de Condição de Propriedade ................................................................................ 83

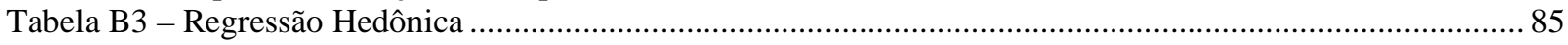

Tabela B4 - Estatística Descritiva do Aluguel Implícito Familiar per Capita ............................................... 86

Tabela C1 - Estatísticas Descritivas das Principais Variáveis...................................................................... 88

Tabela 1.B - Estatísticas Básicas da Variável Renda Familiar per Capita ....................................................... 90

Tabela 3.B - Estatísticas Básicas do Número de Pobres .......................................................................... 91

Tabela 4.B - Estatísticas Básicas do Índice de Gini ....................................................................................... 91

Tabela 5.B - Estatísticas Básicas do Índice de Theil ................................................................................... 92

Tabela 6.B - Regressão em Logaritmo da Linha de Pobreza na Renda .........................................................99

Tabela 7.B - Regressão em Logaritmo da Linha de Pobreza com os Anos de 1991 e 2000 .............................. 93

Tabela 8.B - Linha Híbrida de Pobreza com Renda Média por Estrato e Nacional .........................................93

Tabela 9.B - Incidência da Pobreza com Renda Média por Estrato ................................................................ 94

Tabela 10.B - Incidência da Pobreza com Renda Média Nacional .................................................................95

Tabela 11.B - Variação da Incidência da Pobreza entre os Anos de 1991 e 2000 ..........................................96

Tabela 12.B -Regressões do Modelo Probit para 1991 e 2000 .................................................................. 97

Tabela 14.B - Estimações de Logaritmo da Incidência da Pobreza em Logaritmos da Renda e Desigualdade ....98

Tabela 15.B - Testes de Verificação dos Métodos Aplicados ......................................................................98

Tabela 16.B - Estimações em Logaritmo da Incidência da Pobreza em Renda e Desigualdade por MQVD com

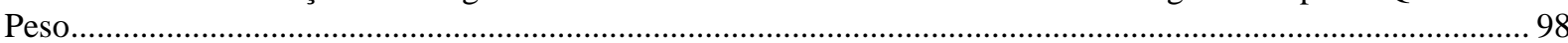

Tabela 17.B - Estimações da Diferença dos Logaritmos da Incidência da Pobreza nas Variáveis de Renda e

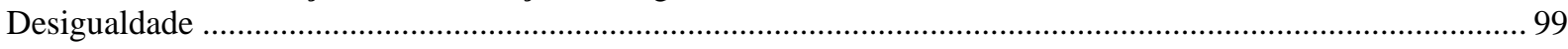

Tabela 18.B - Comparativo entre as Elasticidades-Renda $\left(\varepsilon_{\mathrm{y}}\right.$ e $\left.\varepsilon_{\mathrm{m}}\right)$ e Elasticidades-Desigualdade $\left(\varepsilon_{\mathrm{G}}\right) \ldots \ldots \ldots \ldots \ldots . . . . .99$

Tabela 19.B - Resultados do Teste Log-Normal com base em Bourguignon (2002)..................................... 100

Tabela 20.B - Teste dos Coeficientes dos Termos das Elasticidades .............................................................. 100

Tabela 21.B - Estimações em Logaritmo da Incidência da Pobreza em Renda, Desigualdade e Linha Híbrida. 100

Tabela 22.B - Testes de Verificação dos Métodos Aplicados ................................................................... 101

Tabela 23.B - Estimações em Logaritmo da Incidência da Pobreza em Renda, Desigualdade e Linha Híbrida por

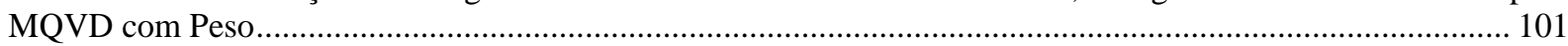

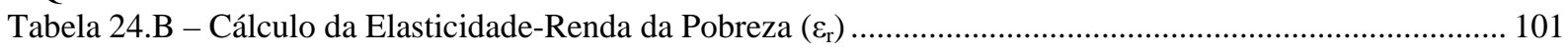


Tabela B3.B - Regressão Hedônica................................................................................................ 102

Tabela B4.B - Estatística Descritiva do Aluguel Implícito Familiar per Capita .......................................... 103

Tabela C1.B - Estatísticas Descritivas das Principais Variáveis ................................................................ 103

Tabela 1.C - Estatísticas Básicas da Variável Renda Familiar per Capita .................................................... 104

Tabela 3.C - Estatísticas Básicas do Número de Pobres ........................................................................ 105

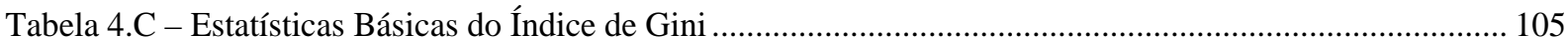

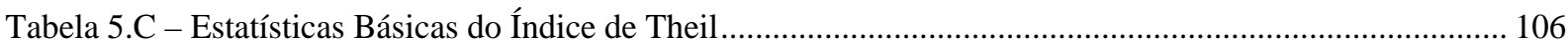

Tabela 6.C - Regressão em Logaritmo da Linha de Pobreza na Renda ....................................................... 106

Tabela 7.C - Regressão em Logaritmo da Linha de Pobreza com os Anos de 1991 e 2000 ............................. 106

Tabela 8.C - Linha Híbrida de Pobreza com Renda Média por Estrato e Nacional .......................................... 107

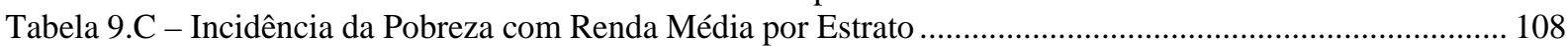

Tabela 10.C - Incidência da Pobreza com Renda Média Nacional ............................................................... 109

Tabela 11.C - Variação da Incidência da Pobreza entre os Anos de 1991 e 2000 .......................................... 110

Tabela 12.C -Regressões do Modelo Probit para 1991 e 2000 ......................................................................... 111

Tabela 14.C - Estimações de Logaritmo da Incidência da Pobreza em Logaritmos da Renda e Desigualdade .. 112

Tabela 15.C - Testes de Verificação dos Métodos Aplicados ......................................................................... 112

Tabela 16.C - Estimações em Logaritmo da Incidência da Pobreza em Renda e Desigualdade por MQVD com

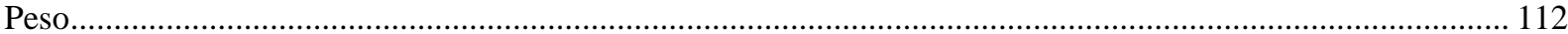

Tabela 17.C - Estimações da Diferença dos Logaritmos da Incidência da Pobreza nas Variáveis de Renda e

Desigualdade

Tabela 18.C - Comparativo entre as Elasticidades-Renda $\left(\varepsilon_{\mathrm{y}}\right.$ e $\left.\varepsilon_{\mathrm{D}}\right)$ e Elasticidades-Desigualdade $\left(\varepsilon_{G}\right)$

Tabela 19.C - Resultados do Teste Log-Normal com base em Bourguignon (2002)

Tabela 20.C - Teste dos Coeficientes dos Termos das Elasticidades .............................................................. 114

Tabela 21.C - Estimações em Logaritmo da Incidência da Pobreza em Renda, Desigualdade e Linha Híbrida. 114

Tabela 22.C - Testes de Verificação dos Métodos Aplicados ..................................................................... 115

Tabela 23.C - Estimações em Logaritmo da Incidência da Pobreza em Renda, Desigualdade e Linha Híbrida por

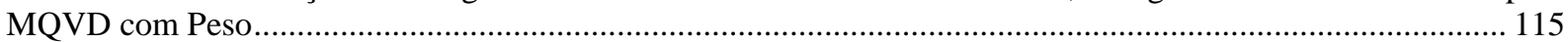

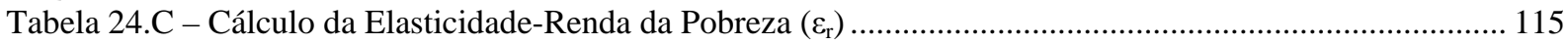

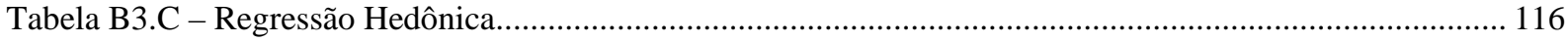

Tabela B4.C - Estatística Descritiva do Aluguel Implícito Familiar per Capita ............................................ 117

Tabela C1.C - Estatísticas Descritivas das Principais Variáveis ................................................................... 117

Tabela 1.D - Estatísticas Básicas da Variável Renda Familiar per Capita ................................................... 118

Tabela 3.D - Estatísticas Básicas do Número de Pobres ........................................................................... 119

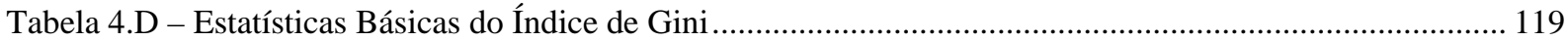

Tabela 5.D - Estatísticas Básicas do Índice de Theil....................................................................................... 120

Tabela 6.D - Regressão em Logaritmo da Linha de Pobreza na Renda ..................................................... 120

Tabela 7.D - Regressão em Logaritmo da Linha de Pobreza com os Anos de 1991 e 2000 ........................... 120

Tabela 8.D - Linha Híbrida de Pobreza com Renda Média por Estrato e Nacional .......................................... 121

Tabela 9.D - Incidência da Pobreza com Renda Média por Estrato ................................................................ 122

Tabela 10.D - Incidência da Pobreza com Renda Média Nacional ................................................................. 123

Tabela 11.D - Variação da Incidência da Pobreza entre os Anos de 1991 e 2000 ........................................ 124

Tabela 12.D -Regressões do Modelo Probit para 1991 e 2000 ......................................................................... 125

Tabela 14.D - Estimações de Logaritmo da Incidência da Pobreza em Logaritmos da Renda e Desigualdade.. 126

Tabela 15.D - Testes de Verificação dos Métodos Aplicados..................................................................... 126

Tabela 16.D - Estimações em Logaritmo da Incidência da Pobreza em Renda e Desigualdade por MQVD com

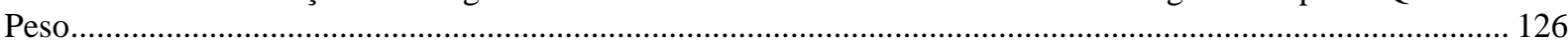

Tabela 17.D - Estimações da Diferença dos Logaritmos da Incidência da Pobreza nas Variáveis de Renda e

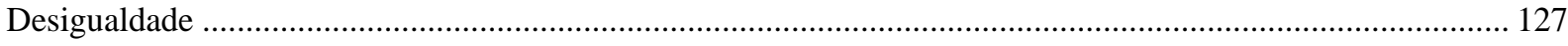

Tabela 18.D - Comparativo entre as Elasticidades-Renda $\left(\varepsilon_{\mathrm{y}}\right.$ e $\left.\varepsilon_{\mathrm{m}}\right)$ e Elasticidades-Desigualdade $\left(\varepsilon_{\mathrm{G}}\right) \ldots \ldots \ldots \ldots . . . .127$

Tabela 19.D - Resultados do Teste Log-Normal com base em Bourguignon (2002)....................................... 128

Tabela 20.D - Teste dos Coeficientes dos Termos das Elasticidades.............................................................. 128

Tabela 21.D - Estimações em Logaritmo da Incidência da Pobreza em Renda, Desigualdade e Linha Híbrida 128

Tabela 22.D - Testes de Verificação dos Métodos Aplicados........................................................................ 129

Tabela 23.D - Estimações em Logaritmo da Incidência da Pobreza em Renda, Desigualdade e Linha Híbrida por

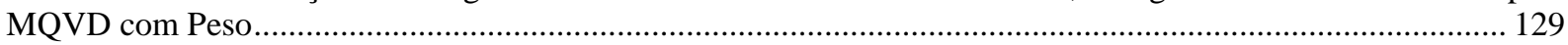

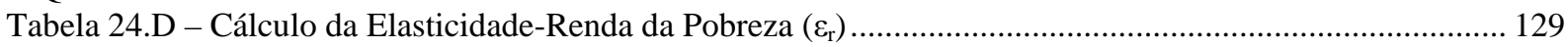

Tabela C1.D - Estatísticas Descritivas das Principais Variáveis .............................................................. 130

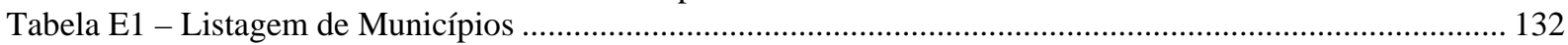




\section{LISTA DE GRÁFICOS}

Gráfico 1 - Decomposição da Mudança na Pobreza nos Efeitos Crescimento e Distribuição. ............................44

Gráfico 2 - Decomposição da Mudança na Pobreza considerando Linha Híbrida.... 


\section{1 - INTRODUÇÃO}

A Pobreza é dos principais temas de debates atualmente. Diversos países buscam entender este fenômeno que assola um grande número de pessoas no mundo. De acordo com o relatório estatístico anual do Banco Mundial, World Development Indicators 2004, nos últimos 20 anos, houve uma queda no número de pessoas que vivem com menos de um dólar por dia (linha de extrema pobreza em paridade do poder de compra - PPP), de 1,5 bilhão em 1981 para 1,1 bilhão de pessoas em 2001. Isto também é observado se representado de forma relativa, em que a extrema pobreza caiu de $40 \%$ em 1981 para $21 \%$ da população mundial em 2001. Contudo este avanço apresentou-se de forma desigual entre regiões. Enquanto no leste e no sul da Ásia, destacando-se a China, aproximadamente 500 milhões de pessoas tenham saído da extrema pobreza, a proporção de pobres cresceu ou mostrou apenas uma suave queda em muitos países da África, América Latina, Europa Oriental e Ásia Central.

No Brasil, a evolução do quadro da pobreza na década de 90 indica que houve um aumento da renda familiar per capita e redução da proporção de pessoas vivendo com renda abaixo da linha de pobreza na maioria dos estados brasileiros. Segundo a Organização das Nações Unidas (ONU), considerando uma linha de extrema pobreza de um dólar por dia (em PPP), a pobreza no Brasil caiu de 14,0\% da população em 1990 para 8,2\% em 2001. Isto, em número de habitantes, indica uma queda de 20,5 para 14,2 milhões de habitantes, respectivamente. Contudo, esta população pobre não está distribuída uniformemente entre as regiões brasileiras, havendo uma concentração em determinados locais, como a região Nordeste.

$\mathrm{Na}$ busca por se conhecer a pobreza, não basta saber apenas quantos pobres um país possui. Mais do que isto, é necessário entender seus determinantes, bem como poder acompanhar a sua evolução, construindo e implementando programas sociais mais eficientes com relação ao combate à pobreza. Neste contexto, a definição clara de uma linha de pobreza é o primeiro passo para se determinar o foco de cada programa social, e conseqüentemente seus resultados ao longo do tempo. Entender a pobreza é fundamental para a eficiência distributiva destes programas.

Um dos objetivos deste trabalho é propor uma nova medida de pobreza para o Brasil, com base nos dados do censo demográfico do Instituto Brasileiro de Geografia e Estatística (IBGE) dos períodos de 1991 e 2000. Considerando que a construção de uma linha de pobreza envolve a escolha de um critério de mensuração de pobreza absoluto ou relativo que possui 
suas vantagens e desvantagens, a medida proposta pondera, através da renda, o padrão absoluto de vida com a posição relativa do indivíduo na sociedade. Entende-se, por linha de pobreza absoluta, o valor constante em termos reais atrelado a algum critério fixo, como por exemplo, o mínimo necessário para obter uma determinada cesta de bens previamente estabelecida pelo analista. Por linha de pobreza relativa, entende-se aquele valor fixado em relação à renda média ou mediana da população, como por exemplo, o valor correspondente a um quarto da renda per capita. Entretanto, ambas possuem vantagens e desvantagens. A linha de pobreza absoluta permite a comparação entre níveis de pobreza de tal modo a precisar a evolução do padrão de vida absoluto ao longo do tempo ou entre regiões sem confundir com mudanças da distribuição de renda. Já a linha de pobreza relativa estabelece considerações distributivas nesta análise.

Entretanto, é crescente a opinião que a pobreza, como total de recursos de um indivíduo, é função não somente do seu padrão de vida, determinado pela renda (linha de pobreza absoluta), mas também de sua posição relativa na população (linha de pobreza relativa). Desta forma, propomos a Linha Híbrida de Pobreza, que é uma média geométrica das linhas absoluta e relativa de pobreza. O resultado que merece destaque nesta parte do trabalho é a elasticidade-renda da linha de pobreza, que mostra o quanto a linha de pobreza responde a variações da renda, ou seja, indica o quanto absoluta ou relativa é a linha de pobreza no Brasil. Assim, podemos verificar a evolução da incidência da pobreza no País tanto considerando linha híbrida quanto linha absoluta de pobreza, possibilitando-nos observar quão informativas são ambas as linhas para o estudo da pobreza no Brasil. Além disso, analisamos os determinantes desta incidência, buscando entender como as características individuais e locais influenciam a probabilidade de um indivíduo ser considerado pobre. Isto nos permitirá entender quais os atributos, além da renda, que influenciam o fato de um indivíduo ser pobre.

Este trabalho também analisa o impacto de variações no crescimento e na desigualdade de renda sobre alterações da pobreza no Brasil. Partindo da relação entre crescimento econômico e redução da pobreza, Cline (2004) destaca que, na década de 90, muitos países tiveram um declínio da pobreza abaixo do previsto, dado o crescimento econômico obtido. Além disso, há países que, mesmo sem passar por expressivo crescimento econômico, conseguem reduzir a pobreza. Assim, uma vez que apenas este crescimento não é capaz de explicar a alteração do quadro de pobreza, a desigualdade de renda passa a ocupar um lugar de destaque como fator complementar no estudo da pobreza. Na busca por entender o fenômeno da pobreza e almejando contribuir para o debate, este trabalho analisa a relação entre a 
redução da pobreza e o crescimento e desigualdade no Brasil. Para tanto, estuda esta relação considerando a incidência da pobreza mensurada através das linhas absoluta e híbrida de pobreza.

No próximo capítulo é apresentada a base de dados utilizada para a elaboração deste trabalho, bem como a metodologia para a construção das principais variáveis. No Capítulo 3, propomos a Linha Híbrida de Pobreza como forma de mensuração da pobreza no País, sendo estimada uma elasticidade-renda da linha de pobreza, que é um ponderador para o cálculo da linha híbrida. No capítulo seguinte, expomos modelos para estimar os efeitos das variáveis de crescimento e desigualdade de renda sobre redução da pobreza no Brasil através da linha absoluta. Além disso, também utilizamos a linha híbrida de pobreza calculada para verificar o impacto de alterações da renda e desigualdade sobre a pobreza. No Capítulo 5, apresentamos as conclusões sobre as estimações e análises feitas neste trabalho. Por fim, há seis apêndices: o primeiro, explicando a metodologia de correção do índice de preços; o seguinte, apresentando a regressão hedônica que estima o aluguel implícito pelo fato do indivíduo possuir casa própria; o terceiro, com as estatísticas descritivas das principais variáveis; o quarto, com as tabelas referentes às possibilidades de cálculo da renda consideradas neste trabalho; o seguinte, com a relação de municípios compatibilizados entre os anos de 1991 e 2000; e o último, com a dedução das elasticidades utilizadas no Capítulo 4. 


\section{2 - METODOLOGIA DE CONSTRUÇÃO DAS VARIÁVEIS}

\section{1- Base de Dados}

A base de dados utilizada para este trabalho é o censo demográfico do IBGE dos períodos de 1991 e 2000. Os micro-dados foram agregados inicialmente por famílias e em seguida por municípios e estados. Como este trabalho utiliza um Painel balanceado para a análise econométrica, foi necessário estudar a evolução dos municípios ao longo do período de 1991 a 2000, considerando eventuais fusões e emancipações de municípios. Assim, foi possível fazer a correlação dos municípios entre os períodos. ${ }^{1}$

As variáveis utilizadas neste trabalho são a renda familiar per capita, a proporção de pessoas com renda abaixo da linha de pobreza, os índices de desigualdade de Gini e Theil, e as variáveis individuais (como sexo, raça, idade e escolaridade) e locais. Visando evitar duplicidade no cálculo da renda familiar, foram excluídas da amostra as pessoas com as seguintes condições de relação com o responsável pela família: pensionista; empregado(a) doméstico(a) e seus parentes. Também foram excluídos os indivíduos em domicílio coletivo.

A unidade de análise para a mensuração da pobreza neste trabalho é o indivíduo, entendendo-se que cada um tem o direito, individualmente, ao bem-estar. Hoffmann (1998) explica que considerando a existência de um intenso processo de redistribuição da renda dentro das famílias, verifica-se que o nível de bem-estar de um indivíduo passa a ser determinado não pela sua renda individual, mas sim pela sua renda per capita da família à qual pertence. Por isso, trabalhamos com informações sobre a distribuição dos indivíduos de acordo com a renda familiar per capita.

Devido ao fato do Brasil ser um país de dimensões continentais, marcado por acentuadas diferenças regionais e de custo de vida, as linhas de pobreza usadas estão divididas por regiões e por níveis de urbanização (rural, urbano e metrópole). Vale ressaltar que são utilizadas as mesmas regiões metropolitanas para ambos os períodos, apesar do censo demográfico de 2000 apresentar mais regiões. Assim, para o cálculo da quantidade de pessoas com renda familiar per capita abaixo da linha de pobreza, utiliza-se como variáveis auxiliares a situação do domicílio em que reside cada família e a região metropolitana onde este se

\footnotetext{
${ }^{1}$ A listagem com a compatibilidade de municípios entre 1991 e 2000 se encontra no Apêndice E.
} 
localiza, obtendo-se a classificação do nível de urbanização do local de moradia de cada família. Isto viabiliza relacionar a renda familiar per capita de cada indivíduo com a respectiva linha de pobreza do local de moradia da família à qual este pertence.

\section{2- Definição e Metodologia de Construção das Principais Variáveis}

Inicialmente é preciso definir as principais variáveis utilizadas na modelagem. A variável renda é calculada no nível familiar per capita e serve de base para as variáveis de pobreza e desigualdade de renda. A pobreza, dentro do âmbito de insuficiência de renda, é mensurada com base numa linha absoluta de pobreza, usando o conceito de incidência da pobreza (proporção da população com renda abaixo de um determinado nível). Já a desigualdade se refere às disparidades na renda média relativa ao longo da população, com base nos índices de Gini e de Theil.

\subsection{1- Renda Familiar per Capita}

O crescimento econômico local de cada região do Brasil é medido pela variação, entre os anos de 1991 e 2000, no nível de renda familiar per capita ${ }^{2}$ de cada localidade. Para tanto, as informações de renda familiar per capita de cada pessoa são agregadas para o nível municipal e em seguida estadual. Em alguns casos, serão utilizados os níveis por estrato ${ }^{3}$ e nacional. Os valores de 1991 foram convertidos de cruzeiros (Cr\$) de agosto de 1991 para reais (R\$) de julho de 2000 pelo Índice Nacional de Preços ao Consumidor (INPC) do IBGE de acordo com a metodologia do IPEA apresentada no Apêndice A.

Entretanto, somente a informação de renda individual apresentada no Censo demográfico não é suficiente para a construção da renda familiar per capita. Diversos estudos

\footnotetext{
${ }^{2}$ Para a renda, utilizamos o total de todos os rendimentos dos Censos de 1991 e 2000. Entretanto, minimizar o problema da utilização de rendas imputadas erroneamente na base de dados, em 1991 e 2000, não consideramos as rendas totais individuais acima de $\mathrm{Cr} \$ 8.888 .888$ e $\mathrm{R} \$ 99.999$, respectivamente.

${ }^{3}$ Neste trabalho, quando especificarmos alguma agregação local por estrato, estaremos utilizando a divisão de estratos de Rocha (2003), que será apresentada na Tabela 2.
} 
sobre distribuição de renda e pobreza no Brasil, destacando-se Ferreira, Lanjouw \& Neri (2000), imputam um rendimento aos indivíduos que declaram possuir casa própria, o que seria equivalente a um aluguel implícito pelo fato de possuírem esta casa. Neste caso, acrescenta-se à renda, informada por cada indivíduo da família, o valor deste aluguel implícito, quando declarado como próprio o imóvel no qual se encontra o domicílio. Entretanto, como na base de dados fornecidas pelo IBGE do Censo não há esta informação, é necessário construí-la, acrescentando-a na renda individual.

Para a sua construção, utiliza-se um modelo hedônico ${ }^{4}$ sobre as bases de dados do Censo e da Pesquisa Nacional por Amostra de Domicílios (PNAD) do IBGE, uma vez que apresentam a informação sobre o aluguel pago ${ }^{5}$ por aqueles que declaram o imóvel, no qual se encontram, como alugado. Com isso, a estimação deste modelo é feita por Mínimos Quadrados Ordinários em que a variável dependente é o aluguel pago. Com os coeficientes estimados, é possível calcular, sobre a base de dados do Censo Demográfico, uma previsão de aluguel que seria pago, caso o indivíduo alugasse a sua casa própria. Esta previsão é chamada de aluguel implícito.

Devido ao fato de não haver a informação do aluguel pago dos imóveis declarados como alugados no Censo de 2000, utilizamos duas possibilidades de base de dados no modelo hedônico para 2000: as bases de dados da PNAD de 1999 e de 2001; e o Censo de 1991. Desta forma, trabalhamos com quatro possibilidades para a construção da renda familiar per capita: - Utilização do Censo de 1991 para a estimação do aluguel implícito de 1991, e das PNAD’s de 1999 e 2001 para a do aluguel implícito de 2000;

- Utilização do Censo de 1991 para a estimação dos alugueis implícitos de 1991 e 2000;

- Utilização das PNAD's de 1990 e 1992 para a estimação do aluguel implícito de 1991, e das PNAD's de 1999 e 2001 para a do aluguel implícito de 2000;

- Sem a utilização de base de dados, não havendo estimação do aluguel implícito.

A primeira possibilidade de construção da renda familiar per capita é discutida ao longo deste trabalho. As outras possibilidades são apresentadas no Apêndice D. Observamos que os resultados entre as quatro possibilidades praticamente não se alteram, corroborando para a robustez dos modelos utilizados neste trabalho. A tabela abaixo apresenta as estatísticas básicas da renda familiar per capita dos municípios brasileiros por unidade da federação calculada a partir da primeira possibilidade.

\footnotetext{
${ }^{4} \mathrm{O}$ Apêndice B tem o detalhamento sobre a metodologia adotada e variáveis utilizadas.

${ }^{5}$ Esta informação está presente apenas no Censo Demográfico de 1991. Assim para 2000, é necessário utilizar outra base de dados diferente do Censo de 2000.
} 
Tabela 1 - Estatísticas Básicas da Variável Renda Familiar per Capita

\begin{tabular}{|c|c|c|c|c|c|c|c|c|c|}
\hline \multirow{2}{*}{$\begin{array}{c}\text { Região } \\
\text { Geográfica }\end{array}$} & \multirow[b]{2}{*}{ Estado } & \multicolumn{4}{|c|}{1991} & \multicolumn{4}{|c|}{2000} \\
\hline & & Média & $\begin{array}{l}\text { Desvio- } \\
\text { Padrão }\end{array}$ & Mínimo & Máximo & Média & $\begin{array}{l}\text { Desvio- } \\
\text { Padrão }\end{array}$ & Mínimo & Máximo \\
\hline \multirow{7}{*}{ Norte } & $\mathrm{RO}$ & 168,20 & 60,79 & 63,94 & 258,95 & 249,56 & 46,81 & 131,73 & 305,10 \\
\hline & $A C$ & 160,10 & 63,68 & 68,94 & 217,16 & 201,47 & 71,53 & 76,16 & 262,78 \\
\hline & AM & 198,18 & 105,95 & 41,99 & 306,49 & 187,75 & 96,99 & 40,49 & 282,56 \\
\hline & $\mathrm{RR}$ & 305,73 & 75,31 & 129,62 & 348,12 & 252,55 & 80,34 & 87,55 & 307,07 \\
\hline & PA & 153,34 & 82,89 & 53,93 & 302,11 & 180,21 & 88,93 & 54,36 & 333,54 \\
\hline & AP & 217,73 & 50,65 & 93,07 & 254,48 & 233,55 & 51,27 & 96,90 & 276,77 \\
\hline & TO & 138,82 & 62,79 & 50,36 & 267,49 & 188,55 & 86,61 & 69,11 & 374,85 \\
\hline \multirow{9}{*}{ Nordeste } & MA & 88,12 & 52,36 & 33,79 & 204,18 & 119,52 & 69,63 & 42,28 & 264,06 \\
\hline & $\mathrm{Pl}$ & 93,85 & 54,54 & 29,37 & 185,56 & 138,00 & 73,04 & 46,29 & 254,32 \\
\hline & CE & 121,97 & 81,82 & 25,85 & 250,70 & 170,96 & 106,60 & 49,04 & 333,54 \\
\hline & $\mathrm{RN}$ & 138,82 & 87,84 & 36,34 & 282,27 & 192,05 & 109,70 & 46,52 & 361,77 \\
\hline & PB & 109,23 & 75,62 & 25,23 & 266,00 & 163,70 & 101,15 & 56,33 & 353,26 \\
\hline & PE & 155,81 & 98,26 & 32,08 & 334,54 & 201,23 & 118,39 & 54,69 & 577,85 \\
\hline & $\mathrm{AL}$ & 121,74 & 79,32 & 37,11 & 255,02 & 152,03 & 93,88 & 42,40 & 297,42 \\
\hline & SE & 147,69 & 91,61 & 51,77 & 296,19 & 179,57 & 116,78 & 55,16 & 374,84 \\
\hline & BA & 129,93 & 92,24 & 25,69 & 315,49 & 177,16 & 107,18 & 47,57 & 375,55 \\
\hline \multirow{4}{*}{ Sudeste } & MG & 215,55 & 115,33 & 46,96 & 457,77 & 301,54 & 148,20 & 66,18 & 607,18 \\
\hline & ES & 216,97 & 109,56 & 71,96 & 489,22 & 314,93 & 148,63 & 115,14 & 702,78 \\
\hline & RJ & 339,56 & 151,81 & 111,19 & 614,15 & 468,66 & 196,67 & 189,86 & 891,01 \\
\hline & SP & 421,21 & 138,37 & 91,98 & 688,93 & 491,86 & 155,70 & 124,16 & 960,89 \\
\hline \multirow{3}{*}{ Sul } & PR & 249,24 & 129,61 & 64,50 & 507,28 & 346,64 & 162,23 & 108,24 & 665,91 \\
\hline & SC & 259,69 & 104,76 & 89,00 & 527,95 & 382,13 & 132,01 & 125,75 & 751,91 \\
\hline & RS & 288,62 & 130,52 & 77,65 & 576,72 & 393,17 & 164,80 & 105,29 & 768,63 \\
\hline \multirow{4}{*}{ Centro-Oeste } & MS & 243,27 & 80,66 & 103,95 & 352,52 & 306,27 & 90,88 & 125,38 & 452,48 \\
\hline & MT & 226,30 & 79,96 & 82,89 & 355,48 & 304,74 & 96,24 & 127,18 & 485,37 \\
\hline & $\mathrm{GO}$ & 235,13 & 90,78 & 64,25 & 376,70 & 304,91 & 119,96 & 95,01 & 508,18 \\
\hline & DF & 524,27 & - & 524,27 & 524,27 & 632,51 & - & 632,51 & 632,51 \\
\hline Brasil & & 253,31 & 161,99 & 25,23 & 688,93 & 326,87 & 192,06 & 40,49 & 960,89 \\
\hline
\end{tabular}

Obs.: $\quad$ Renda familiar per capita em Reais (R\$) de julho de 2000.

Por esta tabela, podemos observar que houve aumento de praticamente $50 \%$ na renda familiar per capita de alguns estados como Rondônia (RO), Piauí (PI), Paraíba (PB), Espírito Santo (ES) e Santa Catarina (SC).

É importante frisar que esta correção da renda familiar per capita merece destaque, visto que permite corrigir a desigualdade inerente entre famílias que têm e não têm casa própria, além de possibilitar uma melhor compreensão dos maiores gastos com aluguel nas regiões metropolitanas e urbanas não-metropolitanas.

\subsection{2- Pobreza}

Podendo ser definida de diversas maneiras, a pobreza pode ser entendida como privação em termos materiais na forma de fome ou baixa qualidade de moradia. Em termos econômicos, é entendida sob a forma de inadequação da renda e, em termos sociais, é definida 
como isolamento da comunidade ou sentimentos de baixa auto-estima. Entretanto, a grande maioria das medidas de pobreza leva em conta a privação econômica, ou seja, a falta de recursos econômicos para a satisfação das necessidades básicas, que impõe às famílias pobres um alto risco de privação material. Embora o ideal fosse obter uma medida que captasse diretamente o nível de privação material das famílias, isto é impraticável através das informações disponíveis, uma vez que é difícil combinar as medidas de qualidade de vida das famílias para as várias necessidades básicas (como comida, abrigo, vestuário) num único indicador que poderia ser analisado objetivamente.

Além disso, vista inicialmente como insuficiência de renda, o conceito de pobreza vem evoluindo. Apenas considerando pobreza como o número de pessoas que vivem com menos de um dólar por dia em média, já há grandes divergências sobre este conceito, uma vez que as necessidades básicas das pessoas divergem sensivelmente de país para país. Vindo ao encontro disto, Amartya Sen trabalha com a idéia de privação de capacidades, na qual o conceito de pobreza sai do âmbito restrito de base na renda para ganhar um sentido mais amplo "em função das capacidades que uma pessoa possui, ou seja, das liberdades substantivas para levar o tipo de vida que ela tem razão para valorizar" (Sen, 1999). Assim, pobreza está relacionada à privação da liberdade das pessoas buscarem o tipo de vida que valorizam.

Neste trabalho, utilizamos a linha absoluta de pobreza, dentro do âmbito de insuficiência de renda, usando o conceito de incidência da pobreza. A linha absoluta de pobreza se refere a um valor fixo de renda e independe de sua distribuição. Tem a vantagem de permitir comparações entre diferentes períodos de tempo, podendo-se acompanhar a evolução da pobreza, porém tem como desvantagem a dificuldade de calibrá-la em economias com grandes taxas de crescimento.

Para o cálculo da proporção de pobres sob o enfoque da linha absoluta de pobreza, considera-se uma população com $n$ pessoas, sendo $\mathrm{x}_{\mathrm{i}}(\operatorname{com} i=1,2, \ldots, n)$ a renda familiar per capita da i-ésima pessoa. Para tanto, admite-se que as pessoas estão ordenadas conforme valores crescentes da renda, isto é, $\mathrm{x}_{1} \leq \mathrm{x}_{2} \leq \ldots \leq \mathrm{x}_{\mathrm{n}}$. Sendo $\mathrm{z}_{\mathrm{a}}$ a linha absoluta de pobreza, admite-se que há $p$ pessoas pobres, ou seja, $\mathrm{x}_{\mathrm{p}} \leq \mathrm{z}_{\mathrm{a}}$ e $\mathrm{x}_{\mathrm{p}+1}>\mathrm{z}_{\mathrm{a}}$. Portanto, a incidência da pobreza $(H)$ é:

$H=\frac{p}{n}$.

Deste modo, são utilizadas as linhas absolutas de pobreza estimadas para o Brasil por Rocha (2003), conforme a Tabela 2. Para a construção desta tabela, seguimos alguns critérios. 
Os valores das linhas de pobreza de cada região e estrato para 1991 foram convertidos de Cr\$ de agosto de 1991 para R \$ de julho de 2000 pelo INPC do IBGE. Com relação aos valores das linhas de 2000, na verdade, foram utilizados os valores das linhas de pobreza derivadas da Pesquisa de Orçamentos Familiares (POF) de 2001, convertendo-os pelo mesmo índice de R\$ de setembro de 2001 para $\mathrm{R} \$$ de julho de 2000, uma vez que Rocha (2003) não os calcula para o ano de 2000. Além disso, utilizamos as linhas de pobreza da parte rural da região Nordeste para o mesmo estrato da região Norte. Para 1991, não é considerada a linha de pobreza de Goiânia, uma vez que Rocha (2003) não a apresenta para o ano de 2001. Assim, Goiânia recebe a linha de pobreza do estrato Urbano da região Centro-Oeste.

Tabela 2 - Linha de Pobreza para 1991 e 2000

\begin{tabular}{|c|c|c|c|}
\hline \multirow{2}{*}{ Regiões } & \multirow{2}{*}{ Estratos } & \multicolumn{2}{|c|}{ Linha de Pobreza } \\
\hline & & 1991 & 2000 \\
\hline \multirow{3}{*}{ Norte } & Belém & 92,00 & 95,02 \\
\hline & Urbano & 82,04 & 82,82 \\
\hline & Rural & 51,60 & 49,37 \\
\hline \multirow{5}{*}{ Nordeste } & Fortaleza & 97,18 & 92,22 \\
\hline & Recife & 145,40 & 133,95 \\
\hline & Salvador & 120,81 & 121,88 \\
\hline & Urbano & 85,47 & 81,86 \\
\hline & Rural & 51,60 & 49,37 \\
\hline \multirow{15}{*}{ Sudeste } & Minas Gerais & & \\
\hline & Belo Horizonte & 107,13 & 115,60 \\
\hline & Urbano & 72,02 & 77,72 \\
\hline & Rural & 42,64 & 46,01 \\
\hline & Espirito Santo & & \\
\hline & Urbano & 72,02 & 77,72 \\
\hline & Rural & 42,64 & 46,01 \\
\hline & Rio de Janeiro & & \\
\hline & Metrópole & 128,38 & 138,24 \\
\hline & Urbano & 79,88 & 86,00 \\
\hline & Rural & 58,31 & 62,78 \\
\hline & São Paulo & & \\
\hline & Metrópole & 153,83 & 172,38 \\
\hline & Urbano & 98,30 & 110,15 \\
\hline & Rural & 61,84 & 69,29 \\
\hline \multirow{4}{*}{ Sul } & Curitiba & 107,17 & 113,79 \\
\hline & Porto Alegre & 83,76 & 88,19 \\
\hline & Urbano & 71,69 & 75,84 \\
\hline & Rural & 48,34 & 51,13 \\
\hline \multirow{3}{*}{ Centro-Oeste } & Brasília & 162,51 & 157,16 \\
\hline & Urbano & 115,47 & 111,43 \\
\hline & Rural & 66,32 & 63,99 \\
\hline
\end{tabular}

Obs.: Valores em Reais (R\$) de julho de 2000.

Fonte: Elaboração própria a partir de Rocha (2003).

Com estas linhas absolutas de pobreza, podemos aplicá-las sobre a população de cada estrato e calcular o número de indivíduos com renda familiar per capita abaixo da correspondente linha de pobreza. A tabela a seguir apresenta as estatísticas básicas da pobreza dos municípios brasileiros por unidade da federação. 
Tabela 3 - Estatísticas Básicas do Número de Pobres

\begin{tabular}{|c|c|c|c|c|c|c|c|c|c|c|c|}
\hline \multirow{2}{*}{$\begin{array}{l}\text { Região } \\
\text { Geográfica }\end{array}$} & \multirow[b]{2}{*}{ Estado } & \multicolumn{5}{|c|}{1991} & \multicolumn{5}{|c|}{2000} \\
\hline & & População & $\mathrm{n}^{\circ}$ de pobres & $\begin{array}{l}\text { Desvio- } \\
\text { Padrão }\end{array}$ & Mínimo & Máximo & População & $\mathrm{n}^{\circ}$ de pobres & $\begin{array}{l}\text { Desvio- } \\
\text { Padrão }\end{array}$ & Mínimo & Máximo \\
\hline \multirow{7}{*}{ Norte } & $\mathrm{RO}$ & 1.125 .046 & 534.318 & 22.731 & 3.894 & 86.437 & 1.369 .444 & 349.355 & 20.008 & 3.649 & 90.307 \\
\hline & AC & 414.102 & 216.940 & 30.746 & 1.315 & 93.292 & 555.471 & 215.643 & 29.647 & 1.649 & 91.715 \\
\hline & AM & 2.087 .753 & 926.907 & 29.931 & 2.204 & 238.237 & 2.807 .323 & 1.322 .030 & 55.272 & 3.786 & 442.338 \\
\hline & RR & 211.419 & 74.104 & 16.535 & 5.387 & 42.612 & 322.523 & 100.063 & 20.015 & 11.936 & 54.768 \\
\hline & PA & 4.905 .433 & 2.721 .049 & 55.303 & 3.175 & 473.230 & 6.166 .634 & 2.701 .546 & 47.507 & 2.815 & 374.924 \\
\hline & AP & 286.673 & 106.735 & 18.379 & 2.758 & 55.654 & 474.658 & 177.913 & 33.742 & 3.525 & 100.956 \\
\hline & TO & 910.157 & 515.966 & 7.864 & 1.446 & 47.339 & 1.150 .882 & 470.266 & 8.017 & 879 & 43.154 \\
\hline \multirow{9}{*}{ Nordeste } & MA & 4.902 .860 & 3.465 .986 & 40.672 & 3.879 & 302.088 & 5.634 .915 & 3.213 .865 & 40.888 & 2.667 & 307.190 \\
\hline & PI & 2.558 .077 & 1.895 .888 & 42.411 & 1.133 & 338.980 & 2.826 .459 & 1.490 .432 & 33.978 & 672 & 268.804 \\
\hline & CE & 6.305 .476 & 4.464.339 & 67.882 & 3.462 & 891.487 & 7.371 .074 & 3.738 .762 & 54.244 & 2.946 & 704.390 \\
\hline & RN & 2.392 .757 & 1.465 .562 & 20.013 & 964 & 219.207 & 2.766 .106 & 1.131 .187 & 16.184 & 833 & 181.415 \\
\hline & PB & 3.175 .867 & 2.237 .389 & 22.202 & 1.532 & 205.067 & 3.414 .992 & 1.570 .826 & 16.449 & 505 & 159.565 \\
\hline & PE & 7.077.995 & 4.816 .005 & 65.780 & 242 & 753.035 & 7.895 .020 & 3.950 .112 & 55.003 & 112 & 613.289 \\
\hline & $\mathrm{AL}$ & 2.491 .971 & 1.609 .122 & 27.447 & 2.678 & 251.723 & 2.817 .468 & 1.471 .632 & 29.021 & 1.875 & 274.747 \\
\hline & SE & 1.478 .474 & 839.567 & 17.403 & 1.368 & 139.882 & 1.776 .661 & 770.979 & 15.447 & 976 & 117.354 \\
\hline & BA & 11.753 .125 & 7.998.316 & 52.353 & 1.769 & 1.019 .851 & 13.018 .111 & 6.210 .392 & 46.275 & 1.482 & 910.424 \\
\hline \multirow{4}{*}{ Sudeste } & MG & 15.542 .085 & 5.905 .796 & 24.542 & 169 & 576.523 & 17.555 .247 & 4.354 .070 & 18.086 & 38 & 399.599 \\
\hline & ES & 2.580 .027 & 853.390 & 15.843 & 1.998 & 84.338 & 3.084 .122 & 576.122 & 13.283 & 709 & 67.972 \\
\hline & RJ & 12.679 .997 & 5.052 .829 & 229.463 & 3.595 & 1.697 .857 & 14.303 .997 & 3.303.335 & 151.323 & 2.180 & 1.087 .790 \\
\hline & $\mathrm{SP}$ & 31.200 .800 & 7.702 .087 & 100.975 & 109 & 2.366 .569 & 36.758 .099 & 8.575 .987 & 115.078 & 193 & 2.681 .644 \\
\hline \multirow{3}{*}{ Sul } & PR & 8.370 .891 & 2.649 .047 & 15.042 & 443 & 225.416 & 9.510 .719 & 1.879 .045 & 13.824 & 293 & 208.055 \\
\hline & SC & 4.497 .033 & 908.614 & 6.382 & 278 & 41.646 & 5.323 .622 & 552.243 & 4.314 & 119 & 32.415 \\
\hline & RS & 9.041 .154 & 2.198.977 & 14.956 & 197 & 162.519 & 10.114 .344 & 1.463 .421 & 12.366 & - & 151.135 \\
\hline & MS & 1.762 .655 & 854.559 & 22.276 & 1.633 & 176.477 & 2.065 .883 & 672.398 & 20.510 & 1.164 & 166.084 \\
\hline Centro- & MT & 2.002 .481 & 985.678 & 21.629 & 924 & 142.272 & 2.492 .199 & 765.291 & 16.874 & 593 & 112.646 \\
\hline \multirow[t]{2}{*}{ Oeste } & GO & 3.976 .645 & 1.906 .226 & 24.503 & 515 & 308.058 & 4.978 .472 & 1.544 .697 & 20.807 & 236 & 225.542 \\
\hline & $\mathrm{DF}$ & 1.565 .191 & 627.396 & - & 627.396 & 627.396 & 2.022 .513 & 656.517 & - & 656.517 & 656.517 \\
\hline \multicolumn{2}{|c|}{ Brasil } & 145.296 .144 & 63.532 .792 & 58.231 & 109 & 2.366 .569 & 168.576 .958 & 53.228 .129 & 55.168 & - & 2.681 .644 \\
\hline
\end{tabular}

Observamos que, do ponto de vista absoluto, há uma redução do número de pessoas com renda familiar per capita abaixo da linha da pobreza. O mesmo ocorre do ponto de vista relativo, uma vez que a população brasileira aumentou entre os anos de 1991 e 2000 . No próximo capítulo discutiremos com mais detalhes a evolução do quadro de pobreza no Brasil.

Além da linha absoluta, utilizamos a linha relativa de pobreza, que usa o conceito de relação entre um certo grupo considerado pobre e com o total da população. Assim estipula um percentual da renda média ${ }^{6}$ da população, como por exemplo, a $30 \%$ da renda média. Com isso, aquelas pessoas ou famílias que possuem renda abaixo deste determinado valor são identificadas como pobres. Como vantagem, leva em consideração aspectos distributivos que as pessoas possam valorar, porém tem como desvantagem o fato de sofrer alteração toda vez que houver uma mudança na distribuição de renda da população, não possibilitando observar se uma variação na pobreza é devido à alteração no valor da linha ou no nível de renda das pessoas. Para este trabalho, serão utilizadas duas linhas relativas: $30 \%$ e 50\% da renda familiar per capita da população de determinado local.

\footnotetext{
${ }^{6}$ Fields (2001) mostra que há dois tipos de linha relativa de pobreza. O primeiro, define um grupo que é relativamente mais pobre, calculando a sua renda média. Já o segundo tipo, usado neste trabalho, considera que a linha de pobreza z é função de $\mu$ que é a renda média, renda mediana ou consumo médio. Assim, z aumenta proporcionalmente a um aumento de $\mu$.
} 


\subsection{3- Distribuição de Renda}

São utilizados os índices de desigualdade de Gini e Theil como proxy para a distribuição da renda relativa. Para cada período foram calculados estes índices para todos os municípios e estados.

\subsubsection{1- Índice de Gini}

Freqüentemente utilizado para expressar o grau de desigualdade de renda, o índice de Gini pode ser associado à chamada curva de Lorenz, que é definida pelo conjunto de pontos que, a partir das rendas ordenadas de forma crescente, relacionam a proporção acumulada de pessoas e a proporção acumulada da renda. Com isso, este índice relaciona a curva de Lorenz da população com a curva representante da situação teórica de desigualdade mínima, em que toda a população tem a mesma renda.

Para se calcular o índice, utiliza-se a fórmula:

$$
\text { Gini }=\frac{1}{\mu \cdot N \cdot(N-1)} \sum_{i>j} \sum_{j}\left|x_{i}-x_{j}\right|
$$

onde $\mu$ é a renda familiar per capita de um determinado local $y, \mathrm{~N}$ é o número de habitantes deste local e $x_{i}$ é a renda familiar per capita do habitante $i$ de $y$.

Nota-se que se todas os habitantes tiverem a mesma renda $\mu$, o Gini será zero, enquanto que se um habitante tiver renda $N \cdot \mu$ e os outros renda igual a zero, haverá $N-1$ diferenças não-zero iguais a $N \cdot \mu$ e o Gini será 1 . Logo, $0 \leq$ Gini $\leq 1$.

Neste trabalho, utilizamos a fórmula da equação (2) para o cálculo do índice de Gini. A tabela abaixo apresenta as estatísticas básicas do índice de Gini. 
Tabela 4 - Estatísticas Básicas do Índice de Gini

\begin{tabular}{|c|c|c|c|c|c|c|c|c|c|}
\hline \multirow{2}{*}{$\begin{array}{l}\text { Região } \\
\text { Geográfica }\end{array}$} & \multirow[b]{2}{*}{ Estado } & \multicolumn{4}{|c|}{1991} & \multicolumn{4}{|c|}{2000} \\
\hline & & Gini & $\begin{array}{l}\text { Desvio- } \\
\text { Padrão }\end{array}$ & Mínimo & Máximo & Gini & $\begin{array}{l}\text { Desvio- } \\
\text { Padrão }\end{array}$ & Mínimo & Máximo \\
\hline \multirow{7}{*}{ Norte } & $\mathrm{RO}$ & 0,608 & 0,031 & 0,486 & 0,658 & 0,592 & 0,022 & 0,475 & $\overline{0,646}$ \\
\hline & $A C$ & 0,621 & 0,018 & 0,464 & 0,634 & 0,631 & 0,021 & 0,561 & 0,670 \\
\hline & AM & 0,610 & 0,050 & 0,402 & 0,712 & 0,668 & 0,037 & 0,528 & 0,787 \\
\hline & RR & 0,635 & 0,051 & 0,597 & 0,734 & 0,605 & 0,019 & 0,574 & 0,640 \\
\hline & PA & 0,616 & 0,049 & 0,390 & 0,703 & 0,633 & 0,039 & 0,454 & 0,744 \\
\hline & AP & 0,567 & 0,019 & 0,513 & 0,650 & 0,616 & 0,012 & 0,583 & 0,668 \\
\hline & TO & 0,607 & 0,048 & 0,410 & 0,685 & 0,628 & 0,038 & 0,462 & 0,722 \\
\hline \multirow{9}{*}{ Nordeste } & $\overline{M A}$ & 0,593 & 0,054 & 0,389 & 0,656 & 0,642 & 0,041 & 0,449 & 0,724 \\
\hline & $\mathrm{PI}$ & 0,637 & 0,049 & 0,411 & 0,760 & 0,648 & 0,042 & 0,427 & 0,663 \\
\hline & CE & 0,647 & 0,063 & 0,380 & 0,673 & 0,662 & 0,045 & 0,475 & 0,701 \\
\hline & $\mathrm{RN}$ & 0,618 & 0,051 & 0,392 & 0,668 & 0,634 & 0,047 & 0,423 & 0,749 \\
\hline & PB & 0,628 & 0,060 & 0,349 & 0,719 & 0,630 & 0,051 & 0,424 & 0,677 \\
\hline & PE & 0,643 & 0,063 & 0,393 & 0,657 & 0,646 & 0,053 & 0,434 & 0,703 \\
\hline & $A L$ & 0,616 & 0,067 & 0,370 & 0,660 & 0,662 & 0,053 & 0,424 & 0,748 \\
\hline & SE & 0,601 & 0,053 & 0,381 & 0,589 & 0,632 & 0,054 & 0,418 & 0,636 \\
\hline & BA & 0,646 & 0,064 & 0,372 & 0,732 & 0,645 & 0,050 & 0,361 & 0,785 \\
\hline \multirow{4}{*}{ Sudeste } & $\overline{M G}$ & 0,599 & 0,048 & 0,348 & 0,718 & 0,599 & 0,052 & 0,341 & 0,740 \\
\hline & ES & 0,585 & 0,048 & 0,422 & 0,693 & 0,589 & 0,037 & 0,419 & 0,667 \\
\hline & RJ & 0,594 & 0,058 & 0,432 & 0,697 & 0,582 & 0,052 & 0,434 & 0,617 \\
\hline & SP & 0,538 & 0,047 & 0,328 & 0,709 & 0,570 & 0,047 & 0,371 & 0,698 \\
\hline \multirow{3}{*}{ Sul } & PR & 0,589 & 0,050 & 0,351 & 0,714 & 0,592 & 0,046 & 0,387 & 0,711 \\
\hline & SC & 0,531 & 0,056 & 0,333 & 0,662 & 0,536 & 0,049 & 0,355 & 0,690 \\
\hline & RS & 0,571 & 0,056 & 0,391 & 0,715 & 0,567 & 0,050 & 0,343 & 0,708 \\
\hline \multirow{4}{*}{ Centro-Oeste } & MS & 0,584 & 0,035 & 0,421 & 0,653 & 0,603 & 0,036 & 0,454 & 0,693 \\
\hline & MT & 0,581 & 0,045 & 0,422 & 0,706 & 0,599 & 0,034 & 0,377 & 0,688 \\
\hline & GO & 0,566 & 0,045 & 0,366 & 0,719 & 0,584 & 0,050 & 0,405 & 0,756 \\
\hline & DF & 0,595 & - & 0,595 & 0,595 & 0,626 & - & 0,626 & 0,626 \\
\hline Brasil & & 0,622 & 0,057 & 0,328 & 0,760 & 0,627 & 0,054 & 0,341 & 0,787 \\
\hline
\end{tabular}

Obs.: Os valores da coluna Gini correspondem aos índices de Gini estaduais e nacional, enquanto que as colunas Desvio-Padrão, Mínimo e Máximo são referentes aos municípios.

Pela Tabela 4, observamos que os estados da região Nordeste possuem os maiores índices de Gini, indicando uma maior desigualdade de renda. Contudo, o estado com a pior evolução do índice entre 1991 e 2000 é o Amazonas (AM) que apresenta um aumento de 10\% no Gini. De maneira geral, a desigualdade de renda no Brasil não apresentou alteração entre os anos analisados, havendo um aumento do Gini na maioria dos estados brasileiros.

\subsubsection{2- Índice de Theil}

Outra maneira de expressar o grau de desigualdade de renda é a medida de entropia de Theil, o chamado índice de Theil-L que é dado por:

Theil $=\frac{1}{N} \sum_{i=1}^{N} \frac{x_{i}}{\mu} \cdot \ln \left(\frac{x_{i}}{\mu}\right)$, 
onde o índice varia entre zero, quando todos têm a mesma renda, e ln $N$, quando um habitante concentra toda a renda. A tabela abaixo apresenta as estatísticas básicas do índice de Theil. ${ }^{7}$

Tabela 5 - Estatísticas Básicas do Índice de Theil

\begin{tabular}{|c|c|c|c|c|c|c|c|c|c|}
\hline \multirow{2}{*}{$\begin{array}{c}\text { Região } \\
\text { Geográfica }\end{array}$} & \multirow[b]{2}{*}{ Estado } & \multicolumn{4}{|c|}{1991} & \multicolumn{4}{|c|}{2000} \\
\hline & & Theil & $\begin{array}{l}\text { Desvio- } \\
\text { Padrão }\end{array}$ & Mínimo & Máximo & Theil & $\begin{array}{l}\text { Desvio- } \\
\text { Padrão }\end{array}$ & Mínimo & Máximo \\
\hline \multirow{7}{*}{ Norte } & $\overline{\mathrm{RO}}$ & 0,768 & 0,115 & 0,422 & 1,004 & 0,722 & 0,093 & 0,371 & 1,036 \\
\hline & $A C$ & 0,801 & 0,042 & 0,393 & 0,906 & 0,867 & 0,058 & 0,536 & 0,891 \\
\hline & AM & 0,754 & 0,161 & 0,315 & 1,251 & 0,940 & 0,174 & 0,432 & 2,089 \\
\hline & $\mathrm{RR}$ & 0,756 & 0,162 & 0,660 & 1,118 & 0,717 & 0,073 & 0,538 & 0,864 \\
\hline & PA & 0,819 & 0,126 & 0,293 & 1,030 & 0,868 & 0,166 & 0,342 & 2,372 \\
\hline & $\mathrm{AP}$ & 0,633 & 0,093 & 0,464 & 1,021 & 0,779 & 0,084 & 0,639 & 0,929 \\
\hline & TO & 0,819 & 0,139 & 0,322 & 1,045 & 0,868 & 0,149 & 0,376 & 1,534 \\
\hline \multirow{9}{*}{ Nordeste } & $\overline{M A}$ & 0,795 & 0,159 & 0,262 & 1,248 & 0,921 & 0,156 & 0,352 & 1,666 \\
\hline & $\mathrm{PI}$ & 0,907 & 0,184 & 0,289 & 1,906 & 0,929 & 0,162 & 0,316 & 1,145 \\
\hline & CE & 0,943 & 0,174 & 0,250 & 1,447 & 0,948 & 0,143 & 0,404 & 1,217 \\
\hline & $\mathrm{RN}$ & 0,806 & 0,144 & 0,260 & 1,311 & 0,843 & 0,157 & 0,229 & 1,827 \\
\hline & PB & 0,870 & 0,156 & 0,211 & 1,075 & 0,844 & 0,152 & 0,296 & 1,225 \\
\hline & PE & 0,895 & 0,166 & 0,262 & 1,183 & 0,887 & 0,165 & 0,361 & 1,864 \\
\hline & $\mathrm{AL}$ & 0,839 & 0,164 & 0,232 & 1,040 & 0,951 & 0,180 & 0,308 & 1,818 \\
\hline & SE & 0,772 & 0,123 & 0,260 & 0,989 & 0,842 & 0,138 & 0,298 & 0,967 \\
\hline & BA & 0,934 & 0,180 & 0,253 & 1,829 & 0,910 & 0,176 & 0,219 & 2,155 \\
\hline \multirow{4}{*}{ Sudeste } & MG & 0,747 & 0,136 & 0,201 & 1,577 & 0,739 & 0,157 & 0,187 & 2,395 \\
\hline & ES & 0,686 & 0,146 & 0,317 & 1,239 & 0,704 & 0,116 & 0,287 & 1,254 \\
\hline & RJ & 0,710 & 0,132 & 0,343 & 1,256 & 0,670 & 0,116 & 0,331 & 1,071 \\
\hline & SP & 0,572 & 0,104 & 0,178 & 1,201 & 0,640 & 0,112 & 0,231 & 1,126 \\
\hline \multirow{3}{*}{ Sul } & PR & 0,704 & 0,161 & 0,207 & 1,408 & 0,721 & 0,143 & 0,260 & 1,795 \\
\hline & SC & 0,558 & 0,140 & 0,211 & 1,215 & 0,588 & 0,139 & 0,228 & 1,572 \\
\hline & $\mathrm{RS}$ & 0,646 & 0,150 & 0,274 & 1,342 & 0,642 & 0,120 & 0,204 & 1,389 \\
\hline \multirow{4}{*}{ Centro-Oeste } & MS & 0,730 & 0,130 & 0,319 & 1,202 & 0,785 & 0,148 & 0,381 & 1,647 \\
\hline & MT & 0,723 & 0,150 & 0,307 & 1,288 & 0,793 & 0,123 & 0,215 & 1,380 \\
\hline & GO & 0,669 & 0,134 & 0,244 & 1,455 & 0,735 & 0,167 & 0,274 & 1,839 \\
\hline & DF & 0,673 & - & 0,673 & 0,673 & 0,740 & - & 0,740 & 0,740 \\
\hline Brasil & & 0,785 & 0,156 & 0,178 & 1,906 & 0,799 & 0,164 & 0,187 & 2,395 \\
\hline
\end{tabular}

Obs.: $\quad$ Os valores da coluna Theil correspondem aos índices de Theil estaduais e nacional, enquanto que as colunas Desvio-Padrão, Mínimo e Máximo são referentes aos municípios.

Assim como na tabela com o índice de Gini, observamos na tabela acima que os estados do Nordeste possuem os maiores índices de Theil, com destaque para o Ceará (CE), Alagoas (AL) e Bahia (BA). Novamente o estado do Amazonas (AM) apresenta o maior aumento do índice. Além disso, com o índice de desigualdade de Theil, percebemos que a desigualdade aumenta em quase todos os estados brasileiros entre os anos de 1991 e 2000.

\footnotetext{
${ }^{7}$ Neste trabalho, sempre que citarmos o índice de desigualdade de Theil, estaremos nos referindo ao índice de Theil-L.
} 


\section{3 - LINHA HÍBRIDA DE POBREZA}

\section{1 - Introdução}

A pobreza é um fenômeno multidimensional e a busca por políticas públicas para combatê-la depende do bom entendimento de sua natureza e causas. Numa primeira aproximação, a pobreza pode ser entendida como insuficiência de renda para alcançar um nível mínimo de padrão de consumo previamente estabelecido pelo analista. A definição clara de uma linha de pobreza é o passo inicial para se determinar o nível de pobreza de um país ou região, permitir comparações entre países ou ao longo do tempo, bem como servir de critério de avaliação de programas sociais.

Recentemente esta temática vem ganhando primazia nas preocupações da sociedade brasileira. Contudo, existem sérias dificuldades de transitar entre, por um lado, o objetivo ético e humanista razoavelmente consensual, e, por outro, as iniciativas concretas de uma política pública eficaz de combate à pobreza.

Primeiramente, destaca-se a questão da definição de pobreza. Apesar das pessoas em geral ter uma noção do que é pobreza, sua mensuração não é tão trivial, envolvendo o estabelecimento de diversos critérios. Na Índia, o programa de combate à fome Antyodaya recorre aos concelhos locais para identificar a população rural mais pobre que recebe as cotas de alimentos subsidiados. Contudo, não é possível expandir esta identificação local da pobreza para um país como um todo. Uma vez que é feita através de indicação, incorre-se em problemas de incentivo à declaração de amigos e familiares como pobres. Adicionando-se a isto, em diversos países, o governo central subsidia provisões de alimentos aos governos regionais de acordo com a respectiva proporção de pobres. Contudo, isto é feito através da auto-identificação da pobreza pelas comunidades locais, o que incentiva determinados grupos de interesse em pressionar a população no sentido de distorcer as declarações na busca por benefícios maiores. Desta forma, há uma forte tendência a uma sobre-estimação da pobreza.

No intuito de minimizar estes problemas e mensurar a pobreza para a elaboração e acompanhamento de políticas públicas, costuma-se trabalhar com linhas de pobreza através do cálculo de um custo mínimo de padrão de vida, com enfoque em particular no acesso à alimentação. Nas economias modernas e monetizadas, onde parcela considerável das 
necessidades das pessoas é atendida através de trocas mercantis, é natural que a noção de atendimento às necessidades seja operacionalizada de forma indireta através da renda. Tratase de estabelecer um valor monetário associado ao custo do atendimento das necessidades mínimas de uma pessoa na sociedade. Esta questão de mensuração é crucial, pois permite distinguir e dimensionar clientelas potenciais, assim como vincular parâmetros à formulação e avaliação de programas sociais.

A construção de uma linha de pobreza envolve escolhas metodológicas e normativas por parte do analista de políticas públicas. Pode-se destacar entre elas a opção por um critério absoluto ou relativo de mensuração da pobreza, que, como já discutido anteriormente, possui tanto vantagens quanto desvantagens. Contudo, é crescente a opinião de que a pobreza, do ponto de vista da renda, é função não somente do padrão de vida do indivíduo, determinado pelos seus rendimentos, como também de sua posição relativa na população.

Metodologicamente, esta escolha envolve a polarização da hipótese sobre a elasticidade-renda da linha de pobreza, qual seja, a mudança percentual da linha de pobreza em relação à mudança percentual da renda média. Em um extremo, o conceito de pobreza absoluta supõe implicitamente que esta elasticidade-renda seja zero. Em outro, a pobreza relativa supõe que seja um. Mas nada obriga-nos a estas duas opções apenas. Em princípio, a elasticidade-renda da linha de pobreza pode ter um valor entre zero (num critério absoluto) e um (num critério relativo), indicando que um acréscimo na renda média aumenta a linha de pobreza menos do que proporcionalmente.

Em 1995, o painel publicado por Citro e Michael (1995) sobre pobreza e assistência familiar, Measuring Poverty: A New Approach da National Academy of Science (NAS), apresentou diversas recomendações para a melhoria das medidas de pobreza, almejando uma linha de pobreza que considerasse fatores relativos e absolutos na sua mensuração e pudesse ser atualizada constantemente. Este painel recomendou que as linhas de pobreza deveriam representar uma quantia monetária para uma cesta básica de bens que inclui alimentos, roupas, abrigo (inclusive utensílios), e uma pequena quantidade adicional para outras necessidades (como por exemplo, cuidados pessoais e transporte não relacionado com o trabalho). Estas linhas deveriam ser desenvolvidas para uma família-referência de dois adultos e duas crianças usando uma base de dados de despesas com consumo, e deveria ser ajustada (usando uma escala de equivalência específica) para refletir as necessidades de diferentes tipos de família e as diferenças geográficas no custo de moradia. Ajustes nas linhas deveriam ser feitos ao longo do tempo para refletir o crescimento real nas despesas com esta cesta básica de bens. 
Foster (1998) exemplifica uma Linha Híbrida de Pobreza que pondera, através da elasticidade-renda, o padrão absoluto de vida e a posição relativa do indivíduo na sociedade. A partir deste conceito, Madden (2000) estima uma elasticidade-renda da linha de pobreza e calcula uma linha híbrida de pobreza para a Irlanda.

A criação de uma linha híbrida de pobreza permite contemplar os dois aspectos das linhas de pobrezas absoluta e relativa. Especificamente, a linha híbrida da pobreza é uma ponderação entre as pobrezas absoluta e relativa, onde os pesos relativos de cada uma dependem da elasticidade-renda da linha de pobreza absoluta. A elasticidade-renda, por sua vez, depende, obviamente, das condições estruturais particulares de cada economia. O seu valor em um dado contexto é, portanto, uma questão empírica.

Este trabalho investiga a construção de uma linha híbrida da pobreza no Brasil a partir da estimação empírica da elasticidade-renda para o País. Utilizando as linhas absolutas de pobreza calculadas através do consumo observado por Rocha (2003), obtemos uma elasticidade-renda desta linha. Em seguida, calculamos uma Linha Híbrida de Pobreza para o Brasil, que é uma média geométrica das linhas de pobreza absoluta e relativa, ponderada pela elasticidade-renda, conforme exemplificado por Foster (1998). Por fim, construímos as incidências brasileiras da pobreza associadas à linha híbrida e comparamos os resultados com aqueles obtidos a partir da linha absoluta.

O objetivo é avaliar até que ponto o uso de uma linha de pobreza híbrida modifica a mensuração da incidência da pobreza em relação ao uso comum da linha absoluta de pobreza. Assim, buscamos examinar a sensibilidade da medida de pobreza com relação à escolha de uma linha absoluta ou relativa de pobreza, determinando em que extensão as linhas de pobreza absoluta e híbrida do Brasil diferem entre si. Até onde podemos verificar, a estimação desta linha híbrida apresenta-se como um estudo que permanece inédito no Brasil. Mesmo ao redor do mundo, poucos países possuem esta estimação, destacando-se os Estados Unidos e a Irlanda. 


\section{2 - Modelo Econométrico}

\subsection{1- Linha Híbrida de Pobreza}

A escolha de uma linha híbrida não precisa ser necessariamente dicotômica entre absoluta e relativa. É possível escolher uma linha de pobreza entre as duas. Assim, a construção da linha híbrida de pobreza depende diretamente de indicadores absolutos e relativos de pobreza. Usando a exemplificação de Foster (1998) em que esta linha é uma ponderação geométrica destes indicadores, sua forma pode ser definida como:

$z=z_{r}^{\rho} z_{a}^{1-\rho}$

onde $z$ é a linha híbrida de pobreza, $z_{r}$ a linha relativa de pobreza, $z_{a}$ a linha absoluta de pobreza e $\rho$ é a elasticidade da linha de pobreza com respeito ao nível de renda, onde $0 \leq \rho$ $\leq 1$.

Fisher (1995) chama $\rho$ de elasticidade-renda da linha de pobreza, mostrando que com $\rho=0, z$ corresponde à linha absoluta de pobreza, e com $\rho=1, z$ é a linha relativa de pobreza. Com isso, o conceito da linha híbrida de pobreza transcende a questão entre linha absoluta ou relativa, passando para a discussão de quanto relativa deve ser a linha de pobreza (Foster, 1998). Portanto a decisão realmente relevante diz respeito ao valor de $\rho$.

Para a estimação da Linha Híbrida de Pobreza, é importante lembrar que a escolha da elasticidade-renda da linha de pobreza ( $\rho$ ) não é somente uma questão normativa, a partir de um simples julgamento se a melhor linha de pobreza para o Brasil é a absoluta ou relativa. Este trabalho estima econometricamente um valor para $\rho$ que indica o quanto relativa é esta linha. Para tanto, tem como base Madden (2000) e o conceito de que um acréscimo de $1 \%$ na renda média ou mediana determina um aumento de $\rho \%$ na linha de pobreza (Foster, 1998).

Madden (2000) estima uma elasticidade-renda da privação segundo uma formulação em que a variável dependente é o consumo observado e a variável independente é o gasto total domiciliar. Com isso, busca estimar quanto varia a medida de consumo com relação à renda que é representada pelo gasto total. Madden (2000) considera que esta elasticidade é um forte candidato ao valor de $\rho$. Desta forma, considera que se for possível identificar o conjunto de bens dos quais sua ausência constitui privação, então a elasticidade-renda deste conjunto de 
bens pode ser uma medida apropriada da elasticidade-renda da linha de pobreza. Ou seja, iguala a elasticidade-renda da linha de pobreza com a elasticidade-renda destes bens dos quais sua ausência na cesta de consumo indica privação.

Vale ressaltar que enquanto Madden (2000) utiliza uma abordagem que mede a elasticidade-renda entre as pessoas no mesmo período de tempo, Citro e Michael (1995) trabalha com uma série de tempo de gastos para uma família-padrão, visando a estimação de uma elasticidade para a atualização da linha de pobreza no tempo. Neste nosso trabalho utilizamos uma metodologia semelhante à do primeiro, medindo a elasticidade-renda entre os estratos brasileiros nos anos de 1991 e 2000.

Diferentemente de Madden (2000), as elasticidades obtidas aqui são simplesmente o resultado das regressões da linha absoluta de pobreza de cada região sobre a respectiva renda familiar per capita média da região. Ou seja, a estimação da elasticidade-renda da linha de pobreza é direta, através da linha de pobreza calculada por Rocha (2003) através do consumo observado.

Assim, a estimação da elasticidade-renda da linha de pobreza seguirá o modelo duplo$\log$ abaixo:

$\log z_{a i, t}=\alpha_{i, t}+\rho_{t} \log y_{i, t}+\varepsilon_{i, t}$

onde $z_{a i, t}$ é o valor da linha absoluta de pobreza da região $i$ conforme a Tabela 2, $y_{i, t}$ é a renda familiar per capita da região $i$ em t, e $\varepsilon_{i, t}$ é o resíduo da equação. Com isso, temos o coeficiente $\rho_{t}$ representando a elasticidade de $z_{a t}$ em relação a $y_{t}$, ou seja, justamente a elasticidade-renda da linha de pobreza.

Desta forma, um coeficiente $\rho_{t}$ elevado indicaria que aumentos da renda familiar per capita impactaria bastante sobre a linha absoluta de pobreza, sendo um indício de que a linha de pobreza muda quase que proporcionalmente à uma mudança na renda média. Esta grande sensibilidade da linha de pobreza à renda significaria que esta linha possui características próximas de uma linha relativa de pobreza.

Uma vez estimado o coeficiente $\rho_{t}$, construímos linhas híbridas de pobreza conforme a equação (4) para cada região, utilizando as respectivas linhas absoluta e relativa.

A partir das linhas híbridas construídas, podemos então estimar as incidências de pobreza através das amostras dos micro-dados dos Censos Demográficos de 1991 e 2000. Utilizamos a metodologia proposta por Deaton (1997) para a ponderação pelos estratos, de forma a tornar a amostra representativa da população e considerando que cada estrato tem 
uma probabilidade diferente de ser selecionado na amostra nacional. Para tanto, aumenta-se o peso das observações sub-representadas e reduz-se o peso das sobre-representadas, através da probabilidade proporcional ao tamanho da população, dada por:

$P_{i}=\frac{w_{i}}{\sum_{k=1}^{n} w_{k}}$,

onde $P_{i}$ é a probabilidade do estrato $i$ a ser selecionado, $w_{i}$ é a população do estrato $i$ e $\mathrm{n}$ é o número total de estratos. O denominador desta equação representa a população total do Brasil.

Vale destacar que a linha híbrida de pobreza obtida através da elasticidade-renda da linha de pobreza não significa uma linha de pobreza "original", ou seja, válida para qualquer período de tempo. Esta linha híbrida representa uma forma alternativa de mensuração da pobreza num determinado período de tempo, uma vez que pode sofrer alterações no tempo devido a mudanças nas linhas absoluta e relativa e na elasticidade-renda da linha de pobreza.

\subsection{2- Determinantes da Probabilidade do Indivíduo Ser Pobre}

Com as linhas híbridas podemos verificar se a incidência da pobreza sofre variação no período analisado. Todavia, não sabemos se os determinantes da incidência da pobreza entre os indivíduos se alteram entre os anos de 1991 e 2000.

Para tanto, buscamos entender quais as características que contribuem para que um indivíduo seja considerado pobre numa sociedade, levando em consideração as linhas absolutas e híbridas deste trabalho. Assim, procuramos encontrar quais indivíduos, dados seus atributos pessoais e regionais, possuem as maiores probabilidades de serem pobres. Ou melhor, estimamos a contribuição de cada atributo sobre a chance de um indivíduo ser pobre. Desta forma, obtemos o efeito marginal de cada atributo sobre a pobreza, ou seja, saberemos o impacto de cada característica que determina se um indivíduo é pobre ou não.

Tomamos como base o estudo de Ferreira, Lanjouw e Neri (2000) em que se estima um modelo probit na regressão da probabilidade de ser pobre sobre variáveis demográficas, características domiciliares e do chefe do domicílio e dummies regionais. Para a estimação neste item, trabalhamos com o nível individual, ao invés do nível domiciliar, não considerando as variáveis domiciliares, inclusive de acesso a serviços públicos, uma vez que 
se entende que a direção da causalidade é mais provável de ser da pobreza para os atributos, ao invés do contrário.

Da mesma forma, para que seja possível a comparação dos resultados, também se trabalha com um modelo probit, regredindo os atributos pessoais e locais de cada indivíduo sobre o fato deste ser pobre. A variável dependente é uma dummy que indica se o indivíduo tem ou não renda familiar per capita abaixo da linha híbrida de pobreza.

Os coeficientes obtidos são indicativos da correlação parcial de cada atributo com a probabilidade de ser pobre. O vetor de variáveis independentes compreende as seguintes variáveis:

- atributos pessoais (mulher, não-branco, idade e escolaridade);

- atributos locais (onde o domicílio se localiza: região metropolitana, unidade da federação e região urbana).

Nos atributos pessoais, há duas variáveis dummy (mulher e não-branco) e duas numéricas (idade e escolaridade). A variável mulher recebe o valor 0 (zero) se o indivíduo é do sexo masculino e 1 (um) se do feminino. A outra variável dummy (não-branco) é 0 (zero), se o indivíduo é da raça branca, e 1 (um), caso contrário. Já as variáveis numéricas, que são idade e escolaridade, indicam o número de anos completos de idade e de estudos, respectivamente. As variáveis locais são definidas de acordo com a Tabela B1 do Apêndice B.

Considerando que se pretende conhecer a influência de determinadas variáveis $\mathrm{X}$ sobre a probabilidade de ser pobre (probabilidade de $\mathrm{y}_{\mathrm{i}}=1$ ), uma maneira de buscar uma solução para a questão é transformar $\mathrm{X} \beta$ (onde $\beta$ é um conjunto de parâmetros) em uma probabilidade. Ao se usar um modelo de probabilidade linear, onde $\operatorname{prob}\left(\mathrm{y}_{\mathrm{i}}=1\right)=\mathrm{X}_{\mathrm{i}} \beta$, enfrenta-se o problema da extrapolação dos valores de $X_{\mathrm{i}} \beta$ além do intervalo entre 0 e 1. Desta forma precisa-se de uma função $F$ tal que:

$\operatorname{prob}\left(\mathrm{y}_{\mathrm{i}}=1\right)=\mathrm{F}\left(\mathrm{X}_{\mathrm{i}} \beta\right)$.

Adotando que F segue uma distribuição normal-padrão chega-se no modelo probit, onde:

$$
\operatorname{prob}\left(y_{i}=1\right)=\Phi\left(X_{i} \beta\right)=\int_{-\infty}^{X_{i} \beta} \frac{1}{\sqrt{2 \pi}} \exp \left(\frac{-z^{2}}{2}\right) d z .
$$

Com esta função F, o modelo retorna um valor entre 0 e 1.

Apesar de não ser observada, existe uma variável latente $y^{*}$ contínua que é indicadora da variável discreta observada y, seguindo a seguinte regra: 
$y_{i}= \begin{cases}1 & \text { se } y_{\mathrm{i}}>0 \\ 0 & \text { caso contrário }\end{cases}$

Além disso, esta variável latente está de acordo com a equação:

$\mathrm{y}_{\mathrm{i}}^{*}=\mathrm{X}_{\mathrm{i}} \beta+\varepsilon_{\mathrm{i}}$,

onde $\varepsilon_{\mathrm{i}}$ tem distribuição normal-padrão.

O efeito marginal de uma variável $X_{k}$ sobre a probabilidade é:

$\frac{\partial E(y)}{\partial X_{k}}=\phi(X \beta) \beta_{k}$

Assim o efeito marginal de $X_{k}$ em $E(y)$ depende de $X$ através da função densidade de probabilidade da normal-padrão $\phi(X \beta)>0$. Desta forma, o efeito marginal segue o sinal matemático de $\beta_{k}$. Por isso, no próximo item deste capítulo, analisamos os resultados com base no sinal de $\beta_{k}$.

\section{3 - Análise dos Resultados}

\subsection{1- Incidência da Pobreza}

As estimações das elasticidades-renda da linha de pobreza e das respectivas linhas de pobreza serão feitas a partir das informações por estrato de acordo com a abertura existente para a linha de pobreza absoluta apresentada na Tabela 2. A estimação a partir do modelo duplo-log da equação (5) resulta na elasticidade-renda da linha de pobreza $(\rho)$ para 1991 e 2000, conforme Tabela 6.

Tabela 6 - Regressão em Logaritmo da Linha de Pobreza na Renda

\begin{tabular}{ccccccc}
\hline \multirow{2}{*}{ Variável } & \multicolumn{2}{c}{1991} & & \multicolumn{2}{c}{2000} \\
\cline { 3 - 4 } \cline { 5 - 6 } & Coeficiente & Desvio-Padrão & & Coeficiente & Desvio-Padrão \\
\hline$\alpha_{i, t}$ & constante & 1,2032 & 0,3417 & & 0,6353 & 0,4624 \\
$\rho_{t}$ & $\log$ (renda) & 0,5977 & 0,0654 & & 0,6712 & 0,0821 \\
\hline número de observações & \multicolumn{2}{c}{26} & & \multicolumn{2}{c}{26} \\
\hline \multicolumn{2}{c}{0,8139} & \multicolumn{2}{c}{0,7910} \\
\hline
\end{tabular}

Obs.: Todas as estimações usam White robusto para heterocedasticidade. 
Observa-se que a elasticidade-renda da linha de pobreza aumenta de 0,5977 em 1991 para 0,6712 em 2000. Contudo, efetuando o teste estatístico:

$$
Z=\left(\rho_{1991}-\rho_{2000}\right) /\left(\sigma_{\rho 1991}^{2}+\sigma_{\rho 2000}^{2}\right)^{0,5},
$$

chegamos em $|Z|=0,70$. Assim não podemos rejeitar a hipótese nula de que os coeficientes $\rho$ de 1991 e 2000 são iguais estatisticamente.

Ao efetuarmos este teste, assumimos que a covariância entre os coeficientes de $1991 \mathrm{e}$ 2000 é zero. Apesar de estarmos analisando amostras e períodos diferentes, a região em questão é a mesma. Assim, talvez esta covariância não seja zero. Para verificarmos se os coeficientes são estatisticamente iguais entre os dois períodos, considerando a existência de covariância diferente de zero, fazemos uma regressão de Mínimos Quadrados Ordinários com os dois anos. Nesta regressão, acrescentamos uma variável dummy de tempo e sua interação com o logaritmo da renda. Desta forma, consideramos a covariância no tempo e podemos verificar a significância do termo de interação, conforme apresentado na Tabela 7.

\section{Tabela 7 - Regressão em Logaritmo da Linha de Pobreza com os Anos de 1991 e 2000}

\begin{tabular}{ccc}
\hline Variável & Coeficiente & Desvio-Padrão \\
\hline constante & 0,6353 & 0,4624 \\
$\log$ (renda) & 0,6712 & 0,0821 \\
dummy 91 & 0,5680 & 0,5750 \\
dummy 91 * $\log$ (renda) & $-0,0735$ & 0,1050 \\
\hline número de observações & \multicolumn{2}{c}{26} \\
\hline $\mathrm{R}^{2}$ & \multicolumn{2}{c}{0,8029} \\
\hline
\end{tabular}

Obs.: Todas as estimações usam White robusto para heterocedasticidade.

Como podemos observar, o coeficiente da interação da dummy do ano de 1991 com o logaritmo da renda não é significativo. Portanto, mesmo considerando covariância no tempo, os coeficientes $\rho$ de 1991 e 2000 não são estatisticamente diferentes.

Vale ressaltar que o intuito da Tabela 7 é testar a igualdade entre os coeficientes $\rho$. Apesar de ser possível calculá-los por esta tabela ${ }^{8}$, os coeficientes em cada período de tempo devem ser analisados pela Tabela 6. Isto se deve ao fato da regressão com os dois anos impor

\footnotetext{
${ }^{8} \mathrm{Na}$ Tabela 7, o coeficiente $\rho$ de 1991 é a soma dos coeficientes do termo $\ln ($ renda), que é o coeficiente $\rho$ de 2000 , e do termo dummy $91 * \ln ($ renda) que captura a diferença entre os coeficientes no tempo.
} 
a restrição de que a variância dos resíduos é a mesma para ambos os períodos ${ }^{9}$, o que pode provocar diferenças entre os desvios-padrão dos coeficientes apresentados nas duas tabelas.

De acordo com Fisher (1995), quanto maior a elasticidade-renda, mais próxima da linha relativa de pobreza está a linha híbrida. Os pontos estimados indicam que a linha híbrida brasileira estaria mais próxima de 1 (um) do que de 0 (zero), levando à conclusão que a linha relativa de pobreza teria um peso pouco maior, com relação à absoluta, na mensuração da pobreza dos estratos brasileiros, uma vez que o expoente que eleva o termo da linha relativa é maior do que o da linha absoluta. Mas devemos ser cautelosos com esta conclusão, pois o coeficiente $\rho$ de 1991 não é estatisticamente diferente de 0,5 embora o de 2000 seja estatisticamente diferente de 0,5 .

Para se calcular as linhas híbridas de pobreza, pela equação (4), utilizamos as linhas absolutas da Tabela 2, as linhas relativas de pobreza de 30\% e 50\% da renda media de cada região e as elasticidades apresentadas na Tabela 6. Desta forma, através da ponderação geométrica das linhas absolutas e relativas, calculamos as linhas híbridas Zh30 e Zh50, onde o número após as letras "Zh" indica o percentual da renda média utilizada no cálculo da linha relativa, conforme apresentado na Tabela 8.

\footnotetext{
${ }^{9}$ Quando estimamos cada período separadamente, temos:

1991: $\log \mathrm{z}_{\mathrm{a}}=\alpha_{01}+\rho_{1} \cdot \log (\mathrm{y})+\varepsilon_{1}, \varepsilon_{1} \sim \mathrm{N}\left(0, \sigma_{1}^{2}\right), \mathrm{e}$

2000: $\log \mathrm{z}_{\mathrm{a}}=\alpha_{02}+\rho_{2} \cdot \log (\mathrm{y})+\varepsilon_{2}, \varepsilon_{2} \sim \mathrm{N}\left(0, \sigma_{2}{ }^{2}\right)$.
}

Quando estimamos através de uma regressão de Mínimos Quadrados Ordinários com os dois anos, temos: $\log z_{a}=\alpha_{02}+\rho_{1} \cdot \log (y)+\left(\alpha_{01}-\alpha_{02}\right) \cdot d 91+\left(\rho_{1}-\rho_{2}\right) \cdot d 91 \cdot \log (y)+\varepsilon, \varepsilon \sim N\left(0, \sigma^{2}\right)$

Como podemos observar, quando estimamos separadamente temos as variâncias dos resíduos $\sigma_{1}^{2}$ e $\sigma_{2}^{2}$ para 1991 e 2000, respectivamente. Já na regressão com os dois anos, a variância é $\sigma^{2}$ independente do período.

No caso analisado neste trabalho, temos a Raiz quadrada da Média dos Quadrados dos Resíduos (RMQR) de 0,176 para 1991 e 0,173 para 2000. Sabemos que um estimador não-viesado da variância é dado por:

$\hat{\sigma}^{2}=\frac{1}{n-2} \sum_{i=1}^{n} \hat{\varepsilon}_{i}{ }^{2}$. Assim, temos $\hat{\sigma}^{2}=\frac{n \cdot R M Q R^{2}}{n-2}$ onde $R M Q R=\sqrt{\frac{1}{n} \sum_{i=1}^{n} \hat{\varepsilon}_{i}{ }^{2}}$. Apesar de estarmos trabalhando com n (número de observações) ponderado a partir de Deaton (1997), os valores de RMQR citados são indicadores da proximidade entre os valores de variância dos resíduos das regressões de 1991 e 2000. Assim, a hipótese de mesma variância para 1991 e 2000 não compromete o teste da Tabela 7. 
Tabela 8 - Linha Híbrida de Pobreza com Renda Média por Estrato e Nacional

\begin{tabular}{|c|c|c|c|c|c|c|c|c|c|c|c|}
\hline \multirow{4}{*}{ Regiões } & \multirow{4}{*}{ Estratos } & \multicolumn{5}{|c|}{1991} & \multicolumn{5}{|c|}{2000} \\
\hline & & \multirow{3}{*}{$\begin{array}{c}\text { Renda } \\
\text { Média } \\
(\mathrm{RM})\end{array}$} & \multicolumn{4}{|c|}{ Linha Híbrida (Zh) } & \multirow{3}{*}{$\begin{array}{c}\text { Renda } \\
\text { Média } \\
(\mathrm{RM})\end{array}$} & \multicolumn{4}{|c|}{ Linha Híbrida $(\mathrm{Zh})$} \\
\hline & & & \multicolumn{2}{|c|}{ RM por Estrato } & \multicolumn{2}{|c|}{ RM Nacional } & & \multicolumn{2}{|c|}{ RM por Estrato } & \multicolumn{2}{|c|}{ RM Nacional } \\
\hline & & & Zh30 & Zh50 & Zh30 & Zh50 & & Zh30 & Zh50 & Zh30 & Zh50 \\
\hline \multirow{3}{*}{ Norte } & Belém & 277,78 & 86,72 & 117,68 & 82,07 & 111,37 & 294,31 & 90,45 & 127,44 & 97,05 & 136,74 \\
\hline & Urbano & 202,82 & 68,62 & 93,12 & 78,37 & 106,35 & 225,83 & 72,38 & 101,98 & 92,77 & 130,70 \\
\hline & Rural & 82,75 & 33,32 & 45,22 & 65,03 & 88,25 & 89,42 & 32,78 & 46,19 & 78,26 & 110,26 \\
\hline \multirow{5}{*}{ Nordeste } & Fortaleza & 215,29 & 76,13 & 103,31 & 83,90 & 113,85 & 277,09 & 86,01 & 121,19 & 96,10 & 135,41 \\
\hline & Recife & 250,60 & 98,03 & 133,03 & 98,66 & 133,89 & 306,49 & 104,06 & 146,61 & 108,65 & 153,09 \\
\hline & Salvador & 287,49 & 98,77 & 134,04 & 91,58 & 124,27 & 343,77 & 108,95 & 153,51 & 105,33 & 148,41 \\
\hline & Urbano & 138,73 & 55,60 & 75,44 & 79,67 & 108,12 & 180,83 & 62,11 & 87,51 & 92,41 & 130,20 \\
\hline & Rural & 51,64 & 25,14 & 34,11 & 65,03 & 88,25 & 62,17 & 25,69 & 36,19 & 78,26 & 110,26 \\
\hline \multirow{15}{*}{ Sudeste } & Minas Gerais & & & & & & & & & & \\
\hline & Belo Horizonte & 350,20 & 105,89 & 143,69 & 87,25 & 118,40 & 423,63 & 123,19 & 173,57 & 103,51 & 145,85 \\
\hline & Urbano & 220,64 & 68,48 & 92,93 & 74,37 & 100,92 & 296,01 & 84,99 & 119,76 & 90,84 & 128,00 \\
\hline & Rural & 82,95 & 30,90 & 41,94 & 60,23 & 81,73 & 125,15 & 40,14 & 56,56 & 76,46 & 107,73 \\
\hline & Espírito Santo & & & & & & & & & & \\
\hline & Urbano & 262,06 & 75,89 & 102,99 & 74,37 & 100,92 & 356,31 & 96,26 & 135,63 & 90,84 & 128,00 \\
\hline & Rural & 89,49 & 32,34 & 43,88 & 60,23 & 81,73 & 154,97 & 46,33 & 65,28 & 76,46 & 107,73 \\
\hline & Rio de Janeiro & & & & & & & & & & \\
\hline & Metrópole & 376,29 & 118,88 & 161,33 & 93,84 & 127,35 & 513,61 & 148,68 & 209,49 & 109,78 & 154,68 \\
\hline & Urbano & 243,72 & 75,77 & 102,82 & 77,53 & 105,22 & 354,05 & 99,09 & 139,62 & 93,92 & 132,33 \\
\hline & Rural & 105,90 & 40,56 & 55,04 & 68,31 & 92,70 & 175,59 & 55,81 & 78,63 & 84,69 & 119,33 \\
\hline & São Paulo & & & & & & & & & & \\
\hline & Metrópole & 506,71 & 152,74 & 207,27 & 100,93 & 136,96 & 567,36 & 170,92 & 240,82 & 118,05 & 166,32 \\
\hline & Urbano & 364,56 & 104,77 & 142,18 & 84,28 & 114,38 & 440,42 & 124,45 & 175,35 & 101,88 & 143,55 \\
\hline & Rural & 159,34 & 53,02 & 71,95 & 69,94 & 94,92 & 222,49 & 67,57 & 95,21 & 87,48 & 123,26 \\
\hline \multirow{4}{*}{ Sul } & Curitiba & 406,37 & 115,75 & 157,08 & 87,26 & 118,42 & 502,29 & 137,39 & 193,59 & 102,98 & 145,09 \\
\hline & Porto Alegre & 400,12 & 103,86 & 140,94 & 79,03 & 107,24 & 509,82 & 127,62 & 179,81 & 94,70 & 133,43 \\
\hline & Urbano & 280,22 & 78,85 & 107,00 & 74,23 & 100,74 & 369,60 & 97,86 & 137,89 & 90,12 & 126,97 \\
\hline & Rural & 118,77 & 40,28 & 54,66 & 63,35 & 85,96 & 192,26 & 55,44 & 78,11 & 79,16 & 111,54 \\
\hline \multirow{4}{*}{$\begin{array}{c}\text { Centro- } \\
\text { Oeste }\end{array}$} & Brasília & 524,27 & 159,36 & 216,26 & 103,18 & 140,02 & 632,51 & 178,35 & 251,29 & 114,51 & 161,35 \\
\hline & Urbano & 266,44 & 92,68 & 125,77 & 89,92 & 122,03 & 329,65 & 102,85 & 144,92 & 102,27 & 144,10 \\
\hline & Rural & 118,37 & 45,66 & 61,96 & 71,94 & 97,63 & 168,55 & 54,64 & 76,98 & 85,22 & 120,08 \\
\hline & BRASIL & 253,31 & \multicolumn{4}{|c|}{$(*)$} & 326,87 & \multicolumn{4}{|c|}{$(*)$} \\
\hline
\end{tabular}

Obs.: (1) Valores em Reais (R\$) de julho de 2000.

(2) As colunas Zh30 e Zh50 indicam as linhas híbridas considerando linhas relativas de 30\% e 50\% da renda média, respectivamente.

(*) As linhas híbridas nacionais são a ponderação das linhas absolutas por estrato com a linha relativa considerando renda média nacional, e estão apresentadas nas colunas de RM Nacional.

Como Rocha (2003) não calcula uma linha absoluta de pobreza nacional, para o cálculo da incidência da pobreza no nível país, calculamos linhas híbridas considerando as linhas absolutas por estrato, conforme a Tabela 2, e uma única linha relativa derivada da renda média nacional. Desta forma, podemos verificar, não somente a pobreza considerando as características locais de padrão de vida por estrato, como também podemos observar a incidência nacional da pobreza a partir de um valor de renda único. Ao compararmos as linhas com renda por estrato e nacional, podemos observar que nos estratos com baixa renda per capita, a linha híbrida com renda nacional apresenta um valor maior do que a linha com renda do estrato. O oposto ocorre quando o estrato possui alta renda per capita, uma vez que sua renda é maior do que a renda média nacional. 
Ao aplicarmos as linhas de pobreza sobre a população de cada estrato com a base de dados dos Censos, chegamos ao número de indivíduos com renda per capita abaixo destas linhas absolutas $(Z a)$ e híbridas $(Z h)$ de pobreza, de acordo com a Tabela 9.

Tabela 9 - Incidência da Pobreza com Renda Média por Estrato

\begin{tabular}{|c|c|c|c|c|c|c|c|c|c|c|c|c|c|c|c|}
\hline \multirow{4}{*}{ Regiões } & \multirow{4}{*}{ Estratos } & \multicolumn{7}{|c|}{1991} & \multicolumn{7}{|c|}{2000} \\
\hline & & \multirow{2}{*}{\multicolumn{2}{|c|}{$\begin{array}{c}\text { Linha Absoluta } \\
\text { de Pobreza } \\
\end{array}$}} & \multicolumn{4}{|c|}{ Linha Híbrida de Pobreza } & \multirow{3}{*}{$\begin{array}{l}\text { População } \\
\text { Total }\end{array}$} & \multirow{2}{*}{\multicolumn{2}{|c|}{$\begin{array}{c}\text { Linha Absoluta } \\
\text { de Pobreza } \\
\end{array}$}} & \multicolumn{4}{|c|}{ Linha Híbrida de Pobreza } & \multirow{3}{*}{$\begin{array}{c}\text { População } \\
\text { Total }\end{array}$} \\
\hline & & & & \multicolumn{2}{|l|}{ Zh30 } & \multicolumn{2}{|l|}{ Zh50 } & & & & \multicolumn{2}{|l|}{ Zh30 } & \multicolumn{2}{|l|}{ Zh50 } & \\
\hline & & $\mathrm{n}^{0}$ de pobres & $\%$ & $\mathrm{n}^{\circ}$ de pobres & $\%$ & $\mathrm{n}^{\circ}$ de pobres & $\%$ & & $n^{\circ}$ de pobres & $\%$ & $n^{\circ}$ de pobres & $\%$ & $\mathrm{n}^{0}$ de pobres & $\%$ & \\
\hline \multirow{3}{*}{ Norte } & Belém & 521 & 39,6 & 436 & 33,1 & 604 & 45,8 & 1.318 & 573 & 32,1 & 544 & 30,5 & 789 & 44,3 & 1.783 \\
\hline & Urbano & 2.267 & 45,7 & 1.395 & 28,1 & 2.026 & 40,9 & 4.958 & 2.790 & 38,6 & 2.425 & 33,5 & 3.401 & 47,0 & 7.237 \\
\hline & Rural & 2.307 & 63,0 & 1.624 & 44,3 & 2.148 & 58,6 & 3.665 & 1.974 & 51,6 & 1.451 & 37,9 & 1.910 & 49,9 & 3.827 \\
\hline \multirow{5}{*}{ Nordeste } & Fortaleza & 1.290 & 56,9 & 930 & 41,1 & 1.212 & 53,5 & 2.265 & 1.161 & 39,3 & 1.085 & 36,7 & 1.492 & 50,5 & 2.954 \\
\hline & Recife & 1.855 & 65,2 & 1.300 & 45,7 & 1.616 & 56,8 & 2.845 & 1.651 & 49,8 & 1.319 & 39,8 & 1.765 & 53,2 & 3.317 \\
\hline & Salvador & 1.308 & 53,5 & 1.011 & 41,3 & 1.298 & 53,1 & 2.447 & 1.223 & 40,9 & 1.091 & 36,5 & 1.503 & 50,3 & 2.989 \\
\hline & Urbano & 11.658 & 64,2 & 6.023 & 33,2 & 8.485 & 46,7 & 18.167 & 10.888 & 45,9 & 8.300 & 35,0 & 11.505 & 48,5 & 23.724 \\
\hline & Rural & 12.681 & 77,3 & 8.044 & 49,0 & 10.504 & 64,0 & 16.413 & 8.624 & 59,3 & 5.295 & 36,4 & 6.971 & 48,0 & 14.537 \\
\hline \multirow{15}{*}{ Sudeste } & Minas Gerais & & & & & & & & & & & & & & \\
\hline & Belo Horizonte & 1.257 & 37,1 & 1.009 & 29,8 & 1.412 & 41,7 & 3.388 & 1.211 & 25,4 & 1.318 & 27,6 & 1.980 & 41,5 & 4.777 \\
\hline & Urbano & 2.730 & 32,5 & 1.848 & 22,0 & 2.883 & 34,3 & 8.392 & 2.164 & 22,1 & 2.383 & 24,4 & 3.577 & 36,6 & 9.779 \\
\hline & Rural & 1.919 & 51,0 & 1.553 & 41,3 & 2.107 & 56,0 & 3.762 & 979 & 32,6 & 878 & 29,3 & 1.217 & 40,6 & 3.000 \\
\hline & Espirito Santo & & & & & & & & & & & & & & \\
\hline & Urbano & 528 & 27,7 & 404 & 21,2 & 624 & 32,8 & 1.906 & 439 & 17,9 & 578 & 23,6 & 898 & 36,6 & 2.450 \\
\hline & Rural & 326 & 48,3 & 297 & 44,1 & 394 & 58,4 & 674 & 137 & 21,7 & 138 & 21,8 & 221 & 34,8 & 634 \\
\hline & Rio de Janeiro & & & & & & & & & & & & & & \\
\hline & Metrópole & 3.971 & 40,9 & 2.925 & 30,1 & 4.096 & 42,2 & 9.711 & 2.675 & 24,7 & 2.916 & 26,9 & 4.416 & 40,8 & 10.821 \\
\hline & Urbano & 793 & 32,4 & 597 & 24,4 & 901 & 36,8 & 2.446 & 498 & 16,6 & 601 & 20,1 & 966 & 32,3 & 2.995 \\
\hline & Rural & 289 & 55,1 & 259 & 49,5 & 333 & 63,6 & 523 & 130 & 26,7 & 109 & 22,3 & 179 & 36,7 & 489 \\
\hline & São Paulo & & & & & & & & & & & & & & \\
\hline & Metrópole & 4.326 & 28,5 & 3.630 & 23,9 & 5.372 & 35,3 & 15.206 & 5.208 & 29,4 & 5.173 & 29,2 & 7.414 & 41,8 & 17.744 \\
\hline & Urbano & 2.649 & 18,8 & 2.216 & 15,7 & 3.751 & 26,6 & 14.076 & 2.976 & 17,1 & 3.509 & 20,2 & 5.736 & 33,0 & 17.356 \\
\hline & Rural & 727 & 37,9 & 756 & 39,4 & 1.040 & 54,2 & 1.919 & 392 & 23,6 & 384 & 23,2 & 614 & 37,0 & 1.658 \\
\hline \multirow{4}{*}{ Sul } & Curitiba & 494 & 25,0 & 426 & 21,6 & 652 & 33,0 & 1.972 & 529 & 19,6 & 680 & 25,1 & 1.029 & 38,0 & 2.704 \\
\hline & Porto Alegre & 513 & 17,1 & 565 & 18,9 & 861 & 28,8 & 2.992 & 466 & 12,8 & 774 & 21,3 & 1.197 & 33,0 & 3.628 \\
\hline & Urbano & 2.521 & 22,0 & 2.035 & 17,7 & 3.266 & 28,5 & 11.475 & 1.970 & 13,9 & 2.749 & 19,3 & 4.428 & 31,2 & 14.214 \\
\hline & Rural & 2.228 & 40,7 & 2.093 & 38,3 & 2.840 & 51,9 & 5.471 & 930 & 21,1 & 997 & 22,6 & 1.495 & 34,0 & 4.403 \\
\hline \multirow{4}{*}{$\begin{array}{l}\text { Centro- } \\
\text { Oeste }\end{array}$} & Brasília & 627 & 40,1 & 566 & 36,1 & 748 & 47,8 & 1.565 & 657 & 32,5 & 740 & 36,6 & 966 & 47,7 & 2.023 \\
\hline & Urbano & 2.803 & 46,1 & 1.716 & 28,2 & 2.563 & 42,1 & 6.082 & 2.486 & 30,7 & 2.266 & 28,0 & 3.402 & 42,1 & 8.087 \\
\hline & Rural & 943 & 56,8 & 753 & 45,4 & 989 & 59,6 & 1.660 & 496 & 34,2 & 409 & 28,2 & 623 & 43,0 & 1.450 \\
\hline & BRASIL & 63.533 & 43,7 & 44.413 & 30,6 & 62.725 & 43,2 & 145.296 & 53.228 & 31,6 & 48.111 & 28,5 & 69.692 & 41,3 & 168.577 \\
\hline
\end{tabular}

Obs.: (1) $n^{o}$ de pobres e População Total em milhares de habitantes.

(2) Os valores das colunas $n^{o}$ de pobres correspondem ao número de pessoas com renda familiar per capita abaixo da linha de pobreza considerada e os valores das colunas \% são o percentual de pessoas pobres em relação ao total populacional de habitantes de cada estrato.

(3) As colunas Zh30 e Zh50 indicam os valores correspondentes às linhas híbridas considerando linhas relativas de $30 \%$ e $50 \%$ da renda média, respectivamente.

Tanto no ano de 1991 quanto no de 2000, observamos que os estratos da região Nordeste apresentam o maior percentual de indivíduos com renda familiar per capita abaixo das linhas de pobreza. Já os estratos da região Sul possuem o menor percentual de indivíduos com renda abaixo das linhas calculadas. Como os valores de elasticidade-renda são elevados, percebemos uma grande diferença entre as linhas híbridas de pobreza, considerando linhas relativas de pobreza de $30 \%$ e $50 \%$, resultando em linhas híbridas entre as linhas absolutas e relativas, porém mais próximas destas últimas. 
Na comparação entre os anos, o principal efeito evidenciado é a queda no percentual de indivíduos considerados pobres, considerando a linha híbrida de pobreza. Durante a década de 90, alguns estratos brasileiros não mostram redução da pobreza. Vale destacar o estado de São Paulo que apresentou aumento da pobreza de aproximadamente $20 \%$ tanto na região metropolitana quanto na região urbana não metropolitana. Enquanto a proporção de pobres residentes na região urbana deste estado aumentou, houve uma queda acima de $30 \%$ na proporção de pobres da região rural. Vale ressaltar que, apesar desta queda significativa da pobreza na região rural, a pobreza não apresenta queda em São Paulo de 1991 para 2000 devido à pequena representatividade desta região no estado e ao fato da população rural ter apresentado redução no período, ao contrário da população urbana. Outros estratos que não apresentam redução da pobreza são Norte Urbano, Nordeste Urbano, Minas Gerais Urbano, Espírito Santo Urbano, Curitiba, Porto Alegre e Sul Urbano. Além disso, observamos que os estratos com maior renda per capita (Brasília e São Paulo) não mostram queda significativa da pobreza. Por outro lado, as regiões rurais dos estratos de Espírito Santo, Rio de Janeiro e Sul apresentam as maiores reduções da pobreza, com queda acima de 30\% na proporção de pobres. Além destes estratos, podemos destacar dentre os estratos de regiões urbanas o Rio de Janeiro com queda de pelo menos $12 \%$ na pobreza. Por fim, com a aplicação de linhas híbridas de pobreza, o Brasil apresenta uma redução de 6,6\% (com Zh30) e 4,2\% (com Zh50) na proporção de pobres na população, enquanto que com a linha absoluta a queda é de $27,8 \%$.

Vale ressaltar que a tabela anterior considera linhas híbridas com linhas absolutas e relativas por estrato para o cálculo das incidências da pobreza nos estratos brasileiros. Entretanto, em políticas públicas, muitas vezes estamos interessados na incidência da pobreza com relação à renda nacional. Assim, calculamos as linhas híbridas para cada estrato considerando as linhas absolutas por estrato e uma linha relativa nacional. Este resultado é apresentado a seguir com a abertura por estrato. 
Tabela 10 - Incidência da Pobreza com Renda Média Nacional

\begin{tabular}{|c|c|c|c|c|c|c|c|c|c|c|c|c|c|c|c|}
\hline \multirow{4}{*}{ Regiões } & \multirow{4}{*}{ Estratos } & \multicolumn{7}{|c|}{1991} & \multicolumn{7}{|c|}{2000} \\
\hline & & \multirow{2}{*}{\multicolumn{2}{|c|}{$\begin{array}{c}\text { Linha Absoluta } \\
\text { de Pobreza }\end{array}$}} & \multicolumn{4}{|c|}{ Linha Híbrida de Pobreza } & \multirow{3}{*}{$\begin{array}{l}\text { População } \\
\text { Total }\end{array}$} & \multirow{2}{*}{\multicolumn{2}{|c|}{$\begin{array}{c}\text { Linha Absoluta } \\
\text { de Pobreza }\end{array}$}} & \multicolumn{4}{|c|}{ Linha Híbrida de Pobreza } & \multirow{3}{*}{$\begin{array}{c}\text { População } \\
\text { Total }\end{array}$} \\
\hline & & & & \multicolumn{2}{|l|}{ Zh30 } & \multicolumn{2}{|l|}{ Zh50 } & & & & Zh30 & & Zh50 & & \\
\hline & & $\mathrm{n}^{0}$ de pobres & $\%$ & $n^{0}$ de pobres & $\%$ & $\mathrm{n}^{0}$ de pobres & $\%$ & & $\mathrm{n}^{\circ}$ de pobres & $\%$ & $\mathrm{n}^{0}$ de pobres & $\%$ & $\mathrm{n}^{0}$ de pobres & $\%$ & \\
\hline \multirow{3}{*}{ Norte } & Belém & 521 & 39,6 & 415 & 31,5 & 576 & 43,7 & 1.318 & 573 & 32,1 & 586 & 32,9 & 841 & 47,2 & 1.783 \\
\hline & Urbano & 2.267 & 45,7 & 2.017 & 40,7 & 2.625 & 52,9 & 4.958 & 2.790 & 38,6 & 3.110 & 43,0 & 4.098 & 56,6 & 7.237 \\
\hline & Rural & 2.307 & 63,0 & 2.520 & 68,8 & 2.897 & 79,0 & 3.665 & 1.974 & 51,6 & 2.637 & 68,9 & 3.051 & 79,7 & 3.827 \\
\hline \multirow{5}{*}{ Nordeste } & Fortaleza & 1.290 & 56,9 & 1.080 & 47,7 & 1.349 & 59,5 & 2.265 & 1.161 & 39,3 & 1.202 & 40,7 & 1.622 & 54,9 & 2.954 \\
\hline & Recife & 1.855 & 65,2 & 1.379 & 48,5 & 1.690 & 59,4 & 2.845 & 1.651 & 49,8 & 1.373 & 41,4 & 1.839 & 55,5 & 3.317 \\
\hline & Salvador & 1.308 & 53,5 & 963 & 39,4 & 1.258 & 51,4 & 2.447 & 1.223 & 40,9 & 1.058 & 35,4 & 1.448 & 48,5 & 2.989 \\
\hline & Urbano & 11.658 & 64,2 & 10.478 & 57,7 & 12.627 & 69,5 & 18.167 & 10.888 & 45,9 & 12.022 & 50,7 & 15.273 & 64,4 & 23.724 \\
\hline & Rural & 12.681 & 77,3 & 13.448 & 81,9 & 14.664 & 89,3 & 16.413 & 8.624 & 59,3 & 11.057 & 76,1 & 12.544 & 86,3 & 14.537 \\
\hline \multirow{15}{*}{ Sudeste } & Minas Gerais & & & & & & & & & & & & & & \\
\hline & Belo Horizonte & 1.257 & 37,1 & 881 & 26,0 & 1.276 & 37,7 & 3.388 & 1.211 & 25,4 & 1.055 & 22,1 & 1.610 & 33,7 & 4.777 \\
\hline & Urbano & 2.730 & 32,5 & 2.541 & 30,3 & 3.657 & 43,6 & 8.392 & 2.164 & 22,1 & 2.594 & 26,5 & 3.860 & 39,5 & 9.779 \\
\hline & Rural & 1.919 & 51,0 & 2.347 & 62,4 & 2.812 & 74,8 & 3.762 & 979 & 32,6 & 1.612 & 53,7 & 2.009 & 67,0 & 3.000 \\
\hline & Espirito Santo & & & & & & & & & & & & & & \\
\hline & Urbano & 528 & 27,7 & 489 & 25,7 & 725 & 38,0 & 1.906 & 439 & 17,9 & 537 & 21,9 & 841 & 34,3 & 2.450 \\
\hline & Rural & 326 & 48,3 & 401 & 59,5 & 486 & 72,1 & 674 & 137 & 21,7 & 269 & 42,5 & 361 & 56,9 & 634 \\
\hline & Rio de Jane & & & & & & & & & & & & & & \\
\hline & Metrópole & 3.971 & 40,9 & 2.509 & 25,8 & 3.597 & 37,0 & 9.711 & 2.675 & 24,7 & 1.969 & 18,2 & 3.140 & 29,0 & 10.821 \\
\hline & Urbano & 793 & 32,4 & 683 & 27,9 & 993 & 40,6 & 2.446 & 498 & 16,6 & 563 & 18,8 & 904 & 30,2 & 2.995 \\
\hline & Rural & 289 & 55,1 & 305 & 58,3 & 377 & 72,1 & 523 & 130 & 26,7 & 192 & 39,3 & 274 & 56,0 & 489 \\
\hline & São Paulo & & & & & & & & & & & & & & \\
\hline & Metrópole & 4.326 & 28,5 & 2.065 & 13,6 & 3.224 & 21,2 & 15.206 & 5.208 & 29,4 & 3.230 & 18,2 & 4.963 & 28,0 & 17.744 \\
\hline & Urbano & 2.649 & 18,8 & 1.727 & 12,3 & 2.927 & 20,8 & 14.076 & 2.976 & 17,1 & 2.719 & 15,7 & 4.322 & 24,9 & 17.356 \\
\hline & Rural & 727 & 37,9 & 768 & 40,0 & 1.043 & 54,4 & 1.919 & 392 & 23,6 & 551 & 33,2 & 819 & 49,4 & 1.658 \\
\hline \multirow{4}{*}{ Sul } & Curitiba & 494 & 25,0 & 318 & 16,1 & 503 & 25,5 & 1.972 & 529 & 19,6 & 469 & 17,3 & 728 & 26,9 & 2.704 \\
\hline & Porto Alegre & 513 & 17,1 & 420 & 14,0 & 667 & 22,3 & 2.992 & 466 & 12,8 & 506 & 13,9 & 820 & 22,6 & 3.628 \\
\hline & Urbano & 2.521 & 22,0 & 2.325 & 20,3 & 3.589 & 31,3 & 11.475 & 1.970 & 13,9 & 2.484 & 17,5 & 3.998 & 28,1 & 14.214 \\
\hline & Rural & 2.228 & 40,7 & 2.671 & 48,8 & 3.385 & 61,9 & 5.471 & 930 & 21,1 & 1.509 & 34,3 & 2.097 & 47,6 & 4.403 \\
\hline \multirow{4}{*}{$\begin{array}{c}\text { Centro- } \\
\text { Oeste }\end{array}$} & Brasília & 627 & 40,1 & 326 & 20,8 & 489 & 31,2 & 1.565 & 657 & 32,5 & 454 & 22,4 & 675 & 33,4 & 2.023 \\
\hline & Urbano & 2.803 & 46,1 & 1.855 & 30,5 & 2.716 & 44,7 & 6.082 & 2.486 & 30,7 & 2.254 & 27,9 & 3.388 & 41,9 & 8.087 \\
\hline & Rural & 943 & 56,8 & 942 & 56,7 & 1.163 & 70,1 & 1.660 & 496 & 34,2 & 678 & 46,8 & 909 & 62,7 & 1.450 \\
\hline & BRASIL & 63.533 & 43,7 & 55.873 & 38,5 & 71.315 & 49,1 & 145.296 & 53.228 & 31,6 & 56.689 & 33,6 & 76.432 & 45,3 & 168.577 \\
\hline
\end{tabular}

Obs.: (1) $n^{o}$ de pobres e População Total em milhares de habitantes.

(2) Os valores das colunas $n^{o}$ de pobres correspondem ao número de pessoas com renda familiar per capita abaixo da linha de pobreza considerada e os valores das colunas \% são o percentual de pessoas pobres em relação ao total populacional de habitantes de cada estrato.

(3) As colunas Zh30 e Zh50 indicam os valores correspondentes às linhas híbridas considerando linhas relativas de $30 \%$ e $50 \%$ da renda média, respectivamente.

Entre as regiões metropolitanas, que possuem renda média acima da nacional, percebemos em São Paulo que a pobreza em cada ano com linha híbrida com renda nacional reduz significativamente quando comparamos com a pobreza a partir da linha com renda por estrato. Entretanto, conforme podemos observar pela Tabela 10, neste estrato, há um aumento de mais de $30 \%$ na pobreza quando observamos a linha com renda nacional entre os anos de 1991 e 2000. Outro estrato que também apresenta um grande aumento da pobreza é São Paulo Urbano. Com relação à redução da pobreza, podemos destacar todo o estado do Rio de Janeiro, com queda de mais de $20 \%$.

Quando comparamos as incidências de pobreza do total Brasil considerando renda média por estrato e nacional, observamos que a pobreza aumenta significativamente com esta última renda, em ambos os anos. Isto indica uma maior concentração da renda abaixo da renda familiar per capita nacional, ou seja, a renda média ( $\mathrm{R} \$ 253,31$ em 1991 e R $\$$ 326,87 em 
2000) é maior do que a renda mediana nacional ( $\mathrm{R} \$ 118,30 \mathrm{em} 1991$ e $\mathrm{R} \$ 152,82 \mathrm{em} \mathrm{2000)}$. A

Tabela 11 mostra as variações do quadro de pobreza no País entre os anos considerados.

Tabela 11 - Variação da Incidência da Pobreza entre os Anos de 1991 e 2000

\begin{tabular}{|c|c|c|c|c|c|c|c|c|c|c|c|}
\hline \multirow{3}{*}{ Regiões } & \multirow{3}{*}{ Estratos } & \multicolumn{5}{|c|}{ Diferença em Pontos Percentuais } & \multicolumn{5}{|c|}{ Variação Percentual para 1991} \\
\hline & & \multirow{2}{*}{$\mathrm{Za}$} & \multicolumn{2}{|c|}{ Zh com RM por Estrato } & \multicolumn{2}{|c|}{ Zh com RM Nacional } & \multirow{2}{*}{$\mathrm{Za}$} & \multicolumn{2}{|c|}{ Zh com RM por Estrato } & \multicolumn{2}{|c|}{ Zh com RM Nacional } \\
\hline & & & Zh30 & Zh50 & Zh30 & Zh50 & & Zh30 & Zh50 & Zh30 & Zh50 \\
\hline \multirow{3}{*}{ Norte } & Belém & $-7,4$ & $-2,6$ & $-1,6$ & 1,4 & 3,5 & $-18,8$ & $-7,7$ & $\overline{-3,4}$ & 4,4 & 7,9 \\
\hline & Urbano & $-7,2$ & 5,4 & 6,1 & 2,3 & 3,7 & $-15,7$ & 19,0 & 15,0 & 5,6 & 7,0 \\
\hline & Rural & $-11,4$ & $-6,4$ & $-8,7$ & 0,2 & 0,7 & $-18,1$ & $-14,4$ & $-14,8$ & 0,2 & 0,8 \\
\hline \multirow{5}{*}{ Nordeste } & Fortaleza & $-17,6$ & $-4,4$ & $-3,0$ & $-7,0$ & $-4,6$ & $-31,0$ & $-10,6$ & $-5,6$ & $-14,6$ & $-7,8$ \\
\hline & Recife & $-15,4$ & $-5,9$ & $-3,6$ & $-7,1$ & $-4,0$ & $-23,7$ & $-13,0$ & $-6,4$ & $-14,6$ & $-6,7$ \\
\hline & Salvador & $-12,5$ & $-4,8$ & $-2,8$ & $-4,0$ & $-2,9$ & $-23,4$ & $-11,6$ & $-5,2$ & $-10,1$ & $-5,7$ \\
\hline & Urbano & $-18,3$ & 1,8 & 1,8 & $-7,0$ & $-5,1$ & $-28,5$ & 5,5 & 3,8 & $-12,1$ & $-7,4$ \\
\hline & Rural & $-17,9$ & $-12,6$ & $-16,0$ & $-5,9$ & $-3,0$ & $-23,2$ & $-25,7$ & $-25,1$ & $-7,2$ & $-3,4$ \\
\hline \multirow{15}{*}{ Sudeste } & Minas Gerais & & & & & & & & & & \\
\hline & Belo Horizonte & $-11,7$ & $-2,2$ & $-0,2$ & $-3,9$ & $-4,0$ & $-31,7$ & $-7,4$ & $-0,6$ & $-15,1$ & $-10,5$ \\
\hline & Urbano & $-10,4$ & 2,4 & 2,2 & $-3,8$ & $-4,1$ & $-32,0$ & 10,7 & 6,5 & $-12,4$ & $-9,4$ \\
\hline & Rural & $-18,4$ & $-12,0$ & $-15,4$ & $-8,7$ & $-7,8$ & $-36,0$ & $-29,1$ & $-27,6$ & $-13,9$ & $-10,4$ \\
\hline & Espirito Santo & & & & & & & & & & \\
\hline & Urbano & $-9,8$ & 2,4 & 3,9 & $-3,7$ & $-3,7$ & $-35,3$ & 11,2 & 11,9 & $-14,5$ & $-9,8$ \\
\hline & Rural & $-26,6$ & $-22,4$ & $-23,5$ & $-17,0$ & $-15,2$ & $-55,2$ & $-50,7$ & $-40,3$ & $-28,6$ & $-21,1$ \\
\hline & Rio de Janeiro & & & & & & & & & & \\
\hline & Metrópole & $-16,2$ & $-3,2$ & $-1,4$ & $-7,6$ & $-8,0$ & $-39,5$ & $-10,6$ & $-3,3$ & $-29,6$ & $-21,7$ \\
\hline & Urbano & $-15,8$ & $-4,3$ & $-4,6$ & $-9,1$ & $-10,4$ & $-48,7$ & $-17,7$ & $-12,4$ & $-32,7$ & $-25,6$ \\
\hline & Rural & $-28,4$ & $-27,3$ & $-26,9$ & $-18,9$ & $-16,1$ & $-51,6$ & $-55,1$ & $-42,3$ & $-32,5$ & $-22,4$ \\
\hline & São Paulo & & & & & & & & & & \\
\hline & Metrópole & 0,9 & 5,3 & 6,5 & 4,6 & 6,8 & 3,2 & 22,1 & 18,3 & 34,0 & 31,9 \\
\hline & Urbano & $-1,7$ & 4,5 & 6,4 & 3,4 & 4,1 & $-8,9$ & 28,5 & 24,0 & 27,7 & 19,7 \\
\hline & Rural & $-14,2$ & $-16,2$ & $-17,2$ & $-6,8$ & $-5,0$ & $-37,6$ & $-41,2$ & $-31,7$ & $-16,9$ & $-9,1$ \\
\hline \multirow{4}{*}{ Sul } & Curitiba & $-5,5$ & 3,5 & 5,0 & 1,2 & 1,4 & $\begin{array}{l}-21,9 \\
\end{array}$ & 16,3 & 15,1 & 7,7 & 5,6 \\
\hline & Porto Alegre & $-4,3$ & 2,4 & 4,2 & $-0,1$ & 0,3 & $-25,2$ & 12,9 & 14,6 & $-0,7$ & 1,4 \\
\hline & Urbano & $-8,1$ & 1,6 & 2,7 & $-2,8$ & $-3,2$ & $-36,9$ & 9,0 & 9,4 & $-13,8$ & $-10,1$ \\
\hline & Rural & $-19,6$ & $-15,6$ & $-17,9$ & $-14,6$ & $-14,3$ & $-48,2$ & $-40,8$ & $-34,6$ & $-29,8$ & $-23,1$ \\
\hline \multirow{4}{*}{$\begin{array}{l}\text { Centro- } \\
\text { Oeste }\end{array}$} & Brasília & $-7,6$ & 0,5 & 0,0 & 1,6 & 2,1 & $-19,0$ & 1,3 & $-0,1$ & 7,8 & 6,9 \\
\hline & Urbano & $-15,3$ & $-0,2$ & $-0,1$ & $-2,6$ & $-2,8$ & $-33,3$ & $-0,7$ & $-0,2$ & $-8,6$ & $-6,2$ \\
\hline & Rural & $-22,6$ & $-17,2$ & $-16,6$ & $-10,0$ & $-7,4$ & $-39,8$ & $-37,9$ & $-27,9$ & $-17,6$ & $-10,5$ \\
\hline & BRASIL & $-12,2$ & $-2,0$ & $-1,8$ & $-4,8$ & $-3,7$ & $-27,8$ & $-6,6$ & $-4,2$ & $-12,6$ & $-7,6$ \\
\hline
\end{tabular}

Obs.: (1) As colunas referentes à Diferença em Pontos Percentuais indicam a diferença da incidência da pobreza entre os anos de 1991 e 2000. Já as colunas da Variação Percentual para 1991, correspondem a relação entre esta diferença e a incidência da pobreza em 1991.

(2) As colunas $Z a$ correspondem aos valores considerando as linhas absolutas de pobreza.

(3) As colunas Zh com RM por Estrato correspondem aos valores utilizando linhas híbridas construídas a partir de linhas relativas por estrato, enquanto que as colunas $Z$ h com RM Nacional correspondem aos valores utilizando linhas híbridas construídas a partir da linha relativa nacional.

(4) As colunas Zh30 e Zh50 indicam os valores correspondentes às linhas híbridas considerando linhas relativas de $30 \%$ e $50 \%$ da renda média, respectivamente.

Esta tabela é um resumo das variações, já discutidas, da pobreza entre os anos de 1991 e 2000, considerando as diversas linhas de pobreza. Observamos que a pobreza no Brasil apresenta redução de 27,8\% quando aplicamos as linhas absolutas de Rocha (2003). Contudo, ao aplicarmos as linhas híbridas, a redução está entre 4,2\% e 12,6\%. Isto se deve ao grande peso das linhas relativas na mensuração da pobreza, uma vez que por representarem o fator 
distributivo refletem o fato da desigualdade de renda no Brasil não ter apresentado redução entre os anos considerados.

\subsection{2- Determinantes da Probabilidade de Ser Pobre}

Até agora verificamos se a incidência da pobreza sofreu alteração entre os anos de 1991 e 2000, considerando o conceito de linha híbrida de pobreza. Contudo não sabemos se os determinantes da incidência da pobreza entre os indivíduos se alteram no período analisado.

Objetivando considerar a heterogeneidade regional do Brasil de forma mais adequada, as estimações com o modelo probit ${ }^{10}$ usam linhas híbridas de pobreza com base nas rendas médias dos estratos.

Para os anos de 1991 e 2000, usamos as linhas híbridas de pobreza estimadas a partir das linhas absolutas e relativas (de 30\% e 50\%). Assim, há três variáveis dependentes para cada ano: pobre (dummy que recebe o valor 1 quando o indivíduo é pobre considerando linha absoluta de pobreza); pobre30 (dummy considerando linha híbrida com linha relativa de $30 \%$ ); e pobre50 (dummy considerando linha híbrida com linha relativa de 50\%).

Na Tabela 12, apresentamos os resultados do modelo probit com as variáveis propostas para o ano de 1991. Observamos praticamente todos os coeficientes são significativos a um nível de significância de $1 \%$.

\footnotetext{
${ }^{10}$ Como no modelo probit trabalhamos no nível individual, não é considerada a metodologia de Deaton (1997) para a construção do peso, uma vez que as probabilidades de seleção de cada indivíduo são extremamente pequenas sobre a população do País, não havendo problemas de sobre-representação. Assim, trabalhamos com o peso de cada indivíduo, dado pelo Censo.
} 
Tabela 12 -Regressões do Modelo Probit para 1991 e 2000

\begin{tabular}{|c|c|c|c|c|c|c|c|c|c|c|c|c|}
\hline \multirow{3}{*}{$\begin{array}{l}\text { Variável } \\
\text { Dependente: }\end{array}$} & \multicolumn{6}{|c|}{1991} & \multicolumn{6}{|c|}{2000} \\
\hline & \multicolumn{2}{|c|}{ pobre } & \multicolumn{2}{|c|}{ pobre 30} & \multicolumn{2}{|c|}{ pobre 50} & \multicolumn{2}{|c|}{ pobre } & \multicolumn{2}{|c|}{ pobre30 } & \multicolumn{2}{|c|}{ pobre 50} \\
\hline & Coeficiente & $\begin{array}{l}\text { Desvio- } \\
\text { Padrão }\end{array}$ & Coeficiente & $\begin{array}{l}\text { Desvio- } \\
\text { Padrão }\end{array}$ & Coeficiente & $\begin{array}{l}\text { Desvio- } \\
\text { Padrão }\end{array}$ & Coeficiente & $\begin{array}{l}\text { Desvio- } \\
\text { Padrão }\end{array}$ & Coeficiente & $\begin{array}{l}\text { Desvio- } \\
\text { Padrão }\end{array}$ & Coeficiente & $\begin{array}{l}\text { Desvio- } \\
\text { Padrão }\end{array}$ \\
\hline \multicolumn{13}{|c|}{ Variáveis Independente: } \\
\hline Intercepto & $-0,2604$ & 0,0004 & $-0,3420$ & 0,0004 & 0,0712 & 0,0004 & $-0,0424$ & 0,0004 & 0,0385 & 0,0004 & 0,4549 & 0,0004 \\
\hline Mulher & 0,0686 & 0,0002 & 0,0698 & 0,0002 & 0,0673 & 0,0002 & 0,0647 & 0,0002 & 0,0667 & 0,0002 & 0,0660 & 0,0002 \\
\hline Não-Branco & 0,3800 & 0,0003 & 0,3291 & 0,0003 & 0,3600 & 0,0002 & 0,3799 & 0,0002 & 0,3449 & 0,0002 & 0,3748 & 0,0002 \\
\hline Idade & $-0,0090$ & 0,00001 & $-0,0093$ & 0,00001 & $-0,0091$ & 0,00001 & $-0,0134$ & 0,00001 & $-0,0131$ & 0,00001 & $-0,0135$ & 0,00001 \\
\hline Escolaridade & $-0,0838$ & 0,0000 & $-0,0754$ & 0,0000 & $-0,0788$ & 0,0000 & $-0,0729$ & 0,0000 & $-0,0667$ & 0,0000 & $-0,0711$ & 0,0000 \\
\hline Reg.Metropolitana & 0,0618 & 0,0001 & 0,0686 & 0,0001 & 0,0656 & 0,0001 & 0,1796 & 0,0003 & 0,2475 & 0,0003 & 0,2315 & 0,0003 \\
\hline Urbano & $-0,2713$ & 0,0003 & $-0,2573$ & 0,0003 & $-0,2713$ & 0,0003 & $-0,2025$ & 0,0003 & $-0,3479$ & 0,0003 & $-0,3239$ & 0,0003 \\
\hline Dummy RO & 0,3752 & 0,0013 & 0,2244 & 0,0013 & 0,1386 & 0,0013 & $-0,1715$ & 0,0013 & $-0,1150$ & 0,0012 & $-0,1595$ & 0,0012 \\
\hline Dummy AC & 0,4051 & 0,0021 & 0,1897 & 0,0021 & 0,1114 & 0,0021 & 0,1361 & 0,0018 & $-0,0048$ & 0,0018 & $-0,0666$ & 0,0018 \\
\hline Dummy AM & 0,2318 & 0,0010 & 0,0262 & 0,0010 & $-0,0221$ & 0,0010 & 0,3811 & 0,0008 & 0,1156 & 0,0009 & 0,0483 & 0,0008 \\
\hline Dummy RR & 0,0300 & 0,0030 & 0,2157 & 0,0029 & 0,0957 & 0,0029 & $-0,0459$ & 0,0025 & $-0,0696$ & 0,0025 & $-0,1415$ & 0,0024 \\
\hline Dummy PA & 0,5497 & 0,0007 & 0,1909 & 0,0007 & 0,1596 & 0,0007 & 0,2336 & 0,0006 & $-0,0974$ & 0,0006 & $-0,1291$ & 0,0006 \\
\hline Dummy AP & 0,0869 & 0,0026 & 0,0545 & 0,0026 & 0,0014 & 0,0025 & 0,1805 & 0,0020 & 0,1348 & 0,0020 & 0,0413 & 0,0019 \\
\hline Dummy TO & 0,5123 & 0,0014 & 0,1709 & 0,0014 & 0,1273 & 0,0014 & 0,2575 & 0,0013 & 0,0255 & 0,0013 & $-0,0247$ & 0,0013 \\
\hline Dummy MA & 0,8365 & 0,0007 & 0,1513 & 0,0007 & 0,1280 & 0,0007 & 0,6178 & 0,0006 & 0,0688 & 0,0006 & 0,0132 & 0,0006 \\
\hline Dummy PI & 1,0279 & 0,0009 & 0,3941 & 0,0009 & 0,3389 & 0,0009 & 0,5412 & 0,0008 & 0,1214 & 0,0009 & 0,0511 & 0,0008 \\
\hline Dummy CE & 1,0795 & 0,0006 & 0,4524 & 0,0006 & 0,4189 & 0,0006 & 0,5214 & 0,0006 & 0,1039 & 0,0006 & 0,0557 & 0,0005 \\
\hline Dummy RN & 0,7833 & 0,0009 & 0,2915 & 0,0009 & 0,2596 & 0,0009 & 0,3520 & 0,0008 & 0,0751 & 0,0009 & 0,0381 & 0,0008 \\
\hline Dummy PB & 1,0232 & 0,0008 & 0,3629 & 0,0008 & 0,3263 & 0,0008 & 0,4663 & 0,0008 & 0,0648 & 0,0008 & 0,0244 & 0,0008 \\
\hline Dummy PE & 1,0342 & 0,0006 & 0,4729 & 0,0006 & 0,4290 & 0,0006 & 0,5373 & 0,0005 & 0,1069 & 0,0005 & 0,0618 & 0,0005 \\
\hline Dummy AL & 0,7487 & 0,0009 & 0,1697 & 0,0009 & 0,1441 & 0,0009 & 0,5358 & 0,0008 & 0,1133 & 0,0009 & 0,0540 & 0,0008 \\
\hline Dummy SE & 0,5673 & 0,0011 & 0,1184 & 0,0012 & 0,0921 & 0,0011 & 0,3296 & 0,0010 & $-0,0182$ & 0,0011 & $-0,0650$ & 0,0010 \\
\hline Dummy BA & 0,8558 & 0,0005 & 0,2893 & 0,0005 & 0,2520 & 0,0005 & 0,3928 & 0,0005 & 0,0014 & 0,0005 & $-0,0432$ & 0,0004 \\
\hline Dummy MG & 0,2517 & 0,0005 & 0,1344 & 0,0005 & 0,1152 & 0,0004 & $-0,0755$ & 0,0004 & $-0,1118$ & 0,0004 & $-0,1093$ & 0,0004 \\
\hline Dummy ES & 0,0995 & 0,0009 & 0,1093 & 0,0009 & 0,0674 & 0,0009 & $-0,2776$ & 0,0009 & $-0,1175$ & 0,0009 & $-0,1378$ & 0,0008 \\
\hline Dummy RJ & 0,4514 & 0,0005 & 0,2736 & 0,0005 & 0,2599 & 0,0005 & $-0,1050$ & 0,0005 & $-0,0993$ & 0,0005 & $-0,1054$ & 0,0004 \\
\hline Dummy PR & 0,1346 & 0,0006 & 0,1033 & 0,0006 & 0,0919 & 0,0005 & $-0,1434$ & 0,0006 & $-0,0645$ & 0,0005 & $-0,0581$ & 0,0005 \\
\hline Dummy SC & $-0,1220$ & 0,0008 & $-0,0158$ & 0,0008 & $-0,0577$ & 0,0007 & $-0,4953$ & 0,0008 & $-0,2373$ & 0,0008 & $-0,2343$ & 0,0007 \\
\hline Dummy RS & $-0,0086$ & 0,0006 & 0,0890 & 0,0006 & 0,0572 & 0,0005 & $-0,3081$ & 0,0006 & $-0,1029$ & 0,0005 & $-0,1313$ & 0,0005 \\
\hline Dummy MS & 0,5538 & 0,0010 & 0,3119 & 0,0011 & 0,3086 & 0,0010 & 0,2174 & 0,0010 & 0,1095 & 0,0010 & 0,1248 & 0,0010 \\
\hline Dummy MT & 0,4841 & 0,0010 & 0,2245 & 0,0010 & 0,1904 & 0,0010 & 0,0798 & 0,0009 & $-0,0225$ & 0,0009 & $-0,0069$ & 0,0009 \\
\hline Dummy GO & 0,5267 & 0,0007 & 0,2185 & 0,0008 & 0,2235 & 0,0007 & 0,1610 & 0,0007 & $-0,0060$ & 0,0007 & 0,0184 & 0,0007 \\
\hline Dummy DF & 0,7779 & 0,0012 & 0,7965 & 0,0012 & 0,7549 & 0,0011 & 0,3144 & 0,0010 & 0,4826 & 0,0010 & 0,3889 & 0,0010 \\
\hline Pseudo- $\mathrm{R}^{2}$ & \multicolumn{2}{|c|}{0,1904} & \multicolumn{2}{|c|}{0,1068} & \multicolumn{2}{|c|}{0,1148} & \multicolumn{2}{|c|}{0,1662} & \multicolumn{2}{|c|}{0,1170} & \multicolumn{2}{|c|}{0,1227} \\
\hline $\begin{array}{l}\text { número de } \\
\text { observações }\end{array}$ & \multicolumn{6}{|c|}{145.296 .144} & \multicolumn{6}{|c|}{168.576 .958} \\
\hline
\end{tabular}

Obs.: (1) A Dummy SP (Estado de São Paulo) foi retirada da regressão para evitar o problema de multicolinearidade perfeita. Portanto, é a variável de estado referência.

(2) As variáveis dependentes são dummies que recebem o valor 1 (um) quando o individuo é pobre, considerando certa linha de pobreza: pobre (dummy considerando linha absoluta de pobreza); pobre30 (dummy considerando linha híbrida com linha relativa de 30\%); e pobre 50 (dummy considerando linha híbrida com linha relativa de $50 \%$ ).

(3) Todas as estimações usam White robusto para heterocedasticidade.

Considerando os coeficientes das estimações feitas, primeiramente percebemos que a variável Mulher tem coeficiente positivo e significante, quando controlamos pelas outras variáveis incluídas. Um indivíduo do sexo feminino tem uma maior probabilidade de ser pobre do que um do sexo masculino, quando controlamos pelas outras variáveis. Isto nos traz indícios de que, apesar dos esforços para a igualdade entre os gêneros na sociedade brasileira, as mulheres ainda apresentam uma maior probabilidade de serem pobres, em relação aos homens. O mesmo ocorre com os indivíduos que não são da raça branca. Esta variável associada à raça mostra o efeito sobre a pobreza maior do que a variável de gênero. Mesmo 
controlando por variáveis, como escolaridade e localização regional, um indivíduo não-branco tende a ser mais pobre do que um branco.

A variável Idade indica que quanto mais velho é o indivíduo, menor a probabilidade de ser pobre. Isto provavelmente deve-se ao efeito da acumulação de riqueza ao longo da vida e à relação crescente e positiva entre idade e renda. Um resultado bastante intuitivo vem do fato de que a probabilidade de um indivíduo ser pobre também é menor quanto maior é a sua escolaridade.

Finalmente, o efeito dos atributos locais sobre a probabilidade de ser pobre tem um forte impacto. As variáveis de região metropolitana e região urbana mostram efeitos diferentes em 1991. Os indivíduos que moram em regiões metropolitanas apresentam uma maior probabilidade de serem pobres. Provavelmente, este resultado está captando a forte influência das periferias das grandes cidades sobre o quadro de pobreza. Assim, apesar das regiões metropolitanas possuírem rendas per capita mais elevadas, isto não significa que merecem menos atenção com relação a políticas públicas de combate à pobreza. Já a dummy Urbano indica uma menor probabilidade para o indivíduo ser pobre. Analisando ambas as variáveis, percebemos que a variável Urbano está captando o efeito do indivíduo residir numa região urbana, controlando pelas outras variáveis, inclusive pela variável Região Metropolitana. Assim, consideramos que a dummy Urbano está captando o efeito da residência em região urbana não metropolitana.

Com relação as dummies de estado, observamos inicialmente em sua maioria apresentam impacto positivo sobre a probabilidade de ser pobre, quando consideramos a linha absoluta de pobreza. Podemos destacar que estes coeficientes vão se tornando menores consoante aumentamos a linha relativa no cálculo da linha híbrida de pobreza. Em muitos estados, estes coeficientes passam a apresentar sinal negativo com a linha Zh50. Vale lembrar que estes coeficientes estão em relação ao estado de São Paulo (SP), unidade federativa com elevada renda familiar per capita. Assim, em relação a este estado, apenas o estado de Santa Catarina (SC) que impacta negativamente sobre a probabilidade, independente da linha de pobreza considerada. Isto indica que, em 1991, os indivíduos localizados neste estado apresentam uma menor probabilidade de serem pobres.

Para 2000, podemos observar que as variáveis individuais Mulher, Não-Branco, Idade e Escolaridade apresentam os mesmos sinais e valores próximos dos de 1991. Quanto aos atributos locais, este comportamento se confirma com as variáveis de região metropolitana e região urbana não metropolitana apresentando sinais contrários, entre si. Percebemos que em 1991 a segunda variável é 4 vezes maior do que a primeira, em módulo. Já em 2000, há um 
aumento do valor do coeficiente da variável Região Metropolitana, sendo apenas $30 \%$ menor do que o coeficiente da variável Urbano.

É possível observar uma melhora nos resultados quando se comparam os anos de 1991 e 2000. Vários estados apresentam inversão no sinal de suas respectivas dummies, destacando-se os estados das regiões Sul e Sudeste. Os estados de Rondônia (RO) e Roraima (RR) na região Norte também apresentam este comportamento.

Apesar de melhoria da situação em grande parte dos estados, o Amapá (AP) mostra uma piora, apresentando um efeito positivo e aumento nos valores de seus coeficientes, independente da linha de pobreza considerada. Na região Nordeste, todos os estados apresentam coeficientes locais positivos em 1991. Já em 2000, os estados cujos moradores têm a menor probabilidade de serem pobres são Sergipe (SE) e Bahia (BA). Vale destacar a região Sudeste que por ser a mais populosa do Brasil, conseqüentemente possui maior peso na regressão no âmbito nacional. Um fato interessante nesta região é que o Espírito Santo (ES), apesar de ser o estado menos rico da região, é o que apresenta a seus residentes a menor probabilidade de terem renda familiar per capita abaixo das linhas híbridas de pobreza estimadas em 2000. Já na região Sul, Santa Catarina (SC) merece destaque por apresentar a menor probabilidade de ser pobre para os indivíduos residentes no estado em relação ao País. Por fim, os indivíduos que residem no estado do Mato Grosso (MT) possuem a menor probabilidade de serem pobres na região Centro-Oeste.

\section{4 - Fatos Estilizados e Conclusões}

Este trabalho analisa a pobreza no Brasil entre os anos de 1991 e 2000 dentro do âmbito da pobreza como insuficiência de renda. Para tanto, estima para diferentes regiões do Brasil a linha híbrida de pobreza. No seu cálculo, inicialmente estimamos a elasticidade-renda da linha de pobreza absoluta. Pelas estimações desta elasticidade, observamos valores por volta de 0,6, indicando que as linhas híbridas calculadas com base nestas elasticidades, possuem características entre as linhas absolutas e relativas, com leve predominância das últimas na mensuração da pobreza no Brasil. Esta leve predominância das linhas relativas de pobreza indica que a renda familiar per capita têm impacto relevante sobre a linha absoluta de pobreza, indicando que a linha de pobreza se altera dada uma mudança na renda média. 
Com isso, concluímos que esta sensibilidade da linha de pobreza à renda é um indício que esta linha possui características próximas de uma linha relativa de pobreza. Entretanto, a metodologia adotada neste trabalho enfrenta a limitação do pequeno número de linhas de pobreza nas regiões e estratos, calculadas por Rocha (2003), as linhas híbridas de pobreza estimadas têm como base um único valor de elasticidade-renda da linha de pobreza para cada ano. Forçoso supor, portanto, que ela é igual para todas as regiões do país.

Madden (2000) obtém uma elasticidade-renda da linha de pobreza de 0,5 para a Irlanda, considerando um conjunto de bens básicos, duráveis, de moradia e secundários (como carro e telefone). Quando considera apenas bens básicos, esta elasticidade é de 0,7 tanto para o ano de 1987 quanto para 1994. Citro e Michael (1995) apresenta a elasticidade dos Estados Unidos entre 0,65 e 0,80, dependendo da especificação utilizada. Considerando uma cesta de alimentos, roupas e moradia, e visando encontrar uma forma de atualizar a linha de pobreza norte-americana, estima uma elasticidade no tempo de 0,65 para o período de 1959 a 1991.

A utilização das linhas híbridas calculadas para a mensuração de pobreza mostra que houve uma redução do quadro de pobreza no Brasil entre os anos de 1991 e 2000, porém inferior à registrada utilizando linhas absolutas de pobreza. Este comportamento de queda da pobreza absoluta, segundo Lavinas (2005), parece se dever principalmente ao sucesso do plano de estabilização de 1994, o Plano Real. Contudo, ao considerarmos o efeito distributivo na construção da linha de pobreza, percebemos uma menor queda da pobreza, consequiência do aumento da pobreza relativa no Brasil. Este fato evidencia a piora dos índices de desigualdade de renda em muitos municípios brasileiros entre os anos de 1991 e 2000, de maneira que os índices de desigualdade de renda para o Brasil não apresentam melhora entre os anos considerados na análise.

Com relação aos determinantes da incidência da pobreza entre os indivíduos, utilizamos como base Ferreira, Lanjouw e Neri (2000) que estima um modelo probit da regressão da probabilidade do domicílio ser pobre sobre variáveis demográficas, características domiciliares e do chefe do domicílio e dummies regionais. Entretanto, o modelo adotado neste capítulo não considera variáveis de características do domicílio e acesso a serviços públicos, uma vez que se entende que a direção da causalidade é mais provável de ser da pobreza para os atributos, ao invés do contrário.

A Tabela 13 mostra os resultados de Ferreira, Lanjouw e Neri (2000) que são apresentados em termos de efeito marginal da variável independente sobre a probabilidade do domicílio ser pobre, com base na PNAD do ano de 1996. 
Tabela 13 - Resultados do Modelo Probit de Ferreira, Lanjouw e Neri (2000)

\begin{tabular}{|c|c|c|}
\hline Variáveis & $\mathrm{dF} / \mathrm{dx}$ & p-valor \\
\hline $\begin{array}{l}\text { Variáveis Demográficas: } \\
\text { Número de moradores do domicílio } \\
\text { (Número de moradores do domicílio) } \\
\text { Proporção de pessoas com idade }<5 \text { anos } \\
\text { Proporção de pessoas com idade entre } 5 \text { e } 15 \text { anos } \\
\text { Proporção de pessoas com idade }>65 \text { anos }\end{array}$ & $\begin{array}{c}0,0838 \\
-0,0035 \\
0,7788 \\
0,4635 \\
0,0050 \\
\end{array}$ & $\begin{array}{l}0,000 \\
0,002 \\
0,000 \\
0,000 \\
0,949 \\
\end{array}$ \\
\hline $\begin{array}{l}\text { Características do Chefe de Domicílio: } \\
\text { Idade } \\
\text { (Idade) }^{2} \\
\text { Escolaridade } \\
\text { dummy Mulher } \\
\text { dummy Negro } \\
\text { dummy Mulato } \\
\text { dummy Indígena } \\
\text { dummy Empregado conta-própria } \\
\text { dummy Desempregado ou Não-remunerado } \\
\text { dummy Empregado }\end{array}$ & $\begin{array}{r}0,0050 \\
-0,0001 \\
-0,0229 \\
-0,0038 \\
-0,0304 \\
0,0157 \\
0,1870 \\
0,0970 \\
0,0688 \\
-0,0530\end{array}$ & $\begin{array}{l}0,204 \\
0,176 \\
0,000 \\
0,882 \\
0,445 \\
0,490 \\
0,183 \\
0,153 \\
0,300 \\
0,368\end{array}$ \\
\hline $\begin{array}{l}\text { Características do Domicílio e Acesso a Serviços: } \\
\text { Piso de terra batida na casa } \\
\text { Número de quartos } \\
\text { Vias de terra batida fora da casa } \\
\text { dummy Favela } \\
\text { dummy Água encanada } \\
\text { dummy Eletricidade } \\
\text { dummy Telefone }\end{array}$ & $\begin{array}{r}0,1226 \\
-0,0676 \\
0,0178 \\
0,0648 \\
-0,1129 \\
-0,1374 \\
-0,2281\end{array}$ & $\begin{array}{l}0,011 \\
0,000 \\
0,494 \\
0,114 \\
0,001 \\
0,008 \\
0,000\end{array}$ \\
\hline $\begin{array}{l}\text { Dummies Regionais: } \\
\text { Região Metropolitana de Fortaleza } \\
\text { Região Metropolitana de Recife } \\
\text { Região Metropolitana de Salvador } \\
\text { Região Metropolitana de Belo Horizonte } \\
\text { Região Metropolitana de Rio de Janeiro } \\
\text { Nordeste - outras regiões urbanas } \\
\text { Nordeste - rural } \\
\text { Sudeste - outras regiões urbanas } \\
\text { Sudeste - rural }\end{array}$ & $\begin{array}{l}0,3603 \\
0,5325 \\
0,4889 \\
0,1249 \\
0,1973 \\
0,5367 \\
0,3549 \\
0,0909 \\
0,1940\end{array}$ & $\begin{array}{l}0,000 \\
0,000 \\
0,000 \\
0,002 \\
0,000 \\
0,000 \\
0,000 \\
0,025 \\
0,001\end{array}$ \\
\hline
\end{tabular}

Dadas as variáveis controladas na estimação da Tabela 13, vale lembrar que esta comparação entre os resultados dos modelos não é imediata uma vez que o modelo de Ferreira, Lanjouw e Neri (2000) trabalha com o nível domiciliar, enquanto que o modelo apresentado neste capítulo está no nível individual. Destacamos que o coeficiente da variável Idade é positivo e não significativo, que é contrário ao obtido pelas estimações neste capítulo. O mesmo ocorre com a variável Mulher que apresenta coeficiente negativo e não significativo. Assim, estas variáveis do chefe do domicílio não são relevantes sobre a probabilidade do domicílio ser pobre, dado o modelo. Já a escolaridade apresenta resultado semelhante em ambos os modelos. Outro resultado que se destaca é o sinal positivo de todos os coeficientes das dummies regionais, que são apresentadas em relação à região metropolitana de São Paulo. Considerando este fato, todas as regiões contribuem para o aumento da probabilidade de ser pobre, inclusive as dummies de outras regiões urbanas. Apesar do resultado das regiões metropolitanas ser semelhante ao obtido neste capítulo, há 
uma divergência quanto às outras regiões urbanas, uma vez que o coeficiente da dummy de região urbana da Tabela 12, que capta o efeito da região urbana não metropolitana, é negativo tanto em 1991 quanto em 2000.

Por fim, o modelo probit considerado neste capítulo, em geral, apresenta resultados coerentes com a teoria econômica. Na análise nacional, observamos que os indivíduos que não pertencem à raça branca ou que são mulheres apresentam uma maior probabilidade de serem pobres, destacando a raça que tem um impacto sobre a probabilidade da ordem de 5 a 6 vezes maior do que o sexo do indivíduo. Com efeito contrário está a idade e principalmente a escolaridade do indivíduo. Isto vem ao encontro da teoria econômica uma vez que o indivíduo com maior escolaridade, tende a ser tecnicamente mais capacitado, apresentando maior produtividade e recebendo um salário maior, o que o distancia da pobreza.

De maneira geral, na comparação entre os anos de 1991 e 2000, concluímos que os determinantes da probabilidade de um indivíduo ser pobre, como sexo, raça, idade e escolaridade, não apresentam grandes alterações. Contudo, considerando as características locais de residência dos indivíduos, percebemos uma melhora nos efeitos de regiões urbanas não metropolitanas e de estados brasileiros sobre a probabilidade de ser pobre, e uma piora no efeito de regiões metropolitanas sobre a incidência da pobreza. 


\section{4 - DETERMINANTES DA REDUÇÃO DA POBREZA NA DÉCADA DE 90}

\section{1 - Introdução}

A relação entre mudanças na renda e desigualdade sobre a redução da pobreza vem se destacando nos últimos anos em decorrência da constatação de que em diversos países do mundo as questões relativas à pobreza não foram equacionadas como resultado do crescimento econômico. Rocha (2003) expõe que mesmo nos casos bem-sucedidos de crescimento econômico, fica evidente que taxas adequadas de expansão do produto não necessariamente se difundem através da sociedade. São patentes tanto as dificuldades dos países ricos em eliminar redutos remanescentes de pobreza, como as crescentes desigualdades sociais resultantes do processo de expansão econômica nos países em desenvolvimento.

$\mathrm{Na}$ busca por medir a relação entre crescimento da renda e redução da pobreza em uma dada região, costuma-se usar a elasticidade-renda. Se elevada, políticas públicas de combate à pobreza baseadas no crescimento econômico são suficientemente eficientes. Caso contrário, sendo esta elasticidade baixa, estratégias de redução da pobreza deveriam envolver uma combinação de crescimento econômico com algum tipo de redistribuição. Cline (2004) destaca o "paradoxo da persistência da pobreza global", explicitando que a maioria das estimações sobre a pobreza no mundo mostram um menor declínio durante a década de 90 do que o previsto pela relação crescimento econômico e pobreza, dada pela elasticidade-renda da pobreza.

Ravallion e Chen (1997) estimaram, para uma amostra de países em desenvolvimento, a elasticidade da pobreza (medida pelo número de pessoas com renda abaixo da linha de pobreza de 1 dólar por dia), chegando ao valor de -3 , ou seja, para cada $1 \%$ de aumento na renda média, há uma redução da proporção de indivíduos com renda abaixo da linha de pobreza em 3\%. Entretanto, há países que conseguem alterar o quadro interno de pobreza sem conhecerem grandes taxas de crescimento econômico. Assim, conhecer as causas desta heterogeneidade entre regiões é fundamental para a elaboração de estratégias de combate à pobreza.

Uma vez que apenas o crescimento econômico não é capaz de explicar a redução da pobreza, a desigualdade de renda passa a se destacar como o fator complementar no estudo da 
evolução da pobreza no Brasil e no mundo. Rocha (2003) explica que o Brasil, dada a sua renda per capita, teria recursos disponíveis suficientes para garantir um mínimo essencial à população, e conclui que a persistência da pobreza absoluta se deve à forte desigualdade na distribuição de renda.

Epaulard (2003) explica que se considerarmos uma distribuição de renda constante num período de crescimento econômico, conhecer esta distribuição permitiria prever quanto este crescimento reduziria a pobreza. Esta elasticidade da pobreza com relação ao crescimento da renda dependeria da distribuição de renda, e diferenças nesta distribuição explicariam diferenças nas elasticidades. Nos casos onde a distribuição de renda se altera ao longo de um processo de crescimento econômico, a mudança na pobreza pode ser decomposta em dois efeitos: o efeito do crescimento e o efeito da mudança na distribuição de renda.

Bourguignon (2002) mostra que a relação entre crescimento da renda média e mudança na pobreza é de $-1,6$, num modelo de regressão linear com aproximadamente 50 países. Contudo, é ressaltado que mudanças na renda média da população explicam apenas $26 \%$ da variação da pobreza. Levando isto em consideração, não faria sentido basear as estratégias de combate à pobreza somente sobre o crescimento econômico, como muitas vezes ocorre. Seria melhor inicialmente identificar a natureza dos remanescentes $74 \%$ e as razões da pobreza reagir de forma diferente em diversas regiões que apresentam crescimentos econômicos semelhantes.

No sentido de considerar a heterogeneidade entre regiões, busca-se explicar variações da pobreza através dos componentes de crescimento econômico e mudança no grau de desigualdade da renda ao longo do tempo, destacando-se Ravallion e Datt (1992), Bourguignon (2002), Marinho e Soares (2003) e Hoffmann (2004).

Este trabalho tem como base Bourguignon (2002) em que é considerada uma aproximação funcional desta identidade na forma de uma distribuição log-normal. Assim, assume que a distribuição de renda se aproxima a uma log-normal. Pelo Gráfico 1, observamos que uma parte da variação na pobreza é explicada pelo crescimento econômico e o restante resulta de mudanças na distribuição da renda. Este gráfico mostra a densidade da distribuição de renda, ou seja, o número de indivíduos em cada nível de renda representado no eixo horizontal em escala logarítmica. 


\section{Gráfico 1 - Decomposição da Mudança na Pobreza nos Efeitos Crescimento e}

\section{Distribuição.}

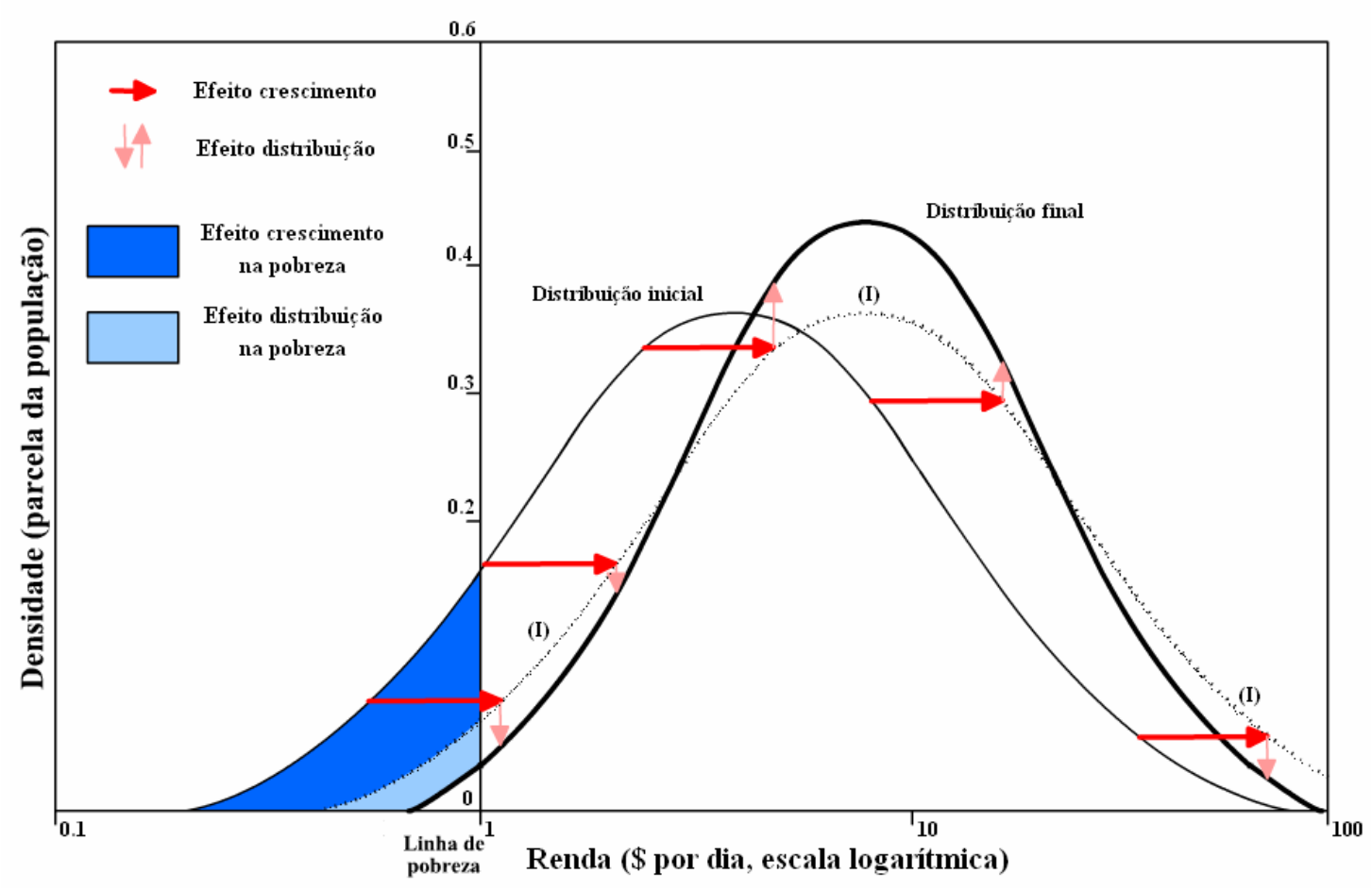

Fonte: Bourguignon (2002).

O movimento da distribuição inicial para a final ocorre através de um passo intermediário [curva (I)], que é a translação horizontal da distribuição inicial. Devido à escala logarítmica no eixo horizontal, esta mudança representa um aumento igualmente proporcional de todas as rendas na população, correspondendo ao efeito crescimento. Já o movimento da curva (I) para a distribuição final ocorre mantendo-se a renda média constante e alterando-se a distribuição da renda relativa, correspondendo ao efeito distribuição.

Vale ressaltar que nesta decomposição existe um certo fator de dependência do caminho, ou seja, ao invés de se mover, a distribuição primeiro horizontalmente e depois para cima, poder-se-ia inicialmente alterar a distribuição para cima e depois movê-la para a direita. Apesar destas duas formas de movimento não serem necessariamente equivalentes, com exceção de mudanças infinitesimais, trabalhamos com a hipótese de que este efeito é suficientemente pequeno, ignorando-se o fator de dependência do caminho.

Toda esta análise considera a variação sobre a pobreza medida a partir de uma linha absoluta, ou seja, analisa os efeitos crescimento e distribuição sobre uma dada linha de pobreza. Entretanto, ao utilizarmos uma linha híbrida de pobreza, incluí-se um efeito da mudança da linha em conseqüência de uma variação da renda relativa. Pelo Gráfico 2, 
observamos que a variação na pobreza medida através de uma linha híbrida é explicada por três efeitos: crescimento econômico; distribuição de renda; e deslocamento da linha. $\mathrm{Na}$ verdade, ainda há dois efeitos, porém o efeito crescimento econômico influência não somente a pobreza como também sua medida de mensuração.

\section{Gráfico 2 - Decomposição da Mudança na Pobreza considerando Linha Híbrida}

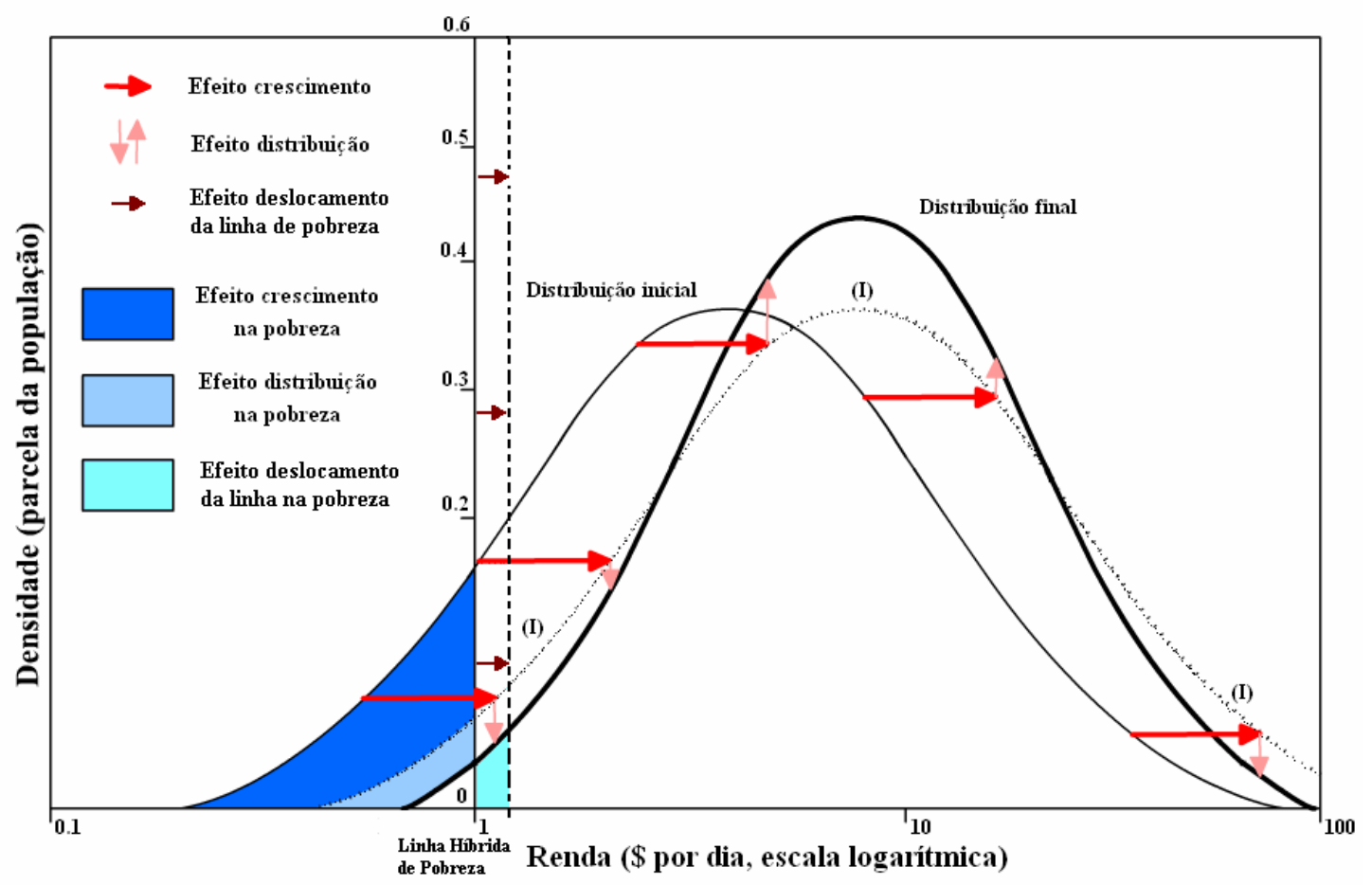

Fonte: Elaboração própria a partir de Bourguignon (2002).

Observa-se pelo Gráfico 2 que a linha híbrida de pobreza sofre um deslocamento para a direita quando há um aumento da renda. Este terceiro efeito é na verdade uma conseqüência do efeito crescimento. Mantendo-se constante a distribuição de renda relativa, um aumento da renda reduz a pobreza diretamente, porém desloca a linha híbrida provocando também um aumento da pobreza. Assim, a elevação da renda provoca efeitos contrários sobre a pobreza, que dependem da magnitude desta elevação, da distribuição de renda e da elasticidade-renda da linha de pobreza. Como já discutido no capítulo anterior, esta elasticidade-renda indicará em que proporção a linha híbrida de pobreza irá se deslocar dado um aumento na renda.

Desta forma, este trabalho decompõe a redução da pobreza ocorrida entre os anos de 1991 e 2000 no Brasil, considerando as linhas absoluta e híbrida e visando analisar a pobreza ao longo dos municípios brasileiros, diferentemente dos trabalhos supracitados em que se 
analisa esta variação entre países. Além disso, vale destacar que a aplicação de uma linha híbrida de pobreza nos modelos de efeito de crescimento e distribuição de renda sobre a variação da pobreza caracteriza-se como um estudo inédito para o Brasil, não somente pelo fato de não haver trabalhos sobre a estimação desta linha, como também devido à inexistência de estudos que consideram alteração na linha híbrida para a decomposição da variação da pobreza.

\section{2- Modelos Econométricos}

A análise da relação entre as variáveis baseia-se na estimação da contribuição de variações no crescimento e na distribuição de renda sobre alterações na pobreza. Para tanto, serão utilizados dois tipos de abordagem sobre o assunto, num contexto de Painel Balanceado.

\subsection{1- Modelo baseado em Ravallion e Datt (1992)}

Ravallion e Datt (1992) propõem uma metodologia para quantificar a contribuição relativa do crescimento versus redistribuição sobre mudança na pobreza. Decompõem esta mudança de acordo com a seguinte equação:

$$
\begin{aligned}
\mathrm{P}_{\mathrm{t}+\mathrm{n}}-\mathrm{P}_{\mathrm{t}}= & \mathrm{G}(\mathrm{t}, \mathrm{t}+\mathrm{n} ; \mathrm{r})+\mathrm{D}(\mathrm{t}, \mathrm{t}+\mathrm{n} ; \mathrm{r})+\mathrm{R}(\mathrm{t}, \mathrm{t}+\mathrm{n} ; \mathrm{r}), \\
\text { componente } & \text { componente resíduo } \\
\text { de crescimento de redistribuição } &
\end{aligned}
$$

onde P é a mensuração da pobreza; G é a variação da pobreza dada uma mudança na renda; D é a variação da pobreza dada uma mudança na distribuição de renda; $\mathrm{R}$ é o resíduo da decomposição; $\mathrm{t}$ e t+n são os períodos inicial e final, respectivamente; e r é o período de referência em que a mudança observada na pobreza é decomposta, podendo ser inclusive t ou $\mathrm{t}+\mathrm{n}$.

O modelo apresentado neste trabalho é baseado no proposto por Ravallion e Datt (1992). Contudo, diferentemente deste, estimamos econometricamente o impacto das variações sobre a redução da pobreza. Assim, o componente crescimento mostra a mudança da 
pobreza devido a uma variação na renda familiar per capita mantendo a distribuição da renda relativa inalterada, e o componente da distribuição de renda mostra a mudança na pobreza devido a uma alteração na distribuição da renda mantendo a renda média constante.

Desta forma, a mudança na pobreza ao longo de um período de tempo pode ser decomposta da seguinte forma:

$$
\begin{aligned}
& P_{i, t}=\beta_{11} G_{i, t}+\beta_{12} D_{i, t}+\theta_{i}+\varepsilon_{i, t} \\
& P_{i, t+1}=\beta_{21} G_{i, t+1}+\beta_{22} D_{i, t+1}+\theta_{i}+\varepsilon_{i, t+1} \\
& \Delta P_{i}=\beta_{1} \Delta G_{i}+\beta_{2} \Delta D_{i}+\Delta \varepsilon_{i}
\end{aligned}
$$

onde $i$ é o local, ou seja, município ou estado; $P_{i, t}$ e $P_{i, t+1}$ são as proporções, em relação à população total, de pessoas com renda familiar per capita abaixo da linha de pobreza em $\mathrm{t}=1991$ e $\mathrm{t}+1=2000$, respectivamente; $G_{i, t}$ e $G_{i, t+1}$ são as rendas per capita familiar dos municípios ou estados nos dois períodos; $D_{i, t}$ e $D_{i, t+1}$ são os índices de desigualdade de renda (Gini ou Theil) para os respectivos períodos em cada local; $\theta_{i}$ é o efeito individual não observado; $\varepsilon_{i, t}$ e $\varepsilon_{i, t+1}$ são os resíduos da estimação para cada período; e $\Delta P_{i}, \Delta G_{i}, \Delta D_{i}$ e $\Delta \varepsilon_{i}$ são as variações de pobreza, crescimento, desigualdade e resíduo, respectivamente. Com isso, a diferença entre as equações (14) e (15) resulta em (16), com o efeito individual local não observado, que é constante no tempo, se anulando.

Basicamente é um modelo de análise de painel com somente dois períodos $(\mathrm{T}=2)$. Neste caso, perde-se uma cross-section ao aplicar Primeiras Diferenças e o modelo torna-se uma regressão linear por mínimos quadrados ordinários de $\Delta P_{i}$ sobre $\Delta G_{i}$ e $\Delta D_{i}$. Além disso, como $\mathrm{T}=2$, as estimações por Primeiras Diferenças ou por Efeitos Fixos produzem estimadores e inferências idênticas.

É importante citar que, ao contrário de trabalhos como Kakwani e Subbarao (1990) que estimam a pobreza sobre o crescimento, considerando o resíduo como o componente de distribuição; este trabalho usa a estimação com as duas variáveis explicativas e o resíduo, buscando o impacto real de cada variável sobre a variação da pobreza e evitando a falsa impressão de que a decomposição é exata. 


\subsection{2- Modelagem de Bourguignon (2002)}

Considerando a equação (16), a elasticidade do crescimento $\left(\beta_{1}\right)$ e a da distribuição $\left(\beta_{2}\right)$, sobre a redução da pobreza, são constantes. Numa expansão deste modelo, apresentada em Bourguignon (2002), permite-se que a elasticidade-renda da pobreza varie, dependendo do inverso do nível inicial de desenvolvimento (linha absoluta de pobreza dividida pela renda familiar per capita) e do nível inicial de desigualdade (índice de Gini ou Theil). Este modelo é descrito da seguinte forma:

$$
\Delta P_{i}=\Delta \alpha_{i}+\beta_{1} \Delta G_{i}+\beta_{2} \Delta D_{i}+\beta_{3}\left[\Delta G_{i}(z / \bar{y})\right]+\beta_{4} \Delta G_{i} D I+\Delta \varepsilon_{i}
$$

onde $z$ é a linha absoluta de pobreza de 1991 para cada indivíduo $i$ que, neste trabalho, é representado pelo município; $\bar{y}$ é a renda familiar per capita de $i$ em 1991; e DI é nível inicial de desigualdade de $i$ no ano de 1991. Para o cálculo de z, utilizou-se as linhas absolutas de pobreza da Tabela 2, ponderando-as pelo número de pessoas distribuídas pelos níveis de urbanização de cada $i$.

Além deste, Bourguignon (2002) acrescenta variabilidade na elasticidade-desigualdade da pobreza, conforme a equação abaixo:

$$
\Delta P_{i}=\Delta \alpha_{i}+\beta_{1} \Delta G_{i}+\beta_{2} \Delta D_{i}+\beta_{3}\left[\Delta G_{i}\left(z / \frac{y}{y}\right)\right]+\beta_{4} \Delta G_{i} D I+\beta_{5}\left[\Delta D_{i}\left(z / \frac{z}{y}\right)\right]+\beta_{6} \Delta D_{i} D I+\Delta \varepsilon_{i}
$$

onde as variáveis são definidas similarmente à equação (17).

Neste modelo, ambas as elasticidades dependem do inverso do nível inicial de desenvolvimento e do nível inicial de desigualdade. Assim, consegue-se não somente mensurar o impacto das variações de crescimento e desigualdade sobre mudanças na pobreza como também as variações nas elasticidades.

\subsection{3- Elasticidades pela Log-Normalidade}

A principal contribuição de Bourguignon (2002) é a proposta do modelo log-normal, focando-se na aproximação funcional da identidade Pobreza-Renda-Distribuição, assumindo que a distribuição de renda aproxima-se a uma log-normal. Assim, parte da variação na 
pobreza é explicada pelo crescimento econômico e outra resulta de mudanças na distribuição da renda.

Bourguignon (2002) considera que os modelos apresentados anteriormente não descrevem a interação entre crescimento da renda, nível inicial de desenvolvimento e nível inicial de desigualdade para determinar a redução da pobreza. Buscando captar este efeito conjunto, calcula elasticidades teóricas sob a hipótese de que a distribuição de renda é lognormal.

Com isso, é possível calcular, diretamente através dos parâmetros da distribuição de renda familiar per capita, as elasticidades da proporção de pobres em relação à renda e à desigualdade. ${ }^{11}$ Hoffmann (2004) calcula estas elasticidades para o Brasil, apresentando-as por estado, com base no índice de Gini. Também explicita as elasticidades com o índice de Theil, apesar de não as calcular.

Com base nas elasticidades, Bourguignon (2002) testa a hipótese de log-normalidade da distribuição de renda através do modelo de identidade log-normal 1, conforme abaixo:

$\Delta P_{i}=\Delta \alpha_{i}+\beta_{1} \varepsilon_{y} \Delta G_{i}+\beta_{2} \Delta D_{i}+\Delta \varepsilon$

onde $\varepsilon_{y}$ é o valor teórico da elasticidade do crescimento sob a hipótese log-normal, dado por:

$\varepsilon_{y}=-\frac{1}{\sigma} \cdot \frac{\phi\left(\frac{1}{2} \sigma+\frac{\ln \left(z_{a} / \bar{y}\right)}{\sigma}\right)}{\Phi\left(\frac{1}{2} \sigma+\frac{\ln \left(z_{a} / \bar{y}\right)}{\sigma}\right)}$,

com $\sigma$ sendo o desvio-padrão do logaritmo da renda ${ }^{12}$, ou seja, o grau de desigualdade da renda, calculado com base no índice de Gini ou de Theil do município $i$ no tempo; $\phi$ representando a função densidade da distribuição normal-padrão e $\Phi($.$) a função de$ distribuição acumulada da normal-padrão. Um menor nível de desenvolvimento e maior grau de desigualdade contribuem para uma redução na elasticidade do crescimento. Assim, o valor teórico da elasticidade do crescimento permite o efeito conjunto do crescimento na renda, do nível de desenvolvimento e do grau de desigualdade, para determinar a redução na pobreza.

Com a equação (19), busca-se testar se o coeficiente $\beta_{1}$ é igual a -1 , o que significaria que o valor teórico da elasticidade do crescimento sob a hipótese log-normal representa a relação entre variações de renda e pobreza, sendo considerado no teste em módulo.

\footnotetext{
${ }^{11}$ No Apêndice F, são apresentadas as deduções das elasticidades com base nos trabalhos de Bourguignon (2002) e Hoffmann (2004).

${ }^{12} \sigma$ é calculado a partir das fórmulas para a distribuição log-normal dos índices de Gini, por: $\sigma=\sqrt{2} \cdot \Phi^{-1}\left(\frac{G+1}{2}\right)$, e de Theil, por: $\sigma=\sqrt{2 T}$.
} 
Contudo, neste modelo, a elasticidade da distribuição permanece constante. Então, Bourguignon (2002) propõe um teste com o modelo de identidade log-normal 2, com a seguinte estrutura:

$\Delta P_{i}=\Delta \alpha_{i}+\beta_{1} \varepsilon_{y} \Delta G_{i}+\beta_{2} \varepsilon_{G} \Delta D_{i}+\Delta \varepsilon$

onde $\varepsilon_{y}$ é o valor teórico da elasticidade do crescimento, conforme o modelo anterior, e $\varepsilon_{G}$ é o valor teórico da elasticidade da desigualdade na pobreza sob a hipótese log-normal, sendo representado por:

$\varepsilon_{G}=\frac{G \cdot\left(\frac{1}{2}-\frac{\ln \left(z_{a} / \bar{y}\right)}{\sigma^{2}}\right)}{\sqrt{2} \cdot \phi\left(\frac{\sigma}{\sqrt{2}}\right)} \cdot \frac{\phi\left(\frac{1}{2} \sigma+\frac{\ln \left(z_{a} / \bar{y}\right)}{\sigma}\right)}{\Phi\left(\frac{1}{2} \sigma+\frac{\ln \left(z_{a} / \bar{y}\right)}{\sigma}\right)}$, com o índice de $\mathrm{Gini}^{13} ; \mathrm{e}$

$\varepsilon_{G}=\left[\frac{\sigma}{4}-\frac{\ln \left(z_{a} / \bar{y}\right)}{2 \sigma}\right] \cdot \frac{\phi\left(\frac{1}{2} \sigma+\frac{\ln \left(z_{a} / \bar{y}\right)}{\sigma}\right)}{\Phi\left(\frac{1}{2} \sigma+\frac{\ln \left(z_{a} / \bar{y}\right)}{\sigma}\right)}$, com o índice de Theil ${ }^{14}$.

Desta forma, o efeito da mudança na distribuição sobre a redução na pobreza é função do nível de desenvolvimento e do grau de desigualdade. Este modelo permite que ambas as elasticidades variem de acordo com as mudanças na renda e na desigualdade, captando o efeito conjunto do crescimento na renda, do nível de desenvolvimento e da desigualdade de renda, para determinar a redução na pobreza. No caso do modelo, busca-se testar se os coeficientes $\beta_{1}$ e $\beta_{2}$ são iguais a -1 e 1 , respectivamente.

Os modelos log-normais oferecem uma maneira de testar a identidade que relaciona redução da pobreza com crescimento e desigualdade na renda, sob a hipótese da distribuição da renda relativa ser log-normal. Assim, podemos verificar se esta hipótese de lognormalidade é coerente com a distribuição de renda brasileira.

\footnotetext{
${ }^{13}$ Vale lembrar que $\sigma$ é calculado a partir do índice de Gini para a distribuição log-normal: $\sigma=\sqrt{2} \cdot \Phi^{-1}\left(\frac{G+1}{2}\right)$

${ }^{14}$ Vale lembrar que $\sigma$ é calculado a partir do índice de Theil para a distribuição log-normal: $\sigma=\sqrt{2 T}$.
} 


\subsection{4- Modelo considerando uma Linha Híbrida de Pobreza}

$\mathrm{Na}$ utilização de uma linha híbrida de pobreza para o estudo dos determinantes da redução da pobreza, conforme já discutido, pelo Gráfico 2, acrescenta-se um efeito da mudança da linha em consequiência de uma variação da renda relativa. Assim, observamos que a variação na pobreza medida por uma linha híbrida é explicada pelos efeitos crescimento econômico, distribuição de renda, e deslocamento da linha. $\mathrm{O}$ efeito renda passa a influenciar a pobreza e sua medida de mensuração.

Considerando um modelo em painel, de acordo com a equação (16), estima-se os determinantes da variação da pobreza a partir de:

$\ln p_{i t}=\alpha_{i}+\alpha_{t}+\beta_{1} \ln r_{i t}+\beta_{2} \ln d_{i t}+\varepsilon_{i t}$

onde $p_{i t}$ é a proporção de pobres medida por uma linha híbrida de pobreza; $\alpha_{i}$ é o efeito individual não observado do município $i ; \alpha_{t}$ é o termo constante em cada período; $r_{i t}$ é a renda familiar per capita do município $i$ no período $t ; d_{i t}$ é o índice de desigualdade de renda do município $i$ em $t$; e $\varepsilon_{i t}$ é o resíduo da regressão.

Pela equação (24), sabe-se que $p_{i t}$ é função de $r_{i t}$ e $d_{i t}$, para uma dada linha absoluta de pobreza $\left(Z a_{i t}\right)$. Assim, pode-se representar $p_{i t}$ como:

$p_{i t}=f\left(r_{i t}, d_{i t} \mid Z a_{i t}\right)$

Entretanto, considerando uma linha híbrida de pobreza $\left(Z h_{i t}\right)$, a proporção de pobreza também é função da linha de pobreza que a mensura, sendo representada por:

$$
p_{i t}=f\left(r_{i t}, d_{i t}, Z h_{i t}\right)
$$

Desta forma, acrescenta-se na equação (24) o termo referente ao efeito do deslocamento da linha híbrida de pobreza $\left(\ln Z h_{i t}\right)$, resultando na equação:

$\ln p_{i t}=\alpha_{i}+\alpha_{t}+\beta_{1} \ln r_{i t}+\beta_{2} \ln d_{i t}+\beta_{3} \ln Z h_{i t}+\varepsilon_{i t}$

A linha híbrida de pobreza usada na equação (27) segue a especificação da equação (4) . Assim, calculando a elasticidade-renda ${ }^{15}$ da pobreza com linha híbrida $\left(\varepsilon_{\mathrm{r}}\right)$, temos:

$\varepsilon_{\mathrm{r}}=\beta_{1}+\beta_{3} \cdot \rho_{t}$

\footnotetext{
15 No Apêndice F, é apresentada a dedução da elasticidade-renda da incidência da pobreza a partir da linha híbrida com base na estimação da equação (27).
} 
A equação (28) apresenta a elasticidade-renda da pobreza. O segundo termo $\beta_{3} . \rho_{t}$ representa a influência do deslocamento da linha híbrida sobre a variação da pobreza. Quanto maior a elasticidade-renda $\rho_{t}$ da linha de pobreza, maior é a influência da linha relativa na mensuração da pobreza e, conseqüentemente, maior é o deslocamento da linha híbrida. Quando a pobreza é medida por uma linha absoluta, tem-se $\rho_{t}=0$ e $\varepsilon_{\mathrm{r}}=\beta_{1}$, que é o resultado da especificação inicial de acordo com as equações (16) e (24).

\section{3 - Análise dos Resultados}

A identidade entre variações na renda familiar per capita e nos índices de desigualdade de renda sobre a redução da pobreza deveria ser aparentemente clara numa base de dados com informações de indivíduos ao longo do tempo. Contudo, isto depende do modelo utilizado, como é mostrado nesta seção.

Com base nas modelagens apresentadas, trabalhamos com um painel de municípios. Como cada município tem uma probabilidade diferente de ser selecionado na amostra nacional, é utilizada a metodologia proposta por Deaton (1997) descrita no capítulo anterior. Já para os modelos de Bourguignon (2002), por trabalhar com variações no tempo, as probabilidades foram calculadas com base nas médias populacionais do período analisado.

\subsection{1- Modelo baseado em Ravallion e Datt (1992)}

Este trabalho utiliza um Painel balanceado de municípios, ou seja, os indivíduos da cross-section são os municípios, e os períodos de tempo são os anos de 1991 e 2000. Como há grandes diferenças no cenário macroeconômico do Brasil entre estes anos, é acrescentada uma dummy de tempo na estimação para verificar efeitos do ano de 1991, que incidem sobre todos os municípios brasileiros e têm impacto sobre a variação na pobreza.

Com base nos modelos apresentados na seção anterior, são estimadas as elasticidades da renda e da desigualdade sobre a pobreza. Para tanto, trabalha-se com a variação do 
logaritmo das variáveis pobreza, renda e desigualdade, buscando-se a variação percentual. Inicialmente estima-se um modelo simples de alterações na pobreza sobre variação na renda familiar per capita. Em seguida, acrescenta-se a variação no índice de desigualdade de renda (Gini ou Theil) dos municípios, estimando-se o modelo baseado em Ravallion e Datt (1992). O primeiro método de estimação utilizado é o de Mínimos Quadrados Ordinários com ambos os anos (MQO), em que é usado o método de mínimos quadrados ordinários sobre as observações ao longo dos municípios e anos. Já o segundo assume a hipótese de exogeneidade forte, ou seja, o resíduo de um período não é correlacionado com as variáveis explicativas de qualquer período e com o efeito individual não observado dos municípios. Com isso, usa-se o método de Efeitos Fixos com estimador de desvios com relação à média. Por fim, o terceiro método introduz a hipótese de não correlação entre as variáveis explicativas e o efeito individual não observado, correspondendo ao método de Efeitos Aleatórios. Não são apresentados resultados da estimação por Primeiras Diferenças, pois os estimadores são idênticos aos de Efeitos Fixos pelo fato do painel possuir apenas dois períodos.

\section{Tabela 14 - Estimações de Logaritmo da Incidência da Pobreza em Logaritmos da}

\section{Renda e Desigualdade}

\begin{tabular}{|c|c|c|c|c|c|c|c|c|c|}
\hline \multirow{2}{*}{$\begin{array}{l}\text { Variável dependente: } \\
\text { Proporção de Pobres }\end{array}$} & \multicolumn{3}{|c|}{ MQO } & \multicolumn{3}{|c|}{ Efeitos Fixos } & \multicolumn{3}{|c|}{ Efeitos Aleatórios } \\
\hline & sem índice & com Gini & com Theil & sem índice & com Gini & com Theil & sem índice & com Gini & com Theil \\
\hline Intercepto & $\begin{array}{l}3,5342 \\
(0,078) \\
\end{array}$ & $\begin{array}{l}4,3183 \\
(0,117) \\
\end{array}$ & $\begin{array}{l}3,9065 \\
(0,091) \\
\end{array}$ & $\begin{array}{l}2,7848 \\
(0,127) \\
\end{array}$ & $\begin{array}{l}4,4402 \\
(0,141) \\
\end{array}$ & $\begin{array}{l}4,1689 \\
(0,138) \\
\end{array}$ & $\begin{array}{l}3,1575 \\
(0,044) \\
\end{array}$ & $\begin{array}{l}4,0078 \\
(0,058) \\
\end{array}$ & $\begin{array}{l}3,5350 \\
(0,047) \\
\end{array}$ \\
\hline Renda Familiar per Capita & $\begin{array}{c}-0,9359 \\
(0,017)\end{array}$ & $\begin{array}{r}-0,9069 \\
(0,015)\end{array}$ & $\begin{array}{l}-0,9492 \\
(0,017)\end{array}$ & $\begin{array}{l}-0,7729 \\
(0,025)\end{array}$ & $\begin{array}{r}-0,9322 \\
(0,024)\end{array}$ & $\begin{array}{c}-1,0003 \\
(0,026)\end{array}$ & $\begin{array}{r}-0,8459 \\
(0,009)\end{array}$ & $\begin{array}{r}-0,8437 \\
(0,009) \\
\end{array}$ & $\begin{array}{r}-0,8740 \\
(0,009)\end{array}$ \\
\hline $\begin{array}{c}\text { Índice de Desigualdade de } \\
\text { Renda }\end{array}$ & & $\begin{array}{l}1,4305 \\
(0,109)\end{array}$ & $\begin{array}{l}0,4841 \\
(0,036)\end{array}$ & & $\begin{array}{l}1,3623 \\
(0,048)\end{array}$ & $\begin{array}{l}0,4094 \\
(0,015)\end{array}$ & & $\begin{array}{l}1,3941 \\
(0,042)\end{array}$ & $\begin{array}{l}0,4309 \\
(0,014)\end{array}$ \\
\hline Dummy do ano de 1991 & $\begin{array}{l}0,1579 \\
(0,012)\end{array}$ & $\begin{array}{l}0,2116 \\
(0,013)\end{array}$ & $\begin{array}{l}0,1755 \\
(0,011)\end{array}$ & $\begin{array}{l}0,1634 \\
(0,008)\end{array}$ & $\begin{array}{l}0,1705 \\
(0,007)\end{array}$ & $\begin{array}{l}0,1171 \\
(0,007)\end{array}$ & $\begin{array}{l}0,1393 \\
(0,004)\end{array}$ & $\begin{array}{l}0,2011 \\
(0,004)\end{array}$ & $\begin{array}{l}0,1603 \\
(0,004)\end{array}$ \\
\hline $\mathrm{R}^{2}$ & 0,6356 & 0,7066 & 0,6957 & 0,6991 & 0,7963 & 0,7646 & 0,6985 & 0,7950 & 0,7616 \\
\hline $\mathrm{n}^{\circ}$ de observações & & 8576 & & & 8576 & & & 8576 & \\
\hline
\end{tabular}

Obs.: (1) MQO corresponde ao método de Mínimos Quadrados Ordinários com os dois anos (1991 e 2000).

(2) Os valores entre parênteses abaixo de cada coeficiente correspondem ao respectivo desvio-padrão.

(3) Todas as estimações usam White robusto para heterocedasticidade.

Pela Tabela 14, os resultados mostram um coeficiente negativo para a variação da renda familiar per capita, que é a elasticidade-renda da pobreza, indicando que quando há um acréscimo de $1 \%$ na renda, a incidência da pobreza apresenta uma redução entre 0,8 e 1,0\%. Enquanto que o índice de desigualdade apresenta tendência contrária, com a elasticidadedesigualdade da pobreza positiva, ou seja, um aumento na desigualdade de renda eleva a incidência da pobreza local. O coeficiente do índice de Gini é aproximadamente três vezes 
maior do que o de Theil, ou seja, um aumento de $1 \%$ no Gini contribui com um acréscimo três vezes maior sobre a pobreza, em relação a $1 \%$ do Theil.

O coeficiente da dummy do ano de 1991 apresenta sinal positivo e é estatisticamente significativo. Assim, o cenário macroeconômico de 1991 em relação a 2000 contribui para o aumento da pobreza. Podemos concluir que o impacto de crises econômicas e planos de estabilização, que provocaram choques na economia brasileira no início da década de 90, não contribuiu para a redução da pobreza.

Ao se usar os efeitos fixos e aleatórios, observamos que há uma melhora no coeficiente de explicação $\mathrm{R}^{2}$ quando é acrescentada a variação no índice de desigualdade, indo de aproximadamente $70 \%$ para $80 \%$ (com índice de Gini) e 76\% (com Theil) e indicando que o modelo com variações na renda e desigualdade é mais representativo da relação que se almeja estudar.

Apesar de todos os métodos, tanto com o índice de desigualdade de renda de Gini quanto com o de Theil, apresentarem os parâmetros das variáveis explicativas significativos, isto não significa que os três métodos são eficientes, uma vez que possuem hipóteses diferentes. Para verificar o método mais eficiente para o modelo considerado, são efetuados alguns testes, visando averiguar a existência de: heterocedasticidade entre os municípios; efeito individual não observado através do teste Breuch Pagan; e correlação entre as variáveis explicativas e o efeito individual não observado pelo teste de Hausman.

Tabela 15 - Testes de Verificação dos Métodos Aplicados

\begin{tabular}{ccccccc}
\hline Testes & \multicolumn{2}{c}{ sem índice } & \multicolumn{2}{c}{ com Gini } & \multicolumn{2}{c}{ com Theil } \\
\cline { 2 - 7 } & Qui-Quadrado & -valor & Qui-Quadrado & p-valor & Qui-Quadrado & p-valor \\
\hline $\begin{array}{c}\text { Wald modificado para } \\
\text { heterocedasticidade em Efeitos Fixos }\end{array}$ & $2,1 \mathrm{E}+31$ & 0,000 & $0,0 \mathrm{E}+00$ & 1,000 & $0,0 \mathrm{E}+00$ & 1,000 \\
\hline $\begin{array}{c}\text { Breuch Pagan - existência de efeito } \\
\text { individual não observado }\end{array}$ & 1787 & 0,000 & 2004 & 0,000 & 1805 & 0,000 \\
\hline Hausman & 13 & 0,001 & 45 & 0,000 & 108 & 0,000 \\
\hline
\end{tabular}

Primeiramente, pelo teste de Wald modificado cuja hipótese nula é de homocedasticidade, percebemos que esta hipótese pode ser aceita nas regressões com índices de desigualdade. Apesar disto, optamos por fazer todas as estimações robustas à heterocedasticidade para garantir que as observações sejam independentes e identicamente distribuídas entre as unidades de cross-section. 
Com relação ao teste de Breuch-Pagan, observamos que não se pode aceitar a hipótese nula de que a variância do efeito individual não observado é zero. Assim, rejeitamos a hipótese de não-existência deste efeito, descartando-se o método MQO.

Para verificar isto, efetua-se o teste de Hausman cuja hipótese nula é a inexistência de correlação entre o efeito individual não observado e as variáveis explicativas. Tanto para a estimação sem índice de desigualdade quanto para as estimações com índice de Gini e Theil, rejeitamos a hipótese nula, concluindo-se que o método de Efeitos Aleatórios é ineficiente, uma vez que sua hipótese básica não é válida. Neste caso, o método mais eficiente para estimar o modelo utilizado é o de Efeitos Fixos.

Com isso, concluímos que a elasticidade-renda da incidência da pobreza é -0,9322 (para o modelo com Gini) e -1,0003 (para o modelo com Theil). Já a elasticidadedesigualdade da incidência da pobreza assume o valor de 1,3623 (com Gini) e 0,4094 (com Theil). Com relação ao sinal dos coeficientes, todos são coerentes com a teoria econômica. O sinal negativo dos coeficientes da renda familiar per capita, que representa a elasticidaderenda da pobreza, indica que um acréscimo na renda leva a uma redução na proporção de pobres, enquanto que o sinal positivo da elasticidade-desigualdade da pobreza mostra que um aumento da desigualdade resulta em um aumento na proporção de pobres.

Entretanto, as estimações apresentadas na Tabela 14, não consideram o peso das observações, devido a limitações no programa econométrico utilizado ${ }^{16}$. Para utilização de ponderação aos municípios de acordo com a metodologia de Deaton (1997), consideramos uma abordagem de Efeitos Fixos através do método de Mínimos Quadrados com Variáveis Dummy (MQVD) na estimação do modelo. Visto que os efeitos individuais não observados representam parâmetros a serem estimados, é possível estimá-los para cada município. Para tanto, as regressões são feitas com dummies para os 4288 municípios envolvidos que representam as observações da cross-section. Com isso, fazemos uma regressão a partir de Mínimos Quadrados Ordinários de variação na pobreza sobre crescimento da renda per capita, variação do índice de desigualdade e as dummies de município, com os dois anos, resultando em estimadores iguais aos do método de Efeitos Fixos. Apesar de não ser possível mostrar a consistência dos estimadores das dummies, pois quando o número de observações $\mathrm{N}$ aumenta, há um aumento conjunto do número de dummies, Amemiya (1967) mostra que num contexto de painel, estes estimadores são consistentes. Contudo, o fato da base de dados envolver somente dois períodos de tempo, pode levar à inconsistência dos estimadores.

\footnotetext{
${ }^{16}$ As estimações deste capítulo foram feitas no programa econométrico Stata.
} 
Desta forma, é possível estimar o modelo baseado em Ravallion e Datt (1992) considerando o peso de cada município em relação ao País, conforme a Tabela 16.

Tabela 16 - Estimações em Logaritmo da Incidência da Pobreza em Renda e Desigualdade por MQVD com Peso

\begin{tabular}{cccc}
\hline Variável dependente: & \multicolumn{3}{c}{ MQVD } \\
\cline { 2 - 4 } Proporção de Pobres & sem índice & com Gini & com Theil \\
\hline \multirow{2}{*}{ Intercepto } & 2,6142 & 5,1409 & 4,7111 \\
& $(0,250)$ & $(0,340)$ & $(0,312)$ \\
\hline \multirow{2}{*}{ Renda Familiar per Capita } & $-0,7557$ & $-1,0537$ & $-1,1065$ \\
& $(0,049)$ & $(0,055)$ & $(0,058)$ \\
\hline \multirow{2}{*}{ Índice de Desigualdade de Renda } & & 1,5369 & 0,4809 \\
\hline \multirow{2}{*}{ Dummy do ano de 1991 } & 0,2182 & $0,129)$ & $(0,039)$ \\
\hline $\mathrm{R}^{2}$ Ajustado & $(0,016)$ & $(0,013)$ & 0,1146 \\
\hline $\mathrm{n}^{\circ}$ de observações & 0,8194 & $0,014)$ \\
\hline
\end{tabular}

Obs.: (1) MQVD corresponde ao método de Mínimos Quadrados com Variáveis Dummy considerando os dois anos (1991 e 2000).

(2) Os valores entre parênteses abaixo de cada coeficiente correspondem ao respectivo desvio-padrão.

(3) Todas as estimações usam White robusto para heterocedasticidade.

Novamente observamos que a dummy de tempo tem coeficiente positivo e significante para todos os modelos. Os demais coeficientes são significativos e coerentes com a teoria econômica. As estimações por MQVD com peso para os municípios mostram um crescimento das elasticidades, com a elasticidade-renda da incidência da pobreza indo para -1,0537 (para o modelo com Gini) e -1,1065 (para o modelo com Theil). Assim, a relação entre variações da renda e pobreza é próxima de -1 , com um aumento de $1 \%$ na renda per capita resultando em um decréscimo de quase 1,1\% na incidência da pobreza. Já a elasticidade-desigualdade da incidência da pobreza passa a assumir o valor de 1,5369 (com Gini) e 0,4809 (com Theil), indicando que um aumento de $1 \%$ no índice de desigualdade de renda de Gini resulta em um acréscimo por volta de 1,5\% na incidência. Já com um aumento de $1 \%$ no índice de Theil responde por um acréscimo de $0,5 \%$ na incidência da pobreza no Brasil. 


\subsection{2- Modelagem de Bourguignon (2002)}

A modelagem baseada em Ravallion e Datt (1992) considera que as elasticidades sobre a redução da pobreza são constantes. Já com a modelagem de Bourguignon (2002), é possível fazer a estimação com ambas as elasticidades dependendo do inverso do nível de desenvolvimento inicial (linha absoluta de pobreza dividida pela renda familiar per capita) e do nível inicial de desigualdade, conforme a tabela abaixo.

\section{Tabela 17 - Estimações da Diferença dos Logaritmos da Incidência da Pobreza nas}

Variáveis de Renda e Desigualdade

\begin{tabular}{|c|c|c|c|c|}
\hline \multirow{3}{*}{$\begin{array}{l}\text { Variável dependente: } \\
\text { Variação na proporção de pobres }\end{array}$} & \multicolumn{4}{|c|}{ Expansão do Modelo Básico } \\
\hline & \multicolumn{2}{|c|}{ Equação (17) } & \multicolumn{2}{|c|}{ Equação (18) } \\
\hline & com Gini & com Theil & com Gini & com Theil \\
\hline Intercepto & $\begin{array}{c}-0,13508 \\
(0,013)\end{array}$ & $\begin{array}{c}-0,08328 \\
(0,016)\end{array}$ & $\begin{array}{c}-0,09135 \\
(0,013)\end{array}$ & $\begin{array}{c}-0,06382 \\
(0,016)\end{array}$ \\
\hline $\begin{array}{l}\text { Variação na Renda } \\
\text { Familiar per Capita }\end{array}$ & $\begin{array}{c}-3,28276 \\
(0,436)\end{array}$ & $\begin{array}{c}-2,29159 \\
(0,231)\end{array}$ & $\begin{array}{c}-3,26081 \\
(0,438)\end{array}$ & $\begin{array}{c}-2,37596 \\
(0,230)\end{array}$ \\
\hline $\begin{array}{l}\text { Variação no Índice de } \\
\text { desigualdade de renda }\end{array}$ & $\begin{array}{l}1,71975 \\
(0,155)\end{array}$ & $\begin{array}{l}0,55046 \\
(0,048)\end{array}$ & $\begin{array}{l}3,92978 \\
(0,883)\end{array}$ & $\begin{array}{l}1,14602 \\
(0,171)\end{array}$ \\
\hline$\Delta G \cdot\left(\frac{\text { linha absoluta de pobreza }}{\text { renda per capita familiar }}\right)$ & $\begin{array}{c}0,68534 \\
(0,060) \\
\end{array}$ & $\begin{array}{c}0,84713 \\
(0,078) \\
\end{array}$ & $\begin{array}{c}0,92893 \\
(0,082)\end{array}$ & $\begin{array}{c}0,99645 \\
(0,088) \\
\end{array}$ \\
\hline $\begin{array}{c}\Delta \text { G.(índice inicial de } \\
\text { desigualdade de renda) }\end{array}$ & $\begin{array}{c}3,33600 \\
(0,702) \\
\end{array}$ & $\begin{array}{c}0,98243 \\
(0,245) \\
\end{array}$ & $\begin{array}{c}2,83541 \\
(0,688) \\
\end{array}$ & $\begin{array}{c}0,85703 \\
(0,230) \\
\end{array}$ \\
\hline$\Delta D \cdot\left(\frac{\text { linha absoluta de pobreza }}{\text { renda per capita familiar }}\right)$ & & & $\begin{array}{c}-2,18289 \\
(0,312) \\
\end{array}$ & $\begin{array}{c}-0,67301 \\
(0,096) \\
\end{array}$ \\
\hline $\begin{array}{c}\Delta \mathrm{D} \text {.(índice inicial de } \\
\text { desigualdade de renda) }\end{array}$ & & & $\begin{array}{c}-1,45129 \\
(1,179) \\
\end{array}$ & $\begin{array}{c}-0,25045 \\
(0,125) \\
\end{array}$ \\
\hline $\mathrm{R}^{2}$ & 0,4908 & 0,4318 & 0,5573 & 0,4759 \\
\hline $\mathrm{n}^{\circ}$ de observações & & & & \\
\hline
\end{tabular}

Obs.: (1) Os valores entre parênteses abaixo de cada coeficiente correspondem ao respectivo desvio-padrão.

(2) Todas as estimações usam White robusto para heterocedasticidade.

Observamos pela Tabela 17 que os modelos não apresentam coeficiente de explicação elevado. Com relação aos coeficientes das variáveis, notemos que o termo de interação entre a variação da renda e o inverso do nível inicial de desenvolvimento apresenta coeficiente positivo, assim como o da interação entre a variação da renda e o índice inicial de desigualdade de renda. Isto significa que o efeito de um aumento na renda sobre a redução da pobreza é menor quando o nível inicial de desenvolvimento é baixo. O mesmo ocorre quando o índice inicial de desigualdade é alto. Com isso, podemos concluir que regiões com baixo nível inicial de desenvolvimento apresentam condições menos propícias à redução da pobreza 
através de crescimento da renda. Além disso, a realidade brasileira de elevada desigualdade inicial prejudica a reversão do quadro de pobreza, via crescimento da renda.

Já com relação ao termo de interação entre a variação na desigualdade e o inverso do nível inicial de desenvolvimento, seu coeficiente é negativo. O mesmo ocorre com o termo de interação entre a variação na desigualdade e o nível inicial de desigualdade. O efeito da variação da desigualdade sobre a redução da pobreza é menor quando o nível inicial de desenvolvimento é baixo ou quando o nível inicial de desigualdade é alto. Podemos concluir que aquelas regiões que possuem baixo nível inicial de desenvolvimento ou elevado nível inicial de desigualdade recebem um efeito menor sobre a redução da pobreza num quadro de melhoria da desigualdade de renda. Em Bourguignon (2002), os sinais dos coeficientes destes modelos são os mesmos dos apresentados na tabela anterior.

Portanto, o baixo nível inicial de desenvolvimento e a grande desigualdade inicial de renda no Brasil são entraves para a redução da pobreza, independente do meio pela qual esta for perseguida: via crescimento econômico ou redução da desigualdade de renda. Assim, os municípios mais pobres e com elevada desigualdade de renda necessitam de políticas mais intensas e focadas para se combater a pobreza.

\subsection{3- Elasticidades pela Log-Normalidade}

Assumindo a hipótese de que a distribuição de renda é log-normal, é possível calcular as elasticidades da pobreza em relação à renda e à desigualdade. Hoffmann (2004) deduz elasticidades apenas dispondo dos valores da renda média $\mu$ e do índice de Gini $(G)$. Com isso, calcula as elasticidades dadas pelas equações (20) e (22) com a base de dados das PNAD's de 1999, 2001 e 2002, conforme mostrado na Tabela 18. Contudo, considera apenas uma única linha de pobreza absoluta para o Brasil em cada período ${ }^{17}$. Neste trabalho, calculamos as elasticidades da pobreza em relação à renda e à desigualdade, considerando as linhas de pobreza de Rocha (2003) dadas pela Tabela 2.

\footnotetext{
${ }^{17}$ Hoffmann (2004) considera uma linha de pobreza $z=92,29$ (em reais de setembro de 1999), $\mathrm{z}=105,98$ (em reais de setembro de 2001) e $\mathrm{z}=116,14$ (em reais de setembro de 2002).
} 
Tabela 18 - Comparativo entre as Elasticidades-Renda $\left(\varepsilon_{\mathrm{y}}\right.$ e $\left.\varepsilon_{\mathrm{m}}\right)$ e Elasticidades-

Desigualdade $\left(\varepsilon_{G}\right)$

\begin{tabular}{|c|c|c|c|c|c|c|c|c|c|c|c|c|c|c|c|c|c|c|c|c|}
\hline \multirow{3}{*}{ Estado } & \multicolumn{7}{|c|}{1991} & \multicolumn{7}{|c|}{2000} & \multicolumn{6}{|c|}{ Hoffmann (2004) } \\
\hline & \multirow{2}{*}{$\begin{array}{l}\text { Linha de } \\
\text { Pobreza }\end{array}$} & \multicolumn{3}{|c|}{ Gini } & \multicolumn{3}{|c|}{ Theil } & \multirow{2}{*}{$\begin{array}{l}\text { Linha de } \\
\text { Pobreza }\end{array}$} & \multicolumn{3}{|c|}{ Gini } & \multicolumn{3}{|c|}{ Theil } & \multicolumn{2}{|c|}{1999} & \multicolumn{2}{|c|}{2001} & \multicolumn{2}{|c|}{2002} \\
\hline & & $\sigma$ & $\varepsilon_{y}$ & $\varepsilon_{G}$ & $\sigma$ & $\varepsilon_{y}$ & $\varepsilon_{G}$ & & $\sigma$ & $\varepsilon_{y}$ & $\varepsilon_{G}$ & $\sigma$ & $\varepsilon_{y}$ & $\varepsilon_{G}$ & $\varepsilon_{m}$ & $\varepsilon_{G}$ & $\varepsilon_{m}$ & $\varepsilon_{G}$ & $\varepsilon_{m}$ & $\varepsilon_{G}$ \\
\hline $\mathrm{RO}$ & 69,26 & $\overline{1,21}$ & $-0,73$ & 1,51 & 1,24 & $-0,69$ & 0,57 & 70,81 & 1,17 & $-0,97$ & 2,38 & 1,20 & $-0,92$ & $\overline{0,91}$ & $-1,01$ & 2,05 & $-0,92$ & 1,60 & $-1,00$ & 1,79 \\
\hline$A C$ & 70,42 & 1,24 & $-0,66$ & 1,37 & 1,27 & $-0,64$ & 0,52 & 71,62 & 1,27 & $-0,72$ & 1,75 & 1,32 & $-0,67$ & 0,64 & $-0,75$ & 1,81 & $-0,74$ & 1,78 & $-0,74$ & 1,75 \\
\hline AM & 73,34 & 1,21 & $-0,77$ & 1,72 & 1,23 & $-0,75$ & 0,66 & 74,42 & 1,37 & $-0,58$ & 1,49 & 1,37 & $-0,58$ & 0,54 & $-0,76$ & 1,04 & $-0,74$ & 1,24 & $-0,76$ & 1,17 \\
\hline $\mathrm{RR}$ & 71,81 & 1,28 & $-0,88$ & 2,66 & 1,23 & $-0,97$ & 1,06 & 74,95 & 1,20 & $-0,89$ & 2,22 & 1,20 & $-0,90$ & 0,87 & $-1,22$ & 2,18 & $-0,90$ & 1,44 & $-0,76$ & 1,14 \\
\hline PA & 72,76 & 1,23 & $-0,64$ & 1,25 & 1,28 & $-0,59$ & 0,47 & 36 & 1,28 & $-0,65$ & 1,44 & 1,32 & $-0,61$ & 0,53 & $-0,77$ & 1,15 & $-0,78$ & 1,16 & $-0,78$ & 1,23 \\
\hline AP & 76,25 & 1,11 & $-0,96$ & 1,97 & 1,12 & $-0,93$ & 0,78 & 79,32 & 1,23 & $-0,79$ & 1,88 & 1,25 & $-0,77$ & 0,71 & $-0,83$ & 1,24 & $-1,28$ & 1,97 & $-0,83$ & 1,31 \\
\hline TO & 69,12 & 1,21 & $-0,65$ & 1,18 & 1,28 & $-0,58$ & 0,44 & 74,33 & 1,26 & $-0,69$ & 1,56 & 1,32 & $-0,63$ & 0,57 & $-0,64$ & 0,78 & $-0,64$ & 1,10 & $-0,70$ & 0,97 \\
\hline MA & 13 & 1,17 & $-0,51$ & 0,64 & 1,26 & $-0,45$ & 0,25 & 65 & 1,30 & $-0,51$ & 0,95 & 1,36 & $-0,47$ & 0,34 & $-0,50$ & 0,51 & $-0,52$ & 0,56 & $-0,54$ & 0,57 \\
\hline $\mathrm{PI}$ & 69,40 & 1,29 & $-0,43$ & 0,65 & 1,35 & $-0,40$ & 0,24 & 69,75 & 1,32 & $-0,54$ & 1,13 & 1,36 & $-0,50$ & 0,41 & $-0,47$ & 0,55 & $-0,52$ & 0,68 & $-0,50$ & 0,77 \\
\hline CE & 7 & 1,31 & $-0,46$ & 0,81 & 1,37 & $-0,42$ & 0,29 & 20 & 1,36 & $-0,55$ & 1,28 & 1,38 & $-0,53$ & 0,46 & $-0,50$ & 0,72 & $-0,53$ & 0,81 & $-0,58$ & 0,80 \\
\hline $\mathrm{RN}$ & 74,93 & 1,24 & $-0,59$ & 1,05 & 1,27 & $-0,56$ & 0,40 & 73,14 & 1,28 & $-0,68$ & 1,61 & 1,30 & $-0,66$ & 0,60 & $-0,62$ & 0,98 & $-0,64$ & 0,97 & $-0,65$ & 0,99 \\
\hline PB & 73,22 & 1,26 & $-0,48$ & 0,76 & 1,32 & $-0,44$ & 0,28 & 42 & 1,27 & $-0,63$ & 1,35 & 1,30 & $-0,60$ & 0,50 & $-0,54$ & 1,20 & $-0,56$ & 0,77 & $-0,59$ & 0,92 \\
\hline PE & 100,32 & 1,30 & $-0,47$ & 0,81 & 1,34 & $-0,44$ & 0,30 & 46 & 1,31 & $-0,56$ & 1,21 & 1,33 & $-0,55$ & 0,44 & $-0,58$ & 0,90 & $-0,56$ & 0,93 & $-0,58$ & 0,96 \\
\hline $\mathrm{AL}$ & 71,48 & 1,23 & $-0,56$ & 0,93 & 1,30 & $-0,50$ & 0,35 & 71,39 & 1,35 & $-0,53$ & 1,22 & 1,38 & $-0,51$ & 0,44 & $-0,55$ & 0,70 & $-0,49$ & 0,65 & $-0,50$ & 0,64 \\
\hline SE & 74,28 & 1,19 & $-0,66$ & 1,17 & 1,24 & $-0,61$ & 0,44 & 72,50 & 1,27 & $-0,67$ & 1,51 & 1,30 & $-0,64$ & 0,56 & $-0,56$ & 1,00 & $-0,64$ & 0,87 & $-0,71$ & 0,98 \\
\hline BA & 79,08 & 1,31 & $-0,48$ & 0,88 & 1,37 & $-0,44$ & 0,32 & 80,40 & 1,31 & $-0,59$ & 1,29 & 1,35 & $-0,55$ & 0,47 & $-0,58$ & 0,78 & $-0,56$ & 0,79 & $-0,58$ & 0,81 \\
\hline$M G$ & 72,56 & 1,19 & $-0,85$ & 1,95 & 1,22 & $-0,81$ & 0,74 & 82,61 & 1,19 & $-0,96$ & 2,44 & 1,22 & $-0,91$ & 0,93 & $-0,88$ & 1,61 & $-0,92$ & 1,68 & $-0,93$ & 1,73 \\
\hline ES & 64,35 & 1,15 & $-0,98$ & 2,30 & 1,17 & $-0,94$ & 0,90 & 71,20 & 1,16 & $-1,11$ & 3,02 & 1,19 & $-1,06$ & 1,16 & $-0,88$ & 1,74 & $-0,82$ & 1,69 & $-0,91$ & 1,89 \\
\hline RJ & 116,13 & 1,17 & $-0,87$ & 1,93 & 1,19 & $-0,84$ & 0,75 & 124,72 & 1,15 & $-1,05$ & 2,60 & 1,16 & $-1,03$ & 1,02 & $-1,19$ & 2,77 & $-1,13$ & 2,73 & $-1,23$ & 2,83 \\
\hline SP & 123,12 & 1,04 & $-1,21$ & 2,58 & 1,07 & $-1,15$ & 1,03 & 138,34 & 1,12 & $-1,08$ & 2,51 & 1,13 & $-1,04$ & 1,00 & $-1,32$ & 3,06 & $-1,27$ & 3,02 & $-1,25$ & 2,97 \\
\hline PR & 74,13 & 1,16 & $-0,96$ & 2,28 & 1,19 & $-0,92$ & 0,88 & 82,59 & 1,17 & $-1,07$ & 2,85 & 1,20 & $-1,01$ & 1,09 & $-0,93$ & 1,98 & $-1,01$ & 2,13 & $-1,15$ & 2,29 \\
\hline SC & 64,80 & 1,02 & $-1,37$ & 3,13 & 1,06 & $-1,28$ & 1,25 & 70,57 & 1,04 & $-1,56$ & 4,16 & 1,08 & $-1,42$ & 1,61 & $-1,24$ & 2,38 & $-1,47$ & 2,86 & $-1,64$ & 2,95 \\
\hline RS & 70,46 & 1,12 & $-1,15$ & 2,91 & 1,14 & $-1,12$ & 1,15 & 76,08 & 1,11 & $-1,32$ & 3,68 & 1,13 & $-1,26$ & 1,44 & $-1,09$ & 2,45 & $-1,14$ & 2,51 & $-1,17$ & 2,52 \\
\hline MS & 105,38 & 1,15 & $-0,78$ & 1,46 & 1,21 & $-0,71$ & 0,55 & 103,87 & 1,20 & $-0,84$ & 1,92 & 1,25 & $-0,76$ & 0,71 & $-0,94$ & 1,73 & $-0,95$ & 1,89 & $-1,00$ & 2,02 \\
\hline MT & 102,39 & 1,14 & $-0,77$ & 1,39 & 1,20 & $-0,69$ & 0,53 & 101,67 & 1,19 & $-0,86$ & 1,97 & 1,26 & $-0,76$ & 0,72 & $-0,98$ & 1,72 & $-0,92$ & 1,82 & $-0,93$ & 1,90 \\
\hline GO & 106,01 & 1,11 & $-0,82$ & 1,42 & 1,16 & $-0,75$ & 0,55 & 105,63 & 1,15 & $-0,90$ & 1,93 & 1,21 & $-0,80$ & 0,72 & $-0,92$ & 1,65 & $-0,91$ & 1,72 & $-0,98$ & 1,82 \\
\hline DF & 162,51 & 1,18 & $-0,91$ & 2,15 & 1,16 & $-0,94$ & 0,87 & 157,16 & 1,26 & $-0,89$ & 2,56 & 1,22 & $-0,96$ & 1,02 & $-1,04$ & 3,35 & $-1,04$ & 3,25 & $-1,04$ & 3,43 \\
\hline Brasil & 91,33 & 1,25 & $-0,74$ & 1,74 & 1,25 & $-0,73$ & 0,66 & 97,76 & 1,26 & $-0,81$ & 2,12 & 1,26 & $-0,80$ & 0,80 & $-0,84$ & 1,81 & $-0,84$ & 1,84 & $-0,87$ & 1,87 \\
\hline
\end{tabular}

Obs.: (1) Os valores da coluna Linha de Pobreza correspondem às linhas da Tabela 2 abertas por estado e ponderadas pela população de cada estrato.

(2) $\sigma$ é o desvio-padrão do logaritmo da renda, calculado a partir do índice de Gini, para a elasticidaderenda e elasticidade-desigualdade de Gini. Já para as elasticidades de Theil, $\sigma$ é calculado a partir do índice de desigualdade de Theil.

(3) Os valores $\varepsilon_{\mathrm{y}}$ e $\varepsilon_{\mathrm{G}}$ correspondem às elasticidades pela metodologia descrita no Apêndice F, usando os Censos de 1991 e 2000.

(4) Os valores $\varepsilon_{\mathrm{m}}$ e $\varepsilon_{\mathrm{G}}$ de Hoffmann (2004) correspondem às elasticidades com relação à renda e desigualdade, respectivamente, usando o índice de Gini, a partir das PNAD's de 1999, 2001 e 2002.

Pela tabela acima, observamos que, usando a metodologia descrita no Apêndice F, há uma pequena diferença entre os valores encontrados em Hoffmann (2004) e os calculados neste capítulo com os Censos de 1991 e 2000, ambos usando o índice de Gini. Isto se deve não somente à utilização de bases de dados diferentes como também pelo uso de linhas de pobreza estaduais e acréscimo do aluguel implícito, uma vez que Hoffmann (2004) utiliza a base de dados da PNAD, uma única linha de pobreza nacional para cada ano e não corrige a renda pelo aluguel implícito.

Comparando os valores das elasticidades calculadas de 1991 e 2000, observamos que apresentam um aumento na maioria dos estados, indicando que houve uma melhoria no cenário de resposta de aumentos na renda e diminuição da desigualdade sobre a redução da 
pobreza. Vale destacar que esta conclusão somente é valida sob a hipótese de log-normalidade da distribuição de renda no Brasil. Não temos como comparar os resultados com Bourguignon (2002), pois além de não serem apresentados, este trabalha com uma base de países, diferentemente de Hoffmann (2004) que utiliza os estados brasileiros, possibilitando uma análise comparativa. Entretanto, é possível comparar apenas as elasticidades calculadas a partir do índice de Gini, uma vez que Hoffmann (2004) não as calcula com o índice de Theil.

Analisando os valores de Hoffmann (2004), não percebemos claramente uma tendência de aumento da elasticidade entre 1999 e 2001. O mesmo ocorre entre 2001 e 2002, com exceção da elasticidade-renda que apresenta um pequeno aumento na maioria dos estados. Como, praticamente, são calculadas para anos consecutivos, este tipo de análise é comprometida. Comparando-as com os valores calculados neste capítulo para o ano de 2000, observamos que as elasticidades-renda calculadas são próximas das de Hoffmann (2004). Este apresenta a elasticidade-renda do Brasil igual a -0,84 (em 1999 e 2001), enquanto a elasticidade-renda calculada neste capítulo é -0,81 (em 2000). Já os valores das elasticidadesdesigualdade calculadas são um pouco maiores do que os obtidos por Hoffmann (2004). Para o Brasil, enquanto este apresenta a elasticidade igual a 1,81 e 1,84 (em 1999 e 2001, respectivamente), a elasticidade-desigualdade calculada neste capítulo é 2,12 (em 2000). Calculando a correlação entre as elasticidades-renda estaduais calculadas neste capítulo, para 2000, e as de Hoffmann (2004) obtemos 0,84 (com 1999) e 0,86 (com 2001). Já a correlação entre as elasticidades-desigualdade é 0,78 (entre 2000 e 1999) e 0,81 (entre 2000 e 2001).

Quando comparamos as elasticidades usando o índice de Gini com as elasticidades usando Theil, observamos que o coeficiente com Gini é aproximadamente três vezes maior do que o com Theil. Tal resultado é semelhante ao do modelo a partir de Ravallion e Datt (1992) em que concluímos que um aumento de $1 \%$ no Gini contribui com um acréscimo três vezes maior sobre a incidência da pobreza, em relação a $1 \%$ do Theil. Entretanto, quando comparamos os resultados das elasticidades do modelo a partir de Ravallion e Datt (1992) com as elasticidades calculadas pela Tabela 18, observamos uma diferença significativa. Enquanto as elasticidades estimadas são por volta de $-1,1$ (com relação à renda), 1,5 (com relação a desigualdade de Gini) e 0,5 (com relação a Theil), as calculadas são -0,8, 2,1 e 0,8, respectivamente. Mostrando uma diferença de praticamente $35 \%$ entre os valores obtidos nas duas metodologias.

Dada esta diferença, testemos a hipótese de log-normalidade da renda que é a base para o cálculo das elasticidades apresentadas na Tabela 18. Assim, na segunda parte deste item, usamos a metodologia de Bourguignon (2002) para testar se estas elasticidades num 
modelo de variação da incidência da pobreza sob variações na renda e desigualdade influenciam os coeficientes de tal maneira que sejam próximos de -1 (para a elasticidaderenda) e 1 (para a elasticidade-desigualdade). Desta forma, Bourguignon (2002) testa a hipótese da distribuição de renda relativa ser log-normal, utilizando dois modelos log-normais, conforme a Tabela $19^{18}$. Para a estimação do teste do modelo log-normal, utilizamos regressões de Mínimos Quadrados Ordinários com peso de acordo com Deaton (1997).

Tabela 19 - Resultados do Teste Log-Normal com base em Bourguignon (2002)

\begin{tabular}{|c|c|c|c|c|c|}
\hline \multirow{3}{*}{\multicolumn{2}{|c|}{$\begin{array}{l}\text { Variável dependente: } \\
\text { Variação na proporção de pobres }\end{array}$}} & \multicolumn{4}{|c|}{ Teste - Modelo Lognormal } \\
\hline & & \multicolumn{2}{|c|}{ Equação (19) } & \multicolumn{2}{|c|}{ Equação (21) } \\
\hline & & com Gini & com Theil & com Gini & com Theil \\
\hline \multicolumn{2}{|r|}{ Intercepto } & $\begin{array}{c}-0,20232 \\
(0,021)\end{array}$ & $\begin{array}{c}-0,16502 \\
(0,026)\end{array}$ & $\begin{array}{c}-0,10080 \\
(0,024)\end{array}$ & $\begin{array}{c}-0,10091 \\
(0,028)\end{array}$ \\
\hline \multirow[t]{3}{*}{$\Delta \mathrm{D}$} & $\begin{array}{l}\text { Variação no Índice de } \\
\text { desigualdade de renda }\end{array}$ & $\begin{array}{l}1,55654 \\
(0,137)\end{array}$ & $\begin{array}{l}0,51222 \\
(0,046)\end{array}$ & & \\
\hline & $\Delta \mathrm{G} . \mathrm{E}_{\mathrm{G}}$ & $\begin{array}{c}-1,00921 \\
(0,089)\end{array}$ & $\begin{array}{c}-1,10799 \\
(0,112)\end{array}$ & $\begin{array}{c}-1,19053 \\
(0,095)\end{array}$ & $\begin{array}{c}-1,27847 \\
(0,118)\end{array}$ \\
\hline & $\Delta \mathrm{D} . \mathrm{E}_{\mathrm{D}}$ & & & $\begin{array}{l}0,62777 \\
(0,065)\end{array}$ & $\begin{array}{c}1,06079 \\
(0,119)\end{array}$ \\
\hline \multirow{2}{*}{\multicolumn{2}{|c|}{$\frac{\mathrm{R}^{2}}{\mathrm{n}^{\circ} \text { de observacões }}$}} & 0,4691 & 0,4032 & 0,6062 & 0,5119 \\
\hline & & & & \multicolumn{2}{|c|}{4288} \\
\hline
\end{tabular}

Obs.: (1) Os valores entre parênteses abaixo de cada coeficiente correspondem ao respectivo desvio-padrão.

(2) Todas as estimações usam White robusto para heterocedasticidade.

Observamos que os sinais destes coeficientes são negativo para a renda e positivo para a desigualdade, a partir das equações das elasticidades. Além disso, os coeficientes dos termos das elasticidades nos dois modelos são elevados e próximos de 1. Para verificarmos isto, apresentamos na Tabela 20 o teste de Wald com hipótese nula do coeficiente do termo da elasticidade-renda ser igual a -1 e do termo da elasticidade-desigualdade ser igual a 1.

\footnotetext{
${ }^{18}$ Assim como Bourguignon (2002), não consideramos o sinal negativo da elasticidade-renda dada pela equação (13). Com isso, temos $E_{G}=-\varepsilon_{y}$ e $E_{D}=\varepsilon_{G}$. Isto permite que observemos sinais negativos nos coeficientes do termo $\Delta \mathrm{G} . \mathrm{E}_{\mathrm{G}}$.
} 


\section{Tabela 20 - Teste dos Coeficientes dos Termos das Elasticidades}

\begin{tabular}{ccccc}
\hline \multirow{2}{*}{ Variável } & \multicolumn{4}{c}{$\mathrm{p}$-valor } \\
\cline { 2 - 5 } & \multicolumn{2}{c}{ Equação (19) } & \multicolumn{2}{c}{ Equação (21) } \\
\cline { 2 - 5 } & com Gini & com Theil & com Gini & com Theil \\
\hline$\Delta \mathrm{G}_{\mathrm{E}} \mathrm{E}_{\mathrm{G}}$ & 0,9180 & 0,3351 & 0,0453 & 0,0182 \\
\hline$\Delta \mathrm{D} . \mathrm{E}_{\mathrm{D}}$ & & & 0,0000 & 0,6081 \\
\hline
\end{tabular}

Obs.: (1) Hipóteses Nulas: Coeficiente da Elasticidade-Renda = -1

e Coeficiente da Elasticidade-Desigualdade $=1$.

Observamos que não podemos rejeitar as hipóteses nulas para os modelos que consideram o índice de desigualdade de Theil. Já com o índice de Gini, o termo da elasticidade-desigualdade é estatisticamente diferente de 1. Portanto, concluímos que a aproximação log-normal é sensível ao índice de desigualdade utilizado, não nos possibilitando afirmar que é a melhor representação da distribuição de renda no Brasil. A hipótese de lognormalidade da renda familiar per capita pode não condizer com a distribuição de renda brasileira, comprometendo os resultados das elasticidades encontradas neste item.

Vale ressaltar que seria necessário estimar os modelos com outras medidas de pobreza, além da incidência da pobreza, e outros índices de desigualdade de renda, para se chegar a um resultado conclusivo para o Brasil com relação à hipótese de distribuição log-normal da renda relativa.

\subsection{4- Modelo considerando uma Linha Híbrida de Pobreza}

Assim como no modelo baseado em Ravallion e Datt (1992), o modelo considerando as linhas híbridas de pobreza estimadas no capítulo anterior trabalha com uma dummy de tempo na estimação para verificar efeitos do ano de 1991, que incidem sobre todos os municípios brasileiros e têm impacto sobre a variação na pobreza, uma vez que há grandes diferenças no cenário macroeconômico do Brasil entre os anos de 1991 e 2000.

De acordo com a equação (27), estima-se o modelo, com o termo que representa a variação da linha híbrida de pobreza, através dos métodos de Efeitos Fixos e Efeitos Aleatórios, conforme a Tabela 21. 
Tabela 21 - Estimações em Logaritmo da Incidência da Pobreza em Renda, Desigualdade e Linha Híbrida

\begin{tabular}{|c|c|c|c|c|c|c|c|c|}
\hline \multirow{3}{*}{$\begin{array}{l}\text { Variável dependente: } \\
\text { Proporção de Pobres }\end{array}$} & \multicolumn{4}{|c|}{ Efeitos Fixos } & \multicolumn{4}{|c|}{ Efeitos Aleatórios } \\
\hline & \multicolumn{2}{|c|}{ Zh30 } & \multicolumn{2}{|c|}{ Zh50 } & \multicolumn{2}{|c|}{ Zh30 } & \multicolumn{2}{|c|}{ Zh50 } \\
\hline & com Gini & com Theil & com Gini & com Theil & com Gini & com Theil & com Gini & com Theil \\
\hline Intercepto & $\begin{array}{l}1,5230 \\
(0,089) \\
\end{array}$ & $\begin{array}{l}1,6559 \\
(0,106) \\
\end{array}$ & $\begin{array}{l}0,2985 \\
(0,053) \\
\end{array}$ & $\begin{array}{l}0,5997 \\
(0,064) \\
\end{array}$ & $\begin{array}{l}1,5182 \\
(0,020) \\
\end{array}$ & $\begin{array}{l}0,8739 \\
(0,022) \\
\end{array}$ & $\begin{array}{l}0,6174 \\
(0,014) \\
\end{array}$ & $\begin{array}{l}0,2371 \\
(0,016) \\
\end{array}$ \\
\hline Renda Familiar per Capita & $\begin{array}{r}-1,1360 \\
(0,032)\end{array}$ & $\begin{array}{l}-0,7811 \\
(0,040)\end{array}$ & $\begin{array}{r}-1,0164 \\
(0,023)\end{array}$ & $\begin{array}{l}-0,8030 \\
(0,026)\end{array}$ & $\begin{array}{r}-1,3926 \\
(0,018)\end{array}$ & $\begin{array}{l}-1,2799 \\
(0,022)\end{array}$ & $\begin{array}{r}-1,1245 \\
(0,011)\end{array}$ & $\begin{array}{r}-1,0594 \\
(0,014)\end{array}$ \\
\hline $\begin{array}{l}\text { Indice de Desigualdade de } \\
\text { Renda }\end{array}$ & $\begin{array}{l}1,9329 \\
(0,034)\end{array}$ & $\begin{array}{l}0,5838 \\
(0,011)\end{array}$ & $\begin{array}{l}1,3012 \\
(0,019)\end{array}$ & $\begin{array}{l}0,4145 \\
(0,007)\end{array}$ & $\begin{array}{l}2,1573 \\
(0,025)\end{array}$ & $\begin{array}{l}0,6817 \\
(0,010)\end{array}$ & $\begin{array}{l}1,4612 \\
(0,013)\end{array}$ & $\begin{array}{l}0,4850 \\
(0,005)\end{array}$ \\
\hline Linha Híbrida & $\begin{array}{l}1,0173 \\
(0,045) \\
\end{array}$ & $\begin{array}{l}0,3173 \\
(0,058) \\
\end{array}$ & $\begin{array}{l}1,0845 \\
(0,030) \\
\end{array}$ & $\begin{array}{l}0,6342 \\
(0,035) \\
\end{array}$ & $\begin{array}{l}1,3781 \\
(0,023) \\
\end{array}$ & $\begin{array}{l}1,1562 \\
(0,030) \\
\end{array}$ & $\begin{array}{l}1,1605 \\
(0,015) \\
\end{array}$ & $\begin{array}{l}1,0253 \\
(0,018) \\
\end{array}$ \\
\hline Dummy do ano de 1991 & $\begin{array}{l}0,0952 \\
(0,004) \\
\end{array}$ & $\begin{array}{l}0,0329 \\
(0,006) \\
\end{array}$ & $\begin{array}{l}0,1173 \\
(0,003) \\
\end{array}$ & $\begin{array}{l}0,0556 \\
(0,004) \\
\end{array}$ & $\begin{array}{l}0,0903 \\
(0,003) \\
\end{array}$ & $\begin{array}{l}0,0379 \\
(0,003) \\
\end{array}$ & $\begin{array}{l}0,1062 \\
(0,002) \\
\end{array}$ & $\begin{array}{l}0,0664 \\
(0,002) \\
\end{array}$ \\
\hline $\mathrm{R}^{2}$ & 0,7941 & 0,6719 & 0,8402 & 0,7597 & 0,7904 & 0,6488 & 0,8368 & 0,7488 \\
\hline $\mathrm{n}^{\circ}$ de observações & \multicolumn{2}{|c|}{8576} & \multicolumn{2}{|c|}{8576} & \multicolumn{2}{|c|}{8576} & \multicolumn{2}{|c|}{8576} \\
\hline
\end{tabular}

Obs.: (1) Os valores entre parênteses abaixo de cada coeficiente correspondem ao respectivo desvio-padrão.

(2) Todas as estimações usam White robusto para heterocedasticidade.

(3) As colunas Zh30 e Zh50 indicam os valores correspondentes às linhas híbridas considerando linhas relativas de $30 \%$ e $50 \%$ da renda média, respectivamente.

Acrescentando-se o termo de variação da linha híbrida de pobreza, a elasticidade-renda da pobreza apresenta valores negativos de acordo com a teoria econômica, indicando que um aumento na renda leva a uma redução da pobreza. Esta coerência também ocorre com relação à elasticidade-desigualdade da pobreza que apresenta valores positivos, ou seja, um aumento da desigualdade aumenta a pobreza. Já a dummy de tempo, repete os resultados das estimações anteriores, indicando que o cenário macroeconômico de 1991 não contribuía para a redução da pobreza, em relação a 2000.

Conforme discutido anteriormente, esperávamos que o coeficiente do termo de variação da linha híbrida fosse positivo, indicando que um aumento no valor desta linha levasse a um aumento da pobreza. Isto ocorre em todas as estimações da Tabela 21. Podemos observar que estes coeficientes possuem a mesma ordem de grandeza da elasticidade-renda e elasticidade-desigualdade. Na maioria dos casos, considerando uma linha híbrida de pobreza, um aumento na renda provoca uma redução direta da pobreza e, através do deslocamento da linha híbrida, provoca um aumento de mesma ordem na pobreza, tornando o efeito final inerte.

Dois pontos precisam ser levados em consideração nestas estimações. Primeiramente, é importante verificar se os métodos aplicados são eficientes, uma vez que possuem hipóteses diferentes. Para tanto, são efetuados os mesmos testes usados anteriormente neste capítulo, visando averiguar a existência de: heterocedasticidade entre os municípios; efeito individual não observado através do teste Breuch Pagan; e correlação entre as variáveis explicativas e o efeito individual não observado pelo teste de Hausman. 
Tabela 22 - Testes de Verificação dos Métodos Aplicados

\begin{tabular}{|c|c|c|c|c|c|c|c|c|}
\hline \multirow{3}{*}{ Testes } & \multicolumn{4}{|c|}{ Zh30 } & \multicolumn{4}{|c|}{ Zh50 } \\
\hline & \multicolumn{2}{|c|}{ com Gini } & \multicolumn{2}{|c|}{ com Theil } & \multicolumn{2}{|c|}{ com Gini } & \multicolumn{2}{|c|}{ com Theil } \\
\hline & Qui-Quadrado & $\mathrm{p}$-valor & Qui-Quadrado & $p$-valor & Qui-Quadrado & $\mathrm{p}$-valor & Qui-Quadrado & $p$-valor \\
\hline $\begin{array}{c}\text { Wald modificado para } \\
\text { heterocedasticidade em Efeitos Fixos }\end{array}$ & $6,7 \mathrm{E}+28$ & 0,000 & $2,9 E+31$ & 0,000 & 1,7E+36 & 0,000 & $2,3 E+35$ & 0,000 \\
\hline $\begin{array}{c}\text { Breuch Pagan - existência de efeito } \\
\text { individual não observado }\end{array}$ & 203 & 0,000 & 337 & 0,000 & 393 & 0,000 & 461 & 0,000 \\
\hline Hausman & 205 & 0,000 & 531 & 0,000 & 149 & 0,000 & 314 & 0,000 \\
\hline
\end{tabular}

Obs.: (1) Os valores entre parênteses abaixo de cada coeficiente correspondem ao respectivo desvio-padrão.

(2) Todas as estimações usam White robusto para heterocedasticidade.

(3) As colunas Zh30 e Zh50 indicam os valores correspondentes às linhas híbridas considerando linhas relativas de $30 \%$ e $50 \%$ da renda média, respectivamente.

Pela Tabela 22, o teste de Wald modificado, cuja hipótese nula é de homocedasticidade, indica que esta hipótese deve ser rejeitada para a maioria das estimações, existindo a necessidade de estimação robusta à heterocedasticidade para garantir que as observações sejam independentes e identicamente distribuídas entre as unidades de crosssection.

Com relação à existência de efeito fixo nas estimações, pelo teste de Breuch-Pagan, observa-se que a hipótese nula, de que a variância do efeito individual não observado é zero, pode ser rejeitada. Com isso, as estimações precisam considerar a existência do efeito fixo.

Além disso, efetua-se o teste de Hausman cuja hipótese nula é a inexistência de correlação entre o efeito individual não observado e as variáveis explicativas. Pelos resultados, deve-se rejeitar a hipótese nula, concluindo-se que o método de Efeitos Aleatórios é ineficiente. Desta forma, o método mais eficiente para estimar o modelo utilizado é o de Efeitos Fixos.

Assim, considerando a parte da Tabela 21 que mostra os resultados pelo método de Efeitos Fixos, conclui-se que o coeficiente da renda familiar per capita é por volta de $-1,0$ (considerando o modelo com Gini) e -0,8 (com Theil). Já a elasticidade-desigualdade da pobreza assume um valor entre 1,3 e 1,9 (com Gini) e entre 0,4 e 0,6 (com Theil). Observamos que à medida que a linha de pobreza se torna mais relativa menor é o valor em módulo das elasticidades-desigualdade. Isto provavelmente se deve ao fato do termo da linha híbrida estar captando uma parte da variação na desigualdade devido à linha relativa.

Vale destacar que as estimações apresentadas na Tabela 21 não consideram o peso dos municípios devido a limitações do programa econométrico utilizado neste trabalho. Para considerar nas estimações as ponderações das observações de acordo com a metodologia de Deaton (1997), estima-se pelo método de MQVD considerando dummies para os municípios, 
visto que por este método obtém-se estimadores iguais aos de Efeitos Fixos, conforme a Tabela 23.

Tabela 23 - Estimações em Logaritmo da Incidência da Pobreza em Renda, Desigualdade e Linha Híbrida por MQVD com Peso

\begin{tabular}{|c|c|c|c|c|}
\hline \multirow{3}{*}{$\begin{array}{l}\text { Variável dependente: } \\
\text { Proporção de Pobres }\end{array}$} & \multicolumn{4}{|c|}{ MQVD } \\
\hline & \multicolumn{2}{|c|}{ Zh30 } & \multicolumn{2}{|c|}{ Zh50 } \\
\hline & com Gini & com Theil & com Gini & com Theil \\
\hline Intercepto & $\begin{array}{l}1,9138 \\
(0,314)\end{array}$ & $\begin{array}{r}1,8755 \\
(0,332) \\
\end{array}$ & $\begin{array}{l}0,6654 \\
(0,104) \\
\end{array}$ & $\begin{array}{l}0,8767 \\
(0,131) \\
\end{array}$ \\
\hline Renda Familiar per Capita & $\begin{array}{c}-1,0410 \\
(0,082)\end{array}$ & $\begin{array}{c}-0,6532 \\
(0,102)\end{array}$ & $\begin{array}{c}-0,9092 \\
(0,046)\end{array}$ & $\begin{array}{l}-0,6806 \\
(0,052)\end{array}$ \\
\hline Índice de Desigualdade de & $\begin{array}{l}2,0698 \\
(0,112)\end{array}$ & $\begin{array}{l}0,6544 \\
(0,035)\end{array}$ & $\begin{array}{l}1,3706 \\
(0,035)\end{array}$ & $\begin{array}{l}0,4551 \\
(0,013)\end{array}$ \\
\hline Linha Híbric & $\begin{array}{l}0,8171 \\
(0,150)\end{array}$ & $\begin{array}{l}0,1019 \\
(0,191)\end{array}$ & $\begin{array}{l}0,8842 \\
(0,066)\end{array}$ & $\begin{array}{l}0,4297 \\
(0,077)\end{array}$ \\
\hline Dummy do ano de 1991 & $\begin{array}{l}0,1068 \\
(0,008)\end{array}$ & $\begin{array}{l}0,0576 \\
(0,011)\end{array}$ & $\begin{array}{l}0,1180 \\
(0,005)\end{array}$ & $\begin{array}{l}0,0634 \\
(0,007)\end{array}$ \\
\hline$R^{2}$ Ajustado & 0,8489 & 0,7956 & 0,9280 & 0,8911 \\
\hline $\mathrm{n}^{\circ}$ de observações & \multicolumn{2}{|c|}{8576} & \multicolumn{2}{|c|}{8576} \\
\hline
\end{tabular}

Obs.: (1) MQVD corresponde ao método de Mínimos Quadrados com Variáveis Dummy considerando os dois anos (1991 e 2000).

(2) Os valores entre parênteses abaixo de cada coeficiente correspondem ao respectivo desvio-padrão.

(3) Todas as estimações usam White robusto para heterocedasticidade.

(4) As colunas Zh30 e Zh50 indicam os valores correspondentes às linhas híbridas considerando linhas relativas de $30 \%$ e $50 \%$ da renda média, respectivamente.

Com o método por MQVD, o coeficiente da renda familiar per capita fica próximo do valor com a linha absoluta para o modelo com índice de Gini e linha híbrida Zh30, ou seja, próximo de -1,1. Já com Theil, esta elasticidade é menor quando consideramos as linhas híbridas, apresentando um valor por volta de $-0,65$ e a elasticidade-desigualdade praticamente se mantém entre 1,4 e 2,1 (no modelo com Gini) e entre 0,4 e 0,7 (com Theil). Novamente o coeficiente da dummy de tempo é positivo e significante, indicando que o cenário macroeconômico de 1991 contribuía para o aumento da incidência da pobreza.

Já o coeficiente do termo da linha híbrida, que é a elasticidade da pobreza com relação a esta linha é significativo em todas das estimações, sendo da ordem de 0,8 (com Gini) e 0,4 (com Theil). Vale destacar que este coeficiente não é significativo para o modelo com índice de Theil e linha híbrida Zh30. Com exceção deste caso, a significância dos modelos é um indício de que o modelo a partir da equação (27) responde adequadamente ao fato da linha híbrida de pobreza sofrer deslocamento dada uma variação na renda. 
De acordo com a equação (28), a elasticidade-renda da pobreza não é somente o valor do coeficiente da renda familiar per capita como é no caso com a linha absoluta de pobreza. Assim, é necessário considerar também o valor da elasticidade-renda da linha de pobreza e o coeficiente do termo da linha híbrida de pobreza obtido pelas estimações da Tabela 23. Os resultados do cálculo da elasticidade-renda da pobreza considerando as elasticidades-renda da linha de pobreza são apresentados na Tabela 24.

Tabela 24 - Cálculo da Elasticidade-Renda da Pobreza $\left(\varepsilon_{r}\right)$

\begin{tabular}{lccccccc}
\hline $\begin{array}{c}\text { Linha } \\
\text { Híbrida }\end{array}$ & $\begin{array}{c}\text { Índice de } \\
\text { Desigualdade }\end{array}$ & \multirow{2}{*}{$\beta_{1}$} & \multirow{2}{*}{$\beta_{3}$} & \multicolumn{2}{c}{1991} & \multicolumn{2}{c}{2000} \\
\cline { 5 - 8 } & & & & $\rho_{t}$ & $\varepsilon_{\mathrm{r}}$ & $\rho_{t}$ & $\varepsilon_{\mathrm{r}}$ \\
\hline Zh30 & \multirow{2}{*}{ Gini } & $-1,04097$ & 0,81706 & 0,59766 & $-0,55264$ & \multirow{2}{*}{0,67120} & $-0,49255$ \\
Zh50 & & $-0,90921$ & 0,88416 & & $-0,38078$ & & $-0,31575$ \\
\hline Zh30 & \multirow{2}{*}{ Theil } & $-0,65318$ & 0,10193 & \multirow{2}{*}{0,59766} & $-0,59226$ & \multirow{2}{*}{0,67120} & $-0,58477$ \\
Zh50 & & $-0,68064$ & 0,42972 & & $-0,42382$ & & $-0,39222$ \\
\hline
\end{tabular}

Obs.: (1) As linhas Zh30 e Zh50 indicam os valores correspondentes às linhas híbridas considerando linhas relativas de $30 \%$ e $50 \%$ da renda média, respectivamente.

(2) As colunas $\beta_{1}$ e $\beta_{3}$ correspondem aos coeficientes da Renda Familiar per Capita e Linha Híbrida de Pobreza da Tabela 23, respectivamente.

(3) As colunas $\rho_{t}$ correspondem aos valores da elasticidade-renda da linha de pobreza calculados no capítulo anterior e apresentados na Tabela 6.

Observamos que a elasticidade-renda da incidência da pobreza considerando a linha híbrida está entre - 0,4 e - -0,6, indicando uma redução com relação ao valor da elasticidaderenda $\left(\beta_{1}\right)$ com a linha absoluta de pobreza que se encontra próximo de -1,1. Isto mostra que, quando se considera uma linha híbrida de pobreza, o impacto da renda sobre a pobreza é reduzido praticamente pela metade uma vez que a renda provoca um aumento no valor da linha de pobreza. Assim, por um lado o impacto da renda aumenta a linha de pobreza e conseqüentemente aumenta a pobreza e por outro lado há um impacto direto elevando a renda da população e reduzindo a pobreza. Como o primeiro impacto de aumento da pobreza é menor em relação ao impacto sobre a redução da pobreza via aumento da renda da população, a elasticidade-renda mantém o sinal negativo. De maneira geral, um acréscimo de $1 \%$ na renda familiar per capita reduz a pobreza entre $0,4 \%$ e $0,5 \%$ no Brasil, quando se considera uma linha híbrida para a mensuração da pobreza. 


\section{4 - Fatos Estilizados e Conclusões}

Os determinantes da redução da pobreza dividem-se basicamente em variações na renda familiar per capita e nos índices de desigualdade de renda. Contudo, o impacto destas variações não é totalmente claro numa base de dados com informações de indivíduos ao longo do tempo. Os resultados dependem do modelo em questão.

Neste capítulo, trabalhamos com um painel de municípios para os anos de 1991 e 2000, estudando-se três tipos de modelagem. A primeira baseia-se num modelo simples de variação da renda e da desigualdade sobre a redução da pobreza. Com esta modelagem, a elasticidade-renda da pobreza é da ordem de $-1,1$ e a elasticidade-desigualdade da pobreza apresenta os valores de 1,5 (com o índice de desigualdade de Gini) e 0,5 (com o índice de Theil). Marinho e Soares (2003) estimam as elasticidades da pobreza em relação à renda e ao índice de desigualdade de Gini através das PNAD's do período de 1985 a 1999, encontrando os valores de $-1,13$ e 2,20 , respectivamente ${ }^{19}$.

Com isso, podemos fazer uma simples verificação de variações. Sabemos que entre 1991 e 2000, a renda, índice de Gini, índice de Theil e incidência da pobreza apresentaram variações percentuais de $+29,0 \%,+0,8 \%,+1,8 \%$ e $-27,8 \%$, respectivamente. A partir de Ravallion e Datt (1992), podemos somar os efeitos renda e desigualdade através da equação:

$\Delta$ pobreza $=\Delta$ desigualdade $-\Delta$ renda + residuo.

Com isso, considerando o índice de Gini, temos um resíduo de $+0,4 \%$ e, com o índice de Theil, um resíduo de $-0,6 \%$.

Entretanto nesta primeira modelagem, as elasticidades são constantes. A segunda modelagem permite que estas elasticidades variem, dependendo do inverso do nível inicial de desenvolvimento e do nível inicial de desigualdade. Pelos resultados, observa-se que o efeito da variação da renda sobre a pobreza é menor quando o nível inicial de desenvolvimento é baixo ou o nível inicial de desigualdade é alto. Desta forma, as regiões menos desenvolvidas como o norte e nordeste brasileiros apresentam uma maior dificuldade de reduzir a pobreza através do crescimento da renda. Nestas regiões, como há muitos indivíduos com renda muito abaixo da linha de pobreza, quando ocorre um aumento da renda, há melhoria da situação destes indivíduos com relação à renda, mas não o suficiente para retirá-los da pobreza. Ou

\footnotetext{
19 Marinho e Soares (2003) também estima um modelo que inclui um termo de interação entre renda e desigualdade e um termo de variação quadrática da renda, que não foi considerado neste trabalho uma vez que se optou por estudar o modelo baseado em Ravallion e Datt (1992) e o de Bourguignon (2002).
} 
seja, estes indivíduos pobres se encontram em um dos extremos da função de distribuição de renda. Quando há um acréscimo na renda per capita, todos os indivíduos melhoram com relação à renda, mas os mais pobres não conseguem sair da situação de pobreza. Este resultado enfatiza que a alta desigualdade de renda do Brasil contribui negativamente para a redução da pobreza através do crescimento da renda.

Considerando o efeito da variação da desigualdade de renda sobre a redução da pobreza, percebemos que este efeito é menor quando o nível inicial de desenvolvimento é baixo ou o nível inicial de desigualdade é alto. Novamente, concluímos que a redução da pobreza nas regiões Norte e Nordeste, que possuem um menor nível de desenvolvimento, responde de forma menos expressiva a uma melhoria da desigualdade de renda. Assim, nas regiões com um grau de desigualdade muito elevado, uma redução do índice de desigualdade tem um impacto menor sobre a melhoria do quadro da pobreza. Desta forma, as regiões Norte, Nordeste e Centro-Oeste, que possuem os maiores índices de desigualdade do País, apresentam uma maior dificuldade de reverter o quadro de elevada pobreza através da redução da desigualdade de renda, quando comparadas com as regiões Sul e Sudeste.

Ao analisarmos a hipótese de log-normalidade da renda, não conseguimos constatar que a distribuição de renda no Brasil segue uma log-normal, uma vez que mostra sensibilidade ao índice de desigualdade utilizado. Apenas com o índice de desigualdade de Theil, não rejeitamos esta hipótese através do teste proposto por Bourguignon (2002).

A última modelagem, que até onde se pôde perceber é inédita no Brasil, analisa a questão do impacto de variações de renda e desigualdade sobre a redução da pobreza, considerando uma linha híbrida de pobreza. Neste caso, introduzimos um termo de variação da linha de pobreza. Assim, quando ocorre um aumento da renda, há um efeito direto de redução da pobreza, porém este aumento provoca um deslocamento da linha de pobreza que, por sua vez, aumenta a pobreza. As estimações mostram que o coeficiente deste novo termo é significativo, sendo um indicativo de que o modelo considerado é adequado. Podemos destacar que o efeito da renda sobre a redução da pobreza cai praticamente pela metade quando utilizamos a incidência da pobreza através de uma linha híbrida, em relação à mensuração com linha absoluta. 


\section{5 - CONCLUSÃO}

Este trabalho analisou a pobreza no Brasil entre os anos de 1991 e 2000 dentro do âmbito da pobreza como insuficiência de renda. Para tanto, estimou para diferentes estratos do Brasil uma linha de pobreza inédita, até onde se pode pesquisar: a Linha Híbrida de Pobreza. No seu cálculo, inicialmente estimamos a elasticidade-renda da linha de pobreza, que se mostrou entre 0,6 e 0,7 para o País, indicando que a linha de pobreza no Brasil possui fatores absolutos e relativos quase de mesma grandeza, com uma pequena prevalência da linha relativa de pobreza.

Com a aplicação destas linhas estimadas, pudemos constatar que entre o ano de $1991 \mathrm{e}$ 2000 houve uma menor redução da pobreza no Brasil, quando comparamos com o que as linhas absolutas de pobreza indicavam. Isto se deve provavelmente à ponderação com linhas relativas, visto que não podemos observar queda da desigualdade de renda no período analisado.

Uma vez que observamos a variação da incidência da pobreza no Brasil no período analisado, decidimos estudar a alteração dos determinantes desta incidência, através da análise da probabilidade de um indivíduo ser pobre. Assim, buscando entender o fenômeno de redução da pobreza, quando utilizamos uma linha híbrida de pobreza, estimamos a contribuição dos atributos individuais e regionais sobre a probabilidade de um indivíduo ser pobre, entendendo que existem fatores além da renda que influenciam o fato de um indivíduo ser pobre. Observamos que os atributos "ser mulher" e "não pertencer à raça branca" aumentam a probabilidade do indivíduo ser pobre. Com efeito contrário, reduzindo esta probabilidade, estão os atributos escolaridade e idade, e os regionais (como viver em região urbana e em alguns estados, destacando-se Santa Catarina). Já as regiões metropolitanas, provavelmente devido à grande pobreza existente nas periferias das grandes cidades, contribui para o aumento da probabilidade de um indivíduo ser pobre.

Em seguida, abordamos o impacto de variações no crescimento e na desigualdade de renda sobre a redução da pobreza no Brasil, considerando vários modelos. Do ponto de vista de políticas públicas, este trabalho busca contribuir para o debate a respeito das diversas políticas de atuação sobre o quadro de pobreza no Brasil.

Além dos efeitos, positivo do crescimento da renda familiar per capita e negativo da desigualdade de renda sobre a redução da pobreza, alguns fatos ficaram estilizados nas estimações efetuadas. Observa-se que o efeito da variação da renda sobre a pobreza é menor 
quando o nível inicial de desenvolvimento é baixo ou quando o índice inicial de desigualdade é alto. Já o efeito da variação da desigualdade sobre a redução da pobreza é menor quando o nível inicial de desenvolvimento é baixo ou quando o nível inicial de desigualdade é alto. Assim, regiões com menor nível inicial de desenvolvimento e maior índice inicial de desigualdade apresentam maiores dificuldades para reduzir a pobreza, independente do meio pelo qual este objetivo for perseguido: através de crescimento econômico ou redução da desigualdade de renda. Percebemos um efeito "perverso" para regiões com baixo desenvolvimento econômico e elevada desigualdade de renda, prejudicando a reversão do quadro da pobreza no Brasil.

Com os resultados obtidos, concluímos que seria necessário um aumento na renda familiar per capita da ordem de $45 \%$ para que a incidência da pobreza fosse reduzida pela metade, considerando que a distribuição de renda não se alterasse. Assim, a renda familiar per capita teria que sair de $\mathrm{R} \$ 326,87$ em 2000, chegando ao valor de $\mathrm{R} \$ 473,96$.

Outra maneira de se obter esta redução na pobreza, sem alterações na renda média, seria através de uma queda de $33 \%$ no índice de desigualdade de Gini, o que corresponderia alterar o índice de 0,63 para 0,44. Já com o índice de Theil, dada a baixa elasticidadedesigualdade obtida, seria necessário reduzir o índice a zero, indicando a inviabilidade de combate à pobreza apenas através de redução da desigualdade.

Considerando uma estratégia de combate à pobreza que combine tanto crescimento econômico quanto distribuição de renda, poderíamos alcançar uma queda na incidência da pobreza pela metade, através de um cenário econômico com renda média de $\mathrm{R} \$ 410,00$ (aumento de $25 \%$ ) e índice de Gini de 0,53 (redução de 15\%).

Quanto ao teste da hipótese de log-normalidade da distribuição de renda, não obtemos resultados conclusivos, uma vez que esta apresentou sensibilidade quanto à utilização de diferentes índices de desigualdade. Isto é um indício de que devemos rejeitar a hipótese de que a renda familiar per capita no Brasil segue uma distribuição log-normal. Contudo, não se pode concluir que esta hipótese é inválida, pois seria necessário estimar modelos com outras medidas de pobreza, além da incidência da pobreza e outros índices de desigualdade de renda. Assim, este assunto ainda demanda estudos mais aprofundados, permanecendo em aberto para futuros trabalhos.

Além destas estimações, aplicamos a linha híbrida de pobreza num modelo que captasse a variação da pobreza a partir de variações de renda e desigualdade. Neste caso, acrescentamos um efeito de deslocamento da linha híbrida, uma vez que ao ocorrer um aumento na renda, há o efeito direto sobre a redução da pobreza e um efeito sobre o 
deslocamento da linha de pobreza que provoca um aumento na pobreza. A elasticidade-renda da incidência da pobreza passa a considerar estes dois efeitos. Os resultados indicam coeficientes significativos para o termo de variação da linha, indicando que o efeito de um aumento da renda per capita sobre a redução da pobreza é reduzido praticamente pela metade devido ao deslocamento da linha híbrida, quando comparamos com uma linha absoluta fixa.

De modo geral, observamos nas estimações que o cenário macroeconômico de 1991, conseqüência de crises e choques na economia, tem um impacto negativo sobre a incidência da pobreza, quando comparado com 2000, não contribuindo para a redução da pobreza no Brasil.

Por fim, dados os resultados, este trabalho objetivou: estimar a elasticidade-renda da linha de pobreza; estimar a Linha Híbrida de Pobreza; identificar o impacto de mudanças nas variáveis renda e desigualdade para a redução da pobreza. Com isso, almejamos oferecer uma significativa contribuição para o debate sobre políticas públicas com estratégias de combate à pobreza focadas no crescimento econômico e na distribuição de renda. 


\section{REFERÊNCIAS}

AMEMIYA, T. A Note on the Estimation of Balestra-Nerlove Models. Technical Report n.4, Institute for Mathematical Studies in Social Sciences, Stanford University, 1967.

BARROS, R.P. et al. Acesso ao Trabalho e Produtividade no Brasil: Implicações para Crescimento, Pobreza e Desigualdade. Rio de Janeiro: Ipea, 2004.

A Estabilidade Inaceitável: Desigualdade e Pobreza no Brasil. em: Henriques, R. (org.) Desigualdade e Pobreza no Brasil. Rio de Janeiro: Ipea, 2000.

BOURGUIGNON, François. The Poverty-Growth-Inequality Triangle. Washington D.C.: The World Bank, 2004

The Growth Elasticity of Poverty Reduction: Explaining Heterogeneity across Countries and Time Periods. em: Eicher, T. e S. Turnovsky, Inequality and Growth: Theory and Policy Implications. Cambridge: The MIT Press, 2002.

BOURGUIGNON, François; ATKINSON, A. Poverty and Inclusion from a World Perspective. Washington D.C.: The World Bank, 1999

CITRO, Constance F.; MICHAEL, Robert T. Measuring Poverty: A New Approach. Washington D.C.: National Academy Press, 1995.

CIVARDI, Marisa; MARTINETTI, Enrica. Poverty Between and Within Groups: a Reformulation of the FGT Class of Index. Itália: Quaderni del Dipartimento di Economia Pubblica e Territoriale, n.3, 2004.

CLINE, William. Trade Policy and Global Poverty. Washington D.C.: Institute for International Economics. 2004.

CORSEUIL, C. H.; FOGUEL, M. N. Uma Sugestão de Deflatores para Rendas Obtidas a Partir de Algumas Pesquisas Domiciliares do IBGE. Texto para Discussão, $n^{\circ}$ 897. Rio de Janeiro: Ipea, 2002.

DEATON, Angus. The Analysis of Household Surveys: A Microeconometric Approach to Development Policy. Washington D.C.: The World Bank, 1997.

EPAULARD, Anne. Macroeconomic Performance and Poverty Reduction. Washington D.C.: IMF Institute, 2003. 
FERREIRA, Francisco; LANJOUW, Peter; NERI, Marcelo. A New Poverty Profile for Brazil Using PPV, PNAD and Census Data. Texto para Discussão $n^{\circ} 418$. Rio de Janeiro: PUC, 2000.

FIELDS, Gary. Distribution and Development: A New Look at the Developing World. Cambridge, MA: The MIT Press, 2001.

FISHER, Gordon. Is There Such a Thing as an Absolute Poverty Line Over Time? Washington D.C.: U.S. Departament of Health and Human Services, 1995.

FOSTER, James. Absolute versus Relative Poverty. The American Economic Review, v.88, n.2, 1998.

FOSTER, J.; Shorrocks , A. Poverty Orderings. Econometrica, v.56(1), p.173-177, 1988.

FOSTER, J. et al. A Class of Decomposable Poverty Measures. Econometrica, v.52(3), p.761-766, 1984.

HOFFMANN, Rodolfo. Elasticidade da Pobreza em Relação à Renda Média e à Desigualdade. Encontro Nacional de Economia - ANPEC, 2004.

1998.

Distribuição de Renda: Medidas de Desigualdade e Pobreza. São Paulo: EDUSP,

JOHNSTON, Jack; DINARDO, John. Econometric Methods. 4th Edition. McGraw-Hill, 1997.

KAKWANI, N. Poverty and Economic Growth with Application to Cote d'Ivoire. Review of Income and Wealth, v.39, p.121-139, 1993.

KAKWANI, N.; SUBBARAO, K. Rural Poverty and its Alleviation in India. Economic and Political Weekly, v.25, A2-A16, 1990.

KALWIJ, Adriaan; VERSCHOOR, Arjan. A Decomposition of Poverty Trend across Regions. United Nations University: World Institute for Development Economics Research, 2005.

LAVINAS, Lena. A Melhor Linha de Pobreza para o Brasil. Texto para Discussão. Rio de Janeiro: IFRJ, 2005.

MADDEN, David. Relative or Absolute Poverty Lines: A New Approach. Review of Income and Wealth, v.46, p.181-199, 2000. 
MARINHO, Emerson; SOARES, Francisco. Impacto do Crescimento Econômico e da Concentração de Renda sobre a Redução da Pobreza nos Estados Brasileiros. Encontro Nacional de Economia - ANPEC, 2003.

MENEZES-FILHO, Naércio; VASCONCELOS, Lígia. Alguns Fatos Estilizados sobre a Evolução da Pobreza no Brasil. Texto para Discussão. São Paulo: USP, 2004.

MORAIS, Maria da Piedade; CRUZ, Bruno de O. Demand for Housing and Urban Services in Brazil: A Hedonic Approach. Texto para Discussão nº 946. Brasília: Ipea, 2003.

RAVALliON, Martin. Growth, Inequality and Poverty: Looking Beyond Averages. Washington D.C.: The World Bank, 2000.

. Growth and Poverty: Evidence for Developing Countries in the 1980s. Economics Letters, v.48, p.411-417, 1995.

Poverty Comparisons. Harwood Academic Publishers, 1994.

RAVAlliOn, Martin, e S. Chen. Can High-Inequality Developing Countries Escape Absolute Poverty? Economic Letters, v.56, p.51-57, 1997.

RAVALLION, Martin; Datt, Gaurav. Growth and Redistribution Components of Changes in Poverty Measures. Journal of Development Economics, v.38(2), p.275-295, 1992.

ROCHA, Sonia. A Pobreza no Brasil. Rio de Janeiro: FGV, 2003.

Do Consumo Observado à Linha de Pobreza. Pesquisa e Planejamento Econômico. Ipea, v.27(2), p.313-52, 1997.

ROSEN, S. Hedonic Prices and Implicit Markets: Product Differentiation in Pure Competition. Journal of Political Economics, v.82, 1974.

SEN, Amartya. Development as Freedom. New York: Alfred A. Knopf, 1999.

SHORT, Kathleen et al. Defining and Redefining Poverty. Washington D.C.: U.S. Census Bureau, 2002.

TAKAGI, Maya et al. 2001. Pobreza e Fome: em Busca de uma Metodologia para Quantificação do Problema no Brasil. Texto para Discussão nº 101. Campinas: IE/UNICAMP.

VARIAN, Hal R. Microeconomia: Princípios Básicos. Rio de Janeiro: Ed. Campus, 2002. 
WOOLDRIDGE, Jeffrey M. Introductory Econometrics: A Modern Approach. Mason, Ohio: Thomson - South Western, 2003.

Econometric Analysis of Cross Section and Panel Data. Cambridge, MA: The MIT Press, 2002.

WORLD BANK. World Development Indicators 2004. World Bank's Annual Statistical Report. Washington D.C.: The World Bank, 2004. 


\section{APÊNDICES}

APÊNDICE A - CORREÇÃO DO INPC

APÊNDICE B - MODELO HEDÔNICO

APÊNDICE C - ESTATÍSTICAS DESCRITIVAS

APÊNDICE D - POSSIBILIDADES DE CONSTRUÇÃO DA RENDA PER CAPITA

APÊNDICE E - COMPATIBILIZAÇÃO ENTRE MUNICÍPIOS DE 1991 E 2000

APÊNDICE F - DEDUÇÃO DAS ELASTICIDADES 


\section{APÊNDICE A - CORREÇÃO DO INPC}

Corseuil e Foguel (2002) sugere uma metodologia para a correção do INPC. Por esta metodologia, o INPC, para ser utilizado como deflator dos rendimentos do Censo, deve sofrer três ajustes:

a) alteração da data de referência;

b) alteração do valor referente a julho de 1994;

c) expansão do índice para períodos anteriores à sua criação.

Como estamos trabalhando basicamente com o período da década de 90 , o último ajuste não nos é relevante, uma vez que o INPC existe desde 1979.

O primeiro ajuste se refere ao fato que, em março de 1986, o IBGE alterou o período de coleta dos preços que entravam no cálculo do índice. Anteriormente era considerado o período entre os dias 15 e 15 de dois meses consecutivos, ou seja, os índices ficavam centralizados no dia primeiro de cada mês. Após março de 1986, o período de coleta passou a ser entre os dias primeiro e 30 de cada mês, com os índices centralizados, portanto, no dia 15 do mês. Uma vez que os rendimentos do trabalho, que são a principal fonte de renda, tendem a se concentrar no início do mês, Corseuil e Foguel (2002) sugere centrar novamente os índices no dia primeiro, mediante o cálculo de uma média geométrica entre os valores dos índices de dois meses consecutivos.

Já o segundo ajuste se refere ao problema da medida de inflação no mês de adoção do Plano Real. Em junho de 1994 havia duas unidades monetárias correntes. Para o cálculo do INPC de julho, o IBGE contrastou a média dos preços nesse mês, em reais (R\$), com a média dos preços em Unidade Real de Valor (URV), em junho. Porém muitos preços de julho de 1994 estavam em cruzeiro real (CR\$) e as pessoas gastaram seus rendimentos nesse mês com base nessa moeda. Como a variação dos preços em URV foi menor do que a variação em $\mathrm{CR}$ \$, entendemos ser necessário incorporar à variação reportada pelo INPC um componente relacionado ao excesso da variação de preços em cruzeiro real em relação à variação em URV. 


\section{APÊNDICE B - MODELO HEDÔNICO}

Neste apêndice, é apresentada a metodologia para a atribuição de um valor monetário mensal aos indivíduos que declaram possuir casa própria. Este valor representa um rendimento em termos de consumo, que seria equivalente a um aluguel implícito pelo fato do indivíduo possuir esta casa. Pode-se pensar que o indivíduo, que possui um imóvel, está de certa forma pagando um aluguel para si mesmo. $\mathrm{Na}$ verdade, isto não ocorre de maneira explícita, mas pode-se entender que o proprietário que mora em seu imóvel faz tal pagamento de forma implícita. Com isso, o aluguel implícito do imóvel é aquele ao qual o indivíduo poderia alugar um imóvel semelhante. Ou seja, é o valor ao qual ele poderia alugar seu próprio imóvel no mercado. Desta forma, morando em seu próprio imóvel, o indivíduo fica impossibilitado de cobrar aluguel a outro indivíduo por este imóvel, e portanto, há um custo de oportunidade.

Conhecendo-se o valor deste aluguel implícito, é possível acrescentá-lo à renda familiar per capita dos indivíduos que declararam como próprio o imóvel no qual se encontra o domicílio.

\section{B.1 - Metodologia}

Na teoria econômica, a casa própria é frequientemente considerada como um bem durável, caracterizado por seus diversos atributos que podem ser analisados independentemente. Assim, o imóvel pode ser classificado como um bem heterogêneo com características específicas, como localização, tamanho, tipo de construção, entre outros. Desta forma, a demanda por imóvel pode ser entendida como uma função dos vários atributos e características da propriedade. Esta abordagem é conhecida na literatura como modelos de preços implícitos ou hedônicos, em que preços hedônicos podem ser interpretados como os preços que refletem o fluxo de retornos dos atributos de uma determinada propriedade.

Rosen (1974) destaca-se por formalizar a teoria de preços hedônicos, determinando a seguinte função $P=f(C)$, onde $P$ é o preço do imóvel e $C$ representa os atributos que 
determinam um certo preço. $\mathrm{O}$ preço hedônico de um dado componente $i$ de $C$ é definido como $\partial P / \partial C_{\mathrm{i}}$. Rosen (1974) mostra que as características presentes na função de preços hedônicos são provenientes dos problemas de maximização dos consumidores e produtores, que determinam as relações de preços entre os atributos. Com um número grande de consumidores e produtores, a função de preços hedônicos representará todos os pontos ótimos, ou seja, o conjunto de Pareto.

Pela teoria, a existência de custos marginais crescentes dos atributos e de restrições quanto ao conjunto de características do imóvel provavelmente levaria a uma função de preços hedônicos não-linear. Contudo, como não há uma definição sobre a forma funcional ótima para a equação hedônica, costuma-se na literatura estimá-la sob especificações lineares, loglineares e logarítmicas, buscando-se a melhor especificação para a regressão.

A estimação do modelo neste trabalho se baseia em Morais e Cruz (2003), contudo impondo algumas restrições quanto às variáveis devido às diferenças de conceituação entre as bases de dados da PNAD e do Censo, visando homogeneizá-las. Como no Censo de 1991, há a informação sobre o valor mensal pago de aluguel, não foi necessário recorrer à outra base de dados para a estimação e imputação do valor do aluguel implícito. Já o Censo de 2000 não apresenta esta informação sobre o aluguel pago, incorrendo na necessidade de utilização de outra base de dados.

Desta forma, conforme explicitado no capítulo 2, opta-se por trabalhar com quatro possibilidades para a construção da renda familiar per capita:

(a) Utilização do Censo de 1991 para a estimação do aluguel implícito de 1991, e das PNAD’s de 1999 e 2001 para a do aluguel implícito de 2000;

(b) Utilização do Censo de 1991 para a estimação dos alugueis implícitos de 1991 e 2000;

(c) Utilização das PNAD’s de 1990 e 1992 para a estimação do aluguel implícito de 1991, e das PNAD's de 1999 e 2001 para a do aluguel implícito de 2000;

(d) Sem a utilização de base de dados, não havendo estimação do aluguel implícito.

A primeira possibilidade de construção da renda familiar per capita foi discutida ao longo deste trabalho. Esta possibilidade de estimação do aluguel implícito é apresentada neste apêndice. Os resultados constantes nas tabelas ao longo deste trabalho são apresentados para as outras possibilidades no Apêndice D.

Como se pode observar nas quatro possibilidades acima, para a estimação do aluguel implícito no ano de 1991, considera-se o Censo de 1991 ou as PNAD’s de 1990 e 1992. Já para a estimação de 2000, utiliza-se o Censo de 1991 ou as PNAD’s de 1999 e 2001. Com isso, estima-se o aluguel implícito para os dois anos e em seguida faz-se a imputação deste no 
Censo do respectivo ano. Tal procedimento leva, após a estimação dos coeficientes, ao cálculo da previsão de aluguel pelo Censo. A Tabela B1 apresenta a definição das variáveis utilizadas nas estimações, de acordo com as bases de dados para cada ano.

Tabela B1 - Descrição das Variáveis

\begin{tabular}{|c|c|c|}
\hline \multirow{2}{*}{ Variável } & \multirow{2}{*}{$\begin{array}{l}\text { Tipo de } \\
\text { Variável } \\
\end{array}$} & Variáveis usadas para a estimação \\
\hline & & 2000 \\
\hline \multicolumn{3}{|l|}{ Variável Dependente: } \\
\hline Aluguel & Valor & Aluguel mensal pago \\
\hline \multicolumn{3}{|c|}{ Variáveis Independentes: } \\
\hline Casa & Dummy & Domicílios que se caracterizam por casa receberam o valor 1 (um) \\
\hline Quartos & Quantidade & $\begin{array}{c}\text { Considerou-se que os domicílios tinham no máximo } 9 \text { cômodos } \\
\text { servindo de dormitório }\end{array}$ \\
\hline Outros Cômodos & Quantidade & Número total de cômodos menos variável Quartos \\
\hline Paredes & Dummy & $\begin{array}{c}\text { Domicílios em que o material } \\
\text { predominante das paredes } \\
\text { externas era alvenaria ou madeira } \\
\text { aparelhada receberam o valor } 1 \\
\text { (um) }\end{array}$ \\
\hline Telhado & Dummy & $\begin{array}{l}\text { Domicílios em que o material } \\
\text { predominante do telhado era telha, } \\
\text { laje de concreto ou madeira } \\
\text { aparelhada receberam o valor } 1 \\
\text { (um) }\end{array}$ \\
\hline Água & Dummy & $\begin{array}{l}\text { Domicílios que têm água canalizada em pelo menos um cômodo } \\
\text { receberam o valor } 1 \text { (um) }\end{array}$ \\
\hline Banheiros & Dummy & $\begin{array}{l}\text { Domicílios que têm banheiro de uso só do prórpio domicílio receberam } \\
\qquad \text { o valor } 1 \text { (um) }\end{array}$ \\
\hline Esgoto & Dummy & $\begin{array}{l}\text { Receberam o valor } 1 \text { (um) os domicílios em que a forma de } \\
\text { escoadouro do banheiro ou sanitário era rede coletora de esgoto ou } \\
\text { pluvial, ou fossa séptica ligada ou não à rede coletora de esgoto ou }\end{array}$ \\
\hline Lixo & Dummy & $\begin{array}{c}\text { Domicílios em que o lixo domiciliar é coletado direta ou indiretamente } \\
\text { receberam o valor } 1 \text { (um) }\end{array}$ \\
\hline Eletricidade & Dummy & $\begin{array}{c}\text { Domicílios com iluminação elétrica (de rede, gerador ou solar) } \\
\text { receberam o valor } 1 \text { (um) }\end{array}$ \\
\hline Região Metropolitana & Dummy & Domicílios localizados em região metropolitana receberam o valor 1 \\
\hline Urbano & Dummy & $\begin{array}{c}\text { Domicílios localizados em cidade ou vila em área urbanizada ou não, } \\
\text { ou em área urbana isolada receberam o valor } 1 \text { (um) }\end{array}$ \\
\hline UF & Dummy & $\begin{array}{l}\text { Existe uma dummy para cada unidade da federação, em que o } \\
\text { domicílio que se localizar em dada UF receberá o valor } 1 \text { (um) }\end{array}$ \\
\hline
\end{tabular}

Obs.: Foram considerados apenas os domicílios particulares de caráter permanente que eram casas ou apartamentos.

A partir deste ponto neste apêndice, será descrito o procedimento adotado para a imputação do aluguel implícito com a casa própria na base de dados dos Censos de 1991 e 2000. Com as informações sobre aluguel da Tabela B1, estima-se a equação que é usada sobre a base de dados do Censo, calculando-se o valor deste aluguel implícito.

Primeiramente, tanto no Censo quanto na PNAD, trabalha-se somente com os indivíduos que pagaram aluguel no mês de referência, convertendo este valor para julho de 2000, de acordo com o INPC “corrigido” pela metodologia sugerida por Corseuil e Foguel 
(2002). A variável dependente do modelo é o aluguel mensal do domicílio, que pode ser considerada uma proxy do valor do imóvel. Com a construção das variáveis explicitadas, segundo a tabela acima, é feita a regressão, visando aplicar os coeficientes no Censo de 1991, da variável Aluguel sobre as variáveis Casa, Quartos, Outros Cômodos, Paredes, Telhado, Água Encanada, Banheiro, Esgoto, Lixo, Eletricidade, Região Metropolitana, Urbano e UF. O mesmo foi feito, visando aplicar os coeficientes no Censo de 2000, contudo com a regressão da variável Aluguel sobre as variáveis Casa, Quartos, Outros Cômodos, Água Encanada, Banheiro, Esgoto, Lixo, Eletricidade, Região Metropolitana, Urbano e UF. Vale destacar que as variáveis usadas em ambas as regressões são as mesmas, contudo a regressão para 1991 tem duas variáveis a mais (Paredes e Telhado) devido ao fato de somente o Censo de 1991 e as PNAD's apresentarem informações ${ }^{20}$ por elas.

Além disso, no Censo de 1991, com relação aos imóveis declarados como próprios pelos indivíduos são utilizadas apenas as informações de imóveis com construção e terreno próprios. Em 1991 não há a abertura sobre a situação do imóvel com relação ao fato de estar quitado ou não. Já no Censo de 2000, esta abertura existe, sendo considerados apenas os imóveis declarados como próprios e quitados. Esta falta de abertura da informação sobre a quitação do imóvel em 1991 pode provocar um erro de considerar um imóvel, em que o proprietário ainda o está pagando, como um ativo do indivíduo. Contudo, para este ano, considera-se a hipótese de que todos os domicílios caracterizados como imóveis declarados pelos indivíduos como próprios são ativos e devem ser considerados na renda familiar per capita.

Neste ponto, é importante atentar para o fato de que a variável dependente é usada com uma transformação log natural. Para calcular o valor previsto da variável Aluguel, teremos como base o modelo:

$\operatorname{Ln}(y)=\beta \cdot x+u$

onde $y=$ Aluguel, $\beta$ é o vetor de coeficientes, $x=$ [1, Quartos, Outros Cômodos, Paredes, Telhado, Água Encanada, Banheiro, Esgoto, Lixo, Eletricidade, Região Metropolitana, Urbano e 26 dummies de UF] e $u$ é o resíduo.

Considerando que o valor previsto de $\operatorname{Ln}(y)$ é $\operatorname{Ln} y$, temos:

$\operatorname{Ln} y=\hat{\beta} \cdot x$

onde $\hat{\beta}$ é o vetor com os estimadores de Mínimos Quadrados Ordinários.

\footnotetext{
${ }^{20}$ O Censo de 2000 não possui as informações sobre paredes e telhado do imóvel de domicílio. Desta forma, com as PNAD's, estas informações não foram utlizadas.
} 
Contudo, para encontrarmos o valor esperado de $y$, não podemos simplesmente aplicar o exponencial sobre $L \hat{n} y$, ou seja, usar a expressão:

$\hat{y}=\exp (\operatorname{Ln} y)$

Isto levaria a uma sub-estimação de $\hat{y}$. Portanto, para encontrarmos o valor previsto de $y$, precisamos fazer um pequeno ajuste, conforme Wooldridge (2003).

$$
\begin{aligned}
& \mathrm{E}(y \mid x)=\exp [\beta \cdot x+u] \\
& \hat{y}=\exp \left(\hat{\beta} \cdot x+\hat{\sigma}^{2} / 2\right) \\
& \hat{y}=\exp \left(\hat{\sigma}^{2} / 2\right) \cdot \exp (\hat{\beta} \cdot x)
\end{aligned}
$$

onde $\hat{\sigma}^{2}$ é o estimador não-viesado de $\sigma^{2}$ que é a variância de $u$.

Para o cálculo deste estimador, usamos a fórmula:

$$
\hat{\sigma}^{2}=\frac{S S R}{n-2}
$$

onde SSR é a soma dos quadrados do erro e n é o número de observações.

Com relação à base de dados, como já citado, consideram-se apenas as propriedades que se encontravam alugadas. São considerados apenas os domicílios classificados como particulares permanentes, desconsiderando conseqüentemente os particulares improvisados e os coletivos. Tanto o Censo quanto a PNAD não apresenta as informações ideais para um estudo sobre condições de moradia uma vez que estas pesquisas são voltadas para informações gerais de demografia, domicílio e renda. Isto leva a uma limitação quanto à quantidade e qualidade das informações disponíveis para medir as unidades domiciliares. Embora estas bases apresentem algumas informações relevantes sobre os atributos do domicílio, como número de moradores, número de quartos e outros cômodos, e nível de urbanização com relação aos serviços oferecidos, não fornecem informações importantes como, por exemplo, idade da moradia, tamanho $\left(\mathrm{m}^{2}\right)$ e preço de mercado. Apesar destas limitações, estas bases de dados são amostras nacionais representativas que permitem estudar as condições de moradia e aproveitar os resultados para o foco deste trabalho, que é o estudo sobre a redução da pobreza com a base de dados do Censo Demográfico.

Sendo o imóvel um bem durável, seu aluguel pode ser interpretado como o valor presente do fluxo de renda derivada do fato da posse do imóvel. Assim, o aluguel implícito, calculado a partir da regressão hedônica, representa o quanto de renda o indivíduo tem, além da sua renda com o trabalho, por possuir um imóvel. Desta maneira, é possível diferenciar dois indivíduos com rendas iguais recebidas na mesma periodicidade, quando um possui um imóvel e o outro não. É claro, neste caso, que o indivíduo possuidor de imóvel é mais rico, 
devido não somente à posse do imóvel, mas também ao fato de poder economizar a correspondente despesa de aluguel. Tal metodologia não está livre de problemas, uma vez que o mercado de alugueis no Brasil apresenta várias imperfeições, estando bastante regulado e sendo pequeno em termos mundiais. Além disso, os imóveis alugados representavam apenas $14,47 \%$ dos imóveis particulares permanentes brasileiros em 2001, conforme a tabela a seguir.

Tabela B2 - Tipos de Condição de Propriedade

\begin{tabular}{lrr}
\hline \multicolumn{1}{c}{ Condição de Propriedade } & \multicolumn{1}{c}{ Unidades } & \multicolumn{1}{c}{$\%$} \\
\hline Próprio - já pago & 31.777 .272 & 68,72 \\
Próprio - ainda pagando & 2.280 .716 & 4,93 \\
Alugado & 6.691 .016 & 14,47 \\
Cedido por empregador & 1.523 .641 & 3,29 \\
Cedido de outra forma & 3.634 .325 & 7,86 \\
Outra condição & 335.932 & 0,73 \\
lgnorado & 1.850 & 0,00 \\
\hline Total & 46.244 .752 & 100,00 \\
\hline
\end{tabular}

Fonte: Elaboração própria a partir da PNAD de 2001 do IBGE.

Para definir os atributos da unidade domiciliar, consideramos os seguintes aspectos:

- tamanho da unidade (número de quartos e outros cômodos);

- qualidade da estrutura física (paredes e telhado);

- acesso a serviços públicos (água, esgoto, coleta de lixo e eletricidade);

- condições de vida (existência de banheiro exclusivo);

- atributos locais (onde o domicílio se localiza: região metropolitana, unidade da federação e região urbana).

Um dos principais problemas neste modelo é a ausência de uma medida de acessibilidade à residência no modelo, visto que a proximidade do imóvel a uma estação de transporte metroviário, por exemplo, tem impacto positivo sobre o valor do aluguel. A omissão desta variável de localização deve-se a sua inexistência no Censo e na PNAD. Embora seja possível usar a variável de Tempo de percurso diário de ida da residência para o local de trabalho como proxy para acessibilidade ao imóvel, esta variável não foi incluída, pois leva em consideração apenas o tempo do(a) chefe da família, ocorrendo a falta desta informação em muitos casos e, conseqüentemente, reduzindo drasticamente o tamanho da amostra. 
Na busca por um modelo que melhor explique o valor de aluguel de um imóvel, seria necessário trabalhar com outras bases de dados, como, por exemplo, a Pesquisa sobre Padrões de Vida (PPV) do IBGE. Contudo, ao substituir o Censo ou a PNAD, perde-se a abrangência nacional da amostra, dificultando a imputação do aluguel implícito no Censo uma vez que a limitação de variáveis não se encontra somente com relação à PNAD, mas também com relação ao Censo que precisa possuir as mesmas variáveis, de acordo com a metodologia adotada.

\section{B.2 - Resultados Obtidos}

Conforme a Tabela B3, tanto para o ano de 1991 quanto para 2000, são efetuadas três regressões:

- com todas as variáveis em nível (regressão linear);

- somente com as variáveis explicativas em logaritmo (log-linear);

- com todas as variáveis em logaritmo (duplo-log). 
Tabela B3 - Regressão Hedônica

\begin{tabular}{|c|c|c|c|c|c|c|c|c|c|c|c|c|}
\hline \multirow{4}{*}{$\begin{array}{l}\text { Ano: } \\
\text { Modelo: } \\
\text { Variável Dependente: }\end{array}$} & \multicolumn{6}{|c|}{1991} & \multicolumn{6}{|c|}{2000} \\
\hline & \multirow{2}{*}{\multicolumn{2}{|c|}{$\begin{array}{c}\text { Linear } \\
\text { Aluguel }\end{array}$}} & \multirow{2}{*}{\multicolumn{2}{|c|}{$\frac{\text { Log-Linear }}{\text { Ln(Aluguel) }}$}} & \multirow{2}{*}{\multicolumn{2}{|c|}{$\begin{array}{c}\text { Duplo-Log } \\
\text { Ln(Aluguel) }\end{array}$}} & \multirow{2}{*}{\multicolumn{2}{|c|}{$\begin{array}{l}\text { Linear } \\
\text { Aluguel }\end{array}$}} & \multirow{2}{*}{\multicolumn{2}{|c|}{$\begin{array}{l}\text { Log-Linear } \\
\text { Ln(Aluguel) }\end{array}$}} & \multicolumn{2}{|c|}{ Duplo-Log } \\
\hline & & & & & & & & & & & Ln(Alug & guel) \\
\hline & Coeficiente & $\begin{array}{l}\text { desvio- } \\
\text { padrão }\end{array}$ & Coeficiente & $\begin{array}{l}\text { desvio- } \\
\text { padrão }\end{array}$ & Coeficiente & $\begin{array}{l}\text { desvio- } \\
\text { padrão }\end{array}$ & Coeficiente & $\begin{array}{l}\text { desvio- } \\
\text { padrão }\end{array}$ & Coeficiente & $\begin{array}{l}\text { desvio- } \\
\text { padrão }\end{array}$ & Coeficiente & $\begin{array}{l}\text { desvio- } \\
\text { padrão }\end{array}$ \\
\hline \multicolumn{13}{|l|}{ Variáveis Independente: } \\
\hline Intercepto & 75,279 & 0,844 & 2,572 & 0,006 & 2,749 & 0,007 & 51,367 & 0,577 & 3,034 & 0,004 & 3,321 & 0,004 \\
\hline Casa & $-127,891$ & 0,316 & $-0,507$ & 0,001 & $-0,536$ & 0,001 & $-117,861$ & 0,167 & $-0,467$ & 0,0004 & $-0,472$ & 0,0004 \\
\hline Quartos & 45,196 & 0,149 & 0,166 & 0,0005 & & & 52,305 & 0,090 & 0,208 & 0,0002 & & \\
\hline Ln(Quartos) & & & & & 0,286 & 0,001 & & & & & 0,357 & 0,0004 \\
\hline Outros Cômodos & 47,435 & 0,120 & 0,161 & 0,0003 & & & 46,333 & 0,085 & 0,150 & 0,0002 & & \\
\hline Ln(Outros Cômodos) & & & & & 0,508 & 0,001 & & & & & 0,535 & 0,0004 \\
\hline Paredes & $-5,759$ & 0,340 & 0,236 & 0,003 & 0,242 & 0,004 & & & & & & \\
\hline Telhado & $-1,127$ & 0,544 & 0,030 & 0,004 & 0,022 & 0,004 & & & & & & \\
\hline Banheiro & $-27,564$ & 0,213 & 0,070 & 0,001 & 0,026 & 0,001 & $-24,264$ & 0,291 & 0,119 & 0,001 & 0,016 & 0,001 \\
\hline Água & $-6,766$ & 0,183 & 0,315 & 0,001 & 0,317 & 0,001 & $-6,625$ & 0,158 & 0,306 & 0,001 & 0,292 & 0,001 \\
\hline Esgoto & 20,566 & 0,151 & 0,205 & 0,001 & 0,207 & 0,001 & 37,554 & 0,087 & 0,337 & 0,0005 & 0,341 & 0,0005 \\
\hline Lixo & 27,798 & 0,146 & 0,342 & 0,001 & 0,353 & 0,001 & 32,677 & 0,188 & 0,432 & 0,001 & 0,440 & 0,001 \\
\hline Eletricidade & $-17,409$ & 0,316 & 0,366 & 0,003 & 0,354 & 0,004 & $-21,850$ & 0,449 & 0,319 & 0,003 & 0,260 & 0,004 \\
\hline Região Metropolitana & 73,112 & 0,194 & 0,359 & 0,001 & 0,357 & 0,001 & 100,175 & 0,125 & 0,437 & 0,0003 & 0,451 & 0,0003 \\
\hline Urbano & 32,694 & 0,374 & 0,542 & 0,004 & 0,567 & 0,004 & 29,819 & 0,212 & 0,263 & 0,001 & 0,246 & 0,001 \\
\hline Dummy RO & $-56,180$ & 0,745 & $-0,160$ & 0,004 & $-0,150$ & 0,004 & $-73,730$ & 0,497 & $-0,330$ & 0,002 & $-0,318$ & 0,002 \\
\hline Dummy AC & $-35,398$ & 1,565 & $-0,140$ & 0,015 & $-0,150$ & 0,018 & 2,542 & 1,326 & 0,021 & 0,005 & 0,087 & 0,005 \\
\hline Dummy AM & 60,711 & 1,344 & 0,397 & 0,004 & 0,405 & 0,004 & $-49,409$ & 0,604 & $-0,339$ & 0,003 & $-0,316$ & 0,003 \\
\hline Dummy RR & 31,840 & 2,244 & 0,389 & 0,009 & 0,443 & 0,010 & $-55,831$ & 1,068 & $-0,227$ & 0,006 & $-0,184$ & 0,006 \\
\hline Dummy PA & $-61,794$ & 0,582 & $-0,308$ & 0,004 & $-0,317$ & 0,004 & $-91,716$ & 0,264 & $-0,413$ & 0,001 & $-0,405$ & 0,001 \\
\hline Dummy AP & 44,315 & 2,503 & 0,455 & 0,011 & 0,449 & 0,012 & 3,839 & 1,348 & 0,068 & 0,005 & 0,075 & 0,005 \\
\hline Dummy TO & $-25,394$ & 1,165 & 0,141 & 0,005 & 0,156 & 0,006 & $-76,649$ & 0,463 & $-0,294$ & 0,003 & $-0,279$ & 0,003 \\
\hline Dummy MA & $-74,381$ & 0,561 & $-0,254$ & 0,004 & $-0,257$ & 0,004 & $-118,769$ & 0,327 & $-0,565$ & 0,002 & $-0,558$ & 0,002 \\
\hline Dummy PI & $-118,786$ & 0,657 & $-0,673$ & 0,004 & $-0,663$ & 0,004 & $-152,964$ & 0,298 & $-0,792$ & 0,002 & $-0,776$ & 0,002 \\
\hline Dummy CE & $-138,622$ & 0,364 & $-0,731$ & 0,002 & $-0,716$ & 0,002 & $-159,006$ & 0,183 & $-0,797$ & 0,001 & $-0,785$ & 0,001 \\
\hline Dummy RN & $-74,302$ & 0,518 & $-0,422$ & 0,003 & $-0,414$ & 0,004 & $-95,965$ & 0,222 & $-0,522$ & 0,001 & $-0,517$ & 0,001 \\
\hline Dummy PB & $-93,920$ & 0,476 & $-0,640$ & 0,003 & $-0,628$ & 0,003 & $-117,985$ & 0,237 & $-0,678$ & 0,002 & $-0,660$ & 0,002 \\
\hline Dummy PE & $-113,471$ & 0,400 & $-0,570$ & 0,002 & $-0,565$ & 0,002 & $-148,030$ & 0,189 & $-0,667$ & 0,001 & $-0,680$ & 0,001 \\
\hline Dummy AL & $-70,395$ & 0,477 & $-0,237$ & 0,003 & $-0,245$ & 0,003 & $-99,381$ & 0,247 & $-0,497$ & 0,001 & $-0,505$ & 0,001 \\
\hline Dummy SE & $-63,890$ & 0,568 & $-0,198$ & 0,004 & $-0,183$ & 0,004 & $-115,915$ & 0,286 & $-0,614$ & 0,002 & $-0,603$ & 0,002 \\
\hline Dummy BA & $-104,404$ & 0,352 & $-0,529$ & 0,002 & $-0,528$ & 0,002 & $-133,715$ & 0,185 & $-0,672$ & 0,001 & $-0,683$ & 0,001 \\
\hline Dummy MG & $-92,093$ & 0,262 & $-0,386$ & 0,001 & $-0,377$ & 0,001 & $-122,239$ & 0,136 & $-0,490$ & 0,0005 & $-0,492$ & 0,0005 \\
\hline Dummy ES & $-88,794$ & 0,473 & $-0,330$ & 0,003 & $-0,331$ & 0,003 & $-114,804$ & 0,234 & $-0,505$ & 0,001 & $-0,504$ & 0,001 \\
\hline Dummy RJ & $-92,931$ & 0,296 & $-0,443$ & 0,001 & $-0,457$ & 0,001 & $-36,196$ & 0,216 & $-0,188$ & 0,000 & $-0,211$ & 0,0005 \\
\hline Dummy PR & $-89,950$ & 0,295 & $-0,386$ & 0,001 & $-0,371$ & 0,001 & $-115,348$ & 0,164 & $-0,490$ & 0,001 & $-0,492$ & 0,001 \\
\hline Dummy SC & $-76,433$ & 0,435 & $-0,260$ & 0,003 & $-0,241$ & 0,003 & $-97,636$ & 0,220 & $-0,320$ & 0,001 & $-0,311$ & 0,001 \\
\hline Dummy RS & $-110,320$ & 0,317 & $-0,445$ & 0,001 & $-0,447$ & 0,001 & $-114,986$ & 0,173 & $-0,421$ & 0,001 & $-0,431$ & 0,001 \\
\hline Dummy MS & $-40,508$ & 0,540 & $-0,066$ & 0,003 & $-0,056$ & 0,003 & $-61,885$ & 0,287 & $-0,205$ & 0,001 & $-0,194$ & 0,001 \\
\hline Dummy MT & $-24,390$ & 0,634 & 0,075 & 0,003 & 0,089 & 0,003 & $-48,300$ & 0,353 & $-0,176$ & 0,002 & $-0,168$ & 0,002 \\
\hline Dummy GO & $-39,612$ & 0,366 & $-0,009$ & 0,002 & 0,000 & 0,002 & $-83,852$ & 0,168 & $-0,332$ & 0,001 & $-0,333$ & 0,001 \\
\hline Dummy DF & 73,131 & 0,971 & 0,330 & 0,002 & 0,344 & 0,002 & $-40,092$ & 0,453 & $-0,236$ & 0,001 & $-0,231$ & 0,001 \\
\hline $\mathrm{R}^{2}$ ajustado & \multicolumn{2}{|c|}{0,3771} & \multicolumn{2}{|c|}{0,4639} & \multicolumn{2}{|c|}{0,4406} & \multicolumn{2}{|c|}{0,4498} & \multicolumn{2}{|c|}{0,5926} & \multicolumn{2}{|c|}{0,5827} \\
\hline $\begin{array}{l}\text { n (número de } \\
\text { observações) }\end{array}$ & \multicolumn{2}{|c|}{5.381 .018} & \multicolumn{2}{|c|}{5.381 .018} & \multicolumn{2}{|c|}{5.222 .062} & . & 80 & 12.203. & 80 & b. & .566 \\
\hline
\end{tabular}

Obs.: (1) A Dummy SP (Estado de São Paulo) foi retirada da regressão para evitar o problema de multicolinearidade perfeita. Portanto, é a variável de estado referência.

(2) Todas as estimações usam White robusto para heterocedasticidade.

Analisando a Tabela B3, observa-se que o modelo linear, além de apresentar o menor $\mathrm{R}^{2}$ ajustado, é contra-intuitivo economicamente uma vez que os coeficientes das variáveis Paredes, Água, Lixo e Eletricidade possuem sinal negativo. Deste modo, ter água encanada ou rede elétrica, por exemplo, reduziria o valor do aluguel. Assim, descarta-se este modelo para o cálculo do aluguel implícito. Já os modelos Log-Linear e Duplo-Log apresentam coeficientes com os sinais de acordo com a coerência econômica e estatisticamente significantes a um 
nível de confiança de $95 \%$. Decidimos trabalhar com o modelo com maior $\mathrm{R}^{2}$, que no caso é o Log-Linear.

Os serviços de infra-estrutura urbana analisados (água, esgoto e coleta de lixo) apresentam coeficientes com sinal positivo e todos significativos a $99 \%$ de confiança, indicando que estes serviços aumentam o valor do aluguel, uma vez que impactam sobre o valor do imóvel. Isto é um forte indício que políticas públicas com foco em infra-estrutura possuem um impacto redistributivo significativamente positivo. Constata-se que a existência de banheiro exclusivo contribui para um aumento no valor do aluguel, visto que apresenta sinal positivo.

$\mathrm{Na}$ tabela a seguir apresentamos as estatísticas básicas do aluguel implícito dos municípios calculado no nível familiar per capita. Desta forma, a tabela mostra o valor que é acrescentado à renda familiar per capita, captando o efeito da posse de casa própria sobre a riqueza.

Tabela B4 - Estatística Descritiva do Aluguel Implícito Familiar per Capita

\begin{tabular}{|c|c|c|c|c|c|c|c|c|c|c|}
\hline \multirow{2}{*}{$\begin{array}{l}\text { Unidade da } \\
\text { Federação }\end{array}$} & \multicolumn{5}{|c|}{1991} & \multicolumn{5}{|c|}{2000} \\
\hline & $\begin{array}{c}\text { Número de } \\
\text { Observações }\end{array}$ & Média & $\begin{array}{l}\text { Desvio- } \\
\text { Padrão }\end{array}$ & Mínimo & Máximo & $\begin{array}{c}\text { Número de } \\
\text { Observações }\end{array}$ & Média & $\begin{array}{l}\text { Desvio- } \\
\text { Padrão }\end{array}$ & Mínimo & Máximo \\
\hline RO & 769.785 & 21,62 & 6,55 & 8,34 & 30,23 & 977.599 & 24,35 & 5,45 & 12,63 & 29,66 \\
\hline$A C$ & 307.279 & 19,34 & 6,90 & 6,97 & 25,03 & 426.780 & 26,32 & 8,53 & 9,87 & 33,77 \\
\hline AM & 1.577 .796 & 33,20 & 18,48 & 5,56 & 51,94 & 2.105 .600 & 19,42 & 10,09 & 4,71 & 29,73 \\
\hline $\mathrm{RR}$ & 147.721 & 37,01 & 12,41 & 14,12 & 44,61 & 244.019 & 28,19 & 8,76 & 10,72 & 34,29 \\
\hline PA & 3.409 .064 & 17,64 & 13,49 & 3,04 & 41,03 & 4.496 .258 & 22,09 & 16,56 & 4,34 & 52,14 \\
\hline AP & 204.486 & 36,54 & 10,27 & 13,89 & 43,92 & 343.898 & 30,40 & 6,56 & 12,44 & 34,51 \\
\hline TO & 621.184 & 21,99 & 8,91 & 9,35 & 40,03 & 807.536 & 25,42 & 8,78 & 11,69 & 38,53 \\
\hline MA & 3.362 .982 & 13,00 & 5,65 & 4,03 & 21,28 & 4.058 .786 & 14,18 & 6,22 & 4,94 & 24,24 \\
\hline PI & 1.532 .545 & 13,45 & 6,81 & 2,93 & 23,67 & 1.700 .885 & 16,67 & 6,32 & 6,59 & 26,67 \\
\hline CE & 3.606 .554 & 19,76 & 13,73 & 3,52 & 40,76 & 4.462 .019 & 24,84 & 15,80 & 5,23 & 49,16 \\
\hline RN & 1.637 .866 & 22,84 & 10,52 & 6,57 & 38,36 & 1.849 .121 & 25,80 & 10,28 & 8,10 & 41,30 \\
\hline PB & 1.873 .213 & 17,69 & 9,41 & 4,19 & 34,41 & 2.051 .370 & 22,39 & 9,15 & 8,74 & 38,18 \\
\hline PE & 4.418 .487 & 26,71 & 16,91 & 4,65 & 56,48 & 5.191 .680 & 30,92 & 15,71 & 9,10 & 57,55 \\
\hline $\mathrm{AL}$ & 1.486 .094 & 23,87 & 11,73 & 5,46 & 41,00 & 1.775 .679 & 23,20 & 9,41 & 9,14 & 36,22 \\
\hline SE & 1.145 .666 & 28,23 & 13,68 & 8,79 & 50,22 & 1.289 .183 & 24,21 & 10,51 & 8,92 & 41,93 \\
\hline $\mathrm{BA}$ & 8.413 .881 & 19,85 & 14,63 & 4,16 & 49,71 & 9.293 .804 & 24,85 & 16,23 & 6,24 & 56,92 \\
\hline MG & 9.992 .974 & 40,14 & 22,66 & 5,97 & 92,09 & 8.821 .208 & 54,62 & 24,17 & 11,66 & 102,25 \\
\hline ES & 1.663 .067 & 37,61 & 13,27 & 15,41 & 64,32 & 1.978 .971 & 42,11 & 11,80 & 20,83 & 68,87 \\
\hline $\mathrm{RJ}$ & 7.534 .693 & 59,35 & 25,53 & 18,31 & 101,86 & 9.303 .559 & 90,47 & 31,16 & 31,54 & 152,55 \\
\hline SP & 18.554 .081 & 81,56 & 25,36 & 18,24 & 133,04 & 20.281 .499 & 100,25 & 28,83 & 28,94 & 167,44 \\
\hline PR & 5.141 .971 & 43,51 & 26,25 & 7,98 & 96,96 & 5.316 .980 & 52,04 & 28,54 & 15,34 & 112,51 \\
\hline SC & 3.238 .194 & 43,13 & 14,84 & 11,24 & 76,31 & 3.658 .811 & 54,31 & 13,37 & 20,88 & 88,30 \\
\hline RS & 5.941 .011 & 47,07 & 24,82 & 9,26 & 103,66 & 6.339 .148 & 59,67 & 27,01 & 14,81 & 123,00 \\
\hline MS & 1.076 .920 & 41,80 & 10,53 & 16,81 & 54,01 & 1.165 .646 & 43,27 & 10,17 & 19,48 & 55,75 \\
\hline MT & 1.365 .950 & 36,81 & 14,28 & 11,99 & 57,66 & 1.582 .289 & 37,57 & 11,08 & 13,82 & 53,76 \\
\hline GO & 2.502 .692 & 45,01 & 16,93 & 10,39 & 70,06 & 2.966 .020 & 42,75 & 13,25 & 16,18 & 62,60 \\
\hline DF & 985.042 & 100,81 & - & 100,81 & 100,81 & 1.018.310 & 73,88 & - & 73,88 & 73,88 \\
\hline Brasil & 92.511 .198 & 44,27 & 30,87 & 2,93 & 133,04 & 103.506 .658 & 53,84 & 37,51 & 4,34 & 167,44 \\
\hline
\end{tabular}

Obs.: $\quad$ Aluguel implícito familiar per capita em Reais (R\$) de julho de 2000. 
As variáveis de atributos locais buscam captar as características específicas dos mercados locais de imóveis. A maioria das dummies de unidade da federação possui sinal negativo, indicando que o aluguel no estado de São Paulo é mais caro que na maioria dos estados brasileiros. Isto indica que, em comparação com a maioria dos estados brasileiros, um indivíduo que vive em São Paulo deve pagar mais para alugar um imóvel com a mesma qualidade e serviços urbanos do que um indivíduo que vive em outro estado. Além disso, o fato do imóvel estar localizado numa região metropolitana ou urbana aumenta o valor do aluguel pago, independentemente das características do imóvel. 


\section{APÊNDICE C - ESTATÍSTICAS DESCRITIVAS}

Apresentamos as estatísticas descritivas das principais variáveis consideradas neste trabalho. Para tanto, a Tabela C1 mostra as estatísticas de média, desvio-padrão, mínimo e máximo para as variáveis dos municípios brasileiros.

Tabela C1 - Estatísticas Descritivas das Principais Variáveis

\begin{tabular}{|c|c|c|c|c|c|c|c|c|}
\hline \multirow[b]{2}{*}{ Variável } & \multicolumn{4}{|c|}{1991} & \multicolumn{4}{|c|}{2000} \\
\hline & Média & $\begin{array}{l}\text { Desvio- } \\
\text { Padrão }\end{array}$ & Mínimo & Máximo & Média & $\begin{array}{l}\text { Desvio- } \\
\text { Padrão }\end{array}$ & Mínimo & Máximo \\
\hline Renda Familiar per Capita & 253,35 & 161,99 & 25,23 & 688,93 & 326,87 & 192,06 & 40,49 & 960,89 \\
\hline Índice de Desigualdade de Gini & 0,535 & 0,057 & 0,328 & 0,760 & 0,559 & 0,054 & 0,341 & 0,787 \\
\hline Índice de Desigualdade de Theil & 0,588 & 0,154 & 0,178 & 1,906 & 0,635 & 0,160 & 0,187 & 2,395 \\
\hline Linha Absoluta de Pobreza Za & 91,08 & 31,79 & 44,45 & 162,51 & 97,32 & 35,10 & 49,94 & 172,38 \\
\hline Linha Híbrida de Pobreza Zh30 & 79,63 & 40,59 & 17,05 & 175,30 & 95,84 & 47,36 & 20,30 & 236,88 \\
\hline Linha Híbrida de Pobreza Zh50 & 108,06 & 55,08 & 23,13 & 237,89 & 135,03 & 66,73 & 28,60 & 333,76 \\
\hline Número de Pobres considerando $\mathrm{Za}$ & 14.806 & 58.231 & 109 & 2.366 .569 & 12.413 & 55.168 & - & 2.681 .644 \\
\hline Número de Pobres considerando Zh30 & 10.350 & 53.437 & 97 & 2.357 .082 & 10.699 & 61.034 & - & 3.014 .793 \\
\hline Número de Pobres considerando Zh50 & 14.618 & 74.457 & 239 & 3.415 .512 & 15.632 & 87.481 & 211 & 4.335 .783 \\
\hline Incidência da Pobreza considerando Za & 0,437 & 0,219 & 0,031 & 0,960 & 0,316 & 0,167 & 0,000 & 0,847 \\
\hline Incidência da Pobreza considerando Zh30 & 0,306 & 0,100 & 0,045 & 0,649 & 0,272 & 0,080 & 0,001 & 0,566 \\
\hline Incidência da Pobreza considerando Zh50 & 0,432 & 0,109 & 0,094 & 0,763 & 0,398 & 0,085 & 0,082 & 0,684 \\
\hline Elasticidade-Renda da Pobreza com Gini & $(1,017)$ & 0,426 & $(0,141)$ & $(3,878)$ & $(1,047)$ & 0,388 & $(0,202)$ & $(4,122)$ \\
\hline Elasticidade-Renda da Pobreza com Theil & $(0,959)$ & 0,406 & $(0,162)$ & $(3,423)$ & $(1,006)$ & 0,371 & $(0,178)$ & $(3,924)$ \\
\hline Elasticidade-Desigualdade da Pobreza com Gini & 3,762 & 2,409 & $(0,238)$ & 13,235 & 4,563 & 2,463 & 0,183 & 16,904 \\
\hline Elasticidade-Desigualdade da Pobreza com Theil & 0,757 & 0,493 & $(0,054)$ & 2,867 & 0,908 & 0,503 & 0,027 & 3,583 \\
\hline População & 33.877 & 189.012 & 715 & 9.452 .474 & 39.314 & 210.811 & 499 & 10.338 .500 \\
\hline População Fem & 17.103 & 98.094 & 364 & 4.886 .388 & 19.952 & 110.322 & 215 & 5.400 .929 \\
\hline População sem Raça Branca & 16.392 & 75.868 & - & 2.896 .545 & 18.172 & 86.494 & - & 3.403 .414 \\
\hline Idade & 25,97 & 2,48 & 17,32 & 34,49 & 28,22 & 2,55 & 18,08 & 38,26 \\
\hline Anos de Estudo & 3,79 & 1,40 & 0,35 & 7,02 & 4,95 & 1,35 & 1,11 & 7,99 \\
\hline
\end{tabular}

Obs.: (1) A renda familiar per capita e as linhas de pobreza estão em Reais (R \$) de julho de 2000.

(2) As colunas Za correspondem aos valores considerando as linhas absolutas de pobreza.

(3) As colunas Zh30 e Zh50 indicam os valores correspondentes às linhas híbridas considerando linhas relativas de $30 \%$ e $50 \%$ da renda média dos estratos, respectivamente. 


\section{APÊNDICE D - POSSIBILIDADES DE CONSTRUÇÃO DA RENDA PER CAPITA}

\section{D.1 - Introdução}

Conforme já explicitado no Capítulo 2 e no Apêndice B, este trabalho utiliza quatro possibilidades para a construção da renda familiar per capita:

(a) Utilização do Censo de 1991 e PNAD's de 1999 e 2001 - Utilização do Censo de 1991 para a estimação do aluguel implícito de 1991, e das PNAD's de 1999 e 2001 para a do aluguel implícito de 2000;

(b) Utilização Somente do Censo de 1991 - Utilização do Censo de 1991 para a estimação dos alugueis implícitos de 1991 e 2000;

(c) Utilização das PNAD's de 1990, 1992, 1999 e 2001 - Utilização das PNAD's de 1990 e 1992 para a estimação do aluguel implícito de 1991, e das PNAD’s de 1999 e 2001 para a do aluguel implícito de 2000;

(d) Sem Estimação de Aluguel Implícito - Sem a utilização de base de dados, não havendo estimação do aluguel implícito.

A possibilidade do item (a) de construção da renda familiar per capita foi discutida através das diversas tabelas ao longo deste trabalho. Neste apêndice, apresentamos as tabelas referentes às outras possibilidades, mantendo-se o nome original da tabela e acrescentando-se no final a letra referente ao item de possibilidade explicitado acima. Assim, a Tabela 16, com base na possibilidade do item (a), mostrada no Capítulo 4, quando apresentada a partir da possibilidade do item (c), receberá o nome de Tabela 16.C - Estimações em Logaritmo da Incidência da Pobreza em Renda e Desigualdade por MQVD com Peso.

Para a apresentação das tabelas de cada possibilidade, seguiremos a seqüência de exposição das tabelas ao longo do texto deste trabalho, começando pelos capítulos e finalizando com os apêndices. 


\section{D.2 - Resultados Obtidos}

D.2.1 - Utilização Somente do Censo de 1991

a) Resultados para o Capítulo 2

Tabela 1.B - Estatísticas Básicas da Variável Renda Familiar per Capita

\begin{tabular}{|c|c|c|c|c|c|c|c|c|c|}
\hline \multirow{2}{*}{$\begin{array}{c}\text { Região } \\
\text { Geográfica }\end{array}$} & \multirow[b]{2}{*}{ Estado } & \multicolumn{4}{|c|}{1991} & \multicolumn{4}{|c|}{2000} \\
\hline & & Média & $\begin{array}{l}\text { Desvio- } \\
\text { Padrão }\end{array}$ & Mínimo & Máximo & Média & $\begin{array}{l}\text { Desvio- } \\
\text { Padrão }\end{array}$ & Mínimo & Máximo \\
\hline \multirow{7}{*}{ Norte } & $\mathrm{RO}$ & 168,20 & 60,79 & 63,94 & 258,95 & 252,85 & 47,17 & 134,22 & 308,07 \\
\hline & $A C$ & 160,10 & 63,68 & 68,94 & 217,16 & 197,93 & 70,36 & 74,29 & 258,23 \\
\hline & AM & 198,18 & 105,95 & 41,99 & 306,49 & 202,34 & 103,53 & 46,06 & 303,61 \\
\hline & $\mathrm{RR}$ & 305,73 & 75,31 & 129,62 & 348,12 & 268,77 & 85,18 & 94,22 & 326,59 \\
\hline & PA & 153,34 & 82,89 & 53,93 & 302,11 & 180,68 & 88,48 & 54,51 & 332,97 \\
\hline & AP & 217,73 & 50,65 & 93,07 & 254,48 & 244,14 & 52,62 & 101,49 & 282,42 \\
\hline & TO & 138,82 & 62,79 & 50,36 & 267,49 & 198,85 & 88,43 & 74,01 & 386,11 \\
\hline \multirow{9}{*}{ Nordeste } & MA & 88,12 & 52,36 & 33,79 & 204,18 & 122,67 & 70,65 & 43,44 & 269,12 \\
\hline & PI & 93,85 & 54,54 & 29,37 & 185,56 & 138,85 & 73,07 & 46,42 & 255,15 \\
\hline & CE & 121,97 & 81,82 & 25,85 & 250,70 & 171,05 & 106,01 & 49,77 & 332,69 \\
\hline & $\mathrm{RN}$ & 138,82 & 87,84 & 36,34 & 282,27 & 193,53 & 110,01 & 46,70 & 363,79 \\
\hline & PB & 109,23 & 75,62 & 25,23 & 266,00 & 163,90 & 101,14 & 56,65 & 353,58 \\
\hline & PE & 155,81 & 98,26 & 32,08 & 334,54 & 201,89 & 118,26 & 55,33 & 577,85 \\
\hline & $\mathrm{AL}$ & 121,74 & 79,32 & 37,11 & 255,02 & 156,05 & 95,42 & 43,67 & 303,66 \\
\hline & SE & 147,69 & 91,61 & 51,77 & 296,19 & 187,93 & 119,46 & 58,86 & 387,49 \\
\hline & BA & 129,93 & 92,24 & 25,69 & 315,49 & 178,64 & 107,37 & 48,51 & 377,10 \\
\hline \multirow{4}{*}{ Sudeste } & $M G$ & 215,55 & 115,33 & 46,96 & 457,77 & 302,55 & 148,28 & 66,18 & 607,57 \\
\hline & ES & 216,97 & 109,56 & 71,96 & 489,22 & 319,20 & 150,15 & 117,50 & 711,04 \\
\hline & RJ & 339,56 & 151,81 & 111,19 & 614,15 & 451,65 & 191,51 & 184,02 & 864,22 \\
\hline & SP & 421,21 & 138,37 & 91,98 & 688,93 & 487,60 & 154,13 & 122,44 & 959,44 \\
\hline \multirow{3}{*}{ Sul } & PR & 249,24 & 129,61 & 64,50 & 507,28 & 348,22 & 162,09 & 108,88 & 666,65 \\
\hline & SC & 259,69 & 104,76 & 89,00 & 527,95 & 382,68 & 132,43 & 125,78 & 753,68 \\
\hline & RS & 288,62 & 130,52 & 77,65 & 576,72 & 389,90 & 163,23 & 105,24 & 761,70 \\
\hline \multirow{4}{*}{ Centro-Oeste } & MS & 243,27 & 80,66 & 103,95 & 352,52 & 310,96 & 91,60 & 128,06 & 458,30 \\
\hline & MT & 226,30 & 79,96 & 82,89 & 355,48 & 311,87 & 97,36 & 135,37 & 493,42 \\
\hline & GO & 235,13 & 90,78 & 64,25 & 376,70 & 315,12 & 121,50 & 101,81 & 517,01 \\
\hline & DF & 524,27 & - & 524,27 & 524,27 & 658,31 & - & 658,31 & 658,31 \\
\hline \multicolumn{2}{|l|}{ Brasil } & 253,31 & 161,99 & 25,23 & 688,93 & 326,23 & 189,38 & 43,44 & 959,44 \\
\hline
\end{tabular}

Obs.: $\quad$ Renda familiar per capita em Reais (R\$) de julho de 2000. 
Tabela 3.B - Estatísticas Básicas do Número de Pobres

\begin{tabular}{|c|c|c|c|c|c|c|c|c|c|c|c|}
\hline \multirow[b]{2}{*}{$\begin{array}{c}\text { Região } \\
\text { Geográfica }\end{array}$} & \multirow[b]{2}{*}{ Estado } & \multicolumn{5}{|c|}{1991} & \multicolumn{5}{|c|}{2000} \\
\hline & & População & $n^{\circ}$ de pobres & $\begin{array}{l}\text { Desvio- } \\
\text { Padrão }\end{array}$ & Mínimo & Máximo & População & $\mathrm{n}^{\circ}$ de pobres & $\begin{array}{l}\text { Desvio- } \\
\text { Padrão }\end{array}$ & Mínimo & Máximo \\
\hline \multirow{7}{*}{ Norte } & $\mathrm{RO}$ & 1.125 .046 & 534.318 & 22.731 & 3.894 & 86.437 & 1.369 .444 & 337.911 & 19.409 & 3.613 & 87.622 \\
\hline & $A C$ & 414.102 & 216.940 & 30.746 & 1.315 & 93.292 & 555.471 & 220.914 & 30.747 & 1.679 & 95.180 \\
\hline & AM & 2.087 .753 & 926.907 & 29.931 & 2.204 & 238.237 & 2.807.323 & 1.201 .329 & 46.066 & 3.619 & 368.780 \\
\hline & $\mathrm{RR}$ & 211.419 & 74.104 & 16.535 & 5.387 & 42.612 & 322.523 & 87.997 & 16.271 & 11.540 & 46.215 \\
\hline & PA & 4.905 .433 & 2.721 .049 & 55.303 & 3.175 & 473.230 & 6.166 .634 & 2.684.551 & 47.443 & 2.815 & 375.889 \\
\hline & AP & 286.673 & 106.735 & 18.379 & 2.758 & 55.654 & 474.658 & 163.287 & 30.555 & 3.363 & 91.698 \\
\hline & TO & 910.157 & 515.966 & 7.864 & 1.446 & 47.339 & 1.150 .882 & 433.717 & 7.326 & 736 & 39.577 \\
\hline \multirow{9}{*}{ Nordeste } & MA & 4.902 .860 & 3.465 .986 & 40.672 & 3.879 & 302.088 & 5.634 .915 & 3.136 .146 & 39.394 & 2.667 & 290.956 \\
\hline & $\mathrm{PI}$ & 2.558.077 & 1.895 .888 & 42.411 & 1.133 & 338.980 & 2.826 .459 & 1.480 .343 & 33.739 & 672 & 267.069 \\
\hline & $\mathrm{CE}$ & 6.305 .476 & 4.464.339 & 67.882 & 3.462 & 891.487 & 7.371 .074 & 3.736 .550 & 54.573 & 2.946 & 708.966 \\
\hline & $\mathrm{RN}$ & 2.392.757 & 1.465 .562 & 20.013 & 964 & 219.207 & 2.766.106 & 1.119 .086 & 15.965 & 831 & 178.875 \\
\hline & PB & 3.175 .867 & 2.237.389 & 22.202 & 1.532 & 205.067 & 3.414 .992 & 1.566 .003 & 16.366 & 505 & 158.337 \\
\hline & PE & 7.077 .995 & 4.816 .005 & 65.780 & 242 & 753.035 & 7.895 .020 & 3.932 .719 & 54.888 & 112 & 612.296 \\
\hline & $\mathrm{AL}$ & 2.491 .971 & 1.609 .122 & 27.447 & 2.678 & 251.723 & 2.817 .468 & 1.427 .150 & 27.512 & 1.875 & 260.293 \\
\hline & SE & 1.478 .474 & 839.567 & 17.403 & 1.368 & 139.882 & 1.776 .661 & & 14.191 & 899 & 107.486 \\
\hline & BA & 11.753 .125 & 7.998.316 & 52.353 & 1.769 & 1.019 .851 & 13.018 .111 & 6.143 .681 & 45.844 & 1.457 & 902.594 \\
\hline \multirow{4}{*}{ Sudeste } & MG & 15.542 .085 & 5.905 .796 & 24.542 & 169 & 576.523 & 17.555 .247 & 4.342 .273 & 18.208 & 38 & 404.001 \\
\hline & ES & 2.580 .027 & 853.390 & 15.843 & 1.998 & 84.338 & 3.084 .122 & 557.130 & 12.724 & 685 & 65.139 \\
\hline & RJ & 12.679 .997 & 5.052 .829 & 229.463 & 3.595 & 1.697 .857 & 14.303 .997 & 3.650 .110 & 169.364 & 2.299 & 1.222 .373 \\
\hline & SP & 31.200 .800 & 7.702 .087 & 100.975 & 109 & 2.366 .569 & 36.758 .099 & 8.744 .953 & 118.013 & 205 & 2.750 .497 \\
\hline \multirow{3}{*}{ Sul } & PR & 8.370 .891 & 2.649 .047 & 15.042 & 443 & 225.416 & 9.510 .719 & 1.866 .473 & 13.874 & 278 & 209.366 \\
\hline & SC & 4.497 .033 & 908.614 & 6.382 & 278 & 41.646 & 5.323 .622 & 555.828 & 4.344 & 119 & 32.775 \\
\hline & RS & 9.041 .154 & 2.198.977 & 14.956 & 197 & 162.519 & 10.114 .344 & 1.497 .485 & 12.681 & - & 155.147 \\
\hline \multirow{4}{*}{$\begin{array}{l}\text { Centro- } \\
\text { Oeste }\end{array}$} & MS & 1.762 .655 & 854.559 & 22.276 & 1.633 & 176.477 & 2.065 .883 & 649.455 & 19.773 & 1.147 & 160.061 \\
\hline & MT & 2.002 .481 & 985.678 & 21.629 & 924 & 142.272 & 2.492 .199 & 722.808 & 15.794 & 545 & 104.722 \\
\hline & $\mathrm{GO}$ & 3.976 .645 & 1.906 .226 & 24.503 & 515 & 308.058 & 4.978 .472 & 1.423 .606 & 19.304 & 183 & 208.965 \\
\hline & DF & 1.565 .191 & 627.396 & - & 627.396 & 627.396 & 2.022 .513 & 606.381 & - & 606.381 & 606.381 \\
\hline \multicolumn{2}{|c|}{ Brasil } & 145.296 .144 & 63.532 .792 & 58.231 & 109 & 2.366 .569 & 168.576 .958 & 53.007 .434 & 55.168 & - & 2.750 .497 \\
\hline
\end{tabular}

Tabela 4.B - Estatísticas Básicas do Índice de Gini

\begin{tabular}{|c|c|c|c|c|c|c|c|c|c|}
\hline \multirow{2}{*}{$\begin{array}{c}\text { Região } \\
\text { Geográfica }\end{array}$} & \multirow[b]{2}{*}{ Estado } & \multicolumn{4}{|c|}{1991} & \multicolumn{4}{|c|}{2000} \\
\hline & & Gini & $\begin{array}{l}\text { Desvio- } \\
\text { Padrão }\end{array}$ & Mínimo & Máximo & Gini & $\begin{array}{l}\text { Desvio- } \\
\text { Padrão }\end{array}$ & Mínimo & Máximo \\
\hline \multirow{7}{*}{ Norte } & $\mathrm{RO}$ & 0,608 & 0,031 & 0,486 & 0,658 & 0,589 & 0,022 & 0,473 & $\overline{0,644}$ \\
\hline & $A C$ & 0,621 & 0,018 & 0,464 & 0,634 & 0,635 & 0,021 & 0,565 & 0,674 \\
\hline & AM & 0,610 & 0,050 & 0,402 & 0,712 & 0,649 & 0,036 & 0,513 & 0,767 \\
\hline & $\mathrm{RR}$ & 0,635 & 0,051 & 0,597 & 0,734 & 0,590 & 0,018 & 0,561 & 0,622 \\
\hline & PA & 0,616 & 0,049 & 0,390 & 0,703 & 0,632 & 0,039 & 0,453 & 0,742 \\
\hline & AP & 0,567 & 0,019 & 0,513 & 0,650 & 0,604 & 0,014 & 0,568 & 0,663 \\
\hline & TO & 0,607 & 0,048 & 0,410 & 0,685 & 0,616 & 0,037 & 0,459 & 0,708 \\
\hline \multirow{9}{*}{ Nordeste } & $\overline{M A}$ & 0,593 & 0,054 & 0,389 & 0,656 & 0,636 & 0,040 & 0,445 & 0,718 \\
\hline & $\mathrm{PI}$ & 0,637 & 0,049 & 0,411 & 0,760 & 0,647 & 0,042 & 0,427 & 0,663 \\
\hline & CE & 0,647 & 0,063 & 0,380 & 0,673 & 0,662 & 0,045 & 0,477 & 0,701 \\
\hline & $\mathrm{RN}$ & 0,618 & 0,051 & 0,392 & 0,668 & 0,633 & 0,047 & 0,425 & 0,746 \\
\hline & PB & 0,628 & 0,060 & 0,349 & 0,719 & 0,630 & 0,051 & 0,425 & 0,679 \\
\hline & PE & 0,643 & 0,063 & 0,393 & 0,657 & 0,645 & 0,053 & 0,434 & 0,703 \\
\hline & $A L$ & 0,616 & 0,067 & 0,370 & 0,660 & 0,656 & 0,053 & 0,425 & 0,743 \\
\hline & SE & 0,601 & 0,053 & 0,381 & 0,589 & 0,622 & 0,054 & 0,420 & 0,626 \\
\hline & BA & 0,646 & 0,064 & 0,372 & 0,732 & 0,644 & 0,050 & 0,362 & 0,785 \\
\hline \multirow{4}{*}{ Sudeste } & $\overline{M G}$ & 0,599 & 0,048 & 0,348 & 0,718 & 0,599 & 0,052 & 0,342 & 0,739 \\
\hline & ES & 0,585 & 0,048 & 0,422 & 0,693 & 0,587 & 0,037 & 0,426 & 0,667 \\
\hline & RJ & 0,594 & 0,058 & 0,432 & 0,697 & 0,590 & 0,051 & 0,445 & 0,622 \\
\hline & SP & 0,538 & 0,047 & 0,328 & 0,709 & 0,572 & 0,047 & 0,373 & 0,700 \\
\hline \multirow{3}{*}{ Sul } & PR & 0,589 & 0,050 & 0,351 & 0,714 & 0,591 & 0,046 & 0,388 & 0,709 \\
\hline & SC & 0,531 & 0,056 & 0,333 & 0,662 & 0,537 & 0,049 & 0,357 & 0,693 \\
\hline & RS & 0,571 & 0,056 & 0,391 & 0,715 & 0,569 & 0,050 & 0,345 & 0,709 \\
\hline \multirow{4}{*}{ Centro-Oeste } & MS & 0,584 & 0,035 & 0,421 & 0,653 & 0,599 & 0,036 & 0,453 & 0,687 \\
\hline & MT & 0,581 & 0,045 & 0,422 & 0,706 & 0,593 & 0,035 & 0,372 & 0,680 \\
\hline & GO & 0,566 & 0,045 & 0,366 & 0,719 & 0,576 & 0,051 & 0,396 & 0,748 \\
\hline & DF & 0,595 & - & 0,595 & 0,595 & 0,620 & - & 0,620 & 0,620 \\
\hline Brasil & & 0,622 & 0,057 & 0,328 & 0,760 & 0,626 & 0,053 & 0,342 & 0,785 \\
\hline
\end{tabular}

Obs.: $\quad$ Os valores da coluna Gini correspondem aos índices de Gini estaduais e nacional, enquanto que as colunas Desvio-Padrão, Mínimo e Máximo são referentes aos municípios. 
Tabela 5.B - Estatísticas Básicas do Índice de Theil

\begin{tabular}{|c|c|c|c|c|c|c|c|c|c|}
\hline \multirow{2}{*}{$\begin{array}{c}\text { Região } \\
\text { Geográfica }\end{array}$} & \multirow[b]{2}{*}{ Estado } & \multicolumn{4}{|c|}{1991} & \multicolumn{4}{|c|}{2000} \\
\hline & & Theil & $\begin{array}{l}\text { Desvio- } \\
\text { Padrão }\end{array}$ & Mínimo & Máximo & Theil & $\begin{array}{l}\text { Desvio- } \\
\text { Padrão }\end{array}$ & Mínimo & Máximo \\
\hline \multirow{7}{*}{ Norte } & $\mathrm{RO}$ & 0,768 & 0,115 & 0,422 & 1,004 & 0,735 & 0,091 & 0,368 & 1,022 \\
\hline & $A C$ & 0,801 & 0,042 & 0,393 & 0,906 & 0,902 & 0,059 & 0,545 & 0,906 \\
\hline & AM & 0,754 & 0,161 & 0,315 & 1,251 & 0,907 & 0,161 & 0,401 & 1,958 \\
\hline & $\mathrm{RR}$ & 0,756 & 0,162 & 0,660 & 1,118 & 0,702 & 0,066 & 0,506 & 0,801 \\
\hline & PA & 0,819 & 0,126 & 0,293 & 1,030 & 0,889 & 0,165 & 0,341 & 2,360 \\
\hline & AP & 0,633 & 0,093 & 0,464 & 1,021 & 0,765 & 0,076 & 0,598 & 0,876 \\
\hline & TO & 0,819 & 0,139 & 0,322 & 1,045 & 0,855 & 0,140 & 0,369 & 1,444 \\
\hline \multirow{9}{*}{ Nordeste } & $\overline{M A}$ & 0,795 & 0,159 & 0,262 & 1,248 & 0,929 & 0,152 & 0,345 & 1,630 \\
\hline & $\mathrm{PI}$ & 0,907 & 0,184 & 0,289 & 1,906 & 0,955 & 0,161 & 0,314 & 1,139 \\
\hline & CE & 0,943 & 0,174 & 0,250 & 1,447 & 0,986 & 0,142 & 0,408 & 1,213 \\
\hline & $\mathrm{RN}$ & 0,806 & 0,144 & 0,260 & 1,311 & 0,875 & 0,155 & 0,229 & 1,805 \\
\hline & PB & 0,870 & 0,156 & 0,211 & 1,075 & 0,879 & 0,152 & 0,297 & 1,229 \\
\hline & PE & 0,895 & 0,166 & 0,262 & 1,183 & 0,919 & 0,165 & 0,360 & 1,860 \\
\hline & $A L$ & 0,839 & 0,164 & 0,232 & 1,040 & 0,976 & 0,175 & 0,308 & 1,770 \\
\hline & SE & 0,772 & 0,123 & 0,260 & 0,989 & 0,833 & 0,134 & 0,300 & 0,915 \\
\hline & $\mathrm{BA}$ & 0,934 & 0,180 & 0,253 & 1,829 & 0,931 & 0,175 & 0,220 & 2,150 \\
\hline \multirow{4}{*}{ Sudeste } & $M G$ & 0,747 & 0,136 & 0,201 & 1,577 & 0,763 & 0,157 & 0,189 & 2,395 \\
\hline & ES & 0,686 & 0,146 & 0,317 & 1,239 & 0,713 & 0,116 & 0,299 & 1,249 \\
\hline & RJ & 0,710 & 0,132 & 0,343 & 1,256 & 0,710 & 0,116 & 0,351 & 1,096 \\
\hline & SP & 0,572 & 0,104 & 0,178 & 1,201 & 0,668 & 0,113 & 0,234 & 1,132 \\
\hline \multirow{3}{*}{ Sul } & PR & 0,704 & 0,161 & 0,207 & 1,408 & 0,738 & 0,142 & 0,261 & 1,779 \\
\hline & SC & 0,558 & 0,140 & 0,211 & 1,215 & 0,600 & 0,139 & 0,231 & 1,582 \\
\hline & $\mathrm{RS}$ & 0,646 & 0,150 & 0,274 & 1,342 & 0,661 & 0,120 & 0,207 & 1,392 \\
\hline \multirow{4}{*}{ Centro-Oeste } & MS & 0,730 & 0,130 & 0,319 & 1,202 & 0,794 & 0,145 & 0,378 & 1,615 \\
\hline & MT & 0,723 & 0,150 & 0,307 & 1,288 & 0,799 & 0,121 & 0,209 & 1,329 \\
\hline & GO & 0,669 & 0,134 & 0,244 & 1,455 & 0,732 & 0,162 & 0,262 & 1,785 \\
\hline & DF & 0,673 & - & 0,673 & 0,673 & 0,744 & - & 0,724 & 0,724 \\
\hline Brasil & & 0,785 & 0,156 & 0,178 & 1,906 & 0,798 & 0,164 & 0,189 & 2,395 \\
\hline
\end{tabular}

Obs.: $\quad$ Os valores da coluna Theil correspondem aos índices de Theil estaduais e nacional, enquanto que as colunas Desvio-Padrão, Mínimo e Máximo são referentes aos municípios.

\section{b) Resultados para o Capítulo 3}

Tabela 6.B - Regressão em Logaritmo da Linha de Pobreza na Renda

\begin{tabular}{lcccccc}
\hline \multirow{2}{*}{ Variável } & \multicolumn{2}{c}{1991} & & \multicolumn{2}{c}{2000} \\
\cline { 3 - 4 } \cline { 5 - 6 } & Coeficiente & Desvio-Padrão & & Coeficiente & Desvio-Padrão \\
\hline$\alpha_{i, t}$ & constante & 1,2032 & 0,3417 & & 0,6839 & 0,4506 \\
$\rho_{t}$ & $\log$ (renda) & 0,5977 & 0,0654 & & 0,6629 & 0,0796 \\
\hline número de observações & \multicolumn{2}{c}{26} & \multicolumn{2}{c}{26} \\
\hline \multicolumn{2}{c}{0,8139} & \multicolumn{2}{c}{0,7929} \\
\hline
\end{tabular}

Obs.: Todas as estimações usam White robusto para heterocedasticidade. 
Tabela 7.B - Regressão em Logaritmo da Linha de Pobreza com os Anos de 1991 e 2000

\begin{tabular}{ccc}
\hline Variável & Coeficiente & Desvio-Padrão \\
\hline constante & 0,6839 & 0,4506 \\
$\log ($ renda $)$ & 0,6629 & 0,0796 \\
dummy 91 & 0,5193 & 0,5655 \\
dummy 91 * log (renda) & $-0,0652$ & 0,1030 \\
\hline número de observações & \multicolumn{2}{c}{26} \\
\hline $\mathrm{R}^{2}$ & \multicolumn{2}{c}{0,8039}
\end{tabular}

Obs.: Todas as estimações usam White robusto para heterocedasticidade.

Tabela 8.B - Linha Híbrida de Pobreza com Renda Média por Estrato e Nacional

\begin{tabular}{|c|c|c|c|c|c|c|c|c|c|c|c|}
\hline \multirow{4}{*}{ Regiões } & \multirow{4}{*}{ Estratos } & \multicolumn{5}{|c|}{1991} & \multicolumn{5}{|c|}{2000} \\
\hline & & \multirow{3}{*}{$\begin{array}{c}\text { Renda } \\
\text { Média } \\
(\mathrm{RM})\end{array}$} & \multicolumn{4}{|c|}{ Linha Híbrida (Zh) } & \multirow{3}{*}{$\begin{array}{c}\text { Renda } \\
\text { Média } \\
(\mathrm{RM})\end{array}$} & \multicolumn{4}{|c|}{ Linha Híbrida (Zh) } \\
\hline & & & \multicolumn{2}{|c|}{ RM por Estrato } & \multicolumn{2}{|c|}{ RM Nacional } & & \multicolumn{2}{|c|}{ RM por Estrato } & \multicolumn{2}{|c|}{ RM Nacional } \\
\hline & & & Zh30 & Zh50 & Zh30 & Zh50 & & Zh30 & Zh50 & Zh30 & Zh50 \\
\hline \multirow{3}{*}{ Norte } & Belém & 277,78 & 86,72 & 117,68 & 82,07 & 111,37 & 293,77 & 90,40 & 126,82 & 96,90 & 135,95 \\
\hline & Urbano & 202,82 & 68,62 & 93,12 & 78,37 & 106,35 & 235,25 & 74,49 & 104,51 & 92,51 & 129,80 \\
\hline & Rural & 82,75 & 33,32 & 45,22 & 65,03 & 88,25 & 89,76 & 33,03 & 46,35 & 77,71 & 109,02 \\
\hline \multirow{5}{*}{ Nordeste } & Fortaleza & 215,29 & 76,13 & 103,31 & 83,90 & 113,85 & 276,36 & 85,94 & 120,57 & 95,93 & 134,58 \\
\hline & Recife & 250,60 & 98,03 & 133,03 & 98,66 & 133,89 & 306,93 & 104,48 & 146,59 & 108,79 & 152,63 \\
\hline & Salvador & 287,49 & 98,77 & 134,04 & 91,58 & 124,27 & 345,22 & 109,41 & 153,50 & 105,38 & 147,85 \\
\hline & Urbano & 138,73 & 55,60 & 75,44 & 79,67 & 108,12 & 183,91 & 63,02 & 88,42 & 92,15 & 129,29 \\
\hline & Rural & 51,64 & 25,14 & 34,11 & 65,03 & 88,25 & 62,13 & 25,89 & 36,32 & 77,71 & 109,02 \\
\hline \multirow{15}{*}{ Sudeste } & Minas Gerais & & & & & & & & & & \\
\hline & Belo Horizonte & 350,20 & 105,89 & 143,69 & 87,25 & 118,40 & 423,75 & 123,11 & 172,73 & 103,52 & 145,24 \\
\hline & Urbano & 220,64 & 68,48 & 92,93 & 74,37 & 100,92 & 297,84 & 85,25 & 119,60 & 90,55 & 127,04 \\
\hline & Rural & 82,95 & 30,90 & 41,94 & 60,23 & 81,73 & 124,90 & 40,15 & 56,34 & 75,88 & 106,46 \\
\hline & Espírito Santo & & & & & & & & & & \\
\hline & Urbano & 262,06 & 75,89 & 102,99 & 74,37 & 100,92 & 361,69 & 96,96 & 136,04 & 90,55 & 127,04 \\
\hline & Rural & 89,49 & 32,34 & 43,88 & 60,23 & 81,73 & 154,96 & 46,33 & 64,99 & 75,88 & 106,46 \\
\hline & Rio de Janeiro & & & & & & & & & & \\
\hline & Metrópole & 376,29 & 118,88 & 161,33 & 93,84 & 127,35 & 493,98 & 144,76 & 203,10 & 109,95 & 154,26 \\
\hline & Urbano & 243,72 & 75,77 & 102,82 & 77,53 & 105,22 & 344,69 & 97,18 & 136,34 & 93,70 & 131,46 \\
\hline & Rural & 105,90 & 40,56 & 55,04 & 68,31 & 92,70 & 170,11 & 54,73 & 76,78 & 84,27 & 118,22 \\
\hline & São Paulo & & & & & & & & & & \\
\hline & Metrópole & 506,71 & 152,74 & 207,27 & 100,93 & 136,96 & 560,42 & 169,55 & 237,88 & 118,45 & 166,18 \\
\hline & Urbano & 364,56 & 104,77 & 142,18 & 84,28 & 114,38 & 438,72 & 123,95 & 173,90 & 101,85 & 142,89 \\
\hline & Rural & 159,34 & 53,02 & 71,95 & 69,94 & 94,92 & 219,98 & 67,09 & 94,12 & 87,11 & 122,22 \\
\hline \multirow{4}{*}{ Sul } & Curitiba & 406,37 & 115,75 & 157,08 & 87,26 & 118,42 & 502,28 & 137,07 & 192,31 & 102,97 & 144,47 \\
\hline & Porto Alegre & 400,12 & 103,86 & 140,94 & 79,03 & 107,24 & 503,31 & 125,96 & 176,72 & 94,49 & 132,57 \\
\hline & Urbano & 280,22 & 78,85 & 107,00 & 74,23 & 100,74 & 370,78 & 97,76 & 137,16 & 89,81 & 126,00 \\
\hline & Rural & 118,77 & 40,28 & 54,66 & 63,35 & 85,96 & 190,41 & 55,03 & 77,21 & 78,63 & 110,32 \\
\hline \multirow{4}{*}{$\begin{array}{c}\text { Centro- } \\
\text { Oeste }\end{array}$} & Brasília & 524,27 & 159,36 & 216,26 & 103,18 & 140,02 & 658,31 & 182,85 & 256,55 & 114,81 & 161,08 \\
\hline & Urbano & 266,44 & 92,68 & 125,77 & 89,92 & 122,03 & 339,15 & 104,91 & 147,19 & 102,24 & 143,45 \\
\hline & Rural & 118,37 & 45,66 & 61,96 & 71,94 & 97,63 & 169,56 & 54,96 & 77,11 & 84,81 & 118,99 \\
\hline & BRASIL & 253,31 & \multicolumn{4}{|c|}{$(*)$} & 326,23 & \multicolumn{4}{|c|}{ (*) } \\
\hline
\end{tabular}

Obs.: (1) Valores em Reais (R\$) de julho de 2000.

(2) As colunas Zh30 e Zh50 indicam as linhas híbridas considerando linhas relativas de $30 \%$ e $50 \%$ da renda média, respectivamente.

(*) As linhas híbridas nacionais são a ponderação das linhas absolutas por estrato com a linha relativa considerando renda média nacional, e estão apresentadas nas colunas de RM Nacional. 
Tabela 9.B - Incidência da Pobreza com Renda Média por Estrato

\begin{tabular}{|c|c|c|c|c|c|c|c|c|c|c|c|c|c|c|c|}
\hline \multirow{4}{*}{ Regiões } & \multirow{4}{*}{ Estratos } & \multicolumn{7}{|c|}{1991} & \multicolumn{7}{|c|}{2000} \\
\hline & & \multirow{2}{*}{\multicolumn{2}{|c|}{$\begin{array}{c}\text { Linha Absoluta } \\
\text { de Pobreza }\end{array}$}} & \multicolumn{4}{|c|}{ Linha Híbrida de Pobreza } & \multirow{3}{*}{$\begin{array}{l}\text { População } \\
\text { Total }\end{array}$} & \multirow{2}{*}{\multicolumn{2}{|c|}{$\begin{array}{c}\text { Linha Absoluta } \\
\text { de Pobreza }\end{array}$}} & \multicolumn{4}{|c|}{ Linha Híbrida de Pobreza } & \multirow{3}{*}{$\begin{array}{c}\text { População } \\
\text { Total }\end{array}$} \\
\hline & & & & \multicolumn{2}{|c|}{ Zh30 } & \multicolumn{2}{|c|}{ Zh50 } & & & & Zh30 & & Zh50 & & \\
\hline & & $\mathrm{n}^{\circ}$ de pobres & $\%$ & $\mathrm{n}^{\circ}$ de pobres & $\%$ & $\mathrm{n}^{\circ}$ de pobres & $\%$ & & $\mathrm{n}^{\circ}$ de pobres & $\%$ & $n^{\circ}$ de pobres & $\%$ & $n^{0}$ de pobres & $\%$ & \\
\hline \multirow{3}{*}{ Norte } & Belém & 521 & $\overline{39,6}$ & 436 & 33,1 & 604 & 45,8 & 1.318 & 574 & 32,2 & 546 & 30,6 & 790 & 44,3 & 1.783 \\
\hline & Urbano & 2.267 & 45,7 & 1.395 & 28,1 & 2.026 & 40,9 & 4.958 & 2.588 & 35,8 & 2.289 & 31,6 & 3.254 & 45,0 & 7.237 \\
\hline & Rural & 2.307 & 63,0 & 1.624 & 44,3 & 2.148 & 58,6 & 3.665 & 1.968 & 51,4 & 1.449 & 37,9 & 1.905 & 49,8 & 3.827 \\
\hline \multirow{5}{*}{ Nordeste } & Fortaleza & 1.290 & 56,9 & 930 & 41,1 & 1.212 & 53,5 & 2.265 & 1.168 & 39,5 & 1.088 & 36,8 & 1.491 & 50,5 & 2.954 \\
\hline & Recife & 1.855 & 65,2 & 1.300 & 45,7 & 1.616 & 56,8 & 2.845 & 1.647 & 49,7 & 1.321 & 39,8 & 1.760 & 53,1 & 3.317 \\
\hline & Salvador & 1.308 & 53,5 & 1.011 & 41,3 & 1.298 & 53,1 & 2.447 & 1.214 & 40,6 & 1.087 & 36,4 & 1.495 & 50,0 & 989 \\
\hline & Urbano & 11.658 & 64,2 & 6.023 & 33,2 & 8.485 & 46,7 & 18.167 & 10.604 & 44,7 & 8.151 & 34,4 & 11.327 & 47,7 & 23.724 \\
\hline & Rural & 12.681 & 77,3 & 8.044 & 49,0 & 10.504 & 64,0 & 16.413 & 8.628 & 59,4 & 5.324 & 36,6 & 6.990 & 48,1 & 14.537 \\
\hline \multirow{16}{*}{ Sudeste } & M & & & & & & & & & & & & & & \\
\hline & Belo & 1.257 & 37,1 & 1.009 & 29,8 & 1.412 & 41,7 & 3.388 & 1.218 & 25,5 & 1.323 & 27,7 & 1.982 & 41,5 & 4.777 \\
\hline & Urbano & 2.730 & 32,5 & 1.848 & 22,0 & 2.883 & 34,3 & 8.392 & 2.141 & 21,9 & 2.367 & 24,2 & 3.543 & 36,2 & 9.779 \\
\hline & Rural & 1.919 & 51,0 & 1.553 & 41,3 & 2.107 & 56,0 & 3.762 & 983 & 32,8 & 881 & 29,4 & 1.215 & 40,5 & 3.000 \\
\hline & Espirito & & & & & & & & & & & & & & \\
\hline & Urban & 528 & 27,7 & 404 & 21,2 & 624 & 32,8 & 1.906 & 420 & 17,1 & 561 & 22,9 & 876 & 35,8 & 2.450 \\
\hline & Rural & 326 & 48,3 & 297 & 44,1 & 394 & 58,4 & 674 & 137 & 21,7 & 138 & 21,8 & 220 & 34,6 & 634 \\
\hline & Rio de Jane & & & & & & & & & & & & & & \\
\hline & Metr & 3.971 & 40,9 & 2.925 & 30,1 & 4.096 & 42,2 & 9.711 & 2.974 & 27,5 & 3.128 & 28,9 & 4.615 & 42,7 & 10.821 \\
\hline & Urba & 793 & 32,4 & 597 & 24,4 & 901 & 36,8 & 2.446 & 537 & 17,9 & 632 & 21,1 & 1.001 & 33,4 & 2.995 \\
\hline & Rural & 289 & 55,1 & 259 & 49,5 & 333 & 63,6 & 523 & 139 & 28,4 & 113 & 23,0 & 185 & 37,8 & 489 \\
\hline & São Paulo & & & & & & & & & & & & & & \\
\hline & Metrópo & 4.326 & 28,5 & 3.630 & 23,9 & 5.372 & 35,3 & 66 & 5.337 & 30,1 & 5.248 & 29,6 & 7.480 & 42,2 & 17.744 \\
\hline & Urbano & 2.649 & 18,8 & 2.216 & 15,7 & 3.751 & 26,6 & 14.076 & 3.009 & 17,3 & 3.549 & 20,4 & 5.726 & 33,0 & 17.356 \\
\hline & Rural & 727 & 37,9 & 756 & 39,4 & 1.040 & 54,2 & & 399 & 24,1 & 388 & 23,4 & 617 & 37,2 & 1.658 \\
\hline & Curitiba & 494 & 25,0 & 426 & 21,6 & 652 & 33,0 & 1.972 & 534 & 19,7 & 683 & 25,3 & 1.029 & 38,1 & 2.704 \\
\hline \multirow{3}{*}{ Sul } & Porto Ale & 513 & 17,1 & 565 & 18,9 & 861 & 28,8 & 2.992 & 482 & 13,3 & 787 & 21,7 & 1.218 & 33,6 & 3.628 \\
\hline & Urbano & 2.521 & 22,0 & 2.035 & 17,7 & 3.266 & 28,5 & 11.475 & 1.957 & 13,8 & 2.724 & 19,2 & 4.360 & 30,7 & 14.214 \\
\hline & Rural & 2.228 & 40,7 & 2.093 & 38,3 & 2.840 & 51,9 & 5.471 & 946 & 21,5 & 1.008 & 22,9 & 1.502 & 34,1 & 4.403 \\
\hline \multirow{4}{*}{$\begin{array}{l}\text { Centro- } \\
\text { Oeste }\end{array}$} & Brasília & 627 & 40,1 & 566 & 36,1 & 748 & 47,8 & 1.565 & 606 & 30,0 & 704 & 34,8 & 935 & 46,2 & 2.023 \\
\hline & Urbano & 2.803 & 46,1 & 1.716 & 28,2 & 2.563 & 42,1 & 6.082 & 2.304 & 28,5 & 2.142 & 26,5 & 3.257 & 40,3 & 8.087 \\
\hline & Rural & 943 & 56,8 & 753 & 45,4 & 989 & 59,6 & 1.660 & 492 & 34,0 & 407 & 28,1 & 621 & 42,8 & 1.450 \\
\hline & BRASIL & 63.533 & 43,7 & 44.413 & 30,6 & 62.725 & 43,2 & 145.296 & 53.007 & 31,4 & 48.039 & 28,5 & 69.394 & 41,2 & 168.577 \\
\hline
\end{tabular}

Obs.: (1) $n^{o}$ de pobres e População Total em milhares de habitantes.

(2) Os valores das colunas $n^{o}$ de pobres correspondem ao número de pessoas com renda familiar per capita abaixo da linha de pobreza considerada e os valores das colunas \% são o percentual de pessoas pobres em relação ao total populacional de habitantes de cada estrato.

(3) As colunas Zh30 e Zh50 indicam os valores correspondentes às linhas híbridas considerando linhas relativas de $30 \%$ e $50 \%$ da renda média, respectivamente. 
Tabela 10.B - Incidência da Pobreza com Renda Média Nacional

\begin{tabular}{|c|c|c|c|c|c|c|c|c|c|c|c|c|c|c|c|}
\hline \multirow{4}{*}{ Regiões } & \multirow{4}{*}{ Estratos } & \multicolumn{7}{|c|}{1991} & \multicolumn{7}{|c|}{2000} \\
\hline & & \multirow{2}{*}{\multicolumn{2}{|c|}{$\begin{array}{c}\text { Linha Absoluta } \\
\text { de Pobreza } \\
\end{array}$}} & \multicolumn{4}{|c|}{ Linha Híbrida de Pobreza } & \multirow{3}{*}{$\begin{array}{l}\text { População } \\
\text { Total }\end{array}$} & \multirow{2}{*}{\multicolumn{2}{|c|}{$\begin{array}{c}\text { Linha Absoluta } \\
\text { de Pobreza }\end{array}$}} & \multicolumn{4}{|c|}{ Linha Híbrida de Pobreza } & \multirow{3}{*}{$\begin{array}{c}\text { População } \\
\text { Total }\end{array}$} \\
\hline & & & & \multicolumn{2}{|c|}{ Zh30 } & \multicolumn{2}{|l|}{ Zh50 } & & & & Zh30 & & Zh50 & & \\
\hline & & $\mathrm{n}^{\circ}$ de pobres & $\%$ & $\mathrm{n}^{\circ}$ de pobres & $\%$ & $\mathrm{n}^{\circ}$ de pobres & $\%$ & & $\mathrm{n}^{0}$ de pobres & $\%$ & $\mathrm{n}^{0}$ de pobres & $\%$ & $\mathrm{n}^{0}$ de pobres & $\%$ & \\
\hline \multirow{3}{*}{ Norte } & Belém & 521 & 39,6 & 415 & 31,5 & 576 & 43,7 & 1.318 & 574 & 32,2 & 585 & 32,8 & 842 & 47,2 & 1.783 \\
\hline & Urbano & 2.267 & 45,7 & 2.017 & 40,7 & 2.625 & 52,9 & 4.958 & 2.588 & 35,8 & 2.892 & 40,0 & 3.883 & 53,7 & 7.237 \\
\hline & Rural & 2.307 & 63,0 & 2.520 & 68,8 & 2.897 & 79,0 & 3.665 & 1.968 & 51,4 & 2.624 & 68,6 & 3.034 & 79,3 & 3.827 \\
\hline \multirow{5}{*}{ Nordeste } & Fortaleza & 1.290 & 56,9 & 1.080 & 47,7 & 1.349 & 59,5 & 2.265 & 1.168 & 39,5 & 1.206 & 40,8 & 1.621 & 54,9 & 2.954 \\
\hline & Recife & 1.855 & 65,2 & 1.379 & 48,5 & 1.690 & 59,4 & 2.845 & 1.647 & 49,7 & 1.370 & 41,3 & 1.835 & 55,3 & 3.317 \\
\hline & Salvador & 1.308 & 53,5 & 963 & 39,4 & 1.258 & 51,4 & 2.447 & 1.214 & 40,6 & 1.049 & 35,1 & 1.438 & 48,1 & 2.989 \\
\hline & Urbano & 11.658 & 64,2 & 10.478 & 57,7 & 12.627 & 69,5 & 18.167 & 10.604 & 44,7 & 11.716 & 49,4 & 14.975 & 63,1 & 23.724 \\
\hline & Rural & 12.681 & 77,3 & 13.448 & 81,9 & 14.664 & 89,3 & 16.413 & 8.628 & 59,4 & 11.034 & 75,9 & 12.500 & 86,0 & 14.537 \\
\hline \multirow{15}{*}{ Sudeste } & Minas Gerais & & & & & & & & & & & & & & \\
\hline & Belo Horizonte & 1.257 & 37,1 & 881 & 26,0 & 1.276 & 37,7 & 3.388 & 1.218 & 25,5 & 1.058 & 22,2 & 1.612 & 33,7 & 4.777 \\
\hline & Urbano & 2.730 & 32,5 & 2.541 & 30,3 & 3.657 & 43,6 & 8.392 & 2.141 & 21,9 & 2.550 & 26,1 & 3.808 & 38,9 & 9.779 \\
\hline & Rural & 1.919 & 51,0 & 2.347 & 62,4 & 2.812 & 74,8 & 3.762 & 983 & 32,8 & 1.609 & 53,7 & 2.002 & 66,7 & 3.000 \\
\hline & Espirito Santo & & & & & & & & & & & & & & \\
\hline & Urbano & 528 & 27,7 & 489 & 25,7 & 725 & 38,0 & 1.906 & 420 & 17,1 & 517 & 21,1 & 807 & 32,9 & 2.450 \\
\hline & Rural & 326 & 48,3 & 401 & 59,5 & 486 & 72,1 & 674 & 137 & 21,7 & 268 & 42,3 & 358 & 56,4 & 634 \\
\hline & Rio de Janeiro & & & & & & & & & & & & & & \\
\hline & Metrópole & 3.971 & 40,9 & 2.509 & 25,8 & 3.597 & 37,0 & 9.711 & 2.974 & 27,5 & 2.217 & 20,5 & 3.437 & 31,8 & 10.821 \\
\hline & Urbano & 793 & 32,4 & 683 & 27,9 & 993 & 40,6 & 2.446 & 537 & 17,9 & 605 & 20,2 & 958 & 32,0 & 2.995 \\
\hline & Rural & 289 & 55,1 & 305 & 58,3 & 377 & 72,1 & 523 & 139 & 28,4 & 202 & 41,2 & 282 & 57,8 & 489 \\
\hline & São Paulo & & & & & & & & & & & & & & \\
\hline & Metrópole & 4.326 & 28,5 & 2.065 & 13,6 & 3.224 & 21,2 & 15.206 & 5.337 & 30,1 & 3.334 & 18,8 & 5.079 & 28,6 & 17.744 \\
\hline & Urbano & 2.649 & 18,8 & 1.727 & 12,3 & 2.927 & 20,8 & 14.076 & 3.009 & 17,3 & 2.742 & 15,8 & 4.350 & 25,1 & 17.356 \\
\hline & Rural & 727 & 37,9 & 768 & 40,0 & 1.043 & 54,4 & 1.919 & 399 & 24,1 & 558 & 33,7 & 827 & 49,9 & 1.658 \\
\hline \multirow{4}{*}{ Sul } & Curitiba & 494 & 25,0 & 318 & 16,1 & 503 & 25,5 & 1.972 & 534 & 19,7 & 473 & 17,5 & 729 & 27,0 & 2.704 \\
\hline & Porto Alegre & 513 & 17,1 & 420 & 14,0 & 667 & 22,3 & 2.992 & 482 & 13,3 & 525 & 14,5 & 832 & 22,9 & 3.628 \\
\hline & Urbano & 2.521 & 22,0 & 2.325 & 20,3 & 3.589 & 31,3 & 11.475 & 1.957 & 13,8 & 2.431 & 17,1 & 3.937 & 27,7 & 14.214 \\
\hline & Rural & 2.228 & 40,7 & 2.671 & 48,8 & 3.385 & 61,9 & 5.471 & 946 & 21,5 & 1.522 & 34,6 & 2.103 & 47,8 & 4.403 \\
\hline \multirow{4}{*}{$\begin{array}{l}\text { Centro- } \\
\text { Oeste }\end{array}$} & Brasília & 627 & 40,1 & 326 & 20,8 & 489 & 31,2 & 1.565 & 606 & 30,0 & 410 & 20,3 & 622 & 30,8 & 2.023 \\
\hline & Urbano & 2.803 & 46,1 & 1.855 & 30,5 & 2.716 & 44,7 & 6.082 & 2.304 & 28,5 & 2.082 & 25,7 & 3.174 & 39,3 & 8.087 \\
\hline & Rural & 943 & 56,8 & 942 & 56,7 & 1.163 & 70,1 & 1.660 & 492 & 34,0 & 671 & 46,3 & 896 & 61,8 & 1.450 \\
\hline & BRASIL & 63.533 & 43,7 & 55.873 & 38,5 & 71.315 & 49,1 & 145.296 & 53.007 & 31,4 & 56.251 & 33,4 & 75.940 & 45,0 & 168.577 \\
\hline \multicolumn{16}{|c|}{$\begin{array}{l}\text { Obs.: (1) } n^{o} \text { de pobres e População Total em milhares de habitantes. } \\
\text { (2) Os valores das colunas } n^{\circ} \text { de pobres correspondem ao número de pessoas com renda familiar per } \\
\text { capita abaixo da linha de pobreza considerada e os valores das colunas \% são o percentual de pessoas pobres em } \\
\text { relação ao total populacional de habitantes de cada estrato. } \\
\text { (3) As colunas } Z h 30 \text { e } Z h 50 \text { indicam os valores correspondentes às linhas híbridas considerando linhas }\end{array}$} \\
\hline
\end{tabular}


Tabela 11.B - Variação da Incidência da Pobreza entre os Anos de 1991 e 2000

\begin{tabular}{|c|c|c|c|c|c|c|c|c|c|c|c|}
\hline \multirow{3}{*}{ Regiões } & \multirow{3}{*}{ Estratos } & \multicolumn{5}{|c|}{ Diferença em Pontos Percentuais } & \multicolumn{5}{|c|}{ Variação Percentual para 1991} \\
\hline & & \multirow{2}{*}{$\mathrm{Za}$} & \multicolumn{2}{|c|}{ Zh com RM por Estrato } & \multicolumn{2}{|c|}{ Zh com RM Nacional } & \multirow{2}{*}{$\mathrm{Za}$} & \multicolumn{2}{|c|}{ Zh com RM por Estrato } & \multicolumn{2}{|c|}{ Zh com RM Nacional } \\
\hline & & & Zh30 & Zh50 & Zh30 & Zh50 & & Zh30 & Zh50 & Zh30 & Zh50 \\
\hline \multirow{3}{*}{ Norte } & Belém & $-7,4$ & $-2,5$ & $-1,5$ & 1,3 & 3,5 & $-18,6$ & $-7,4$ & $-3,3$ & 4,2 & 8,0 \\
\hline & Urbano & $-10,0$ & 3,5 & 4,1 & $-0,7$ & 0,7 & $-21,8$ & 12,4 & 10,0 & $-1,8$ & 1,3 \\
\hline & Rural & $-11,5$ & $-6,5$ & $-8,8$ & $-0,2$ & 0,2 & $-18,3$ & $-14,6$ & $-15,1$ & $-0,3$ & 0,3 \\
\hline \multirow{5}{*}{ Nordeste } & Fortaleza & $-17,4$ & $-4,2$ & $-3,0$ & $-6,9$ & $-4,7$ & $-30,6$ & $-10,3$ & $-5,7$ & $-14,4$ & $-7,8$ \\
\hline & Recife & $-15,5$ & $-5,9$ & $-3,8$ & $-7,2$ & $-4,1$ & $-23,8$ & $-12,9$ & $-6,6$ & $-14,8$ & $-6,9$ \\
\hline & Salvador & $-12,8$ & $-4,9$ & $-3,0$ & $-4,3$ & $-3,3$ & $-24,0$ & $-12,0$ & $-5,7$ & $-10,8$ & $-6,4$ \\
\hline & Urbano & $-19,5$ & 1,2 & 1,0 & $-8,3$ & $-6,4$ & $-30,4$ & 3,6 & 2,2 & $-14,4$ & $-9,2$ \\
\hline & Rural & $-17,9$ & $-12,4$ & $-15,9$ & $-6,0$ & $-3,4$ & $-23,2$ & $-25,3$ & $-24,9$ & $-7,4$ & $-3,8$ \\
\hline \multirow{15}{*}{ Sudeste } & Minas Gerais & & & & & & & & & & \\
\hline & Belo Horizonte & $-11,6$ & $-2,1$ & $-0,2$ & $-3,9$ & $-3,9$ & $-31,3$ & $-7,0$ & $-0,5$ & $-14,8$ & $-10,4$ \\
\hline & Urbano & $-10,6$ & 2,2 & 1,9 & $-4,2$ & $-4,6$ & $-32,7$ & 10,0 & 5,5 & $-13,9$ & $-10,6$ \\
\hline & Rural & $-18,2$ & $-11,9$ & $-15,5$ & $-8,7$ & $-8,0$ & $-35,7$ & $-28,9$ & $-27,7$ & $-14,0$ & $-10,7$ \\
\hline & Espirito Santo & & & & & & & & & & \\
\hline & Urbano & $-10,6$ & 1,7 & 3,0 & $-4,5$ & $-5,1$ & $-38,1$ & 7,9 & 9,2 & $-17,7$ & $-13,4$ \\
\hline & Rural & $-26,7$ & $-22,3$ & $-23,8$ & $-17,2$ & $-15,6$ & $-55,2$ & $-50,5$ & $-40,7$ & $-29,0$ & $-21,7$ \\
\hline & Rio de Janeiro & & & & & & & & & & \\
\hline & Metrópole & $-13,4$ & $-1,2$ & 0,5 & $-5,4$ & $-5,3$ & $-32,8$ & $-4,0$ & 1,1 & $-20,7$ & $-14,2$ \\
\hline & Urbano & $-14,5$ & $-3,3$ & $-3,4$ & $-7,7$ & $-8,6$ & $-44,7$ & $-13,5$ & $-9,2$ & $-27,6$ & $-21,2$ \\
\hline & Rural & $-26,8$ & $-26,5$ & $-25,8$ & $-17,1$ & $-14,3$ & $-48,5$ & $-53,6$ & $-40,5$ & $-29,3$ & $-19,9$ \\
\hline & São Paulo & & & & & & & & & & \\
\hline & Metrópole & 1,6 & 5,7 & 6,8 & 5,2 & 7,4 & 5,7 & 23,9 & 19,3 & 38,3 & 35,0 \\
\hline & Urbano & $-1,5$ & 4,7 & 6,3 & 3,5 & 4,3 & $-7,9$ & 29,9 & 23,8 & 28,7 & 20,5 \\
\hline & Rural & $-13,8$ & $-16,0$ & $-17,0$ & $-6,4$ & $-4,5$ & $-36,4$ & $-40,6$ & $-31,4$ & $-15,9$ & $-8,3$ \\
\hline \multirow{4}{*}{ Sul } & Curitiba & $-5,3$ & 3,6 & 5,0 & 1,4 & 1,5 & $-21,1$ & 16,8 & 15,2 & 8,7 & 5,7 \\
\hline & Porto Alegre & $-3,9$ & 2,8 & 4,8 & 0,4 & 0,6 & $-22,5$ & 14,8 & 16,7 & 3,1 & 2,8 \\
\hline & Urbano & $-8,2$ & 1,4 & 2,2 & $-3,2$ & $-3,6$ & $-37,3$ & 8,1 & 7,8 & $-15,6$ & $-11,4$ \\
\hline & Rural & $-19,2$ & $-15,4$ & $-17,8$ & $-14,3$ & $-14,1$ & $-47,2$ & $-40,1$ & $-34,3$ & $-29,2$ & $-22,8$ \\
\hline \multirow{4}{*}{$\begin{array}{c}\text { Centro- } \\
\text { Oeste }\end{array}$} & Brasília & $-10,1$ & $-1,3$ & $-1,5$ & $-0,5$ & $-0,4$ & $-25,2$ & $-3,7$ & $-3,2$ & $-2,6$ & $-1,4$ \\
\hline & Urbano & $-17,6$ & $-1,7$ & $-1,9$ & $-4,8$ & $-5,4$ & $-38,2$ & $-6,1$ & $-4,4$ & $-15,6$ & $-12,1$ \\
\hline & Rural & $-22,9$ & $-17,3$ & $-16,8$ & $-10,5$ & $-8,3$ & $-40,2$ & $-38,1$ & $-28,2$ & $-18,5$ & $-11,8$ \\
\hline & BRASIL & $-12,3$ & $-2,1$ & $-2,0$ & $-5,1$ & $-4,0$ & $-28,1$ & $-6,8$ & $-4,6$ & $-13,2$ & $-8,2$ \\
\hline
\end{tabular}

Obs.: (1) As colunas referentes à Diferença em Pontos Percentuais indicam a diferença da incidência da pobreza entre os anos de 1991 e 2000. Já as colunas da Variação Percentual para 1991, correspondem a relação entre esta diferença e a incidência da pobreza em 1991.

(2) As colunas Za correspondem aos valores considerando as linhas absolutas de pobreza.

(3) As colunas Zh com RM por Estrato correspondem aos valores utilizando linhas híbridas construídas a partir de linhas relativas por estrato, enquanto que as colunas Zh com RM Nacional correspondem aos valores utilizando linhas híbridas construídas a partir da linha relativa nacional.

(4) As colunas Zh30 e Zh50 indicam os valores correspondentes às linhas híbridas considerando linhas relativas de $30 \%$ e $50 \%$ da renda média, respectivamente. 
Tabela 12.B -Regressões do Modelo Probit para 1991 e 2000

\begin{tabular}{|c|c|c|c|c|c|c|c|c|c|c|c|c|}
\hline \multirow{3}{*}{$\begin{array}{l}\text { Variável } \\
\text { Dependente: }\end{array}$} & \multicolumn{6}{|c|}{1991} & \multicolumn{6}{|c|}{2000} \\
\hline & \multicolumn{2}{|c|}{ pobre } & \multicolumn{2}{|c|}{ pobre30 } & \multicolumn{2}{|c|}{ pobre50 } & \multicolumn{2}{|c|}{ pobre } & \multicolumn{2}{|c|}{ pobre30 } & \multicolumn{2}{|c|}{ pobre50 } \\
\hline & Coeficiente & $\begin{array}{l}\text { desvio- } \\
\text { padrão }\end{array}$ & Coeficiente & $\begin{array}{l}\text { desvio- } \\
\text { padrão }\end{array}$ & Coeficiente & $\begin{array}{l}\text { desvio- } \\
\text { padrão }\end{array}$ & Coeficiente & $\begin{array}{l}\text { desvio- } \\
\text { padrão }\end{array}$ & Coeficiente & $\begin{array}{l}\text { desvio- } \\
\text { padrão }\end{array}$ & Coeficiente & $\begin{array}{l}\text { desvio- } \\
\text { padrão }\end{array}$ \\
\hline \multicolumn{13}{|l|}{ Variáveis } \\
\hline \multicolumn{13}{|l|}{ Independente: } \\
\hline Intercepto & $-0,2604$ & 0,0004 & $-0,3420$ & 0,0004 & 0,0712 & 0,0004 & $-0,0061$ & 0,0004 & 0,0693 & 0,0004 & 0,4839 & 0,0004 \\
\hline Mulher & 0,0686 & 0,0002 & 0,0698 & 0,0002 & 0,0673 & 0,0002 & 0,0642 & 0,0002 & 0,0668 & 0,0002 & 0,0659 & 0,0002 \\
\hline Não-Branco & 0,3800 & 0,0003 & 0,3291 & 0,0003 & 0,3600 & 0,0002 & 0,3797 & 0,0002 & 0,3454 & 0,0002 & 0,3747 & 0,0002 \\
\hline Idade & $-0,0090$ & 0,00001 & $-0,0093$ & 0,00001 & $-0,0091$ & 0,00001 & $-0,0134$ & 0,00001 & $-0,0131$ & 0,00001 & $-0,0136$ & 0,00001 \\
\hline Escolaridade & $-0,0838$ & 0,0000 & $-0,0754$ & 0,0000 & $-0,0788$ & 0,0000 & $-0,0728$ & 0,0000 & $-0,0666$ & 0,0000 & $-0,0710$ & 0,0000 \\
\hline Reg.Metropolitana & 0,0618 & 0,0001 & 0,0686 & 0,0001 & 0,0656 & 0,0001 & 0,2036 & 0,0003 & 0,2632 & 0,0003 & 0,2467 & 0,0003 \\
\hline Urbano & $-0,2713$ & 0,0003 & $-0,2573$ & 0,0003 & $-0,2713$ & 0,0003 & $-0,2353$ & 0,0003 & $-0,3792$ & 0,0003 & $-0,3552$ & 0,0003 \\
\hline Dummy RO & 0,3752 & 0,0013 & 0,2244 & 0,0013 & 0,1386 & 0,0013 & $-0,2167$ & 0,0013 & $-0,1428$ & 0,0012 & $-0,1908$ & 0,0012 \\
\hline Dummy AC & 0,4051 & 0,0021 & 0,1897 & 0,0021 & 0,1114 & 0,0021 & 0,1496 & 0,0018 & $-0,0005$ & 0,0018 & $-0,0635$ & 0,0018 \\
\hline Dummy AM & 0,2318 & 0,0010 & 0,0262 & 0,0010 & $-0,0221$ & 0,0010 & 0,2464 & 0,0008 & 0,0199 & 0,0009 & $-0,0453$ & 0,0008 \\
\hline Dummy RR & 0,0300 & 0,0030 & 0,2157 & 0,0029 & 0,0957 & 0,0029 & $-0,1804$ & 0,0025 & $-0,1531$ & 0,0025 & $-0,2424$ & 0,0024 \\
\hline Dummy PA & 0,5497 & 0,0007 & 0,1909 & 0,0007 & 0,1596 & 0,0007 & 0,2054 & 0,0006 & $-0,1152$ & 0,0006 & $-0,1460$ & 0,0006 \\
\hline Dummy AP & 0,0869 & 0,0026 & 0,0545 & 0,0026 & 0,0014 & 0,0025 & 0,0822 & 0,0020 & 0,0664 & 0,0020 & $-0,0188$ & 0,0020 \\
\hline Dummy TO & 0,5123 & 0,0014 & 0,1709 & 0,0014 & 0,1273 & 0,0014 & 0,1538 & 0,0013 & $-0,0340$ & 0,0013 & $-0,0861$ & 0,0013 \\
\hline Dummy MA & 0,8365 & 0,0007 & 0,1513 & 0,0007 & 0,1280 & 0,0007 & 0,5631 & 0,0006 & 0,0342 & 0,0006 & $-0,0174$ & 0,0006 \\
\hline Dummy PI & 1,0279 & 0,0009 & 0,3941 & 0,0009 & 0,3389 & 0,0009 & 0,5163 & 0,0008 & 0,1086 & 0,0009 & 0,0374 & 0,0008 \\
\hline Dummy CE & 1,0795 & 0,0006 & 0,4524 & 0,0006 & 0,4189 & 0,0006 & 0,4995 & 0,0006 & 0,0949 & 0,0006 & 0,0449 & 0,0005 \\
\hline Dummy RN & 0,7833 & 0,0009 & 0,2915 & 0,0009 & 0,2596 & 0,0009 & 0,3274 & 0,0008 & 0,0602 & 0,0009 & 0,0224 & 0,0008 \\
\hline Dummy PB & 1,0232 & 0,0008 & 0,3629 & 0,0008 & 0,3263 & 0,0008 & 0,4499 & 0,0008 & 0,0619 & 0,0008 & 0,0187 & 0,0008 \\
\hline Dummy PE & 1,0342 & 0,0006 & 0,4729 & 0,0006 & 0,4290 & 0,0006 & 0,5111 & 0,0005 & 0,0941 & 0,0005 & 0,0485 & 0,0005 \\
\hline Dummy AL & 0,7487 & 0,0009 & 0,1697 & 0,0009 & 0,1441 & 0,0009 & 0,4780 & 0,0008 & 0,0839 & 0,0009 & 0,0226 & 0,0008 \\
\hline Dummy SE & 0,5673 & 0,0011 & 0,1184 & 0,0012 & 0,0921 & 0,0011 & 0,2334 & 0,0010 & $-0,0671$ & 0,0011 & $-0,1146$ & 0,0010 \\
\hline Dummy BA & 0,8558 & 0,0005 & 0,2893 & 0,0005 & 0,2520 & 0,0005 & 0,3594 & 0,0005 & $-0,0142$ & 0,0005 & $-0,0600$ & 0,0004 \\
\hline Dummy MG & 0,2517 & 0,0005 & 0,1344 & 0,0005 & 0,1152 & 0,0004 & $-0,0937$ & 0,0004 & $-0,1224$ & 0,0004 & $-0,1234$ & 0,0004 \\
\hline Dummy ES & 0,0995 & 0,0009 & 0,1093 & 0,0009 & 0,0674 & 0,0009 & $-0,3142$ & 0,0009 & $-0,1393$ & 0,0009 & $-0,1627$ & 0,0008 \\
\hline Dummy RJ & 0,4514 & 0,0005 & 0,2736 & 0,0005 & 0,2599 & 0,0005 & $-0,0390$ & 0,0005 & $-0,0618$ & 0,0005 & $-0,0742$ & 0,0004 \\
\hline Dummy PR & 0,1346 & 0,0006 & 0,1033 & 0,0006 & 0,0919 & 0,0005 & $-0,1649$ & 0,0006 & $-0,0774$ & 0,0005 & $-0,0758$ & 0,0005 \\
\hline Dummy SC & $-0,1220$ & 0,0008 & $-0,0158$ & 0,0008 & $-0,0577$ & 0,0007 & $-0,5030$ & 0,0008 & $-0,2446$ & 0,0008 & $-0,2438$ & 0,0007 \\
\hline Dummy RS & $-0,0086$ & 0,0006 & 0,0890 & 0,0006 & 0,0572 & 0,0005 & $-0,3098$ & 0,0006 & $-0,1068$ & 0,0005 & $-0,1370$ & 0,0005 \\
\hline Dummy MS & 0,5538 & 0,0010 & 0,3119 & 0,0011 & 0,3086 & 0,0010 & 0,1737 & 0,0010 & 0,0870 & 0,0010 & 0,0994 & 0,0010 \\
\hline Dummy MT & 0,4841 & 0,0010 & 0,2245 & 0,0010 & 0,1904 & 0,0010 & 0,0145 & 0,0009 & $-0,0609$ & 0,0009 & $-0,0450$ & 0,0009 \\
\hline Dummy GO & 0,5267 & 0,0007 & 0,2185 & 0,0008 & 0,2235 & 0,0007 & 0,0756 & 0,0007 & $-0,0500$ & 0,0007 & $-0,0295$ & 0,0007 \\
\hline Dummy DF & 0,7779 & 0,0012 & 0,7965 & 0,0012 & 0,7549 & 0,0011 & 0,2316 & 0,0010 & 0,4288 & 0,0010 & 0,3476 & 0,0010 \\
\hline Pseudo- $\mathrm{R}^{2}$ & \multicolumn{2}{|c|}{0,1904} & \multicolumn{2}{|c|}{0,1068} & \multicolumn{2}{|c|}{0,1148} & \multicolumn{2}{|c|}{0,1632} & \multicolumn{2}{|c|}{0,1176} & \multicolumn{2}{|c|}{0,1232} \\
\hline $\begin{array}{l}\text { número de } \\
\text { observações }\end{array}$ & \multicolumn{6}{|c|}{145.303 .385} & \multicolumn{6}{|c|}{168.584 .058} \\
\hline
\end{tabular}

Obs.: (1) A Dummy SP (Estado de São Paulo) foi retirada da regressão para evitar o problema de multicolinearidade perfeita. Portanto, é a variável de estado referência.

(2) As variáveis dependentes são dummies que recebem o valor 1 (um) quando o individuo é pobre, considerando certa linha de pobreza: pobre (dummy considerando linha absoluta de pobreza); pobre30 (dummy considerando linha híbrida com linha relativa de 30\%); e pobre50 (dummy considerando linha híbrida com linha relativa de $50 \%$ ).

(3) Todas as estimações usam White robusto para heterocedasticidade. 


\section{c) Resultados para o Capítulo 4}

Tabela 14.B - Estimações de Logaritmo da Incidência da Pobreza em Logaritmos da Renda e Desigualdade

\begin{tabular}{|c|c|c|c|c|c|c|c|c|c|}
\hline \multirow{2}{*}{$\begin{array}{l}\text { Variável dependente: } \\
\text { Proporção de Pobres }\end{array}$} & \multicolumn{3}{|c|}{$\mathrm{MQO}$} & \multicolumn{3}{|c|}{ Efeitos Fixos } & \multicolumn{3}{|c|}{ Efeitos Aleatórios } \\
\hline & sem índice & com Gini & com Theil & sem índice & com Gini & com Theil & sem índice & com Gini & com Theil \\
\hline Intercepto & $\begin{array}{l}3,5131 \\
(0,074)\end{array}$ & $\begin{array}{l}4,2890 \\
(0,109)\end{array}$ & $\begin{array}{l}3,8899 \\
(0,086)\end{array}$ & $\begin{array}{l}2,7200 \\
(0,121)\end{array}$ & $\begin{array}{l}4,5445 \\
(0,130)\end{array}$ & $\begin{array}{l}4,2304 \\
(0,129)\end{array}$ & $\begin{array}{l}3,1444 \\
(0,042)\end{array}$ & $\begin{array}{l}4,0236 \\
(0,055)\end{array}$ & $\begin{array}{l}3,5439 \\
(0,046)\end{array}$ \\
\hline $\mathrm{R}$ & $\begin{array}{r}-0,9317 \\
(0,016) \\
\end{array}$ & $\begin{array}{l}-0,9058 \\
(0,015) \\
\end{array}$ & $\begin{array}{l}-0,9471 \\
(0,016) \\
\end{array}$ & $\begin{array}{l}-0,7604 \\
(0,024) \\
\end{array}$ & $\begin{array}{l}-0,9497 \\
(0,022) \\
\end{array}$ & $\begin{array}{c}-1,0113 \\
(0,025) \\
\end{array}$ & $\begin{array}{l}-0,8433 \\
(0,009) \\
\end{array}$ & $\begin{array}{l}-0,8471 \\
(0,008) \\
\end{array}$ & $\begin{array}{l}-0,8758 \\
(0,009) \\
\end{array}$ \\
\hline $\begin{array}{c}\text { Indice de Desigualdade de } \\
\text { Renda } \\
\end{array}$ & & $\begin{array}{l}1,3910 \\
(0,101) \\
\end{array}$ & $\begin{array}{l}0,4708 \\
(0,033) \\
\end{array}$ & & $\begin{array}{l}1,3812 \\
(0,046)\end{array}$ & $\begin{array}{l}0,4127 \\
(0,014)\end{array}$ & & $\begin{array}{l}1,3886 \\
(0,039)\end{array}$ & $\begin{array}{l}0,4262 \\
(0,013)\end{array}$ \\
\hline Dummy do & $\begin{array}{l}0,1588 \\
(0,012) \\
\end{array}$ & $\begin{array}{l}0,2088 \\
(0,012) \\
\end{array}$ & $\begin{array}{l}0,1727 \\
(0,011) \\
\end{array}$ & $\begin{array}{l}0,1686 \\
(0,008) \\
\end{array}$ & $\begin{array}{l}0,1626 \\
(0,007) \\
\end{array}$ & $\begin{array}{l}0,1101 \\
(0,007) \\
\end{array}$ & $\begin{array}{l}0,1403 \\
(0,004) \\
\end{array}$ & $\begin{array}{l}0,1979 \\
(0,004) \\
\end{array}$ & $\begin{array}{l}0,1571 \\
(0,004)\end{array}$ \\
\hline $\mathrm{R}^{2}$ & 0,6517 & 0,7204 & 0,7098 & 0,7161 & 0,8121 & 0,7798 & 0,7152 & 0,8106 & 0,7769 \\
\hline$n^{\circ}$ de observações & & 8576 & & & 8576 & & & 8576 & \\
\hline
\end{tabular}

Obs.: (1) MQO corresponde ao método de Mínimos Quadrados Ordinários com os dois anos (1991 e 2000).

(2) Os valores entre parênteses abaixo de cada coeficiente correspondem ao respectivo desvio-padrão.

(3) Todas as estimações usam White robusto para heterocedasticidade.

Tabela 15.B - Testes de Verificação dos Métodos Aplicados

\begin{tabular}{ccccccc}
\hline Testes & \multicolumn{2}{c}{ sem índice } & \multicolumn{2}{c}{ com Gini } & \multicolumn{2}{c}{ com Theil } \\
\cline { 2 - 7 } & Qui-Quadrado & p-valor & Qui-Quadrado & p-valor & Qui-Quadrado & p-valor \\
\hline $\begin{array}{c}\text { Wald modificado para } \\
\text { heterocedasticidade em Efeitos Fixos }\end{array}$ & $7,9 \mathrm{E}+30$ & 0,000 & $0,0 \mathrm{E}+00$ & 1,000 & $0,0 \mathrm{E}+00$ & 1,000 \\
\hline $\begin{array}{c}\text { Breuch Pagan - existência de efeito } \\
\text { individual não observado }\end{array}$ & 1806 & 0,000 & 2065 & 0,000 & 1849 & 0,000 \\
\hline Hausman & 18 & 0,000 & 50 & 0,000 & 107 & 0,000 \\
\hline
\end{tabular}

Tabela 16.B - Estimações em Logaritmo da Incidência da Pobreza em Renda e Desigualdade por MQVD com Peso

\begin{tabular}{cccc}
\hline Variável dependente: & \multicolumn{3}{c}{ MQVD } \\
\cline { 2 - 4 } Proporção de Pobres & sem índice & com Gini & com Theil \\
\hline Intercepto & 2,5266 & 5,1951 & 4,7355 \\
& $(0,223)$ & $(0,304)$ & $(0,273)$ \\
\hline \multirow{2}{*}{ Renda Familiar per Capita } & $-0,7389$ & $-1,0640$ & $-1,1106$ \\
& $(0,044)$ & $(0,048)$ & $(0,050)$ \\
\hline \multirow{2}{*}{ Índice de Desigualdade de Renda } & & 1,5330 & 0,4785 \\
& & $(0,126)$ & $(0,038)$ \\
\hline \multirow{2}{*}{ Dummy do ano de 1991 } & 0,2256 & 0,1498 & 0,1082 \\
& $(0,016)$ & $(0,012)$ & $(0,013)$ \\
\hline $\mathrm{R}^{2}$ Ajustado & 0,8310 & 0,8810 & 0,8650 \\
\hline $\mathrm{n}^{\circ}$ de observações & \multicolumn{3}{c}{8576} \\
\hline Obs. (1) MQVD corresponde ao método de Mínimos Quadrados com Variáveis
\end{tabular}

Dummy considerando os dois anos (1991 e 2000).

(2) Os valores entre parênteses abaixo de cada coeficiente correspondem ao respectivo desvio-padrão.

(3) Todas as estimações usam White robusto para heterocedasticidade. 
Tabela 17.B - Estimações da Diferença dos Logaritmos da Incidência da Pobreza nas
Variáveis de Renda e Desigualdade

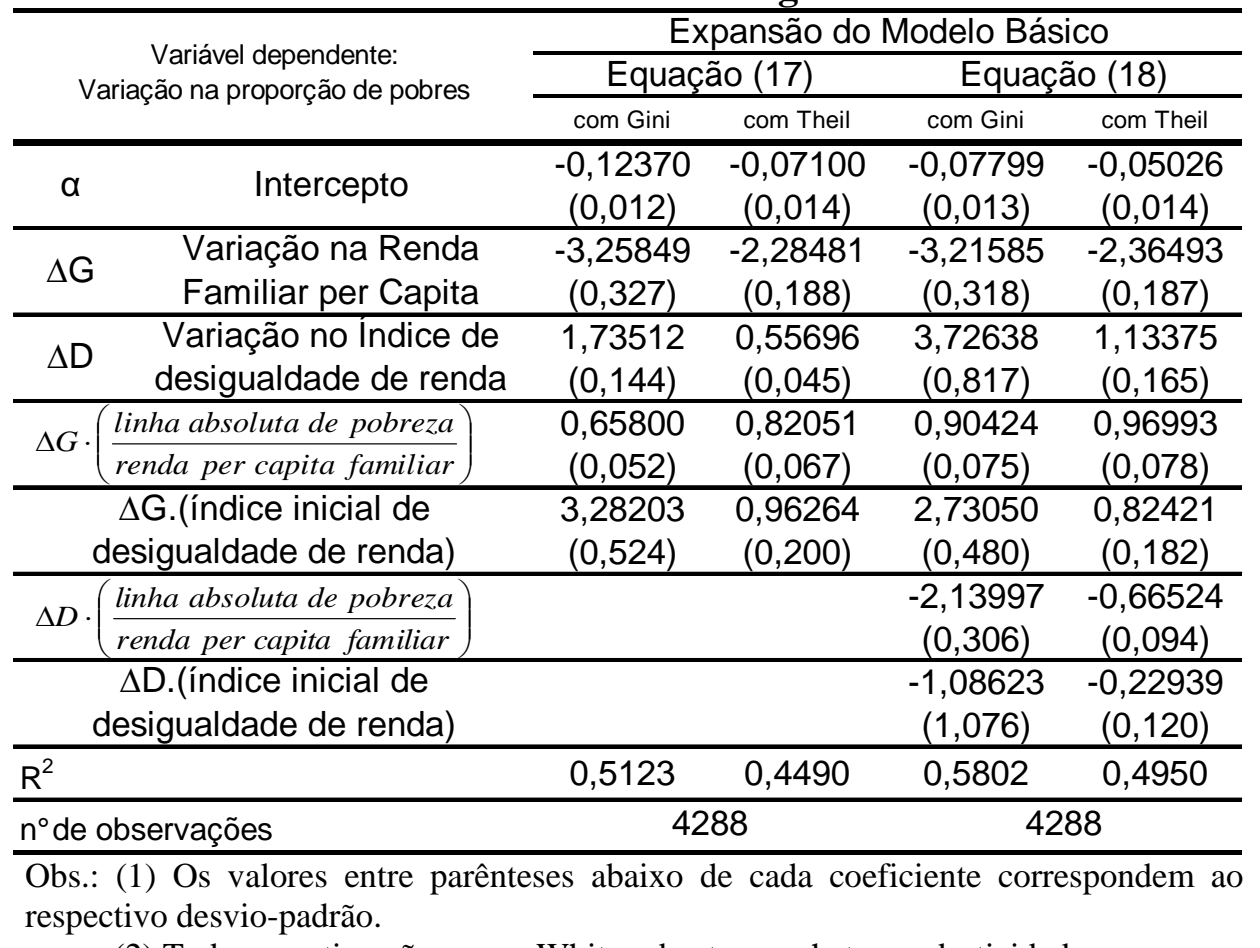

(2) Todas as estimações usam White robusto para heterocedasticidade.

Tabela 18.B - Comparativo entre as Elasticidades-Renda $\left(\varepsilon_{\mathrm{y}}\right.$ e $\left.\varepsilon_{\mathrm{m}}\right)$ e ElasticidadesDesigualdade $\left(\varepsilon_{\mathrm{G}}\right)$

\begin{tabular}{|c|c|c|c|c|c|c|c|c|c|c|c|c|c|c|c|c|c|c|c|c|}
\hline \multirow{3}{*}{ Estado } & \multicolumn{7}{|c|}{1991} & \multicolumn{7}{|c|}{2000} & \multicolumn{6}{|c|}{ Hoffmann (2004) } \\
\hline & \multirow{2}{*}{$\begin{array}{l}\text { Linha de } \\
\text { Pobreza }\end{array}$} & \multicolumn{3}{|c|}{ Gini } & \multicolumn{3}{|c|}{ Theil } & \multirow[t]{2}{*}{ a de } & \multicolumn{3}{|c|}{ Gini } & \multicolumn{3}{|c|}{ Theil } & \multicolumn{2}{|c|}{1999} & \multicolumn{2}{|c|}{2001} & \multicolumn{2}{|c|}{2002} \\
\hline & & $\sigma$ & $\varepsilon_{y}$ & $\varepsilon_{G}$ & $\sigma$ & $\varepsilon_{y}$ & $\varepsilon_{G}$ & & $\sigma$ & $\varepsilon_{y}$ & $\varepsilon_{G}$ & $\sigma$ & $\varepsilon_{y}$ & $\varepsilon_{G}$ & $m$ & $G$ & $\varepsilon_{m}$ & $\varepsilon_{G}$ & $\varepsilon_{m}$ & \\
\hline RO & 6926 & 21 & 73 & $\overline{51}$ & 1,24 & $\overline{69}$ & 57 & 281 & & $-0,99$ & 2,43 & 21 & 91 & $\overline{91}$ & $\overline{01}$ & $\overline{05}$ & $\overline{0,92}$ & 1,60 &, 00 & \\
\hline & & & & & & & & & & & & & & & & & & & & \\
\hline AN & & & 77 & 1,72 & 23 & $-0,75$ & & & & $-0,65$ & 1,65 & & $-0,63$ & & & & -0 & & & \\
\hline $\mathrm{RF}$ & & 28 & $-0,88$ & 2,66 & 23 & $-0,97$ & & & & $-0,99$ & 2,43 & & $-0,95$ & & |,22 & 2,18 & $-0,90$ & 1,44 & 0,76 & \\
\hline PA & & & & & 28 & & & & & & & & 59 & & 77 & 5 & $-0,78$ & 0 & 78 & $1,<$ \\
\hline A & & & & & & & & & & & 01 & & & & & & & & & \\
\hline $\mathrm{TC}$ & & & & & & 58 & & & & $-0,75$ & 68 & & $-0,66$ & & 64 & 0,78 & $-0,64$ & 0 & , & \\
\hline MA & & & 051 & 0,64 & 26 & & & & & & 0,99 & & & & & 0,51 & 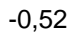 & 0,56 & & \\
\hline$P$ & & & & & & & & & & & 4 & & & & 47 & 5 & 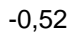 & 8 & & , \\
\hline U & & & 6 & 81 & & 2 & & & & & 28 & & & & & 2 & 0,53 & 1 & 1.58 & 0, \\
\hline RI & & & & & 7 & 6 & & & & & 3 & & & & & & $-0,64$ & & & 0 \\
\hline$P R$ & & & & & & & & & & & & & & & & & & & & \\
\hline $\mathrm{PE}$ & & & & 0,81 & & & & & & & 1,2 & & & & & 0 & 0, & 3 & & 0 \\
\hline $\mathrm{Al}$ & & 23 & 56 & 93 & & D & & & & -0 & 27 & & & & & 0 & 0,49 & 5 & 1.50 & 0,6 \\
\hline SE & & & & & & 1 & & & & & 61 & & & & & & & & & 0 \\
\hline & & & & & & & & & & & & & & & & & & & & \\
\hline MC & & & & & & & & & & & 45 & & & & & & -0.9 & & & 1,7 \\
\hline$E$ & & & 98 & & & 4 & & & & & & & & & & & & & & 1,8 \\
\hline R & & & & & & & & & & & & & & & & & & & & 2, \\
\hline & & & & & & & & & & & & & & & & & & & & \\
\hline & & & & & & & & & & & & & & & & & 01 & & & 2,2 \\
\hline & & & & 3 & & & & & & & & & & & & & & & & \\
\hline & & & & 2 & & & & & & & & & & & & & 14 & & & 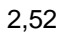 \\
\hline & & & & & & & & & & & & & & & & & & & & \\
\hline & & & & & & & & & & & & & & & & & & & & \\
\hline $\mathrm{GC}$ & & & $-0,82$ & 1,42 & 16 & $-0,75$ & 0 , & & 1,13 & & 2,0 & & $-0,82$ & & & & $-0,91$ & 1,72 & 0,98 & 1,8 \\
\hline & & & & 2,10 & & & $0, \mathrm{o}$ & & & & 69 & $C<$ & $-0,97$ & & & 35 & & & $-1,04$ & \\
\hline & & & $-0,74$ & & & $-0,73$ & & & $1, \angle U$ & & IIL & 1,26 & $-0,00$ & 0,0 & 0,07 & 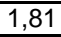 & , & (1) & 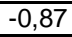 & \\
\hline
\end{tabular}

Obs.: (1) Os valores da coluna Linha de Pobreza correspondem às linhas da Tabela 2 abertas por estado e ponderadas pela população de cada estrato. 
(2) $\sigma$ é o desvio-padrão do logaritmo da renda, calculado a partir do índice de Gini, para a elasticidaderenda e elasticidade-desigualdade de Gini. Já para as elasticidades de Theil, $\sigma$ é calculado a partir do índice de desigualdade de Theil.

(3) Os valores $\varepsilon_{\mathrm{y}}$ e $\varepsilon_{\mathrm{G}}$ correspondem às elasticidades pela metodologia descrita no Apêndice F, usando os Censos de 1991 e 2000.

(4) Os valores $\varepsilon_{\mathrm{m}}$ e $\varepsilon_{\mathrm{G}}$ de Hoffmann (2004) correspondem às elasticidades com relação à renda e desigualdade, respectivamente, usando o índice de Gini, a partir das PNAD's de 1999, 2001 e 2002.

Tabela 19.B - Resultados do Teste Log-Normal com base em Bourguignon (2002)

\begin{tabular}{|c|c|c|c|c|c|}
\hline \multirow{3}{*}{\multicolumn{2}{|c|}{$\begin{array}{l}\text { Variável dependente: } \\
\text { Variação na proporção de pobres }\end{array}$}} & \multicolumn{4}{|c|}{ Teste - Modelo Lognormal } \\
\hline & & \multicolumn{2}{|c|}{ Equação (19) } & \multicolumn{2}{|c|}{ Equação (21) } \\
\hline & & com Gini & com Theil & com Gini & com Theil \\
\hline \multicolumn{2}{|r|}{ Intercepto } & $\begin{array}{c}-0,20977 \\
(0,017) \\
\end{array}$ & $\begin{array}{c}-0,17373 \\
(0,022) \\
\end{array}$ & $\begin{array}{c}-0,10920 \\
(0,020) \\
\end{array}$ & $\begin{array}{c}-0,11062 \\
(0,025) \\
\end{array}$ \\
\hline \multirow[t]{3}{*}{$\Delta \mathrm{D}$} & $\begin{array}{l}\text { Variação no Índice de } \\
\text { desigualdade de renda }\end{array}$ & $\begin{array}{l}1,54098 \\
(0,131) \\
\end{array}$ & $\begin{array}{r}0,50507 \\
(0,043) \\
\end{array}$ & & \\
\hline & $\Delta \mathrm{G} . \mathrm{E}_{\mathrm{G}}$ & $\begin{array}{c}-0,98615 \\
(0,072) \\
\end{array}$ & $\begin{array}{c}-1,07840 \\
(0,096) \\
\end{array}$ & $\begin{array}{c}-1,17035 \\
(0,080) \\
\end{array}$ & $\begin{array}{c}-1,24997 \\
(0,102) \\
\end{array}$ \\
\hline & $\Delta \mathrm{D} . \mathrm{E}_{\mathrm{D}}$ & & & $\begin{array}{c}0,62068 \\
(0,064) \\
\end{array}$ & $\begin{array}{l}1,04625 \\
(0,115)\end{array}$ \\
\hline \multirow{2}{*}{\multicolumn{2}{|c|}{$\frac{R^{2}}{n^{\circ} d e}$}} & 0,4689 & 0,3972 & 0,6094 & 0,5105 \\
\hline & & & & \multicolumn{2}{|c|}{4288} \\
\hline
\end{tabular}

Obs.: (1) Os valores entre parênteses abaixo de cada coeficiente correspondem ao respectivo desvio-padrão.

(2) Todas as estimações usam White robusto para heterocedasticidade.

Tabela 20.B - Teste dos Coeficientes dos Termos das Elasticidades

\begin{tabular}{ccccc}
\hline \multirow{2}{*}{ Variável } & \multicolumn{4}{c}{$\mathrm{p}$-valor } \\
\cline { 2 - 5 } & \multicolumn{2}{c}{ Equação (19) } & \multicolumn{2}{c}{ Equação (21) } \\
\cline { 2 - 5 } & com Gini & com Theil & com Gini & com Theil \\
\hline$\Delta$ G.E $_{\mathrm{G}}$ & 0,8481 & 0,4130 & 0,0322 & 0,0144 \\
\hline$\Delta \mathrm{D} . \mathrm{E}_{\mathrm{D}}$ & & & 0,0000 & 0,6870 \\
\hline
\end{tabular}

Obs.: (1) Hipóteses Nulas: Coeficiente da Elasticidade-Renda $=-1$

e Coeficiente da Elasticidade-Desigualdade $=1$.

Tabela 21.B - Estimações em Logaritmo da Incidência da Pobreza em Renda, Desigualdade e Linha Híbrida

\begin{tabular}{|c|c|c|c|c|c|c|c|c|}
\hline \multirow{3}{*}{$\begin{array}{l}\text { Variável dependente: } \\
\text { Proporção de Pobres }\end{array}$} & \multicolumn{4}{|c|}{ Efeitos Fixos } & \multicolumn{4}{|c|}{ Efeitos Aleatórios } \\
\hline & \multicolumn{2}{|c|}{ Zh30 } & \multicolumn{2}{|c|}{ Zh50 } & \multicolumn{2}{|c|}{ Zh30 } & \multicolumn{2}{|c|}{ Zh50 } \\
\hline & com Gini & com Theil & com Gini & com Theil & com Gini & com Theil & com Gini & com Theil \\
\hline Intercepto & $\begin{array}{l}1,6417 \\
(0.093)\end{array}$ & $\begin{array}{l}1,8211 \\
(0,112)\end{array}$ & $\begin{array}{l}0,3477 \\
(0,056)\end{array}$ & $\begin{array}{l}0,6899 \\
(0.068)\end{array}$ & $\begin{array}{l}1,5336 \\
(0.020)\end{array}$ & $\begin{array}{l}0,8845 \\
(0,023)\end{array}$ & $\begin{array}{l}0,6314 \\
(0.014)\end{array}$ & $\begin{array}{l}0,2459 \\
(0.017)\end{array}$ \\
\hline Renda Familiar per Capita & $\begin{array}{l}-1,1420 \\
(0,032)\end{array}$ & $\begin{array}{l}-0,7742 \\
(0,041)\end{array}$ & $\begin{array}{l}-1,0261 \\
(0,023)\end{array}$ & $\begin{array}{l}-0,8034 \\
(0,027)\end{array}$ & $\begin{array}{l}-1,3934 \\
(0,018)\end{array}$ & $\begin{array}{l}-1,2874 \\
(0,022)\end{array}$ & $\begin{array}{r}-1,1231 \\
(0,011)\end{array}$ & $\begin{array}{l}-1,0626 \\
(0,014)\end{array}$ \\
\hline $\begin{array}{c}\text { Indice de Desigualdade de } \\
\text { Renda }\end{array}$ & $\begin{array}{l}1,9509 \\
(0,034)\end{array}$ & $\begin{array}{l}0,5922 \\
(0,011)\end{array}$ & $\begin{array}{l}1,3058 \\
(0,019)\end{array}$ & $\begin{array}{l}0,4173 \\
(0,007)\end{array}$ & $\begin{array}{l}2,1649 \\
(0,025)\end{array}$ & $\begin{array}{l}0,6838 \\
(0,010)\end{array}$ & $\begin{array}{l}1,4643 \\
(0,013)\end{array}$ & $\begin{array}{l}0,4855 \\
(0,005)\end{array}$ \\
\hline Linha Híbrida de Pobreza & $\begin{array}{l}0,9989 \\
(0,047)\end{array}$ & $\begin{array}{l}0,2702 \\
(0,062)\end{array}$ & $\begin{array}{l}1,0853 \\
(0,031)\end{array}$ & $\begin{array}{l}0,6147 \\
(0,037)\end{array}$ & $\begin{array}{l}1,3767 \\
(0,023)\end{array}$ & $\begin{array}{l}1,1641 \\
(0,030)\end{array}$ & $\begin{array}{l}1,1564 \\
(0,015)\end{array}$ & $\begin{array}{l}1,0274 \\
(0,019)\end{array}$ \\
\hline Dummy do ano de 1991 & $\begin{array}{l}0,0883 \\
(0,004)\end{array}$ & $\begin{array}{l}0,0208 \\
(0,006)\end{array}$ & $\begin{array}{l}0,1142 \\
(0,003)\end{array}$ & $\begin{array}{l}0,0502 \\
(0,004)\end{array}$ & $\begin{array}{l}0,0890 \\
(0,003)\end{array}$ & $\begin{array}{l}0,0346 \\
(0,003)\end{array}$ & $\begin{array}{l}0,1048 \\
(0,002)\end{array}$ & $\begin{array}{l}0,0644 \\
(0,002)\end{array}$ \\
\hline $\mathrm{R}^{2}$ & 0,7967 & 0,6743 & 0,8460 & 0,7667 & 0,7929 & 0,6505 & 0,8430 & 0,7554 \\
\hline $\mathrm{n}^{\circ} \mathrm{de}$ & & & & & & & & \\
\hline
\end{tabular}

Obs.: (1) Os valores entre parênteses abaixo de cada coeficiente correspondem ao respectivo desvio-padrão.

(2) Todas as estimações usam White robusto para heterocedasticidade.

(3) As colunas Zh30 e Zh50 indicam os valores correspondentes às linhas híbridas considerando linhas relativas de $30 \%$ e $50 \%$ da renda média, respectivamente. 
Tabela 22.B - Testes de Verificação dos Métodos Aplicados

\begin{tabular}{|c|c|c|c|c|c|c|c|c|}
\hline \multirow{3}{*}{ Testes } & \multicolumn{4}{|c|}{ Zh30 } & \multicolumn{4}{|c|}{ Zh50 } \\
\hline & \multicolumn{2}{|c|}{ com Gini } & \multicolumn{2}{|c|}{ com Theil } & \multicolumn{2}{|c|}{ com Gini } & \multicolumn{2}{|c|}{ com Theil } \\
\hline & Qui-Quadrado & p-valor & Qui-Quadrado & p-valor & Qui-Quadrado & p-valor & Qui-Quadrado & p-valor \\
\hline $\begin{array}{c}\text { Wald modificado para } \\
\text { heterocedasticidade em Efeitos Fixos }\end{array}$ & $4,4 \mathrm{E}+32$ & 0,000 & $1,4 \mathrm{E}+33$ & 0,000 & $0,0 \mathrm{E}+00$ & 1,000 & $0,0 \mathrm{E}+00$ & 1,000 \\
\hline $\begin{array}{c}\text { Breuch Pagan - existência de efeito } \\
\text { individual não observado }\end{array}$ & 206 & 0,000 & 336 & 0,000 & 400 & 0,000 & 459 & 0,000 \\
\hline Hausman & 209 & 0,000 & 540 & 0,000 & 144 & 0,000 & 323 & 0,000 \\
\hline
\end{tabular}

Obs.: (1) Os valores entre parênteses abaixo de cada coeficiente correspondem ao respectivo desvio-padrão.

(2) Todas as estimações usam White robusto para heterocedasticidade.

(3) As colunas Zh30 e Zh50 indicam os valores correspondentes às linhas híbridas considerando linhas relativas de $30 \%$ e $50 \%$ da renda média, respectivamente.

Tabela 23.B - Estimações em Logaritmo da Incidência da Pobreza em Renda, Desigualdade e Linha Híbrida por MQVD com Peso

\begin{tabular}{ccccc}
\hline \multirow{2}{*}{$\begin{array}{c}\text { Variável dependente: } \\
\text { Proporção de Pobres }\end{array}$} & \multicolumn{3}{c}{ Zh30 } & \multicolumn{2}{c}{ Zh50 } \\
\cline { 2 - 5 } Intercepto & 2,0601 & 2,0738 & 0,7431 & 0,9948 \\
& $(0,331)$ & $(0,352)$ & $(0,111)$ & $(0,139)$ \\
\hline \multirow{2}{*}{ Renda Familiar per Capita } & $-1,0533$ & $-0,6584$ & $-0,9155$ & $-0,6818$ \\
& $(0,085)$ & $(0,107)$ & $(0,047)$ & $(0,054)$ \\
\hline \multirow{2}{*}{ Índice de Desigualdade de Renda } & 2,0933 & 0,6653 & 1,3680 & 0,4553 \\
& $(0,112)$ & $(0,035)$ & $(0,035)$ & $(0,013)$ \\
\hline \multirow{2}{*}{ Linha Híbrida de Pobreza } & 0,8012 & 0,0630 & 0,8734 & 0,4043 \\
& $(0,160)$ & $(0,205)$ & $(0,069)$ & $(0,082)$ \\
\hline \multirow{2}{*}{ Dummy do ano de 1991 } & 0,0959 & 0,0403 & 0,1130 & 0,0559 \\
& $(0,008)$ & $(0,011)$ & $(0,005)$ & $(0,007)$ \\
\hline $\mathrm{R}^{2}$ Ajustado & 0,8492 & 0,7954 & 0,9285 & 0,8916 \\
\hline $\mathrm{n}^{\circ}$ de observações & \multicolumn{3}{c}{8576} & \multicolumn{3}{c}{8576} \\
\hline
\end{tabular}

Obs.: (1) MQVD corresponde ao método de Mínimos Quadrados com Variáveis Dummy considerando os dois anos (1991 e 2000).

(2) Os valores entre parênteses abaixo de cada coeficiente correspondem ao respectivo desvio-padrão.

(3) Todas as estimações usam White robusto para heterocedasticidade.

(4) As colunas Zh30 e Zh50 indicam os valores correspondentes às linhas híbridas considerando linhas relativas de $30 \%$ e $50 \%$ da renda média, respectivamente.

Tabela 24.B - Cálculo da Elasticidade-Renda da Pobreza $\left(\varepsilon_{r}\right)$

\begin{tabular}{|c|c|c|c|c|c|c|c|}
\hline \multirow{2}{*}{$\begin{array}{l}\text { Linha } \\
\text { Híbrida }\end{array}$} & \multirow{2}{*}{$\begin{array}{c}\text { Índice de } \\
\text { Desigualdade }\end{array}$} & \multirow{2}{*}{$\beta_{1}$} & \multirow{2}{*}{$\beta_{3}$} & \multicolumn{2}{|c|}{1991} & \multicolumn{2}{|c|}{2000} \\
\hline & & & & $\rho_{t}$ & $\varepsilon_{\mathrm{r}}$ & $\rho_{t}$ & $\varepsilon_{\mathrm{r}}$ \\
\hline $\begin{array}{l}\text { Zh30 } \\
\text { Zh50 }\end{array}$ & Gini & $\begin{array}{l}-1,05333 \\
-0,91554\end{array}$ & $\begin{array}{l}0,80117 \\
0,87337\end{array}$ & 0,59766 & $\begin{array}{l}-0,57450 \\
-0,39356\end{array}$ & 0,66288 & $\begin{array}{l}-0,52225 \\
-0,33660\end{array}$ \\
\hline $\begin{array}{l}\text { Zh30 } \\
\text { Zh50 }\end{array}$ & Theil & $\begin{array}{l}-0,65843 \\
-0,68183\end{array}$ & $\begin{array}{l}0,06296 \\
0,40427\end{array}$ & 0,59766 & $\begin{array}{l}-0,62081 \\
-0,44021\end{array}$ & 0,66288 & $\begin{array}{l}-0,61670 \\
-0,41384\end{array}$ \\
\hline
\end{tabular}

Obs.: (1) As linhas Zh30 e Zh50 indicam os valores correspondentes às linhas híbridas considerando linhas relativas de $30 \%$ e $50 \%$ da renda média, respectivamente.

(2) As colunas $\beta_{1}$ e $\beta_{3}$ correspondem aos coeficientes da Renda Familiar per Capita e Linha Híbrida de Pobreza da Tabela 23, respectivamente.

(3) As colunas $\rho_{\mathrm{t}}$ correspondem aos valores da elasticidade-renda da linha de pobreza calculados no capítulo anterior e apresentados na Tabela 6. 


\section{d) Resultados para o Apêndice B}

Tabela B3.B - Regressão Hedônica

\begin{tabular}{|c|c|c|c|c|c|c|c|c|c|c|c|c|}
\hline \multirow{4}{*}{$\begin{array}{l}\text { Ano: } \\
\text { Modelo: } \\
\text { Variável Dependente: }\end{array}$} & \multicolumn{6}{|c|}{1991} & \multicolumn{6}{|c|}{2000} \\
\hline & \multirow{2}{*}{\multicolumn{2}{|c|}{$\frac{\text { Linear }}{\text { Aluguel }}$}} & \multirow{2}{*}{\multicolumn{2}{|c|}{$\frac{\text { Log-Linear }}{\text { Ln(Aluguel) }}$}} & \multirow{2}{*}{\multicolumn{2}{|c|}{$\begin{array}{c}\text { Duplo-Log } \\
\text { Ln(Aluguel) }\end{array}$}} & \multirow{2}{*}{\multicolumn{2}{|c|}{$\begin{array}{l}\text { Linear } \\
\text { Aluguel }\end{array}$}} & \multirow{2}{*}{\multicolumn{2}{|c|}{$\begin{array}{l}\text { Log-Linear } \\
\text { Ln(Aluguel) }\end{array}$}} & \multirow{2}{*}{\multicolumn{2}{|c|}{ Duplo-Log }} \\
\hline & & & & & & & & & & & & \\
\hline & Coeficiente & $\begin{array}{l}\text { desvio- } \\
\text { padrão }\end{array}$ & Coeficiente & \multirow[t]{2}{*}{$\begin{array}{l}\text { desvio- } \\
\text { padrão }\end{array}$} & \multirow[t]{2}{*}{ Coeficiente } & \multirow[t]{2}{*}{$\begin{array}{l}\text { desvio- } \\
\text { padrão }\end{array}$} & Coeficiente & \multirow[t]{2}{*}{$\begin{array}{l}\text { desvio- } \\
\text { padrão }\end{array}$} & Coeficiente & \multirow[t]{2}{*}{$\begin{array}{l}\text { desvio- } \\
\text { padrão }\end{array}$} & Coeficiente & $\begin{array}{l}\text { desvio- } \\
\text { padrão }\end{array}$ \\
\hline ariáveis Ir & & & & & & & & & & & & \\
\hline Intercepto & 75,279 & 0,844 & 2,572 & 0,006 & 2,749 & 0,007 & 69,622 & 0,627 & 2,788 & 0,005 & 2,965 & 0,005 \\
\hline Casa & $-127,891$ & 0,316 & $-0,507$ & 0,001 & $-0,536$ & 0,001 & $-127,900$ & 0,316 & $-0,507$ & 0,0009 & $-0,536$ & 0,0009 \\
\hline Quartos & 45,196 & 0,149 & 0,166 & 0,0005 & & & 45,193 & 0,149 & 0,166 & 0,0005 & & \\
\hline Ln(Quartos) & & & & & 0,286 & 0,001 & & & & & 0,287 & 0,0008 \\
\hline Outros Cômodos & 47,435 & 0,120 & 0,161 & 0,0003 & & & 47,425 & 0,120 & 0,161 & 0,0003 & & \\
\hline Ln(Outros Cômodos) & & & & & 0,508 & 0,001 & & & & & 0,510 & 0,0008 \\
\hline Paredes & $-5,759$ & 0,340 & 0,236 & 0,003 & 0,242 & 0,004 & & & & & & \\
\hline Telhado & $-1,127$ & 0,544 & 0,030 & 0,004 & 0,022 & 0,004 & & & & & & \\
\hline Banheiro & $-27,564$ & 0,213 & 0,070 & 0,001 & 0,026 & 0,001 & $-27,696$ & 0,213 & 0,076 & 0,001 & 0,031 & 0,001 \\
\hline Água & $-6,766$ & 0,183 & 0,315 & 0,001 & 0,317 & 0,001 & $-6,967$ & 0,184 & 0,323 & 0,001 & 0,325 & 0,001 \\
\hline Esgoto & 20,566 & 0,151 & 0,205 & 0,001 & 0,207 & 0,001 & 20,540 & 0,151 & 0,206 & 0,0009 & 0,208 & 0,0010 \\
\hline Lixo & 27,798 & 0,146 & 0,342 & 0,001 & 0,353 & 0,001 & 27,686 & 0,146 & 0,346 & 0,001 & 0,356 & 0,001 \\
\hline Eletricidade & $-17,409$ & 0,316 & 0,366 & 0,003 & 0,354 & 0,004 & $-18,074$ & 0,315 & 0,393 & 0,003 & 0,380 & 0,004 \\
\hline Região Metropolitana & 73,112 & 0,194 & 0,359 & 0,001 & 0,357 & 0,001 & 73,105 & 0,194 & 0,359 & 0,0008 & 0,358 & 0,0008 \\
\hline Urbano & 32,694 & 0,374 & 0,542 & 0,004 & 0,567 & 0,004 & 32,646 & 0,374 & 0,544 & 0,004 & 0,570 & 0,004 \\
\hline Dummy RO & $-56,180$ & 0,745 & $-0,160$ & 0,004 & $-0,150$ & 0,004 & $-56,320$ & 0,745 & $-0,154$ & 0,004 & $-0,145$ & 0,004 \\
\hline Dummy AC & $-35,398$ & 1,565 & $-0,140$ & 0,015 & $-0,150$ & 0,018 & $-34,956$ & 1,520 & $-0,148$ & 0,015 & $-0,155$ & 0,018 \\
\hline Dummy AM & 60,711 & 1,344 & 0,397 & 0,004 & 0,405 & 0,004 & 61,119 & 1,247 & 0,387 & 0,004 & 0,397 & 0,004 \\
\hline Dummy RR & 31,840 & 2,244 & 0,389 & 0,009 & 0,443 & 0,010 & 31,835 & 2,244 & 0,390 & 0,009 & 0,442 & 0,010 \\
\hline Dummy PA & $-61,794$ & 0,582 & $-0,308$ & 0,004 & $-0,317$ & 0,004 & $-61,769$ & 0,582 & $-0,309$ & 0,004 & $-0,319$ & 0,004 \\
\hline y AP & 44,315 & 2,503 & 0,455 & 0,0 & 0,449 & 0,012 & 44,321 & 2,503 & 0,456 & 0 , & 0,451 & 0,012 \\
\hline Dummy TO & $-25,394$ & 1,165 & 0,141 & 0,005 & 0,156 & 0,006 & $-25,364$ & 1,164 & 0,140 & 0,005 & 0,155 & 0,006 \\
\hline Dummy MA & $-74,381$ & 0,561 & $-0,254$ & 0,004 & $-0,257$ & 0,004 & $-73,415$ & & $-0,293$ & 0, & $-0,294$ & 0,004 \\
\hline $\mathrm{PI}$ & $-118,786$ & 0,6 & $-0,673$ & 0, & $-0,663$ & 0 & 399 & 56 & $-0,688$ & 0 & $-0,677$ & 0,004 \\
\hline Dummy CE & $-138,622$ & 0,364 & $-0,731$ & 0,002 & $-0,716$ & 0,002 & $-138,591$ & 0,364 & $-0,733$ & 0,002 & $-0,717$ & 0,002 \\
\hline Dummy RN & $-74,302$ & 0,518 & $-0,422$ & 0,003 & $-0,414$ & 0,004 & $-74,272$ & 0,518 & $-0,424$ & 0,003 & $-0,416$ & 0,004 \\
\hline y PB & ,920 & 0,476 & $-0,640$ & 0, & $-0,628$ & 0,003 & ,758 & 0,475 & $-0,647$ & 0,003 & $-0,634$ & 0,003 \\
\hline Dummy PE & $-113,471$ & 0,400 & $-0,570$ & 0,002 & $-0,565$ & 0,002 & $-113,347$ & 0,399 & $-0,575$ & 0,002 & $-0,570$ & 0,002 \\
\hline Dummy AL & $-70,395$ & 0,477 & $-0,237$ & 0,003 & $-0,245$ & 0,003 & $-70,018$ & 0,475 & $-0,253$ & 0,003 & $-0,260$ & 0,003 \\
\hline Dummy SE & $-63,890$ & 0,568 & $-0,198$ & 0,004 & $-0,183$ & 0,004 & $-63,818$ & 0,568 & $-0,201$ & 0,004 & $-0,186$ & 0,004 \\
\hline Dummy BA & $-104,404$ & 0,352 & $-0,529$ & 0,002 & $-0,528$ & 0,002 & $-104,356$ & 0,352 & $-0,531$ & 0,002 & $-0,531$ & 0,002 \\
\hline Dummy MG & $-92,093$ & 0,262 & $-0,386$ & 0,001 & $-0,377$ & 0,001 & $-92,131$ & 0,262 & $-0,384$ & 0,0012 & $-0,376$ & 0,0012 \\
\hline Dummy ES & $-88,794$ & 0,473 & $-0,330$ & 0,003 & $-0,331$ & 0,003 & $-88,799$ & 0,473 & $-0,330$ & 0,003 & $-0,331$ & 0,003 \\
\hline Dummy RJ & $-92,931$ & 0,296 & $-0,443$ & 0,001 & $-0,457$ & 0,001 & $-92,944$ & 0,296 & $-0,442$ & 0,001 & $-0,456$ & 0,0011 \\
\hline Dummy PR & $-89,950$ & 0,295 & $-0,386$ & 0,001 & $-0,371$ & 0,001 & $-89,989$ & 0,295 & $-0,384$ & 0,001 & $-0,370$ & 0,001 \\
\hline Dummy SC & $-76,433$ & 0,435 & $-0,260$ & 0,003 & $-0,241$ & 0,003 & $-76,449$ & 0,435 & $-0,259$ & 0,003 & $-0,241$ & 0,003 \\
\hline Dummy RS & $-110,320$ & 0,317 & $-0,445$ & 0,001 & $-0,447$ & 0,001 & $-110,272$ & 0,314 & $-0,446$ & 0,001 & $-0,448$ & 0,001 \\
\hline Dummy MS & $-40,508$ & 0,540 & $-0,066$ & 0,003 & $-0,056$ & 0,003 & $-40,550$ & 0,540 & $-0,064$ & 0,003 & $-0,054$ & 0,003 \\
\hline Dummy MT & $-24,390$ & 0,634 & 0,075 & 0,003 & 0,089 & 0,003 & $-24,485$ & 0,634 & 0,079 & 0,003 & 0,092 & 0,003 \\
\hline Dummy GO & $-39,612$ & 0,366 & $-0,009$ & 0,002 & 0,000 & 0,002 & $-39,678$ & 0,366 & $-0,007$ & 0,002 & 0,002 & 0,002 \\
\hline Dummy DF & 73,131 & 0,971 & 0,330 & 0,002 & 0,344 & 0,002 & 73,174 & 0,971 & 0,328 & 0,002 & 0,342 & 0,002 \\
\hline $\mathrm{R}^{2}$ ajustado & 0,377 & & 0,463 & & 0,440 & & 0,377 & & 0,463 & & 0,44 & \\
\hline $\begin{array}{l}\text { n (número de } \\
\text { observações) }\end{array}$ & 5.38 & 8 & 5.381 & 018 & 5.22 & & 5.38 & & 5.38 & 018 & 5.222. & \\
\hline
\end{tabular}

Obs.: (1) A Dummy SP (Estado de São Paulo) foi retirada da regressão para evitar o problema de multicolinearidade perfeita. Portanto, é a variável de estado referência.

(2) Todas as estimações usam White robusto para heterocedasticidade. 
Tabela B4.B - Estatística Descritiva do Aluguel Implícito Familiar per Capita

\begin{tabular}{|c|c|c|c|c|c|c|c|c|c|c|}
\hline \multirow{2}{*}{$\begin{array}{l}\text { Unidade da } \\
\text { Federação }\end{array}$} & \multicolumn{5}{|c|}{1991} & \multicolumn{5}{|c|}{2000} \\
\hline & $\begin{array}{c}\text { Número de } \\
\text { Observações }\end{array}$ & Média & $\begin{array}{l}\text { Desvio- } \\
\text { Padrão }\end{array}$ & Mínimo & Máximo & $\begin{array}{c}\text { Número de } \\
\text { Observações }\end{array}$ & Média & $\begin{array}{l}\text { Desvio- } \\
\text { Padrão }\end{array}$ & Mínimo & Máximo \\
\hline RO & 769.785 & 21,62 & 6,55 & 8,34 & 30,23 & 977.599 & 28,95 & 6,30 & 15,07 & 36,79 \\
\hline$A C$ & 307.279 & 19,34 & 6,90 & 6,97 & 25,03 & 426.780 & 21,70 & 6,90 & 8,66 & 27,73 \\
\hline AM & 1.577 .796 & 33,20 & 18,48 & 5,56 & 51,94 & 2.105 .600 & 38,87 & 19,87 & 9,22 & 59,16 \\
\hline $\mathrm{RR}$ & 147.721 & 37,01 & 12,41 & 14,12 & 44,61 & 244.019 & 49,63 & 15,65 & 18,87 & 60,53 \\
\hline PA & 3.409 .064 & 17,64 & 13,49 & 3,04 & 41,03 & 4.496 .258 & 22,74 & 15,84 & 4,41 & 51,30 \\
\hline AP & 204.486 & 36,54 & 10,27 & 13,89 & 43,92 & 343.898 & 45,01 & 9,08 & 18,32 & 50,60 \\
\hline TO & 621.184 & 21,99 & 8,91 & 9,35 & 40,03 & 807.536 & 40,10 & 13,19 & 18,64 & 57,95 \\
\hline MA & 3.362 .982 & 13,00 & 5,65 & 4,03 & 21,28 & 4.058 .786 & 18,54 & 7,98 & 6,45 & 31,39 \\
\hline PI & 1.532 .545 & 13,45 & 6,81 & 2,93 & 23,67 & 1.700 .885 & 18,08 & 6,54 & 7,03 & 28,23 \\
\hline CE & 3.606 .554 & 19,76 & 13,73 & 3,52 & 40,76 & 4.462 .019 & 24,98 & 14,73 & 5,54 & 47,67 \\
\hline RN & 1.637 .866 & 22,84 & 10,52 & 6,57 & 38,36 & 1.849 .121 & 28,00 & 10,94 & 8,44 & 44,64 \\
\hline PB & 1.873 .213 & 17,69 & 9,41 & 4,19 & 34,41 & 2.051 .370 & 22,73 & 9,13 & 8,79 & 38,84 \\
\hline PE & 4.418 .487 & 26,71 & 16,91 & 4,65 & 56,48 & 5.191 .680 & 31,92 & 15,51 & 9,65 & 58,21 \\
\hline$A L$ & 1.486 .094 & 23,87 & 11,73 & 5,46 & 41,00 & 1.775 .679 & 29,58 & 12,10 & 10,62 & 46,37 \\
\hline SE & 1.145 .666 & 28,23 & 13,68 & 8,79 & 50,22 & 1.289 .183 & 35,73 & 15,14 & 12,74 & 61,18 \\
\hline BA & 8.413 .881 & 19,85 & 14,63 & 4,16 & 49,71 & 9.293 .804 & 26,92 & 16,56 & 6,62 & 59,26 \\
\hline MG & 9.992 .974 & 40,14 & 22,66 & 5,97 & 92,09 & 8.821 .208 & 56,62 & 23,59 & 11,84 & 102,88 \\
\hline ES & 1.663 .067 & 37,61 & 13,27 & 15,41 & 64,32 & 1.978 .971 & 48,77 & 14,02 & 22,71 & 80,58 \\
\hline $\mathrm{RJ}$ & 7.534 .693 & 59,35 & 25,53 & 18,31 & 101,86 & 9.303 .559 & 64,33 & 21,68 & 22,49 & 109,03 \\
\hline SP & 18.554 .081 & 81,56 & 25,36 & 18,24 & 133,04 & 20.281 .499 & 92,52 & 24,86 & 26,49 & 150,84 \\
\hline PR & 5.141 .971 & 43,51 & 26,25 & 7,98 & 96,96 & 5.316 .980 & 54,86 & 27,98 & 15,33 & 113,91 \\
\hline $\mathrm{SC}$ & 3.238.194 & 43,13 & 14,84 & 11,24 & 76,31 & 3.658 .811 & 55,11 & 14,06 & 21,49 & 93,08 \\
\hline RS & 5.941 .011 & 47,07 & 24,82 & 9,26 & 103,66 & 6.339 .148 & 54,46 & 23,04 & 14,69 & 109,71 \\
\hline MS & 1.076 .920 & 41,80 & 10,53 & 16,81 & 54,01 & 1.165 .646 & 51,59 & 11,93 & 22,03 & 65,91 \\
\hline MT & 1.365 .950 & 36,81 & 14,28 & 11,99 & 57,66 & 1.582 .289 & 48,80 & 13,56 & 17,82 & 67,43 \\
\hline GO & 2.502 .692 & 45,01 & 16,93 & 10,39 & 70,06 & 2.966 .020 & 59,89 & 16,87 & 21,09 & 84,94 \\
\hline DF & 985.042 & 100,81 & - & 100,81 & 100,81 & 1.018 .310 & 125,13 & - & 125,13 & 125,13 \\
\hline Brasil & 92.511 .198 & 44,27 & 30,87 & 2,93 & 133,04 & 103.506 .658 & 52,79 & 32,25 & 4,41 & 150,84 \\
\hline
\end{tabular}

Obs.: $\quad$ Aluguel implícito familiar per capita em Reais (R\$) de julho de 2000.

e) Resultados para o Apêndice C

Tabela C1.B - Estatísticas Descritivas das Principais Variáveis

\begin{tabular}{|c|c|c|c|c|c|c|c|c|}
\hline \multirow[b]{2}{*}{ Variável } & \multicolumn{4}{|c|}{1991} & \multicolumn{4}{|c|}{2000} \\
\hline & Média & $\begin{array}{l}\text { Desvio- } \\
\text { Padrão }\end{array}$ & Mínimo & Máximo & Média & $\begin{array}{l}\text { Desvio- } \\
\text { Padrão }\end{array}$ & Mínimo & Máximo \\
\hline Renda Familiar per Capita & 253.35 & 161.99 & 25.23 & 688.93 & 326.23 & 189.38 & 43.44 & 959.44 \\
\hline Índice de Desigualdade de Gini & 0.535 & 0.057 & 0.328 & 0.760 & 0.559 & 0.053 & 0.342 & 0.785 \\
\hline Índice de Desigualdade de Theil & 0.588 & 0.154 & 0.178 & 1.906 & 0.634 & 0.156 & 0.189 & 2.395 \\
\hline Linha Absoluta de Pobreza Za & 91.08 & 31.79 & 44.45 & 162.51 & 97.32 & 35.10 & 49.94 & 172.38 \\
\hline Linha Híbrida de Pobreza Zh30 & 79.63 & 40.59 & 17.05 & 175.30 & 95.71 & 46.56 & 20.95 & 234.30 \\
\hline Linha Híbrida de Pobreza Zh50 & 108.06 & 55.08 & 23.13 & 237.89 & 134.28 & 65.33 & 29.39 & 328.72 \\
\hline Número de Pobres considerando Za & 14,806 & 58,231 & 109 & $2,366,569$ & 12,362 & 56,474 & - & $2,750,497$ \\
\hline Número de Pobres considerando Zh30 & 10,350 & 53,437 & 97 & $2,357,082$ & 10,694 & 61,997 & - & $3,065,747$ \\
\hline Número de Pobres considerando Zh50 & 14,618 & 74,457 & 239 & $3,415,512$ & 15,575 & 88,236 & 211 & $4,374,021$ \\
\hline Incidência da Pobreza considerando Za & 0.437 & 0.219 & 0.031 & 0.960 & 0.314 & 0.164 & 0.000 & 0.817 \\
\hline Incidência da Pobreza considerando Zh30 & 0.306 & 0.100 & 0.045 & 0.649 & 0.272 & 0.079 & 0.001 & 0.561 \\
\hline Incidência da Pobreza considerando Zh50 & 0.432 & 0.109 & 0.094 & 0.763 & 0.396 & 0.083 & 0.082 & 0.672 \\
\hline Elasticidade-Renda da Pobreza com Gini & $(1.017)$ & 0.426 & $(0.141)$ & (3.878) & $(1.044)$ & 0.377 & $(0.227)$ & $(4.037)$ \\
\hline Elasticidade-Renda da Pobreza com Theil & $(0.959)$ & 0.406 & $(0.162)$ & $(3.423)$ & $(1.003)$ & 0.359 & $(0.180)$ & (3.855) \\
\hline Elasticidade-Desigualdade da Pobreza com Gini & 3.762 & 2.409 & $(0.238)$ & 13.235 & 4.553 & 2.427 & 0.216 & 16.660 \\
\hline Elasticidade-Desigualdade da Pobreza com Theil & 0.757 & 0.493 & $(0.054)$ & 2.867 & 0.905 & 0.494 & 0.030 & 3.493 \\
\hline População & 33,877 & 189,012 & $715^{\prime}$ & $9,452,474$ & 39,314 & 210,811 & 499 & $10,338,500$ \\
\hline População Feminina & 17,103 & 98,094 & 364 & $4,886,388$ & 19,952 & 110,322 & 215 & $5,400,929$ \\
\hline População sem Raça Branca & 16,392 & 75,868 & - & $2,896,545$ & 18,172 & 86,494 & - & $3,403,414$ \\
\hline Idade & 25.97 & 2.48 & 17.32 & 34.49 & 28.22 & 2.55 & 18.08 & 38.26 \\
\hline Anos de Estudo & 3.79 & 1.40 & 0.35 & 7.02 & 4.95 & 1.35 & 1.11 & 7.99 \\
\hline
\end{tabular}

Obs.: $\quad$ (1) A renda familiar per capita e as linhas de pobreza estão em Reais (R\$) de julho de 2000.

(2) As colunas Za correspondem aos valores considerando as linhas absolutas de pobreza.

(3) As colunas Zh30 e Zh50 indicam os valores correspondentes às linhas híbridas considerando linhas relativas de $30 \%$ e $50 \%$ da renda média dos estratos, respectivamente. 
D.2.2 - Utilização das PNAD's de 1990, 1992, 1999 e 2001

a) Resultados para o Capítulo 2

Tabela 1.C - Estatísticas Básicas da Variável Renda Familiar per Capita

\begin{tabular}{|c|c|c|c|c|c|c|c|c|c|}
\hline \multirow{2}{*}{$\begin{array}{c}\text { Região } \\
\text { Geográfica }\end{array}$} & \multirow[b]{2}{*}{ Estado } & \multicolumn{4}{|c|}{1991} & \multicolumn{4}{|c|}{2000} \\
\hline & & Média & $\begin{array}{l}\text { Desvio- } \\
\text { Padrão }\end{array}$ & Mínimo & Máximo & Média & $\begin{array}{l}\text { Desvio- } \\
\text { Padrão }\end{array}$ & Mínimo & Máximo \\
\hline \multirow{7}{*}{ Norte } & $\mathrm{RO}$ & 164,88 & 60,10 & 61,88 & 254,86 & 249,56 & 46,81 & 131,73 & 305,10 \\
\hline & $A C$ & 155,36 & 61,68 & 66,70 & 210,61 & 201,47 & 71,53 & 76,16 & 262,78 \\
\hline & AM & 189,40 & 101,36 & 39,79 & 292,99 & 187,75 & 96,99 & 40,49 & 282,56 \\
\hline & $\mathrm{RR}$ & 293,55 & 71,56 & 124,57 & 333,46 & 252,55 & 80,34 & 87,55 & 307,07 \\
\hline & PA & 149,09 & 80,48 & 51,99 & 299,91 & 180,21 & 88,93 & 54,36 & 333,54 \\
\hline & AP & 204,47 & 47,87 & 87,43 & 239,21 & 233,55 & 51,27 & 96,90 & 276,77 \\
\hline & TO & 132,57 & 61,02 & 45,99 & 261,18 & 188,55 & 86,61 & 69,11 & 374,85 \\
\hline \multirow{9}{*}{ Nordeste } & $\mathrm{MA}$ & 84,80 & 51,35 & 31,53 & 199,21 & 119,52 & 69,63 & 42,28 & 264,06 \\
\hline & $\mathrm{PI}$ & 90,94 & 53,00 & 28,14 & 180,09 & 138,00 & 73,04 & 46,29 & 254,32 \\
\hline & $\mathrm{CE}$ & 117,60 & 79,02 & 24,83 & 242,06 & 170,96 & 106,60 & 49,04 & 333,54 \\
\hline & $\mathrm{RN}$ & 132,93 & 85,38 & 33,09 & 272,46 & 192,05 & 109,70 & 46,52 & 361,77 \\
\hline & PB & 104,12 & 73,06 & 24,08 & 256,12 & 163,70 & 101,15 & 56,33 & 353,26 \\
\hline & PE & 148,12 & 94,21 & 29,44 & 320,63 & 201,23 & 118,39 & 54,69 & 577,85 \\
\hline & $A L$ & 116,20 & 76,77 & 33,38 & 245,40 & 152,03 & 93,88 & 42,40 & 297,42 \\
\hline & SE & 138,94 & 88,47 & 48,93 & 282,54 & 179,57 & 116,78 & 55,16 & 374,84 \\
\hline & BA & 124,72 & 88,77 & 23,55 & 303,14 & 177,16 & 107,18 & 47,57 & 375,55 \\
\hline \multirow{4}{*}{ Sudeste } & MG & 209,36 & 112,84 & 44,94 & 446,24 & 301,54 & 148,20 & 66,18 & 607,18 \\
\hline & ES & 208,82 & 106,65 & 68,55 & 475,20 & 314,93 & 148,63 & 115,14 & 702,78 \\
\hline & RJ & 330,01 & 148,76 & 107,37 & 599,79 & 468,66 & 196,67 & 189,86 & 891,01 \\
\hline & SP & 406,89 & 135,04 & 88,24 & 672,21 & 491,86 & 155,70 & 124,16 & 960,89 \\
\hline \multirow{3}{*}{ Sul } & PR & 242,07 & 125,86 & 63,41 & 491,91 & 346,64 & 162,23 & 108,24 & 665,91 \\
\hline & SC & 251,77 & 102,32 & 85,98 & 516,13 & 382,13 & 132,01 & 125,75 & 751,91 \\
\hline & $\mathrm{RS}$ & 283,27 & 128,54 & 76,16 & 566,99 & 393,17 & 164,80 & 105,29 & 768,63 \\
\hline \multirow{4}{*}{ Centro-Oeste } & MS & 234,02 & 78,26 & 99,91 & 340,03 & 306,27 & 90,88 & 125,38 & 452,48 \\
\hline & MT & 216,42 & 76,53 & 78,86 & 338,95 & 304,74 & 96,24 & 127,18 & 485,37 \\
\hline & GO & 227,59 & 89,00 & 61,96 & 366,60 & 304,91 & 119,96 & 95,01 & 508,18 \\
\hline & DF & 500,04 & - & 500,04 & 500,04 & 632,51 & - & 632,51 & 632,51 \\
\hline Brasil & & 244,96 & 157,44 & 23,55 & 672,21 & 326,87 & 192,06 & 40,49 & 960,89 \\
\hline
\end{tabular}

Obs.: $\quad$ Renda familiar per capita em Reais (R\$) de julho de 2000. 
Tabela 3.C - Estatísticas Básicas do Número de Pobres

\begin{tabular}{|c|c|c|c|c|c|c|c|c|c|c|c|}
\hline \multirow[b]{2}{*}{$\begin{array}{l}\text { Região } \\
\text { Geográfica }\end{array}$} & \multirow[b]{2}{*}{ Estado } & \multicolumn{5}{|c|}{1991} & \multicolumn{5}{|c|}{2000} \\
\hline & & População & $n^{\circ}$ de pobres & $\begin{array}{l}\text { Desvio- } \\
\text { Padrão }\end{array}$ & Mínimo & Máximo & População & $\mathrm{n}^{\circ}$ de pobres & $\begin{array}{l}\text { Desvio- } \\
\text { Padrão }\end{array}$ & Mínimo & Máximo \\
\hline \multirow{7}{*}{ Norte } & $\overline{\mathrm{RO}}$ & 1.125 .046 & 550.377 & 23.654 & 3.982 & 90.198 & 1.369 .444 & 349.355 & 20.008 & 3.649 & 90.307 \\
\hline & AC & 414.102 & 224.265 & 32.418 & 1.350 & 98.599 & 555.471 & 215.643 & 29.647 & 1.649 & 91.715 \\
\hline & $A M$ & 2.087 .753 & 980.291 & 33.841 & 2.222 & 269.652 & 2.807 .323 & 1.322 .030 & 55.272 & 3.786 & 442.338 \\
\hline & RR & 211.419 & 81.709 & 19.399 & 5.689 & 48.856 & 322.523 & 100.063 & 20.015 & 11.936 & 54.768 \\
\hline & PA & 4.905 .433 & 2.794 .550 & 57.873 & 3.179 & 499.487 & 6.166 .634 & 2.701 .546 & 47.507 & 2.815 & 374.924 \\
\hline & AP & 286.673 & 120.015 & 21.161 & 2.883 & 63.674 & 474.658 & 177.913 & 33.742 & 3.525 & 100.956 \\
\hline & TO & 910.157 & 539.195 & 8.314 & 1.473 & 50.630 & 1.150 .882 & 470.266 & 8.017 & 879 & 43.154 \\
\hline \multirow{9}{*}{ Nordeste } & MA & 4.902 .860 & 3.539 .364 & 42.015 & 3.905 & 307.742 & 5.634 .915 & 3.213 .865 & 40.888 & 2.667 & 307.190 \\
\hline & PI & 2.558 .077 & 1.926 .840 & 43.670 & 1.142 & 351.653 & 2.826 .459 & 1.490 .432 & 33.978 & 672 & 268.804 \\
\hline & CE & 6.305 .476 & 4.561 .849 & 70.898 & 3.571 & 931.548 & 7.371 .074 & 3.738 .762 & 54.244 & 2.946 & 704.390 \\
\hline & $\mathrm{RN}$ & 2.392 .757 & 1.524 .567 & 21.506 & 964 & 237.530 & 2.766 .106 & 1.131 .187 & 16.184 & 833 & 181.415 \\
\hline & PB & 3.175 .867 & 2.306 .561 & 23.480 & 1.544 & 218.003 & 3.414 .992 & 1.570 .826 & 16.449 & 505 & 159.565 \\
\hline & PE & 7.077.995 & 4.976 .080 & 68.260 & 242 & 779.883 & 7.895 .020 & 3.950 .112 & 55.003 & 112 & 613.289 \\
\hline & $A L$ & 2.491 .971 & 1.671 .327 & 29.426 & 2.735 & 270.119 & 2.817 .468 & 1.471 .632 & 29.021 & 1.875 & 274.747 \\
\hline & SE & 1.478 .474 & 896.821 & 19.313 & 1.442 & 155.996 & 1.776 .661 & 770.979 & 15.447 & 976 & 117.354 \\
\hline & $\mathrm{BA}$ & 11.753 .125 & 8.219 .843 & 55.072 & 2.014 & 1.074 .214 & 13.018.111 & 6.210 .392 & 46.275 & 1.482 & 910.424 \\
\hline \multirow{4}{*}{ Sudeste } & MG & 15.542 .085 & 6.238 .976 & 26.130 & 169 & 615.004 & 17.555 .247 & 4.354 .070 & 18.086 & 38 & 399.599 \\
\hline & ES & 2.580 .027 & 922.000 & 17.423 & 2.088 & 92.829 & 3.084 .122 & 576.122 & 13.283 & 709 & 67.972 \\
\hline & RJ & 12.679 .997 & 5.315 .785 & 242.492 & 3.648 & 1.799 .476 & 14.303 .997 & 3.303.335 & 151.323 & 2.180 & 1.087 .790 \\
\hline & SP & 31.200 .800 & 8.387.354 & 109.227 & 109 & 2.559 .754 & 36.758 .099 & 8.575 .987 & 115.078 & 193 & 2.681 .644 \\
\hline \multirow{3}{*}{ Sul } & $P R$ & 8.370 .891 & 2.811 .080 & 16.451 & 469 & 248.695 & 9.510 .719 & 1.879 .045 & 13.824 & 293 & 208.055 \\
\hline & SC & 4.497 .033 & 983.108 & 6.893 & 294 & 44.878 & 5.323 .622 & 552.243 & 4.314 & 119 & 32.415 \\
\hline & RS & 9.041 .154 & 2.308 .092 & 15.805 & 207 & 171.389 & 10.114 .344 & 1.463 .421 & 12.366 & - & 151.135 \\
\hline \multirow{4}{*}{$\begin{array}{l}\text { Centro- } \\
\text { Oeste }\end{array}$} & MS & 1.762 .655 & 908.319 & 24.526 & 1.685 & 195.496 & 2.065 .883 & 672.398 & 20.510 & 1.164 & 166.084 \\
\hline & MT & 2.002 .481 & 1.049 .316 & 23.622 & 955 & 158.353 & 2.492.199 & 765.291 & 16.874 & 593 & 112.646 \\
\hline & GO & 3.976 .645 & 2.003 .601 & 26.145 & 515 & 330.171 & 4.978 .472 & 1.544 .697 & 20.807 & 236 & 225.542 \\
\hline & $\mathrm{DF}$ & 1.565 .191 & 681.902 & - & 681.902 & 681.902 & 2.022 .513 & 656.517 & - & 656.517 & 656.517 \\
\hline \multicolumn{2}{|c|}{ Brasil } & 45.296 .144 & 66.523 .187 & 58.231 & 109 & 2.559 .754 & 168.576 .958 & 53.228 .129 & 55.168 & - & 2.681 .644 \\
\hline
\end{tabular}

Tabela 4.C - Estatísticas Básicas do Índice de Gini

\begin{tabular}{|c|c|c|c|c|c|c|c|c|c|}
\hline \multirow{2}{*}{$\begin{array}{c}\text { Região } \\
\text { Geográfica }\end{array}$} & \multirow[b]{2}{*}{ Estado } & \multicolumn{4}{|c|}{1991} & \multicolumn{4}{|c|}{2000} \\
\hline & & Gini & $\begin{array}{l}\text { Desvio- } \\
\text { Padrão }\end{array}$ & Mínimo & Máximo & Gini & $\begin{array}{l}\text { Desvio- } \\
\text { Padrão }\end{array}$ & Mínimo & Máximo \\
\hline \multirow{7}{*}{ Norte } & $\mathrm{RO}$ & 0,613 & 0,031 & 0,492 & 0,665 & 0,592 & 0,022 & 0,475 & $\overline{0,646}$ \\
\hline & $A C$ & 0,627 & 0,020 & 0,469 & 0,649 & 0,631 & 0,021 & 0,561 & 0,670 \\
\hline & AM & 0,620 & 0,052 & 0,411 & 0,734 & 0,668 & 0,037 & 0,528 & 0,787 \\
\hline & $\mathrm{RR}$ & 0,650 & 0,050 & 0,613 & 0,748 & 0,605 & 0,019 & 0,574 & 0,640 \\
\hline & PA & 0,623 & 0,050 & 0,392 & 0,708 & 0,633 & 0,039 & 0,454 & 0,744 \\
\hline & AP & 0,582 & 0,020 & 0,524 & 0,683 & 0,616 & 0,012 & 0,583 & 0,668 \\
\hline & TO & 0,617 & 0,048 & 0,411 & 0,697 & 0,628 & 0,038 & 0,462 & 0,722 \\
\hline \multirow{9}{*}{ Nordeste } & MA & 0,602 & 0,056 & 0,392 & 0,666 & 0,642 & 0,041 & 0,449 & 0,724 \\
\hline & PI & 0,642 & 0,051 & 0,411 & 0,767 & 0,648 & 0,042 & 0,427 & 0,663 \\
\hline & CE & 0,653 & 0,064 & 0,381 & 0,678 & 0,662 & 0,045 & 0,475 & 0,701 \\
\hline & $\mathrm{RN}$ & 0,628 & 0,052 & 0,402 & 0,682 & 0,634 & 0,047 & 0,423 & 0,749 \\
\hline & PB & 0,636 & 0,062 & 0,345 & 0,738 & 0,630 & 0,051 & 0,424 & 0,677 \\
\hline & PE & 0,652 & 0,064 & 0,399 & 0,667 & 0,646 & 0,053 & 0,434 & 0,703 \\
\hline & $A L$ & 0,624 & 0,070 & 0,371 & 0,663 & 0,662 & 0,053 & 0,424 & 0,748 \\
\hline & SE & 0,614 & 0,056 & 0,385 & 0,602 & 0,632 & 0,054 & 0,418 & 0,636 \\
\hline & $\mathrm{BA}$ & 0,654 & 0,066 & 0,377 & 0,740 & 0,645 & 0,050 & 0,361 & 0,785 \\
\hline \multirow{4}{*}{ Sudeste } & $M G$ & 0,606 & 0,048 & 0,352 & 0,725 & 0,599 & 0,052 & 0,341 & 0,740 \\
\hline & ES & 0,593 & 0,047 & 0,431 & 0,700 & 0,589 & 0,037 & 0,419 & 0,667 \\
\hline & RJ & 0,601 & 0,058 & 0,439 & 0,702 & 0,582 & 0,052 & 0,434 & 0,617 \\
\hline & SP & 0,546 & 0,047 & 0,328 & 0,719 & 0,570 & 0,047 & 0,371 & 0,698 \\
\hline \multirow{3}{*}{ Sul } & PR & 0,594 & 0,050 & 0,354 & 0,717 & 0,592 & 0,046 & 0,387 & 0,711 \\
\hline & SC & 0,538 & 0,056 & 0,339 & 0,669 & 0,536 & 0,049 & 0,355 & 0,690 \\
\hline & $\mathrm{RS}$ & 0,576 & 0,056 & 0,398 & 0,718 & 0,567 & 0,050 & 0,343 & 0,708 \\
\hline \multirow{4}{*}{ Centro-Oeste } & MS & 0,594 & 0,036 & 0,426 & 0,667 & 0,603 & 0,036 & 0,454 & 0,693 \\
\hline & MT & 0,592 & 0,045 & 0,436 & 0,713 & 0,599 & 0,034 & 0,377 & 0,688 \\
\hline & $\mathrm{GO}$ & 0,574 & 0,045 & 0,375 & 0,728 & 0,584 & 0,050 & 0,405 & 0,756 \\
\hline & DF & 0,606 & - & 0,606 & 0,606 & 0,626 & - & 0,626 & 0,626 \\
\hline Brasil & & 0,629 & 0,058 & 0,328 & 0,767 & 0,627 & 0,054 & 0,341 & 0,787 \\
\hline
\end{tabular}

Obs.: $\quad$ Os valores da coluna Gini correspondem aos índices de Gini estaduais e nacional, enquanto que as colunas Desvio-Padrão, Mínimo e Máximo são referentes aos municípios. 
Tabela 5.C - Estatísticas Básicas do Índice de Theil

\begin{tabular}{|c|c|c|c|c|c|c|c|c|c|}
\hline \multirow{2}{*}{$\begin{array}{c}\text { Região } \\
\text { Geográfica }\end{array}$} & \multirow[b]{2}{*}{ Estado } & \multicolumn{4}{|c|}{1991} & \multicolumn{4}{|c|}{2000} \\
\hline & & Theil & $\begin{array}{l}\text { Desvio- } \\
\text { Padrão }\end{array}$ & Mínimo & Máximo & Theil & $\begin{array}{l}\text { Desvio- } \\
\text { Padrão }\end{array}$ & Mínimo & Máximo \\
\hline \multirow{7}{*}{ Norte } & $\mathrm{RO}$ & 0,785 & 0,117 & 0,435 & 1,026 & 0,722 & 0,093 & 0,371 & 1,036 \\
\hline & $A C$ & 0,822 & 0,046 & 0,403 & 0,949 & 0,867 & 0,058 & 0,536 & 0,891 \\
\hline & AM & 0,785 & 0,171 & 0,324 & 1,317 & 0,940 & 0,174 & 0,432 & 2,089 \\
\hline & $\mathrm{RR}$ & 0,799 & 0,165 & 0,702 & 1,168 & 0,717 & 0,073 & 0,538 & 0,864 \\
\hline & PA & 0,840 & 0,129 & 0,296 & 1,045 & 0,868 & 0,166 & 0,342 & 2,372 \\
\hline & AP & 0,674 & 0,108 & 0,487 & 1,073 & 0,779 & 0,084 & 0,639 & 0,929 \\
\hline & TO & 0,854 & 0,143 & 0,325 & 1,089 & 0,868 & 0,149 & 0,376 & 1,534 \\
\hline \multirow{9}{*}{ Nordeste } & $\overline{M A}$ & 0,825 & 0,167 & 0,266 & 1,319 & 0,921 & 0,156 & 0,352 & 1,666 \\
\hline & PI & 0,930 & 0,191 & 0,289 & 1,960 & 0,929 & 0,162 & 0,316 & 1,145 \\
\hline & CE & 0,967 & 0,180 & 0,251 & 1,481 & 0,948 & 0,143 & 0,404 & 1,217 \\
\hline & $\mathrm{RN}$ & 0,840 & 0,151 & 0,264 & 1,386 & 0,843 & 0,157 & 0,229 & 1,827 \\
\hline & PB & 0,903 & 0,165 & 0,210 & 1,115 & 0,844 & 0,152 & 0,296 & 1,225 \\
\hline & PE & 0,930 & 0,171 & 0,274 & 1,241 & 0,887 & 0,165 & 0,361 & 1,864 \\
\hline & $A L$ & 0,871 & 0,173 & 0,234 & 1,092 & 0,951 & 0,180 & 0,308 & 1,818 \\
\hline & SE & 0,815 & 0,132 & 0,274 & 1,058 & 0,842 & 0,138 & 0,298 & 0,967 \\
\hline & BA & 0,965 & 0,188 & 0,258 & 1,882 & 0,910 & 0,176 & 0,219 & 2,155 \\
\hline \multirow{4}{*}{ Sudeste } & $\overline{M G}$ & 0,768 & 0,139 & 0,206 & 1,620 & 0,739 & 0,157 & 0,187 & 2,395 \\
\hline & ES & 0,709 & 0,148 & 0,316 & 1,268 & 0,704 & 0,116 & 0,287 & 1,254 \\
\hline & RJ & 0,731 & 0,133 & 0,357 & 1,287 & 0,670 & 0,116 & 0,331 & 1,071 \\
\hline & SP & 0,591 & 0,107 & 0,179 & 1,242 & 0,640 & 0,112 & 0,231 & 1,126 \\
\hline \multirow{3}{*}{ Sul } & PR & 0,722 & 0,163 & 0,214 & 1,438 & 0,721 & 0,143 & 0,260 & 1,795 \\
\hline & SC & 0,575 & 0,142 & 0,218 & 1,250 & 0,588 & 0,139 & 0,228 & 1,572 \\
\hline & RS & 0,659 & 0,152 & 0,280 & 1,358 & 0,642 & 0,120 & 0,204 & 1,389 \\
\hline \multirow{4}{*}{ Centro-Oeste } & MS & 0,758 & 0,135 & 0,330 & 1,247 & 0,785 & 0,148 & 0,381 & 1,647 \\
\hline & MT & 0,755 & 0,154 & 0,331 & 1,325 & 0,793 & 0,123 & 0,215 & 1,380 \\
\hline & GO & 0,693 & 0,139 & 0,258 & 1,495 & 0,735 & 0,167 & 0,274 & 1,839 \\
\hline & DF & 0,702 & - & 0,702 & 0,702 & 0,740 & - & 0,740 & 0,740 \\
\hline Brasil & & 0,807 & 0,156 & 0,179 & 1,960 & 0,799 & 0,164 & 0,187 & 2,395 \\
\hline
\end{tabular}

Obs.: $\quad$ Os valores da coluna Theil correspondem aos índices de Theil estaduais e nacional, enquanto que as colunas Desvio-Padrão, Mínimo e Máximo são referentes aos municípios.

\section{b) Resultados para o Capítulo 3}

Tabela 6.C - Regressão em Logaritmo da Linha de Pobreza na Renda

\begin{tabular}{lcccccc}
\hline \multirow{2}{*}{ Variável } & \multicolumn{2}{c}{1991} & & \multicolumn{2}{c}{2000} \\
\cline { 3 - 4 } \cline { 6 - 6 } & Coeficiente & Desvio-Padrãon & & Coeficiente & Desvio-Padrão \\
\hline$\alpha_{i, t}$ & constante & 1,1677 & 0,3449 & & 0,6353 & 0,4624 \\
$\rho_{t}$ & $\log$ (renda) & 0,6073 & 0,0666 & & 0,6712 & 0,0821 \\
\hline número de observações & \multicolumn{2}{c}{26} & \multicolumn{2}{c}{26} \\
\hline \multicolumn{2}{c}{0,8090} & \multicolumn{2}{c}{0,7910} \\
\hline
\end{tabular}

Obs.: Todas as estimações usam White robusto para heterocedasticidade.

Tabela 7.C - Regressão em Logaritmo da Linha de Pobreza com os Anos de 1991 e 2000

\begin{tabular}{ccc}
\hline Variável & Coeficiente & Desvio-Padrão \\
\hline constante & 0,6353 & 0,4624 \\
$\log$ (renda) & 0,6712 & 0,0821 \\
dummy 91 & 0,5324 & 0,5768 \\
dummy $91 * \log$ (renda) & $-0,0639$ & 0,1057 \\
\hline número de observações & \multicolumn{2}{c}{26} \\
\hline $\mathrm{R}^{2}$ & \multicolumn{2}{c}{0,8004} \\
\hline
\end{tabular}

Obs.: Todas as estimações usam White robusto para heterocedasticidade. 
Tabela 8.C - Linha Híbrida de Pobreza com Renda Média por Estrato e Nacional

\begin{tabular}{|c|c|c|c|c|c|c|c|c|c|c|c|}
\hline \multirow{4}{*}{ Regiões } & \multirow{4}{*}{ Estratos } & \multicolumn{5}{|c|}{1991} & \multicolumn{5}{|c|}{2000} \\
\hline & & \multirow{3}{*}{$\begin{array}{c}\text { Renda } \\
\text { Média } \\
(\mathrm{RM})\end{array}$} & \multicolumn{4}{|c|}{ Linha Híbrida (Zh) } & \multirow{3}{*}{$\begin{array}{l}\text { Renda } \\
\text { Média } \\
(\mathrm{RM})\end{array}$} & \multicolumn{4}{|c|}{ Linha Híbrida (Zh) } \\
\hline & & & \multicolumn{2}{|c|}{ RM por Estrato } & \multicolumn{2}{|c|}{ RM Nacional } & & \multicolumn{2}{|c|}{ RM por Estrato } & \multicolumn{2}{|c|}{ RM Nacional } \\
\hline & & & Zh30 & Zh50 & Zh30 & Zh50 & & Zh30 & Zh50 & Zh30 & Zh50 \\
\hline \multirow{3}{*}{ Norte } & Belém & 269,55 & 85,07 & 116,01 & 80,27 & 109,46 & 294,31 & 90,45 & 127,44 & 97,05 & 136,74 \\
\hline & Urbano & 194,38 & 66,68 & 90,93 & 76,73 & 104,65 & 225,83 & 72,38 & 101,98 & 92,77 & 130,70 \\
\hline & Rural & 81,59 & 32,81 & 44,74 & 63,96 & 87,22 & 89,42 & 32,78 & 46,19 & 78,26 & 110,26 \\
\hline \multirow{5}{*}{ Nordeste } & Fortaleza & 207,21 & 74,09 & 101,04 & 82,01 & 111,84 & 277,09 & 86,01 & 121,19 & 96,10 & 135,41 \\
\hline & Recife & 238,13 & 94,44 & 128,79 & 96,07 & 131,02 & 306,49 & 104,06 & 146,61 & 108,65 & 153,09 \\
\hline & Salvador & 276,00 & 96,04 & 130,98 & 89,33 & 121,82 & 343,77 & 108,95 & 153,51 & 105,33 & 148,41 \\
\hline & Urbano & 131,94 & 53,55 & 73,03 & 77,98 & 106,34 & 180,83 & 62,11 & 87,51 & 92,41 & 130,20 \\
\hline & Rural & 50,50 & 24,51 & 33,43 & 63,96 & 87,22 & 62,17 & 25,69 & 36,19 & 78,26 & 110,26 \\
\hline \multirow{15}{*}{ Sudeste } & Minas Gerais & & & & & & & & & & \\
\hline & Belo Horizonte & 339,90 & 103,97 & 141,78 & 85,21 & 116,20 & 423,63 & 123,19 & 173,57 & 103,51 & 145,85 \\
\hline & Urbano & 213,72 & 67,11 & 91,52 & 72,91 & 99,43 & 296,01 & 84,99 & 119,76 & 90,84 & 128,00 \\
\hline & Rural & 82,10 & 30,55 & 41,67 & 59,34 & 80,93 & 125,15 & 40,14 & 56,56 & 76,46 & 107,73 \\
\hline & Espírito Santo & & & & & & & & & & \\
\hline & Urbano & 251,53 & 74,09 & 101,04 & 72,91 & 99,43 & 356,31 & 96,26 & 135,63 & 90,84 & 128,00 \\
\hline & Rural & 88,06 & 31,88 & 43,48 & 59,34 & 80,93 & 154,97 & 46,33 & 65,28 & 76,46 & 107,73 \\
\hline & Rio de Janeiro & & & & & & & & & & \\
\hline & Metrópole & 365,47 & 116,65 & 159,08 & 91,49 & 124,76 & 513,61 & 148,68 & 209,49 & 109,78 & 154,68 \\
\hline & Urbano & 237,33 & 74,49 & 101,58 & 75,93 & 103,55 & 354,05 & 99,09 & 139,62 & 93,92 & 132,33 \\
\hline & Rural & 105,17 & 40,16 & 54,76 & 67,11 & 91,52 & 175,59 & 55,81 & 78,63 & 84,69 & 119,33 \\
\hline & São Paulo & & & & & & & & & & \\
\hline & Metrópole & 489,21 & 149,50 & 203,88 & 98,22 & 133,95 & 567,36 & 170,92 & 240,82 & 118,05 & 166,32 \\
\hline & Urbano & 351,86 & 102,64 & 139,98 & 82,38 & 112,34 & 440,42 & 124,45 & 175,35 & 101,88 & 143,55 \\
\hline & Rural & 158,30 & 52,68 & 71,84 & 68,67 & 93,65 & 222,49 & 67,57 & 95,21 & 87,48 & 123,26 \\
\hline \multirow{4}{*}{ Sul } & Curitiba & 393,07 & 113,57 & 154,89 & 85,22 & 116,22 & 502,29 & 137,39 & 193,59 & 102,98 & 145,09 \\
\hline & Porto Alegre & 391,22 & 102,80 & 140,20 & 77,36 & 105,50 & 509,82 & 127,62 & 179,81 & 94,70 & 133,43 \\
\hline & Urbano & 272,69 & 77,67 & 105,93 & 72,78 & 99,25 & 369,60 & 97,86 & 137,89 & 90,12 & 126,97 \\
\hline & Rural & 117,90 & 39,99 & 54,53 & 62,34 & 85,01 & 192,26 & 55,44 & 78,11 & 79,16 & 111,54 \\
\hline \multirow{4}{*}{$\begin{array}{c}\text { Centro- } \\
\text { Oeste }\end{array}$} & Brasília & 500,04 & 154,80 & 211,11 & 100,36 & 136,87 & 632,51 & 178,35 & 251,29 & 114,51 & 161,35 \\
\hline & Urbano & 255,94 & 90,13 & 122,91 & 87,76 & 119,68 & 329,65 & 102,85 & 144,92 & 102,27 & 144,10 \\
\hline & Rural & 117,06 & 45,08 & 61,47 & 70,58 & 96,26 & 168,55 & 54,64 & 76,98 & 85,22 & 120,08 \\
\hline & BRASIL & 244,96 & \multicolumn{4}{|c|}{$(*)$} & 326,87 & \\
\hline
\end{tabular}

Obs.: (1) Valores em Reais (R $\$$ ) de julho de 2000.

(2) As colunas Zh30 e Zh50 indicam as linhas híbridas considerando linhas relativas de $30 \%$ e $50 \%$ da renda média, respectivamente.

(*) As linhas híbridas nacionais são a ponderação das linhas absolutas por estrato com a linha relativa considerando renda média nacional, e estão apresentadas nas colunas de RM Nacional. 
Tabela 9.C - Incidência da Pobreza com Renda Média por Estrato

\begin{tabular}{|c|c|c|c|c|c|c|c|c|c|c|c|c|c|c|c|}
\hline \multirow{4}{*}{ Regiões } & \multirow{4}{*}{ Estratos } & \multicolumn{7}{|c|}{1991} & \multicolumn{7}{|c|}{2000} \\
\hline & & \multirow{2}{*}{\multicolumn{2}{|c|}{$\begin{array}{c}\text { Linha Absoluta } \\
\text { de Pobreza }\end{array}$}} & \multicolumn{4}{|c|}{ Linha Híbrida de Pobreza } & \multirow{3}{*}{$\begin{array}{l}\text { População } \\
\text { Total }\end{array}$} & \multirow{2}{*}{\multicolumn{2}{|c|}{$\begin{array}{c}\text { Linha Absoluta } \\
\text { de Pobreza }\end{array}$}} & \multicolumn{4}{|c|}{ Linha Híbrida de Pobreza } & \multirow{3}{*}{$\begin{array}{l}\text { População } \\
\text { Total }\end{array}$} \\
\hline & & & & \multicolumn{2}{|l|}{ Zh30 } & \multicolumn{2}{|l|}{ Zh50 } & & & & \multicolumn{2}{|l|}{ Zh30 } & \multicolumn{2}{|l|}{ Zh50 } & \\
\hline & & $\mathrm{n}^{\circ}$ de pobres & $\%$ & $\mathrm{n}^{0}$ de pobres & $\%$ & $\mathrm{n}^{0}$ de pobres & $\%$ & & $n^{\circ}$ de pobres & $\%$ & $n^{0}$ de pobres & $\%$ & $n^{0}$ de pobres & $\%$ & \\
\hline \multirow{3}{*}{ Norte } & Belém & 549 & 41,7 & 455 & 34,6 & 622 & 47,2 & 1.318 & 573 & 32,1 & 544 & 30,5 & 789 & 44,3 & 1.783 \\
\hline & Urbano & 2.408 & 48,6 & 1.507 & 30,4 & 2.141 & 43,2 & 4.958 & 2.790 & 38,6 & 2.425 & 33,5 & 3.401 & 47,0 & 7.237 \\
\hline & Rural & 2.333 & 63,7 & 1.626 & 44,4 & 2.152 & 58,7 & 3.665 & 1.974 & 51,6 & 1.451 & 37,9 & 1.910 & 49,9 & 3.827 \\
\hline \multirow{5}{*}{ Nordeste } & Fortaleza & 1.344 & 59,3 & 970 & 42,8 & 1.248 & 55,1 & 2.265 & 1.161 & 39,3 & 1.085 & 36,7 & 1.492 & 50,5 & 2.954 \\
\hline & Recife & 1.927 & 67,7 & 1.351 & 47,5 & 1.667 & 58,6 & 2.845 & 1.651 & 49,8 & 1.319 & 39,8 & 1.765 & 53,2 & 3.317 \\
\hline & Salvador & 1.373 & 56,1 & 1.062 & 43,4 & 1.343 & 54,9 & 2.447 & 1.223 & 40,9 & 1.091 & 36,5 & 1.503 & 50,3 & 2.989 \\
\hline & Urbano & 12.175 & 67,0 & 6.460 & 35,6 & 8.919 & 49,1 & 18.167 & 10.888 & 45,9 & 8.300 & 35,0 & 11.505 & 48,5 & 23.724 \\
\hline & Rural & 12.804 & 78,0 & 7.993 & 48,7 & 10.468 & 63,8 & 16.413 & 8.624 & 59,3 & 5.295 & 36,4 & 6.971 & 48,0 & 14.537 \\
\hline \multirow{15}{*}{ Sudeste } & Minas Gerais & & & & & & & & & & & & & & \\
\hline & Belo Horizonte & 1.337 & 39,5 & 1.055 & 31,1 & 1.468 & 43,3 & 3.388 & 1.211 & 25,4 & 1.318 & 27,6 & 1.980 & 41,5 & 4.777 \\
\hline & Urbano & 2.956 & 35,2 & 1.987 & 23,7 & 3.064 & 36,5 & 8.392 & 2.164 & 22,1 & 2.383 & 24,4 & 3.577 & 36,6 & 9.779 \\
\hline & Rural & 1.946 & 51,7 & 1.548 & 41,1 & 2.107 & 56,0 & 3.762 & 979 & 32,6 & 878 & 29,3 & 1.217 & 40,6 & 3.000 \\
\hline & Espirito Santo & & & & & & & & & & & & & & \\
\hline & Urbano & 588 & 30,8 & 440 & 23,1 & 669 & 35,1 & 1.906 & 439 & 17,9 & 578 & 23,6 & 898 & 36,6 & 2.450 \\
\hline & Rural & 334 & 49,6 & 295 & 43,8 & 394 & 58,5 & 674 & 137 & 21,7 & 138 & 21,8 & 221 & 34,8 & 634 \\
\hline & Rio de Janeil & & & & & & & & & & & & & & \\
\hline & Metrópole & 4.176 & 43,0 & 3.029 & 31,2 & 4.237 & 43,6 & 9.711 & 2.675 & 24,7 & 2.916 & 26,9 & 4.416 & 40,8 & 10.821 \\
\hline & Urbano & 848 & 34,7 & 634 & 25,9 & 940 & 38,4 & 2.446 & 498 & 16,6 & 601 & 20,1 & 966 & 32,3 & 2.995 \\
\hline & Rural & 291 & 55,6 & 258 & 49,3 & 333 & 63,7 & 523 & 130 & 26,7 & 109 & 22,3 & 179 & 36,7 & 489 \\
\hline & São Paulo & & & & & & & & & & & & & & \\
\hline & Metrópole & 4.684 & 30,8 & 3.817 & 25,1 & 5.652 & 37,2 & 15.206 & 5.208 & 29,4 & 5.173 & 29,2 & 7.414 & 41,8 & 17.744 \\
\hline & Urbano & 2.967 & 21,1 & 2.396 & 17,0 & 4.045 & 28,7 & 14.076 & 2.976 & 17,1 & 3.509 & 20,2 & 5.736 & 33,0 & 17.356 \\
\hline & Rural & 735 & 38,3 & 747 & 38,9 & 1.033 & 53,8 & 1.919 & 392 & 23,6 & 384 & 23,2 & 614 & 37,0 & 1.658 \\
\hline \multirow{4}{*}{ Sul } & Curitiba & 538 & 27,3 & 452 & 22,9 & 690 & 35,0 & 1.972 & 529 & 19,6 & 680 & 25,1 & 1.029 & 38,0 & 2.704 \\
\hline & Porto Alegre & 550 & 18,4 & 591 & 19,7 & 902 & 30,1 & 2.992 & 466 & 12,8 & 774 & 21,3 & 1.197 & 33,0 & 3.628 \\
\hline & Urbano & 2.749 & 24,0 & 2.178 & 19,0 & 3.481 & 30,3 & 11.475 & 1.970 & 13,9 & 2.749 & 19,3 & 4.428 & 31,2 & 14.214 \\
\hline & Rural & 2.265 & 41,4 & 2.093 & 38,3 & 2.849 & 52,1 & 5.471 & 930 & 21,1 & 997 & 22,6 & 1.495 & 34,0 & 4.403 \\
\hline \multirow{4}{*}{$\begin{array}{l}\text { Centro- } \\
\text { Oeste }\end{array}$} & Brasília & 682 & 43,6 & 603 & 38,5 & 779 & 49,8 & 1.565 & 657 & 32,5 & 740 & 36,6 & 966 & 47,7 & 2.023 \\
\hline & Urbano & 3.006 & 49,4 & 1.846 & 30,3 & 2.706 & 44,5 & 6.082 & 2.486 & 30,7 & 2.266 & 28,0 & 3.402 & 42,1 & 8.087 \\
\hline & Rural & 955 & 57,5 & 746 & 44,9 & 985 & 59,4 & 1.660 & 496 & 34,2 & 409 & 28,2 & 623 & 43,0 & 1.450 \\
\hline & BRASIL & 66.523 & 45,8 & 46.139 & 31,8 & 64.895 & 44,7 & 145.296 & 53.228 & 31,6 & 48.111 & 28,5 & 69.692 & 41,3 & 168.577 \\
\hline
\end{tabular}
relativas de $30 \%$ e $50 \%$ da renda média, respectivamente. 
Tabela 10.C - Incidência da Pobreza com Renda Média Nacional

\begin{tabular}{|c|c|c|c|c|c|c|c|c|c|c|c|c|c|c|c|}
\hline \multirow{4}{*}{ Regiões } & \multirow{4}{*}{ Estratos } & \multicolumn{7}{|c|}{1991} & \multicolumn{7}{|c|}{2000} \\
\hline & & \multirow{2}{*}{\multicolumn{2}{|c|}{$\begin{array}{c}\text { Linha Absoluta } \\
\text { de Pobreza } \\
\end{array}$}} & \multicolumn{4}{|c|}{ Linha Híbrida de Pobreza } & \multirow{3}{*}{$\begin{array}{l}\text { População } \\
\text { Total }\end{array}$} & \multirow{2}{*}{\multicolumn{2}{|c|}{$\begin{array}{c}\text { Linha Absoluta } \\
\text { de Pobreza } \\
\end{array}$}} & \multicolumn{4}{|c|}{ Linha Híbrida de Pobreza } & \multirow{3}{*}{$\begin{array}{c}\text { População } \\
\text { Total }\end{array}$} \\
\hline & & & & \multicolumn{2}{|c|}{ Zh30 } & \multicolumn{2}{|l|}{ Zh50 } & & & & Zh30 & & Zh50 & & \\
\hline & & $\mathrm{n}^{\circ}$ de pobres & $\%$ & $\mathrm{n}^{0}$ de pobres & $\%$ & $\mathrm{n}^{\circ}$ de pobres & $\%$ & & $\mathrm{n}^{0}$ de pobres & $\%$ & $\mathrm{n}^{0}$ de pobres & $\%$ & $n^{0}$ de pobres & $\%$ & \\
\hline \multirow{3}{*}{ Norte } & Belém & 549 & 41,7 & 432 & 32,8 & 594 & 45,0 & 1.318 & 573 & 32,1 & 586 & 32,9 & 841 & 47,2 & 1.783 \\
\hline & Urbano & 2.408 & 48,6 & 2.127 & 42,9 & 2.730 & 55,1 & 4.958 & 2.790 & 38,6 & 3.110 & 43,0 & 4.098 & 56,6 & 7.237 \\
\hline & Rural & 2.333 & 63,7 & 2.514 & 68,6 & 2.900 & 79,1 & 3.665 & 1.974 & 51,6 & 2.637 & 68,9 & 3.051 & 79,7 & 3.827 \\
\hline \multirow{5}{*}{ Nordeste } & Fortaleza & 1.344 & 59,3 & 1.122 & 49,6 & 1.387 & 61,2 & 2.265 & 1.161 & 39,3 & 1.202 & 40,7 & 1.622 & 54,9 & 2.954 \\
\hline & Recife & 1.927 & 67,7 & 1.442 & 50,7 & 1.753 & 61,6 & 2.845 & 1.651 & 49,8 & 1.373 & 41,4 & 1.839 & 55,5 & 3.317 \\
\hline & Salvador & 1.373 & 56,1 & 1.019 & 41,7 & 1.306 & 53,4 & 2.447 & 1.223 & 40,9 & 1.058 & 35,4 & 1.448 & 48,5 & 2.989 \\
\hline & Urbano & 12.175 & 67,0 & 10.925 & 60,1 & 12.983 & 71,5 & 18.167 & 10.888 & 45,9 & 12.022 & 50,7 & 15.273 & 64,4 & 23.724 \\
\hline & Rural & 12.804 & 78,0 & 13.463 & 82,0 & 14.684 & 89,5 & 16.413 & 8.624 & 59,3 & 11.057 & 76,1 & 12.544 & 86,3 & 14.537 \\
\hline \multirow{15}{*}{ Sudeste } & Minas Gerais & & & & & & & & & & & & & & \\
\hline & Belo Horizonte & 1.337 & 39,5 & 928 & 27,4 & 1.331 & 39,3 & 3.388 & 1.211 & 25,4 & 1.055 & 22,1 & 1.610 & 33,7 & 4.777 \\
\hline & Urbano & 2.956 & 35,2 & 2.690 & 32,1 & 3.823 & 45,6 & 8.392 & 2.164 & 22,1 & 2.594 & 26,5 & 3.860 & 39,5 & 9.779 \\
\hline & Rural & 1.946 & 51,7 & 2.350 & 62,5 & 2.816 & 74,8 & 3.762 & 979 & 32,6 & 1.612 & 53,7 & 2.009 & 67,0 & 3.000 \\
\hline & Espirito Santo & & & & & & & & & & & & & & \\
\hline & Urbano & 588 & 30,8 & 531 & 27,9 & 772 & 40,5 & 1.906 & 439 & 17,9 & 537 & 21,9 & 841 & 34,3 & 2.450 \\
\hline & Rural & 334 & 49,6 & 404 & 60,0 & 489 & 72,6 & 674 & 137 & 21,7 & 269 & 42,5 & 361 & 56,9 & 634 \\
\hline & Rio de Janeiro & & & & & & & & & & & & & & \\
\hline & Metrópole & 4.176 & 43,0 & 2.563 & 26,4 & 3.729 & 38,4 & 9.711 & 2.675 & 24,7 & 1.969 & 18,2 & 3.140 & 29,0 & 10.821 \\
\hline & Urbano & 848 & 34,7 & 713 & 29,1 & 1.028 & 42,0 & 2.446 & 498 & 16,6 & 563 & 18,8 & 904 & 30,2 & 2.995 \\
\hline & Rural & 291 & 55,6 & 304 & 58,1 & 373 & 71,2 & 523 & 130 & 26,7 & 192 & 39,3 & 274 & 56,0 & 489 \\
\hline & São Paulo & & & & & & & & & & & & & & \\
\hline & Metrópole & 4.684 & 30,8 & 2.185 & 14,4 & 3.439 & 22,6 & 15.206 & 5.208 & 29,4 & 3.230 & 18,2 & 4.963 & 28,0 & 17.744 \\
\hline & Urbano & 2.967 & 21,1 & 1.864 & 13,2 & 3.208 & 22,8 & 14.076 & 2.976 & 17,1 & 2.719 & 15,7 & 4.322 & 24,9 & 17.356 \\
\hline & Rural & 735 & 38,3 & 744 & 38,8 & 1.041 & 54,2 & 1.919 & 392 & 23,6 & 551 & 33,2 & 819 & 49,4 & 1.658 \\
\hline \multirow{4}{*}{ Sul } & Curitiba & 538 & 27,3 & 336 & 17,0 & 535 & 27,1 & 1.972 & 529 & 19,6 & 469 & 17,3 & 728 & 26,9 & 2.704 \\
\hline & Porto Alegre & 550 & 18,4 & 434 & 14,5 & 691 & 23,1 & 2.992 & 466 & 12,8 & 506 & 13,9 & 820 & 22,6 & 3.628 \\
\hline & Urbano & 2.749 & 24,0 & 2.455 & 21,4 & 3.784 & 33,0 & 11.475 & 1.970 & 13,9 & 2.484 & 17,5 & 3.998 & 28,1 & 14.214 \\
\hline & Rural & 2.265 & 41,4 & 2.668 & 48,8 & 3.386 & 61,9 & 5.471 & 930 & 21,1 & 1.509 & 34,3 & 2.097 & 47,6 & 4.403 \\
\hline \multirow{4}{*}{$\begin{array}{l}\text { Centro- } \\
\text { Oeste }\end{array}$} & Brasília & 682 & 43,6 & 363 & 23,2 & 527 & 33,7 & 1.565 & 657 & 32,5 & 454 & 22,4 & 675 & 33,4 & 2.023 \\
\hline & Urbano & 3.006 & 49,4 & 1.999 & 32,9 & 2.871 & 47,2 & 6.082 & 2.486 & 30,7 & 2.254 & 27,9 & 3.388 & 41,9 & 8.087 \\
\hline & Rural & 955 & 57,5 & 944 & 56,9 & 1.153 & 69,5 & 1.660 & 496 & 34,2 & 678 & 46,8 & 909 & 62,7 & 1.450 \\
\hline & BRASIL & 66.523 & 45,8 & 57.521 & 39,6 & 73.334 & 50,5 & 145.296 & 53.228 & 31,6 & 56.689 & 33,6 & 76.432 & 45,3 & 168.577 \\
\hline \multicolumn{16}{|c|}{$\begin{array}{l}\text { Obs.: (1) } n^{o} \text { de pobres e População Total em milhares de habitantes. } \\
\text { (2) Os valores das colunas } n^{\circ} \text { de pobres correspondem ao número de pessoas com renda familiar pei } \\
\text { capita abaixo da linha de pobreza considerada e os valores das colunas \% são o percentual de pessoas pobres em } \\
\text { relação ao total populacional de habitantes de cada estrato. } \\
\text { (3) As colunas } Z h 30 \text { e } Z h 50 \text { indicam os valores correspondentes às linhas híbridas considerando linhas }\end{array}$} \\
\hline
\end{tabular}


Tabela 11.C - Variação da Incidência da Pobreza entre os Anos de 1991 e 2000

\begin{tabular}{|c|c|c|c|c|c|c|c|c|c|c|c|}
\hline \multirow{3}{*}{ Regiões } & \multirow{3}{*}{ Estratos } & \multicolumn{5}{|c|}{ Diferença em Pontos Percentuais } & \multicolumn{5}{|c|}{ Variação Percentual para 1991} \\
\hline & & \multirow{2}{*}{$\mathrm{Za}$} & \multicolumn{2}{|c|}{ Zh com RM por Estrato } & \multicolumn{2}{|c|}{ Zh com RM Nacional } & \multirow{2}{*}{$\mathrm{Za}$} & \multicolumn{2}{|c|}{ Zh com RM por Estrato } & \multicolumn{2}{|c|}{ Zh com RM Nacional } \\
\hline & & & Zh30 & Zh50 & Zh30 & Zh50 & & Zh30 & Zh50 & Zh30 & Zh50 \\
\hline \multirow{3}{*}{ Norte } & Belém & $-9,5$ & $-4,0$ & $-2,9$ & $\overline{0,1}$ & $\overline{2,1}$ & $-22,9$ & $-11,7$ & $-6,2$ & $\overline{0,3}$ & 4,8 \\
\hline & Urbano & $-10,0$ & 3,1 & 3,8 & 0,1 & 1,6 & $-20,6$ & 10,2 & 8,8 & 0,1 & 2,8 \\
\hline & Rural & $-12,1$ & $-6,4$ & $-8,8$ & 0,3 & 0,6 & $-19,0$ & $-14,5$ & $-15,0$ & 0,5 & 0,8 \\
\hline \multirow{5}{*}{ Nordeste } & Fortaleza & $-20,0$ & $-6,1$ & $-4,6$ & $-8,9$ & $-6,3$ & $-33,8$ & $-14,2$ & $-8,3$ & $-17,9$ & $-10,3$ \\
\hline & Recife & $-18,0$ & $-7,7$ & $-5,4$ & $-9,3$ & $-6,2$ & $-26,5$ & $-16,3$ & $-9,2$ & $-18,4$ & $-10,0$ \\
\hline & Salvador & $-15,2$ & $-6,9$ & $-4,6$ & $-6,3$ & $-4,9$ & $-27,1$ & $-15,8$ & $-8,4$ & $-15,1$ & $-9,2$ \\
\hline & Urbano & $-21,1$ & $-0,6$ & $-0,6$ & $-9,5$ & $-7,1$ & $-31,5$ & $-1,6$ & $-1,2$ & $-15,7$ & $-9,9$ \\
\hline & Rural & $-18,7$ & $-12,3$ & $-15,8$ & $-6,0$ & $-3,2$ & $-23,9$ & $-25,2$ & $-24,8$ & $-7,3$ & $-3,5$ \\
\hline \multirow{15}{*}{ Sudeste } & Minas Gerais & & & & & & & & & & \\
\hline & Belo Horizonte & $-14,1$ & $-3,6$ & $-1,9$ & $-5,3$ & $-5,6$ & $-35,7$ & $-11,4$ & $-4,3$ & $-19,4$ & $-14,2$ \\
\hline & Urbano & $-13,1$ & 0,7 & 0,1 & $-5,5$ & $-6,1$ & $-37,2$ & 2,9 & 0,2 & $-17,3$ & $-13,4$ \\
\hline & Rural & $-19,1$ & $-11,9$ & $-15,4$ & $-8,7$ & $-7,9$ & $-36,9$ & $-28,8$ & $-27,6$ & $-14,0$ & $-10,5$ \\
\hline & Espirito Santo & & & & & & & & & & \\
\hline & Urbano & $-12,9$ & 0,5 & 1,5 & $-5,9$ & $-6,2$ & $-41,9$ & 2,1 & 4,4 & $-21,3$ & $-15,3$ \\
\hline & Rural & $-27,9$ & $-22,0$ & $-23,6$ & $-17,5$ & $-15,7$ & $-56,3$ & $-50,3$ & $-40,4$ & $-29,2$ & $-21,7$ \\
\hline & Rio de Janeiro & & & & & & & & & & \\
\hline & Metrópole & $-18,3$ & $-4,3$ & $-2,8$ & $-8,2$ & $-9,4$ & $-42,5$ & $-13,6$ & $-6,5$ & $-31,1$ & $-24,4$ \\
\hline & Urbano & $-18,1$ & $-5,9$ & $-6,2$ & $-10,3$ & $-11,8$ & $-52,0$ & $-22,6$ & $-16,1$ & $-35,5$ & $-28,2$ \\
\hline & Rural & $-29,0$ & $-27,1$ & $-27,0$ & $-18,8$ & $-15,3$ & $-52,0$ & $-54,9$ & $-42,4$ & $-32,3$ & $-21,4$ \\
\hline & São Paulo & & & & & & & & & & \\
\hline & Metrópole & $-1,5$ & 4,0 & 4,6 & 3,8 & 5,4 & $-4,7$ & 16,1 & 12,4 & 26,7 & 23,7 \\
\hline & Urbano & $-3,9$ & 3,2 & 4,3 & 2,4 & 2,1 & $-18,7$ & 18,8 & 15,0 & 18,3 & 9,3 \\
\hline & Rural & $-14,7$ & $-15,7$ & $-16,8$ & $-5,5$ & $-4,8$ & $-38,4$ & $-40,5$ & $-31,2$ & $-14,2$ & $-8,9$ \\
\hline \multirow{4}{*}{ Sul } & Curitiba & $-7,7$ & 2,2 & 3,1 & 0,3 & $-0,2$ & $-28,3$ & 9,8 & 8,8 & 1,7 & $-0,8$ \\
\hline & Porto Alegre & $-5,5$ & 1,6 & 2,8 & $-0,6$ & $-0,5$ & $-30,1$ & 8,1 & 9,4 & $-4,0$ & $-2,0$ \\
\hline & Urbano & $-10,1$ & 0,4 & 0,8 & $-3,9$ & $-4,8$ & $-42,1$ & 1,9 & 2,7 & $-18,3$ & $-14,7$ \\
\hline & Rural & $-20,3$ & $-15,6$ & $-18,1$ & $-14,5$ & $-14,3$ & $-49,0$ & $-40,8$ & $-34,8$ & $-29,7$ & $-23,1$ \\
\hline \multirow{4}{*}{$\begin{array}{c}\text { Centro- } \\
\text { Oeste }\end{array}$} & Brasília & $-11,1$ & $-1,9$ & $-2,0$ & $-0,7$ & $-0,3$ & $-25,5$ & $-5,0$ & $-4,1$ & $-3,1$ & $-0,9$ \\
\hline & Urbano & $-18,7$ & $-2,3$ & $-2,4$ & $-5,0$ & $-5,3$ & $-37,8$ & $-7,6$ & $-5,4$ & $-15,2$ & $-11,3$ \\
\hline & Rural & $-23,3$ & $-16,8$ & $-16,4$ & $-10,1$ & $-6,8$ & $-40,5$ & $-37,3$ & $-27,6$ & $-17,8$ & $-9,8$ \\
\hline & BRASIL & $-14,2$ & $-3,2$ & $-3,3$ & $-6,0$ & $-5,1$ & $-31,0$ & $-10,1$ & $-7,4$ & $-15,1$ & $-10,2$ \\
\hline
\end{tabular}

Obs.: (1) As colunas referentes à Diferença em Pontos Percentuais indicam a diferença da incidência da pobreza entre os anos de 1991 e 2000. Já as colunas da Variação Percentual para 1991, correspondem a relação entre esta diferença e a incidência da pobreza em 1991.

(2) As colunas Za correspondem aos valores considerando as linhas absolutas de pobreza.

(3) As colunas Zh com RM por Estrato correspondem aos valores utilizando linhas híbridas construídas a partir de linhas relativas por estrato, enquanto que as colunas Zh com RM Nacional correspondem aos valores utilizando linhas híbridas construídas a partir da linha relativa nacional.

(4) As colunas Zh30 e Zh50 indicam os valores correspondentes às linhas híbridas considerando linhas relativas de $30 \%$ e $50 \%$ da renda média, respectivamente. 
Tabela 12.C -Regressões do Modelo Probit para 1991 e 2000

\begin{tabular}{|c|c|c|c|c|c|c|c|c|c|c|c|c|}
\hline \multirow{3}{*}{$\begin{array}{l}\text { Variável } \\
\text { Dependente: }\end{array}$} & \multicolumn{6}{|c|}{1991} & \multicolumn{6}{|c|}{2000} \\
\hline & \multicolumn{2}{|c|}{ pobre } & \multicolumn{2}{|c|}{ pobre30 } & \multicolumn{2}{|c|}{ pobre50 } & \multicolumn{2}{|c|}{ pobre } & \multicolumn{2}{|c|}{ pobre 30} & \multicolumn{2}{|c|}{ pobre50 } \\
\hline & Coeficiente & $\begin{array}{l}\text { desvio- } \\
\text { padrão }\end{array}$ & Coeficiente & $\begin{array}{l}\text { desvio- } \\
\text { padrão }\end{array}$ & Coeficiente & $\begin{array}{l}\text { desvio- } \\
\text { padrão }\end{array}$ & Coeficiente & $\begin{array}{l}\text { desvio- } \\
\text { padrão }\end{array}$ & Coeficiente & $\begin{array}{l}\text { desvio- } \\
\text { padrão }\end{array}$ & Coeficiente & $\begin{array}{l}\text { desvio- } \\
\text { padrão }\end{array}$ \\
\hline \multicolumn{13}{|l|}{ Variáveis } \\
\hline \multicolumn{13}{|l|}{ Independente: } \\
\hline Intercepto & $-0,2376$ & 0,0004 & $-0,3523$ & 0,0004 & 0,0685 & 0,0004 & $-0,0424$ & 0,0004 & 0,0385 & 0,0004 & 0,4549 & 0,0004 \\
\hline Mulher & 0,0704 & 0,0002 & 0,0712 & 0,0002 & 0,0695 & 0,0002 & 0,0647 & 0,0002 & 0,0667 & 0,0002 & 0,0660 & 0,0002 \\
\hline Não-Branco & 0,3773 & 0,0003 & 0,3237 & 0,0003 & 0,3549 & 0,0002 & 0,3799 & 0,0002 & 0,3449 & 0,0002 & 0,3748 & 0,0002 \\
\hline Idade & $-0,0084$ & 0,00001 & $-0,0088$ & 0,00001 & $-0,0085$ & 0,00001 & $-0,0134$ & 0,00001 & $-0,0131$ & 0,00001 & $-0,0135$ & 0,00001 \\
\hline Escolaridade & $-0,0845$ & 0,0000 & $-0,0756$ & 0,0000 & $-0,0793$ & 0,0000 & $-0,0729$ & 0,0000 & $-0,0667$ & 0,0000 & $-0,0711$ & 0,0000 \\
\hline Reg.Metropolitana & 0,0540 & 0,0001 & 0,0582 & 0,0001 & 0,0560 & 0,0001 & 0,1796 & 0,0003 & 0,2475 & 0,0003 & 0,2315 & 0,0003 \\
\hline Urbano & $-0,2257$ & 0,0003 & $-0,2000$ & 0,0003 & $-0,2167$ & 0,0003 & $-0,2025$ & 0,0003 & $-0,3479$ & 0,0003 & $-0,3239$ & 0,0003 \\
\hline Dummy RO & 0,3549 & 0,0013 & 0,2219 & 0,0013 & 0,1238 & 0,0013 & $-0,1715$ & 0,0013 & $-0,1150$ & 0,0012 & $-0,1595$ & 0,0012 \\
\hline Dummy AC & 0,3943 & 0,0021 & 0,1947 & 0,0021 & 0,1071 & 0,0020 & 0,1361 & 0,0018 & $-0,0048$ & 0,0018 & $-0,0666$ & 0,0018 \\
\hline Dummy AM & 0,2492 & 0,0010 & 0,0494 & 0,0010 & $-0,0083$ & 0,0010 & 0,3811 & 0,0008 & 0,1156 & 0,0009 & 0,0483 & 0,0008 \\
\hline Dummy RR & 0,0699 & 0,0029 & 0,2858 & 0,0029 & 0,1117 & 0,0028 & $-0,0459$ & 0,0025 & $-0,0696$ & 0,0025 & $-0,1415$ & 0,0024 \\
\hline Dummy PA & 0,5331 & 0,0007 & 0,1858 & 0,0007 & 0,1405 & 0,0007 & 0,2336 & 0,0006 & $-0,0974$ & 0,0006 & $-0,1291$ & 0,0006 \\
\hline Dummy AP & 0,1501 & 0,0025 & 0,0914 & 0,0026 & 0,0308 & 0,0025 & 0,1805 & 0,0020 & 0,1348 & 0,0020 & 0,0413 & 0,0019 \\
\hline Dummy TO & 0,5311 & 0,0014 & 0,1920 & 0,0014 & 0,1319 & 0,0014 & 0,2575 & 0,0013 & 0,0255 & 0,0013 & $-0,0247$ & 0,0013 \\
\hline Dummy MA & 0,8455 & 0,0007 & 0,1634 & 0,0007 & 0,1307 & 0,0007 & 0,6178 & 0,0006 & 0,0688 & 0,0006 & 0,0132 & 0,0006 \\
\hline Dummy PI & 1,0174 & 0,0009 & 0,3872 & 0,0009 & 0,3215 & 0,0009 & 0,5412 & 0,0008 & 0,1214 & 0,0009 & 0,0511 & 0,0008 \\
\hline Dummy CE & 1,0580 & 0,0006 & 0,4305 & 0,0006 & 0,3878 & 0,0006 & 0,5214 & 0,0006 & 0,1039 & 0,0006 & 0,0557 & 0,0005 \\
\hline Dummy RN & 0,7954 & 0,0009 & 0,3067 & 0,0009 & 0,2617 & 0,0009 & 0,3520 & 0,0008 & 0,0751 & 0,0009 & 0,0381 & 0,0008 \\
\hline Dummy PB & 1,0327 & 0,0008 & 0,3676 & 0,0008 & 0,3270 & 0,0008 & 0,4663 & 0,0008 & 0,0648 & 0,0008 & 0,0244 & 0,0008 \\
\hline Dummy PE & 1,0379 & 0,0006 & 0,4708 & 0,0006 & 0,4160 & 0,0006 & 0,5373 & 0,0005 & 0,1069 & 0,0005 & 0,0618 & 0,0005 \\
\hline Dummy AL & 0,7644 & 0,0009 & 0,1824 & 0,0009 & 0,1463 & 0,0009 & 0,5358 & 0,0008 & 0,1133 & 0,0009 & 0,0540 & 0,0008 \\
\hline Dummy SE & 0,6173 & 0,0011 & 0,1520 & 0,0012 & 0,1170 & 0,0011 & 0,3296 & 0,0010 & $-0,0182$ & 0,0011 & $-0,0650$ & 0,0010 \\
\hline Dummy BA & 0,8578 & 0,0005 & 0,2946 & 0,0005 & 0,2461 & 0,0005 & 0,3928 & 0,0005 & 0,0014 & 0,0005 & $-0,0432$ & 0,0004 \\
\hline Dummy MG & 0,2459 & 0,0004 & 0,1338 & 0,0005 & 0,1079 & 0,0004 & $-0,0755$ & 0,0004 & $-0,1118$ & 0,0004 & $-0,1093$ & 0,0004 \\
\hline Dummy ES & 0,1126 & 0,0009 & 0,1189 & 0,0009 & 0,0749 & 0,0009 & $-0,2776$ & 0,0009 & $-0,1175$ & 0,0009 & $-0,1378$ & 0,0008 \\
\hline Dummy RJ & 0,4365 & 0,0005 & 0,2666 & 0,0005 & 0,2441 & 0,0004 & $-0,1050$ & 0,0005 & $-0,0993$ & 0,0005 & $-0,1054$ & 0,0004 \\
\hline Dummy PR & 0,1253 & 0,0006 & 0,1047 & 0,0006 & 0,0898 & 0,0005 & $-0,1434$ & 0,0006 & $-0,0645$ & 0,0005 & $-0,0581$ & 0,0005 \\
\hline Dummy SC & $-0,1245$ & 0,0008 & $-0,0106$ & 0,0008 & $-0,0578$ & 0,0007 & $-0,4953$ & 0,0008 & $-0,2373$ & 0,0008 & $-0,2343$ & 0,0007 \\
\hline Dummy RS & $-0,0280$ & 0,0006 & 0,0864 & 0,0006 & 0,0507 & 0,0005 & $-0,3081$ & 0,0006 & $-0,1029$ & 0,0005 & $-0,1313$ & 0,0005 \\
\hline Dummy MS & 0,5709 & 0,0010 & 0,3251 & 0,0011 & 0,3159 & 0,0010 & 0,2174 & 0,0010 & 0,1095 & 0,0010 & 0,1248 & 0,0010 \\
\hline Dummy MT & 0,5053 & 0,0010 & 0,2425 & 0,0010 & 0,2022 & 0,0010 & 0,0798 & 0,0009 & $-0,0225$ & 0,0009 & $-0,0069$ & 0,0009 \\
\hline Dummy GO & 0,5289 & 0,0007 & 0,2226 & 0,0008 & 0,2153 & 0,0007 & 0,1610 & 0,0007 & $-0,0060$ & 0,0007 & 0,0184 & 0,0007 \\
\hline Dummy DF & 0,7592 & 0,0012 & 0,7655 & 0,0012 & 0,7040 & 0,0011 & 0,3144 & 0,0010 & 0,4826 & 0,0010 & 0,3889 & 0,0010 \\
\hline Pseudo- $\mathrm{R}^{2}$ & \multicolumn{2}{|c|}{0,1872} & \multicolumn{2}{|c|}{0,1017} & \multicolumn{2}{|c|}{0,1093} & \multicolumn{2}{|c|}{0,1662} & \multicolumn{2}{|c|}{0,1170} & \multicolumn{2}{|c|}{0,1227} \\
\hline $\begin{array}{l}\text { número de } \\
\text { observações }\end{array}$ & \multicolumn{6}{|c|}{145.303 .385} & \multicolumn{6}{|c|}{168.584 .058} \\
\hline
\end{tabular}

Obs.: (1) A Dummy SP (Estado de São Paulo) foi retirada da regressão para evitar o problema de multicolinearidade perfeita. Portanto, é a variável de estado referência.

(2) As variáveis dependentes são dummies que recebem o valor 1 (um) quando o individuo é pobre, considerando certa linha de pobreza: pobre (dummy considerando linha absoluta de pobreza); pobre30 (dummy considerando linha híbrida com linha relativa de 30\%); e pobre 50 (dummy considerando linha híbrida com linha relativa de $50 \%$ ).

(3) Todas as estimações usam White robusto para heterocedasticidade. 


\section{c) Resultados para o Capítulo 4}

Tabela 14.C - Estimações de Logaritmo da Incidência da Pobreza em Logaritmos da Renda e Desigualdade

\begin{tabular}{|c|c|c|c|c|c|c|c|c|c|}
\hline \multirow{2}{*}{$\begin{array}{l}\text { Variável dependente: } \\
\text { Proporção de Pobres }\end{array}$} & \multicolumn{3}{|c|}{ MQO } & \multicolumn{3}{|c|}{ Efeitos Fixos } & \multicolumn{3}{|c|}{ Efeitos Aleatórios } \\
\hline & sem indice & com Gini & com Theil & sem índice & com Gini & com Theil & sem índice & com Gini & com Theil \\
\hline Intercepto & 3,4134 & 4,2012 & 3,7866 & 2,4725 & 4,2723 & 3,8893 & 3,0166 & 3,8872 & 3,3912 \\
\hline mетсеріо & $(0,077)$ & $(0,117)$ & $(0$, & $(0,125)$ & $(0,141)$ & $(0,136)$ & $(0,043)$ & $(0,057)$ & $(0,046)$ \\
\hline Ren & $\begin{array}{l}-0,9123 \\
(0,017) \\
\end{array}$ & $\begin{array}{c}-0,8848 \\
(0,015) \\
\end{array}$ & $\begin{array}{r}-0,9261 \\
(0,017) \\
\end{array}$ & $\begin{array}{l}-0,7118 \\
(0,025) \\
\end{array}$ & $\begin{array}{r}-0,8960 \\
(0,024) \\
\end{array}$ & $\begin{array}{r}-0,9462 \\
(0,026) \\
\end{array}$ & $\begin{array}{r}-0,8183 \\
(0,009) \\
\end{array}$ & $\begin{array}{l}-0,8178 \\
(0,008) \\
\end{array}$ & $\begin{array}{l}-0,8457 \\
(0,009) \\
\end{array}$ \\
\hline $\begin{array}{c}\text { Indice de Desigualdade de } \\
\text { Renda }\end{array}$ & & $\begin{array}{l}1,4242 \\
(0,109) \\
\end{array}$ & $\begin{array}{l}0,4815 \\
(0,035) \\
\end{array}$ & & $\begin{array}{l}1,3897 \\
(0,048) \\
\end{array}$ & $\begin{array}{l}0,4035 \\
(0,015) \\
\end{array}$ & & $\begin{array}{l}1,4135 \\
(0,043) \\
\end{array}$ & $\begin{array}{l}0,4324 \\
(0,014) \\
\end{array}$ \\
\hline Dummy do ano de 1991 & $\begin{array}{l}0,1759 \\
(0,012)\end{array}$ & $\begin{array}{l}0,2149 \\
(0,012) \\
\end{array}$ & $\begin{array}{l}0,1784 \\
(0,011) \\
\end{array}$ & $\begin{array}{l}0,2019 \\
(0,009) \\
\end{array}$ & $\begin{array}{l}0,1786 \\
(0,007)\end{array}$ & $\begin{array}{l}0,1311 \\
(0,008)\end{array}$ & $\begin{array}{l}0,1626 \\
(0,004)\end{array}$ & $\begin{array}{l}0,2082 \\
(0,004)\end{array}$ & $\begin{array}{l}0,1693 \\
(0,004) \\
\end{array}$ \\
\hline $\mathrm{R}^{2}$ & 0,6375 & 0,7079 & 0,6969 & 0,7217 & 0,8091 & 0,7768 & 0,7204 & 0,8082 & 0,7747 \\
\hline $\mathrm{n}^{\circ}$ de observações & & 8576 & & & 8576 & & & 8576 & \\
\hline
\end{tabular}

Obs.: (1) MQO corresponde ao método de Mínimos Quadrados Ordinários com os dois anos (1991 e 2000).

(2) Os valores entre parênteses abaixo de cada coeficiente correspondem ao respectivo desvio-padrão.

(3) Todas as estimações usam White robusto para heterocedasticidade.

Tabela 15.C - Testes de Verificação dos Métodos Aplicados

\begin{tabular}{ccccccc}
\hline Testes & \multicolumn{2}{c}{ sem índice } & \multicolumn{2}{c}{ com Gini } & \multicolumn{2}{c}{ com Theil } \\
\cline { 2 - 7 } & Qui-Quadrado & p-valor & Qui-Quadrado & p-valor & Qui-Quadrado & p-valor \\
\hline $\begin{array}{c}\text { Wald modificado para } \\
\text { heterocedasticidade em Efeitos Fixos }\end{array}$ & $2,6 \mathrm{E}+31$ & 0,000 & $0,0 \mathrm{E}+00$ & 1,000 & $0,0 \mathrm{E}+00$ & 1,000 \\
\hline $\begin{array}{c}\text { Breuch Pagan - existência de efeito } \\
\text { individual não observado }\end{array}$ & 1651 & 0,000 & 1859 & 0,000 & 1639 & 0,000 \\
\hline Hausman & 27 & 0,000 & 32 & 0,000 & 87 & 0,000 \\
\hline
\end{tabular}

Tabela 16.C - Estimações em Logaritmo da Incidência da Pobreza em Renda e Desigualdade por MQVD com Peso

\begin{tabular}{cccc}
\hline Variável dependente: & \multicolumn{3}{c}{ MQVD } \\
\cline { 2 - 4 } Proporção de Pobres & sem índice & com Gini & com Theil \\
\hline Intercepto & 2,2716 & 4,9001 & 4,3584 \\
& $(0,239)$ & $(0,331)$ & $(0,294)$ \\
\hline \multirow{2}{*}{ Renda Familiar per Capita } & $-0,6887$ & $-1,0075$ & $-1,0395$ \\
& $(0,047)$ & $(0,053)$ & $(0,055)$ \\
\hline \multirow{2}{*}{ Índice de Desigualdade de Renda } & & 1,5299 & 0,4654 \\
& & $(0,128)$ & $(0,038)$ \\
\hline \multirow{2}{*}{ Dummy do ano de 1991 } & 0,2605 & 0,1638 & 0,1288 \\
& $(0,018)$ & $(0,014)$ & $(0,016)$ \\
\hline $\mathrm{R}^{2}$ Ajustado & 0,8148 & 0,8640 & 0,8468 \\
\hline $\mathrm{n}^{\circ}$ de observações & \multicolumn{3}{c}{8576} \\
\hline
\end{tabular}

Obs.: (1) MQVD corresponde ao método de Mínimos Quadrados com Variáveis Dummy considerando os dois anos (1991 e 2000).

(2) Os valores entre parênteses abaixo de cada coeficiente correspondem ao respectivo desvio-padrão.

(3) Todas as estimações usam White robusto para heterocedasticidade. 
Tabela 17.C - Estimações da Diferença dos Logaritmos da Incidência da Pobreza nas Variáveis de Renda e Desigualdade

\begin{tabular}{|c|c|c|c|c|c|}
\hline \multirow{3}{*}{\multicolumn{2}{|c|}{$\begin{array}{l}\text { Variável dependente: } \\
\text { Variação na proporção de pobres }\end{array}$}} & \multicolumn{4}{|c|}{ Expansão do Modelo Básico } \\
\hline & & \multicolumn{2}{|c|}{ Equação (17) } & \multicolumn{2}{|c|}{ Equação (18) } \\
\hline & & \multirow{2}{*}{$\begin{array}{c}\text { com Gini } \\
-0,12385 \\
(0,015)\end{array}$} & \multirow{2}{*}{$\begin{array}{c}\text { com Theil } \\
-0,07428 \\
(0,018)\end{array}$} & \multirow{2}{*}{$\begin{array}{c}\text { com Gini } \\
-0,07673 \\
(0,015)\end{array}$} & \multirow{2}{*}{$\begin{array}{c}\text { com Theil } \\
-0,05134 \\
(0,018)\end{array}$} \\
\hline$\alpha$ & Intercepto & & & & \\
\hline$\Delta \mathrm{G}$ & $\begin{array}{l}\text { Variação na Renda } \\
\text { Familiar per Capita }\end{array}$ & $\begin{array}{c}-3,34027 \\
(0,400)\end{array}$ & $\begin{array}{c}-2,31094 \\
(0,211)\end{array}$ & $\begin{array}{c}-3,22598 \\
(0,389)\end{array}$ & $\begin{array}{c}-2,34485 \\
(0,205)\end{array}$ \\
\hline$\Delta \mathrm{D}$ & $\begin{array}{l}\text { Variação no Índice de } \\
\text { desigualdade de renda }\end{array}$ & $\begin{array}{c}1,76259 \\
(0,155)\end{array}$ & $\begin{array}{l}0,55903 \\
(0,047)\end{array}$ & $\begin{array}{c}3,87557 \\
(0,861)\end{array}$ & $\begin{array}{c}1,12503 \\
(0,161)\end{array}$ \\
\hline$\Delta G$ & $\left(\frac{\text { linha absoluta de pobreza }}{\text { renda per capita familiar }}\right)$ & $\begin{array}{c}0,68767 \\
(0,051)\end{array}$ & $\begin{array}{c}0,83761 \\
(0,067)\end{array}$ & $\begin{array}{c}0,85481 \\
(0,064)\end{array}$ & $\begin{array}{c}0,92973 \\
(0,071)\end{array}$ \\
\hline & $\begin{array}{c}\Delta \mathrm{G} \text {.(índice inicial de } \\
\text { desigualdade de renda) }\end{array}$ & $\begin{array}{c}3,38733 \\
(0,641)\end{array}$ & $\begin{array}{c}0,98487 \\
(0,220)\end{array}$ & $\begin{array}{c}2,78516 \\
(0,609)\end{array}$ & $\begin{array}{c}0,82276 \\
(0,202)\end{array}$ \\
\hline & $\left(\frac{\text { linha absoluta de pobreza }}{\text { renda per capita familiar }}\right)$ & & & $\begin{array}{c}-1,92789 \\
(0,275)\end{array}$ & $\begin{array}{c}-0,59955 \\
(0,085)\end{array}$ \\
\hline & $\begin{array}{c}\Delta \mathrm{D} \text {.(índice inicial de } \\
\text { desigualdade de renda) }\end{array}$ & & & $\begin{array}{c}-1,46881 \\
(1,157) \\
\end{array}$ & $\begin{array}{c}-0,24364 \\
(0,116) \\
\end{array}$ \\
\hline $\mathrm{R}^{2}$ & & 0,4942 & 0,4312 & 0,5555 & 0,4731 \\
\hline $\mathrm{n}^{\circ} \mathrm{de}$ & observações & & 88 & & \\
\hline
\end{tabular}

(2) Todas as estimações usam White robusto para heterocedasticidade.

Tabela 18.C - Comparativo entre as Elasticidades-Renda $\left(\varepsilon_{\mathrm{y}}\right.$ e $\left.\varepsilon_{\mathrm{m}}\right)$ e ElasticidadesDesigualdade $\left(\boldsymbol{\varepsilon}_{\mathrm{G}}\right)$

\begin{tabular}{|c|c|c|c|c|c|c|c|c|c|c|c|c|c|c|c|c|c|c|c|c|}
\hline \multirow{3}{*}{ Estado } & \multicolumn{7}{|c|}{1991} & \multicolumn{7}{|c|}{2000} & \multicolumn{6}{|c|}{ Hoffmann (2004) } \\
\hline & \multirow{2}{*}{$\begin{array}{l}\text { Linha de } \\
\text { Pobreza }\end{array}$} & \multicolumn{3}{|c|}{ Gini } & \multicolumn{3}{|c|}{ Theil } & \multirow{2}{*}{ ha de } & \multicolumn{3}{|c|}{ Gini } & \multicolumn{3}{|c|}{ Theil } & \multicolumn{2}{|c|}{1999} & \multicolumn{2}{|c|}{2001} & \multicolumn{2}{|c|}{2002} \\
\hline & & $\sigma$ & $\varepsilon_{y}$ & $\varepsilon_{G}$ & $\sigma$ & $\varepsilon_{y}$ & G & & $\sigma$ & $\varepsilon_{y}$ & $\varepsilon_{G}$ & $\sigma$ & $\varepsilon_{y}$ & $\varepsilon_{G}$ & $m$ & G & $\varepsilon_{m}$ & G & $\varepsilon_{m}$ & $\varepsilon_{G}$ \\
\hline O & 6926 & ,22 & $-0,70$ & 1,47 & 1,25 & $-0,67$ & 0,55 & 18 & 7 & $-0,97$ & 2,38 & 1,20 & $-0,92$ & & 1,01 & 2,05 & 0,92 & 1,60 & 1,00 & \\
\hline & & & & & & & & & & & 75 & & $-0,67$ & & & & 0,14 & 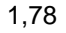 & & \\
\hline AM & & & & & & & & & & & & & & & & & & & & \\
\hline $\mathrm{RF}$ & & 2 & $-0,81$ & 2,49 & 26 & $-0,89$ & 0 & & 1,20 & $-0,89$ & 2,22 & 1,20 & $-0,90$ & & ,22 & 2,18 & $-0,90$ & & ),76 & 1,1 \\
\hline $\mathrm{P} /$ & & & $-0,61$ & 1,20 & 30 & $-0,57$ & & & & $-0,65$ & 1,44 & & $-0,61$ & & $-0,77$ & 15 & $-0,78$ & 1,16 & ,78 & \\
\hline $\mathrm{AF}$ & & & & & & 84 & & & & & 88 & & $-0,77$ & & & 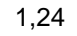 & $x_{2}$ & 97 & & 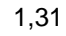 \\
\hline . & & & 60 & & & $-0,54$ & & & & & 1,56 & & $-0,63$ & & & & $-0,64$ & 0 & & \\
\hline MA & & & 48 & & & $-0,42$ & & & & & & & $-0,47$ & & & & 52 & & & \\
\hline$P$ & & & 41 & 0,62 & & & & & & & & & & & & & 52 & 8 & & , \\
\hline $\mathrm{CE}$ & & & 44 & & & D & & & & & 28 & & & & & & $-0,53$ & 1 & & 0,8 \\
\hline $\mathrm{nl}$ & & & 55 & & &, 52 & & & & $-0,68$ & 61 & & $-0,66$ & & & 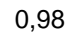 & $-0,64$ & yl & & 0,9 \\
\hline $\mathrm{PE}$ & & & & & & & & & & & & & & & & & & & & \\
\hline$P E$ & & & & & & & & & & & , & & & & & 0 & $-0,56$ & 3 & & 0, \\
\hline & & & 52 & 87 & & 7 & & & & -0 & & & & & & 70 & 0,49 & 55 & & 0,6 \\
\hline$S$ & & & 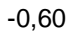 & & &, 55 & & & & -0 & & & & & & 1,00 & $-0,64$ & 0,87 & & $0, \mathrm{c}$ \\
\hline & & & & & & & & & & & & & & & & & & & & $0, \mathrm{c}$ \\
\hline & & & & & & & & & & & & & & & & & -0 & 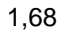 & & 17 \\
\hline $\mathrm{ES}$ & & & - & & & 9 & & & & & 02 & & & & & 1,74 & 0,82 & 1,69 & & 1,8 \\
\hline $\mathrm{h}$ & & & $-0,83$ & , & 21 & $-0,80$ & 0,7 & & & & 2 & & & & & 5 & 3 & 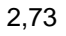 & 3 & 2,8 \\
\hline & & & & & & & & & & & & & & & & & & & & 2,9 \\
\hline & & & & & & & & & & & & & & & & & & & & \\
\hline & & & & & & 2 & & & & & & & & & & & 47 & 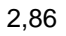 & & 2,9 \\
\hline $\mathrm{R}$ & & & & 2,82 & & & & & & & 3 & & & & & 2,45 & 14 & 2,51 & & 2,5 \\
\hline & & & & & & & & & & & & & & & & & & & & \\
\hline & & & & & & & & & & & & & & & & & & & & \\
\hline & & & & & & 1 & & & & & & & -0 & & & 1,65 & $-0,91$ & 1,72 & 98 & 1,8 \\
\hline & & & & & & & & & & & & & & & & & & & 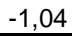 & \\
\hline & & & $0, r 1$ & & & $0, \pi 0$ & & & $T, \angle U$ & & 2,16 & $T, \angle U$ & & & & 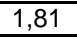 & . & 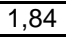 & , & \\
\hline
\end{tabular}

Obs.: (1) Os valores da coluna Linha de Pobreza correspondem às linhas da Tabela 2 abertas por estado e ponderadas pela população de cada estrato. 
(2) $\sigma$ é o desvio-padrão do logaritmo da renda, calculado a partir do índice de Gini, para a elasticidaderenda e elasticidade-desigualdade de Gini. Já para as elasticidades de Theil, $\sigma$ é calculado a partir do índice de desigualdade de Theil.

(3) Os valores $\varepsilon_{\mathrm{y}}$ e $\varepsilon_{\mathrm{G}}$ correspondem às elasticidades pela metodologia descrita no Apêndice F, usando os Censos de 1991 e 2000.

(4) Os valores $\varepsilon_{\mathrm{m}}$ e $\varepsilon_{\mathrm{G}}$ de Hoffmann (2004) correspondem às elasticidades com relação à renda e desigualdade, respectivamente, usando o índice de Gini, a partir das PNAD's de 1999, 2001 e 2002.

Tabela 19.C - Resultados do Teste Log-Normal com base em Bourguignon (2002)

\begin{tabular}{|c|c|c|c|c|c|}
\hline \multirow{3}{*}{\multicolumn{2}{|c|}{$\begin{array}{l}\text { Variável dependente: } \\
\text { Variação na proporção de pobres }\end{array}$}} & \multicolumn{4}{|c|}{ Teste - Modelo Lognormal } \\
\hline & & \multicolumn{2}{|c|}{ Equação (19) } & \multicolumn{2}{|c|}{ Equação (21) } \\
\hline & & com Gini & com Theil & com Gini & com Theil \\
\hline & Intercepto & $\begin{array}{c}-0,20242 \\
(0,024)\end{array}$ & $\begin{array}{c}-0,16874 \\
(0,029)\end{array}$ & $\begin{array}{c}-0,09925 \\
(0,028)\end{array}$ & $\begin{array}{c}-0,10449 \\
(0,032)\end{array}$ \\
\hline \multirow[t]{2}{*}{$\Delta \mathrm{D}$} & $\begin{array}{l}\text { Variação no Índice de } \\
\text { desigualdade de renda }\end{array}$ & $\begin{array}{l}1,57033 \\
(0,136) \\
\end{array}$ & $\begin{array}{c}0,51531 \\
(0,045) \\
\end{array}$ & & \\
\hline & $\Delta \mathrm{G} \cdot \mathrm{E}_{\mathrm{G}}$ & $\begin{array}{c}-1,04675 \\
(0,092) \\
\end{array}$ & $\begin{array}{c}-1,14332 \\
(0,116) \\
\end{array}$ & $\begin{array}{c}-1,21680 \\
(0,097) \\
\end{array}$ & $\begin{array}{c}-1,30124 \\
(0,120) \\
\end{array}$ \\
\hline \multicolumn{2}{|r|}{$\Delta \mathrm{D} . \mathrm{E}_{\mathrm{D}}$} & & & $\begin{array}{c}0,65399 \\
(0,069)\end{array}$ & $\begin{array}{l}1,11601 \\
(0,126)\end{array}$ \\
\hline \multirow{2}{*}{\multicolumn{2}{|c|}{$\frac{\mathrm{R}^{2}}{\mathrm{n}^{\circ} \text { de observações }}$}} & 0,4764 & 0,4079 & 0,6062 & 0,5133 \\
\hline & & \multicolumn{2}{|c|}{4288} & \multicolumn{2}{|c|}{4288} \\
\hline
\end{tabular}

Obs.: (1) Os valores entre parênteses abaixo de cada coeficiente correspondem ao respectivo desvio-padrão.

(2) Todas as estimações usam White robusto para heterocedasticidade.

Tabela 20.C - Teste dos Coeficientes dos Termos das Elasticidades

\begin{tabular}{ccccc}
\hline \multirow{2}{*}{ variável } & \multicolumn{4}{c}{$\mathrm{p}$-valor } \\
\cline { 2 - 5 } & \multicolumn{2}{c}{ Equação (19) } & \multicolumn{2}{c}{ Equação (21) } \\
\cline { 2 - 5 } & com Gini & com Theil & com Gini & com Theil \\
\hline$\Delta$ G.E $_{\mathrm{G}}$ & 0,6118 & 0,2168 & 0,0257 & 0,0123 \\
\hline$\Delta \mathrm{D} . \mathrm{E}_{\mathrm{D}}$ & & & 0,0000 & 0,3563 \\
\hline
\end{tabular}

Obs.: (1) Hipóteses Nulas: Coeficiente da Elasticidade-Renda $=-1$

e Coeficiente da Elasticidade-Desigualdade $=1$.

Tabela 21.C - Estimações em Logaritmo da Incidência da Pobreza em Renda, Desigualdade e Linha Híbrida

\begin{tabular}{|c|c|c|c|c|c|c|c|c|}
\hline \multirow{3}{*}{$\begin{array}{l}\text { Variável dependente: } \\
\text { Proporção de Pobres }\end{array}$} & \multicolumn{4}{|c|}{ Efeitos Fixos } & \multicolumn{4}{|c|}{ Efeitos Aleatórios } \\
\hline & \multicolumn{2}{|c|}{ Zh30 } & \multicolumn{2}{|c|}{ Zh50 } & \multicolumn{2}{|c|}{ Zh30 } & \multicolumn{2}{|c|}{ Zh50 } \\
\hline & com Gini & com Theil & com Gini & com Theil & com Gini & com Theil & com Gini & com Theil \\
\hline Intercepto & $\begin{array}{l}1,5325 \\
(0,090) \\
\end{array}$ & $\begin{array}{l}1,6342 \\
(0,107) \\
\end{array}$ & $\begin{array}{l}0,3980 \\
(0,054) \\
\end{array}$ & $\begin{array}{l}0,6902 \\
(0,066) \\
\end{array}$ & $\begin{array}{l}1,5022 \\
(0,020) \\
\end{array}$ & $\begin{array}{l}0,8434 \\
(0,022) \\
\end{array}$ & $\begin{array}{l}0,6082 \\
(0,013) \\
\end{array}$ & $\begin{array}{l}0,2218 \\
(0,016) \\
\end{array}$ \\
\hline Renda Familiar per Capita & $\begin{array}{r}-1,0291 \\
(0,035) \\
\end{array}$ & $\begin{array}{l}-0,6340 \\
(0,043)\end{array}$ & $\begin{array}{l}-0,8788 \\
(0,024)\end{array}$ & $\begin{array}{l}-0,6422 \\
(0,028)\end{array}$ & $\begin{array}{r}-1,3563 \\
(0,018) \\
\end{array}$ & $\begin{array}{r}-1,2479 \\
(0,023) \\
\end{array}$ & $\begin{array}{r}-1,0730 \\
(0,011) \\
\end{array}$ & $\begin{array}{r}-1,0098 \\
(0,014) \\
\end{array}$ \\
\hline $\begin{array}{c}\text { Indice de Desigualdade de } \\
\text { Renda }\end{array}$ & $\begin{array}{l}1,9142 \\
(0,034)\end{array}$ & $\begin{array}{l}0,5758 \\
(0,011)\end{array}$ & $\begin{array}{l}1,2709 \\
(0,019)\end{array}$ & $\begin{array}{l}0,4045 \\
(0,007)\end{array}$ & $\begin{array}{l}2,1488 \\
(0,025)\end{array}$ & $\begin{array}{l}0,6793 \\
(0,010)\end{array}$ & $\begin{array}{l}1,4403 \\
(0,013)\end{array}$ & $\begin{array}{l}0,4779 \\
(0,005)\end{array}$ \\
\hline Linha Híbrida c & $\begin{array}{l}0,8768 \\
(0,049) \\
\end{array}$ & $\begin{array}{l}0,1352 \\
(0,065) \\
\end{array}$ & $\begin{array}{l}0,8968 \\
(0,032) \\
\end{array}$ & $\begin{array}{l}0,4246 \\
(0,038) \\
\end{array}$ & $\begin{array}{l}1,3347 \\
(0,023) \\
\end{array}$ & $\begin{array}{l}1,1230 \\
(0,030) \\
\end{array}$ & $\begin{array}{l}1,0995 \\
(0,015) \\
\end{array}$ & $\begin{array}{l}0,9699 \\
(0,019) \\
\end{array}$ \\
\hline Dummy do ano de 1991 & $\begin{array}{l}0,0968 \\
(0,005)\end{array}$ & $\begin{array}{l}0,0373 \\
(0,007)\end{array}$ & $\begin{array}{l}0,1205 \\
(0,003)\end{array}$ & $\begin{array}{l}0,0615 \\
(0,004)\end{array}$ & $\begin{array}{l}0,0862 \\
(0,002)\end{array}$ & $\begin{array}{l}0,0361 \\
(0,003)\end{array}$ & $\begin{array}{l}0,1063 \\
(0,002) \\
\end{array}$ & $\begin{array}{l}0,0687 \\
(0,002)\end{array}$ \\
\hline $\mathrm{R}^{2}$ & 0,8112 & 0,6984 & 0,8629 & 0,7939 & 0,8064 & 0,6742 & 0,8585 & 0,7790 \\
\hline$\overline{n^{\circ} d}$ & & & & & & & & \\
\hline
\end{tabular}

Obs.: (1) Os valores entre parênteses abaixo de cada coeficiente correspondem ao respectivo desvio-padrão.

(2) Todas as estimações usam White robusto para heterocedasticidade.

(3) As colunas Zh30 e Zh50 indicam os valores correspondentes às linhas híbridas considerando linhas relativas de $30 \%$ e $50 \%$ da renda média, respectivamente. 
Tabela 22.C - Testes de Verificação dos Métodos Aplicados

\begin{tabular}{|c|c|c|c|c|c|c|c|c|}
\hline \multirow{3}{*}{ Testes } & \multicolumn{4}{|c|}{ Zh30 } & \multicolumn{4}{|c|}{ Zh50 } \\
\hline & \multicolumn{2}{|c|}{ com Gini } & \multicolumn{2}{|c|}{ com Theil } & \multicolumn{2}{|c|}{ com Gini } & \multicolumn{2}{|c|}{ com Theil } \\
\hline & Qui-Quadrado & $p$-valor & Qui-Quadrado & $p$-valor & Qui-Quadrado & $p$-valor & Qui-Quadrado & p-valor \\
\hline $\begin{array}{c}\text { Wald modificado para } \\
\text { heterocedasticidade em Efeitos Fixos }\end{array}$ & $5,5 E+31$ & 0,000 & $3,4 \mathrm{E}+31$ & 0,000 & $3,8 \mathrm{E}+31$ & 0,000 & $2,4 \mathrm{E}+35$ & 0,000 \\
\hline $\begin{array}{l}\text { Breuch Pagan - existência de efeito } \\
\text { individual não observado }\end{array}$ & 189 & 0,000 & 308 & 0,000 & 375 & 0,000 & 409 & 0,000 \\
\hline Hausman & 220 & 0,000 & 529 & 0,000 & 170 & 0,000 & 332 & 0,000 \\
\hline
\end{tabular}

Obs.: (1) Os valores entre parênteses abaixo de cada coeficiente correspondem ao respectivo desvio-padrão.

(2) Todas as estimações usam White robusto para heterocedasticidade.

(3) As colunas Zh30 e Zh50 indicam os valores correspondentes às linhas híbridas considerando linhas relativas de $30 \%$ e $50 \%$ da renda média, respectivamente.

Tabela 23.C - Estimações em Logaritmo da Incidência da Pobreza em Renda, Desigualdade e Linha Híbrida por MQVD com Peso

\begin{tabular}{ccccc}
\hline \multirow{2}{*}{ Variável dependente: } & \multicolumn{4}{c}{ MQVD } \\
\cline { 2 - 5 } Proporção de Pobres & \multicolumn{3}{c}{ Zh30 } & \multicolumn{2}{c}{ Zh50 } \\
\cline { 2 - 5 } Intercepto & com Gini & com Theil & com Gini & com Theil \\
\hline \multirow{2}{*}{ Renda Familiar per Capita } & $-0,9022$ & 1,8148 & 0,7085 & 0,9033 \\
& $(0,311)$ & $(0,327)$ & $(0,110)$ & $(0,140)$ \\
\hline \multirow{2}{*}{ Índice de Desigualdade de Renda } & $2,0,0564$ & $-0,5286$ & $-0,7801$ & $-0,5355$ \\
& $(0,109)$ & $(0,033)$ & $(0,038)$ & $(0,013)$ \\
\hline \multirow{2}{*}{ Linha Híbrida de Pobreza } & 0,6993 & $-0,0424$ & 0,7187 & 0,2523 \\
& $(0,166)$ & $(0,211)$ & $(0,077)$ & $(0,089)$ \\
\hline \multirow{2}{*}{ Dummy do ano de 1991 } & 0,1021 & 0,0550 & 0,1227 & 0,0701 \\
& $(0,009)$ & $(0,012)$ & $(0,005)$ & $(0,007)$ \\
\hline $\mathrm{R}^{2}$ Ajustado & 0,8488 & 0,7943 & 0,9278 & 0,8914 \\
\hline $\mathrm{n}^{\circ}$ de observações & \multicolumn{2}{c}{8576} & 8576 \\
\hline
\end{tabular}

Obs.: (1) MQVD corresponde ao método de Mínimos Quadrados com Variáveis Dummy considerando os dois anos (1991 e 2000).

(2) Os valores entre parênteses abaixo de cada coeficiente correspondem ao respectivo desvio-padrão.

(3) Todas as estimações usam White robusto para heterocedasticidade.

(4) As colunas Zh30 e Zh50 indicam os valores correspondentes às linhas híbridas considerando linhas relativas de $30 \%$ e $50 \%$ da renda média, respectivamente.

Tabela 24.C - Cálculo da Elasticidade-Renda da Pobreza $\left(\varepsilon_{r}\right)$

\begin{tabular}{cccccccc}
\hline \multirow{2}{*}{$\begin{array}{c}\text { Linha } \\
\text { Híbrida }\end{array}$} & $\begin{array}{c}\text { Índice de } \\
\text { Desigualdade }\end{array}$ & \multirow{2}{*}{$\beta_{1}$} & \multirow{2}{*}{$\beta_{3}$} & & \multicolumn{2}{c}{1991} & \multicolumn{2}{c}{2000} \\
\cline { 5 - 8 } & & & & $\rho_{t}$ & $\varepsilon_{r}$ & $\rho_{t}$ & $\varepsilon_{\mathrm{r}}$ \\
\hline Zh30 & \multirow{2}{*}{ Gini } & $-0,94763$ & 0,69935 & 0,60730 & $-0,52291$ & \multirow{2}{*}{0,67120} & $-0,47822$ \\
Zh50 & & $-0,78011$ & 0,71875 & & $-0,34362$ & & $-0,29769$ \\
\hline Zh30 & \multirow{2}{*}{ Theil } & $-0,52860$ & $-0,04238$ & \multirow{2}{*}{0,60730} & $-0,55433$ & \multirow{2}{*}{0,67120} & $-0,55704$ \\
Zh50 & & $-0,53546$ & 0,25233 & & $-0,38222$ & & $-0,36609$ \\
\hline
\end{tabular}

Obs.: (1) As linhas Zh30 e Zh50 indicam os valores correspondentes às linhas híbridas considerando linhas relativas de $30 \%$ e $50 \%$ da renda média, respectivamente.

(2) As colunas $\beta_{1}$ e $\beta_{3}$ correspondem aos coeficientes da Renda Familiar per Capita e Linha Hibrida de Pobreza da Tabela 23, respectivamente.

(3) As colunas $\rho_{t}$ correspondem aos valores da elasticidade-renda da linha de pobreza calculados no capítulo anterior e apresentados na Tabela 6. 


\section{d) Resultados para o Apêndice B}

Tabela B3.C - Regressão Hedônica

\begin{tabular}{|c|c|c|c|c|c|c|c|c|c|c|c|c|}
\hline \multirow{4}{*}{$\begin{array}{l}\text { Ano: } \\
\text { Modelo: } \\
\text { Variável Dependente: }\end{array}$} & \multicolumn{6}{|c|}{1991} & \multicolumn{6}{|c|}{2000} \\
\hline & \multirow{2}{*}{\multicolumn{2}{|c|}{$\begin{array}{c}\text { Linear } \\
\text { Aluguel }\end{array}$}} & \multirow{2}{*}{\multicolumn{2}{|c|}{$\begin{array}{l}\text { Log-Linear } \\
\text { Ln(Aluguel) }\end{array}$}} & \multirow{2}{*}{\multicolumn{2}{|c|}{$\begin{array}{c}\text { Duplo-Log } \\
\text { Ln(Aluguel) }\end{array}$}} & \multirow{2}{*}{\multicolumn{2}{|c|}{$\begin{array}{l}\text { Linear } \\
\text { Aluguel }\end{array}$}} & \multirow{2}{*}{\multicolumn{2}{|c|}{$\begin{array}{l}\text { Log-Linear } \\
\text { Ln(Aluguel) }\end{array}$}} & \multirow{2}{*}{\multicolumn{2}{|c|}{ Duplo-Log }} \\
\hline & & & & & & & & & & & & \\
\hline & Coeficiente & $\begin{array}{l}\text { desvio- } \\
\text { padrão }\end{array}$ & Coeficiente & $\begin{array}{l}\text { desvio- } \\
\text { padrão }\end{array}$ & Coeficiente & $\begin{array}{l}\text { desvio- } \\
\text { padrão }\end{array}$ & Coeficiente & $\begin{array}{l}\text { desvio- } \\
\text { padrão }\end{array}$ & oeficiente & $\begin{array}{l}\text { desvio- } \\
\text { padrão }\end{array}$ & oeficiente & $\begin{array}{l}\text { desvio- } \\
\text { padrão }\end{array}$ \\
\hline \multicolumn{13}{|l|}{ Variáveis Independente: } \\
\hline Intercepto & 5,527 & 0,508 & 1,823 & 0,006 & 2,048 & 0,007 & 51,367 & 0,577 & 3,034 & 0,004 & 3,321 & 0,004 \\
\hline Casa & $-87,792$ & 0,164 & $-0,589$ & 0,001 & $-0,613$ & 0,001 & $-117,861$ & 0,167 & $-0,467$ & 0,0004 & $-0,472$ & 0,0004 \\
\hline Quartos & 33,864 & 0,071 & 0,201 & 0,0004 & & & 52,305 & 0,090 & 0,208 & 0,0002 & & \\
\hline Ln(Quartos) & & & & & 0,345 & 0,001 & & & & & 0,357 & 0,0004 \\
\hline Outros Cômodos & 35,536 & 0,074 & 0,190 & 0,0002 & & & 46,333 & 0,085 & 0,150 & 0,0002 & & \\
\hline Ln(Outros Cômodos) & & & & & 0,594 & 0,001 & & & & & 0,535 & 0,0004 \\
\hline Paredes & 18,534 & 0,331 & 0,455 & 0,004 & 0,473 & 0,005 & & & & & & \\
\hline Telhado & 1,959 & 0,257 & $-0,048$ & 0,002 & $-0,056$ & 0,003 & & & & & & \\
\hline Banheiro & $-28,434$ & 0,137 & 0,038 & 0,001 & $-0,055$ & 0,001 & $-24,264$ & 0,291 & 0,119 & 0,001 & 0,016 & 0,001 \\
\hline Água & $-6,424$ & 0,092 & 0,345 & 0,001 & 0,330 & 0,001 & $-6,625$ & 0,158 & 0,306 & 0,001 & 0,292 & 0,001 \\
\hline Esgoto & 16,704 & 0,082 & 0,261 & 0,001 & 0,273 & 0,001 & 37,554 & 0,087 & 0,337 & 0,0005 & 0,341 & 0,0005 \\
\hline Lixo & 16,994 & 0,078 & 0,331 & 0,001 & 0,346 & 0,001 & 32,677 & 0,188 & 0,432 & 0,001 & 0,440 & 0,001 \\
\hline Eletricidade & $-2,161$ & 0,171 & 0,528 & 0,003 & 0,551 & 0,004 & $-21,850$ & 0,449 & 0,319 & 0,003 & 0,260 & 0,004 \\
\hline Região Metropolitana & 43,405 & 0,106 & 0,333 & 0,001 & 0,335 & 0,001 & 100,175 & 0,125 & 0,437 & 0,0003 & 0,451 & 0,0003 \\
\hline Urbano & 18,124 & 0,149 & 0,310 & 0,002 & 0,322 & 0,002 & 29,819 & 0,212 & 0,263 & 0,001 & 0,246 & 0,001 \\
\hline Dummy RO & $-27,063$ & 0,472 & $-0,019$ & 0,004 & $-0,027$ & 0,004 & $-73,730$ & 0,497 & $-0,330$ & 0,002 & $-0,318$ & 0,002 \\
\hline Dummy AC & $-13,483$ & 0,897 & $-0,147$ & 0,011 & $-0,103$ & 0,010 & 2,542 & 1,326 & 0,021 & 0,005 & 0,087 & 0,005 \\
\hline AM & 71,028 & 1,081 & 0,368 & 0,004 & 0,371 & 0,004 & $-49,409$ & 0,604 & $-0,339$ & 0,003 & $-0,316$ & 0,003 \\
\hline Dummy RR & 3,090 & 1,040 & 0,180 & 0,010 & 0,245 & 0,010 & $-55,831$ & 1,068 & $-0,227$ & 0,006 & $-0,184$ & 0,006 \\
\hline Dummy PA & $-46,543$ & 0,331 & $-0,351$ & 0,002 & $-0,340$ & 0,003 & $-91,716$ & 0,264 & $-0,413$ & 0,001 & $-0,405$ & 0,001 \\
\hline Dummy AP & 5,790 & 1,902 & 0,181 & 0,008 & 0,289 & 0,008 & 3,839 & 1,348 & 0,068 & 0,005 & 0,075 & 0,005 \\
\hline Dummy TO & & & & & & & $-76,649$ & 0,463 & $-0,294$ & 0,003 & $-0,279$ & 0,003 \\
\hline Dummy MA & $-51,504$ & 0,3 & $-0,354$ & 0,0 & $-0,346$ & 0,003 & $-118,769$ & 0,327 & $-0,565$ & 0,002 & $-0,558$ & 0,002 \\
\hline Dummy PI & $-90,977$ & 0,331 & $-0,761$ & 0,004 & $-0,744$ & 0,004 & $-152,964$ & 0,298 & $-0,792$ & 0,002 & $-0,776$ & 0,002 \\
\hline Dummy CE & $-95,883$ & 0,182 & $-0,849$ & 0,002 & $-0,848$ & 0,002 & $-159,006$ & 0,183 & $-0,797$ & 0,001 & $-0,785$ & 0,001 \\
\hline Dummy RN & $-60,493$ & 0,239 & $-0,523$ & 0,003 & $-0,501$ & 0,003 & $-95,965$ & 0,222 & $-0,522$ & 0,001 & $-0,517$ & 0,001 \\
\hline Dummy PB & $-85,173$ & 0,231 & $-0,950$ & 0,003 & $-0,944$ & 0,003 & $-117,985$ & 0,237 & $-0,678$ & 0,002 & $-0,660$ & 0,002 \\
\hline Dummy PE & $-90,595$ & 0,186 & $-0,808$ & 0,002 & $-0,811$ & 0,002 & $-148,030$ & 0,189 & $-0,667$ & 0,001 & $-0,680$ & 0,001 \\
\hline Dummy AL & $-56,139$ & 0,277 & $-0,348$ & 0,003 & $-0,332$ & 0,003 & $-99,381$ & 0,247 & $-0,497$ & 0,001 & $-0,505$ & 0,001 \\
\hline Dummy SE & $-43,064$ & 0,310 & $-0,337$ & 0,003 & $-0,318$ & 0,003 & $-115,915$ & 0,286 & $-0,614$ & 0,002 & $-0,603$ & 0,002 \\
\hline Dummy BA & $-65,438$ & 0,228 & $-0,612$ & 0,002 & $-0,621$ & 0,002 & $-133,715$ & 0,185 & $-0,672$ & 0,001 & $-0,683$ & 0,001 \\
\hline Dummy MG & $-60,590$ & 0,139 & $-0,342$ & 0,001 & $-0,329$ & 0,001 & $-122,239$ & 0,136 & $-0,490$ & 0,0005 & $-0,492$ & 0,0005 \\
\hline Dummy ES & $-64,637$ & 0,291 & $-0,413$ & 0,002 & $-0,410$ & 0,002 & $-114,804$ & 0,234 & $-0,505$ & 0,001 & $-0,504$ & 0,001 \\
\hline Dummy RJ & $-48,527$ & 0,156 & $-0,398$ & 0,001 & $-0,418$ & 0,001 & $-36,196$ & 0,216 & $-0,188$ & 0,000 & $-0,211$ & 0,0005 \\
\hline Dummy PR & $-61,142$ & 0,162 & $-0,372$ & 0,001 & $-0,353$ & 0,001 & $-115,348$ & 0,164 & $-0,490$ & 0,001 & $-0,492$ & 0,001 \\
\hline Dummy SC & $-41,930$ & 0,301 & $-0,245$ & 0,003 & $-0,239$ & 0,003 & $-97,636$ & 0,220 & $-0,320$ & 0,001 & $-0,311$ & 0,001 \\
\hline Dummy RS & $-60,985$ & 0,174 & $-0,305$ & 0,001 & $-0,304$ & 0,001 & $-114,986$ & 0,173 & $-0,421$ & 0,001 & $-0,431$ & 0,001 \\
\hline Dummy MS & $-25,631$ & 0,349 & $-0,135$ & 0,003 & $-0,128$ & 0,003 & $-61,885$ & 0,287 & $-0,205$ & 0,001 & $-0,194$ & 0,001 \\
\hline Dummy MT & $-26,238$ & 0,259 & $-0,031$ & 0,003 & $-0,014$ & 0,003 & $-48,300$ & 0,353 & $-0,176$ & 0,002 & $-0,168$ & 0,002 \\
\hline Dummy GO & $-15,402$ & 0,240 & 0,036 & 0,002 & 0,048 & 0,002 & $-83,852$ & 0,168 & $-0,332$ & 0,001 & $-0,333$ & 0,001 \\
\hline Dummy DF & 40,326 & 0,639 & 0,122 & 0,002 & 0,123 & 0,002 & $-40,092$ & 0,453 & $-0,236$ & 0,001 & $-0,231$ & 0,001 \\
\hline $\mathrm{R}^{2}$ ajustado & \multicolumn{2}{|c|}{0,3771} & \multicolumn{2}{|c|}{0,4639} & \multicolumn{2}{|c|}{0,4406} & \multicolumn{2}{|c|}{0,3771} & \multicolumn{2}{|c|}{0,4632} & \multicolumn{2}{|c|}{0,4400} \\
\hline $\begin{array}{l}\text { n (número de } \\
\text { observações) }\end{array}$ & \multicolumn{2}{|c|}{5.381 .018} & \multicolumn{2}{|c|}{5.381 .018} & \multicolumn{2}{|c|}{5.222 .062} & 5 & & $5.381 . C$ & 8 & 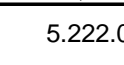 & \\
\hline
\end{tabular}

Obs.: (1) A Dummy SP (Estado de São Paulo) foi retirada da regressão para evitar o problema de multicolinearidade perfeita. Portanto, é a variável de estado referência.

(2) Todas as estimações usam White robusto para heterocedasticidade. 
Tabela B4.C - Estatística Descritiva do Aluguel Implícito Familiar per Capita

\begin{tabular}{|c|c|c|c|c|c|c|c|c|c|c|}
\hline \multirow{2}{*}{$\begin{array}{l}\text { Unidade da } \\
\text { Federação }\end{array}$} & \multicolumn{5}{|c|}{1991} & \multicolumn{5}{|c|}{2000} \\
\hline & $\begin{array}{c}\text { Número de } \\
\text { Observações }\end{array}$ & Média & $\begin{array}{l}\text { Desvio- } \\
\text { Padrão }\end{array}$ & Mínimo & Máximo & $\begin{array}{c}\text { Número de } \\
\text { Observações }\end{array}$ & Média & $\begin{array}{l}\text { Desvio- } \\
\text { Padrão }\end{array}$ & Mínimo & Máximo \\
\hline RO & 769.785 & 16,78 & 5,48 & 6,00 & 24,34 & 977.599 & 24,35 & 5,45 & 12,63 & 29,66 \\
\hline$A C$ & 307.279 & 12,96 & 4,69 & 4,47 & 16,82 & 426.780 & 26,32 & 8,53 & 9,87 & 33,77 \\
\hline AM & 1.577 .796 & 21,59 & 12,32 & 3,34 & 34,09 & 2.105 .600 & 19,42 & 10,09 & 4,71 & 29,73 \\
\hline $\mathrm{RR}$ & 147.721 & 19,58 & 6,69 & 7,38 & 23,67 & 244.019 & 28,19 & 8,76 & 10,72 & 34,29 \\
\hline PA & 3.409 .064 & 11,53 & 9,42 & 1,88 & 27,97 & 4.496 .258 & 22,09 & 16,56 & 4,34 & 52,14 \\
\hline AP & 204.486 & 17,95 & 5,40 & 6,46 & 21,91 & 343.898 & 30,40 & 6,56 & 12,44 & 34,51 \\
\hline TO & 621.184 & 12,83 & 5,45 & 5,12 & 23,83 & 807.536 & 25,42 & 8,78 & 11,69 & 38,53 \\
\hline MA & 3.362.982 & 8,16 & 4,12 & 2,28 & 14,93 & 4.058 .786 & 14,18 & 6,22 & 4,94 & 24,24 \\
\hline PI & 1.532 .545 & 8,61 & 4,55 & 1,77 & 15,44 & 1.700 .885 & 16,67 & 6,32 & 6,59 & 26,67 \\
\hline CE & 3.606 .554 & 12,12 & 8,80 & 1,96 & 25,74 & 4.462 .019 & 24,84 & 15,80 & 5,23 & 49,16 \\
\hline RN & 1.637 .866 & 14,24 & 7,15 & 4,12 & 24,97 & 1.849 .121 & 25,80 & 10,28 & 8,10 & 41,30 \\
\hline PB & 1.873 .213 & 9,02 & 5,24 & 2,17 & 18,63 & 2.051 .370 & 22,39 & 9,15 & 8,74 & 38,18 \\
\hline PE & 4.418 .487 & 14,41 & 9,57 & 2,63 & 31,77 & 5.191 .680 & 30,92 & 15,71 & 9,10 & 57,55 \\
\hline $\mathrm{AL}$ & 1.486 .094 & 14,59 & 7,66 & 3,38 & 26,02 & 1.775 .679 & 23,20 & 9,41 & 9,14 & 36,22 \\
\hline SE & 1.145 .666 & 16,93 & 8,98 & 5,05 & 31,59 & 1.289 .183 & 24,21 & 10,51 & 8,92 & 41,93 \\
\hline BA & 8.413 .881 & 12,57 & 9,52 & 2,40 & 32,09 & 9.293 .804 & 24,85 & 16,23 & 6,24 & 56,92 \\
\hline MG & 9.992 .974 & 30,51 & 18,30 & 4,63 & 73,18 & 8.821 .208 & 54,62 & 24,17 & 11,66 & 102,25 \\
\hline ES & 1.663 .067 & 24,97 & 9,54 & 10,30 & 44,79 & 1.978 .971 & 42,11 & 11,80 & 20,83 & 68,87 \\
\hline $\mathrm{RJ}$ & 7.534 .693 & 43,28 & 20,07 & 13,38 & 78,31 & 9.303 .559 & 90,47 & 31,16 & 31,54 & 152,55 \\
\hline SP & 18.554 .081 & 57,48 & 18,87 & 12,38 & 94,85 & 20.281 .499 & 100,25 & 28,83 & 28,94 & 167,44 \\
\hline PR & 5.141 .971 & 31,82 & 20,42 & 5,91 & 73,73 & 5.316 .980 & 52,04 & 28,54 & 15,34 & 112,51 \\
\hline $\mathrm{SC}$ & 3.238 .194 & 32,13 & 11,43 & 8,11 & 59,89 & 3.658 .811 & 54,31 & 13,37 & 20,88 & 88,30 \\
\hline RS & 5.941 .011 & 38,93 & 20,74 & 7,46 & 87,28 & 6.339 .148 & 59,67 & 27,01 & 14,81 & 123,00 \\
\hline MS & 1.076 .920 & 26,67 & 7,41 & 10,08 & 35,42 & 1.165 .646 & 43,27 & 10,17 & 19,48 & 55,75 \\
\hline MT & 1.365 .950 & 22,32 & 9,46 & 6,56 & 36,51 & 1.582 .289 & 37,57 & 11,08 & 13,82 & 53,76 \\
\hline GO & 2.502 .692 & 33,03 & 13,89 & 7,41 & 54,01 & 2.966 .020 & 42,75 & 13,25 & 16,18 & 62,60 \\
\hline DF & 985.042 & 62,30 & - & 62,30 & 62,30 & 1.018 .310 & 73,88 & - & 73,88 & 73,88 \\
\hline Brasil & 92.511 .198 & 31,14 & 22,99 & 1,77 & 94,85 & 103.506 .658 & 53,84 & 37,51 & 4,34 & 167,44 \\
\hline
\end{tabular}

Obs.: $\quad$ Aluguel implícito familiar per capita em Reais (R\$) de julho de 2000.

e) Resultados para o Apêndice C

Tabela C1.C - Estatísticas Descritivas das Principais Variáveis

\begin{tabular}{|c|c|c|c|c|c|c|c|c|}
\hline \multirow[b]{2}{*}{ Variável } & \multicolumn{4}{|c|}{1991} & \multicolumn{4}{|c|}{2000} \\
\hline & Média & $\begin{array}{l}\text { Desvio- } \\
\text { Padrão }\end{array}$ & Mínimo & Máximo & Média & $\begin{array}{l}\text { Desvio- } \\
\text { Padrão }\end{array}$ & Mínimo & Máximo \\
\hline Renda Familiar per Capita & 245.00 & 157.43 & 23.55 & 672.21 & 326.87 & 192.06 & 40.49 & 960.89 \\
\hline Índice de Desigualdade de Gini & 0.543 & 0.058 & 0.328 & 0.767 & 0.559 & 0.054 & 0.341 & 0.787 \\
\hline Índice de Desigualdade de Theil & 0.608 & 0.159 & 0.179 & 1.960 & 0.635 & 0.160 & 0.187 & 2.395 \\
\hline Linha Absoluta de Pobreza Za & 91.08 & 31.79 & 44.45 & 162.51 & 97.32 & 35.10 & 49.94 & 172.38 \\
\hline Linha Híbrida de Pobreza Zh30 & 77.85 & 40.04 & 15.86 & 172.83 & 95.84 & 47.36 & 20.30 & 236.88 \\
\hline Linha Híbrida de Pobreza Zh50 & 106.17 & 54.60 & 21.63 & 235.70 & 135.03 & 66.73 & 28.60 & 333.76 \\
\hline Número de Pobres considerando $\mathrm{Za}$ & 15,503 & 62,041 & 109 & $2,559,754$ & 12,413 & 55,168 & - & $2,681,644$ \\
\hline Número de Pobres considerando Zh30 & 10,752 & 55,902 & 97 & $2,482,511$ & 10,699 & 61,034 & - & $3,014,793$ \\
\hline Número de Pobres considerando Zh50 & 15,123 & 77,810 & 221 & $3,599,372$ & 15,632 & 87,481 & 211 & $4,335,783$ \\
\hline Incidência da Pobreza considerando $Z a$ & 0.405 & 0.215 & 0.028 & 0.949 & 0.316 & 0.167 & 0.000 & 0.847 \\
\hline Incidência da Pobreza considerando Zh30 & 0.296 & 0.097 & 0.043 & 0.646 & 0.272 & 0.080 & 0.001 & 0.566 \\
\hline Incidência da Pobreza considerando Zh50 & 0.422 & 0.107 & 0.088 & 0.739 & 0.398 & 0.085 & 0.082 & 0.684 \\
\hline Elasticidade-Renda da Pobreza com Gini & $(0.961)$ & 0.408 & $(0.126)$ & $(3.684)$ & $(1.047)$ & 0.388 & $(0.202)$ & $(4.122)$ \\
\hline Elasticidade-Renda da Pobreza com Theil & $(0.892)$ & 0.382 & $(0.130)$ & $(3.154)$ & $(0.972)$ & 0.365 & $(0.171)$ & (3.924) \\
\hline Elasticidade-Desigualdade da Pobreza com Gini & 3.552 & 2.316 & $(0.257)$ & 12.644 & 4.563 & 2.463 & 0.183 & 16.904 \\
\hline Elasticidade-Desigualdade da Pobreza com Theil & 0.705 & 0.466 & $(0.056)$ & 2.729 & 0.890 & 0.494 & 0.031 & 3.525 \\
\hline População & 33,877 & 189,012 & 715 & $9,452,474$ & 39,314 & 210,811 & 499 & $10,338,500$ \\
\hline População Feminina & 17,103 & 98,094 & 364 & $4,886,388$ & 19,952 & 110,322 & 215 & $5,400,929$ \\
\hline População sem Raça Branca & 16,392 & 75,868 & - & $2,896,545$ & 18,172 & 86,494 & - & $3,403,414$ \\
\hline Idade & 25.97 & 2.48 & 17.32 & 34.49 & 28.22 & 2.55 & 18.08 & 38.26 \\
\hline Anos de Estudo & 3.79 & 1.40 & 0.35 & 7.02 & 4.95 & 1.35 & 1.11 & 7.99 \\
\hline
\end{tabular}

Obs.: (1) A renda familiar per capita e as linhas de pobreza estão em Reais (R\$) de julho de 2000.

(2) As colunas Za correspondem aos valores considerando as linhas absolutas de pobreza.

(3) As colunas Zh30 e Zh50 indicam os valores correspondentes às linhas híbridas considerando linhas relativas de $30 \%$ e $50 \%$ da renda média dos estratos, respectivamente. 


\section{D.2.3 - Sem Estimação de Aluguel Implícito}

a) Resultados para o Capítulo 2

Tabela 1.D - Estatísticas Básicas da Variável Renda Familiar per Capita

\begin{tabular}{|c|c|c|c|c|c|c|c|c|c|}
\hline \multirow{2}{*}{$\begin{array}{c}\text { Região } \\
\text { Geográfica }\end{array}$} & \multirow[b]{2}{*}{ Estado } & \multicolumn{4}{|c|}{1991} & \multicolumn{4}{|c|}{2000} \\
\hline & & Média & $\begin{array}{l}\text { Desvio- } \\
\text { Padrão }\end{array}$ & Mínimo & Máximo & Média & $\begin{array}{l}\text { Desvio- } \\
\text { Padrão }\end{array}$ & Mínimo & Máximo \\
\hline \multirow{7}{*}{ Norte } & $\mathrm{RO}$ & 153,40 & 56,36 & 56,93 & 238,48 & 232,19 & 43,30 & 119,72 & 283,79 \\
\hline & $A C$ & 145,75 & 57,49 & 62,71 & 197,20 & 181,25 & 65,48 & 64,42 & 237,30 \\
\hline & AM & 173,09 & 92,21 & 36,12 & 267,21 & 173,18 & 90,22 & 34,82 & 261,29 \\
\hline & RR & 279,87 & 67,21 & 119,05 & 316,89 & 231,22 & 74,19 & 78,78 & 281,56 \\
\hline & PA & 141,08 & 74,83 & 49,24 & 296,18 & 164,10 & 78,78 & 51,05 & 298,13 \\
\hline & AP & 191,67 & 44,72 & 82,13 & 224,02 & 211,53 & 47,72 & 86,79 & 266,11 \\
\hline & TO & 123,81 & 58,30 & 41,58 & 253,72 & 170,71 & 82,61 & 60,42 & 352,50 \\
\hline \multirow{9}{*}{ Nordeste } & $\overline{M A}$ & 79,20 & 48,22 & 28,21 & 186,90 & 109,31 & 65,80 & 38,19 & 246,92 \\
\hline & $\mathrm{PI}$ & 85,79 & 49,94 & 25,91 & 169,82 & 127,97 & 70,29 & 39,98 & 240,22 \\
\hline & CE & 110,67 & 74,01 & 23,28 & 227,27 & 155,93 & 97,83 & 42,77 & 305,25 \\
\hline & RN & 123,18 & 80,19 & 29,23 & 254,18 & 174,81 & 104,54 & 39,05 & 336,82 \\
\hline & PB & 98,80 & 69,81 & 23,02 & 244,45 & 150,25 & 97,40 & 49,97 & 334,49 \\
\hline & PE & 139,13 & 88,81 & 26,14 & 302,74 & 180,90 & 109,36 & 47,14 & 577,85 \\
\hline & $\mathrm{AL}$ & 107,50 & 71,92 & 28,58 & 228,69 & 137,41 & 88,68 & 35,74 & 275,13 \\
\hline & SE & 125,82 & 82,21 & 40,95 & 259,40 & 162,00 & 110,63 & 46,43 & 347,27 \\
\hline & BA & 115,72 & 82,30 & 19,10 & 280,64 & 159,42 & 97,05 & 39,35 & 337,72 \\
\hline \multirow{4}{*}{ Sudeste } & $\overline{M G}$ & 189,74 & 102,27 & 37,51 & 401,64 & 274,09 & 132,77 & 57,70 & 543,51 \\
\hline & ES & 192,72 & 99,64 & 62,38 & 443,04 & 287,91 & 140,35 & 100,48 & 654,25 \\
\hline & RJ & 304,29 & 137,22 & 97,47 & 552,01 & 409,81 & 179,31 & 164,72 & 797,11 \\
\hline & SP & 372,71 & 125,01 & 80,23 & 614,50 & 436,55 & 142,26 & 103,74 & 890,72 \\
\hline \multirow{3}{*}{ Sul } & PR & 222,52 & 112,88 & 60,31 & 443,14 & 317,55 & 148,72 & 96,25 & 606,59 \\
\hline & SC & 228,63 & 93,98 & 76,75 & 473,04 & 344,81 & 124,82 & 112,09 & 700,81 \\
\hline & $\mathrm{RS}$ & 257,69 & 117,02 & 69,09 & 515,13 & 355,77 & 153,05 & 94,83 & 704,47 \\
\hline \multirow{4}{*}{ Centro-Oeste } & MS & 217,73 & 72,95 & 93,44 & 316,23 & 281,85 & 86,43 & 113,93 & 430,62 \\
\hline & MT & 201,19 & 70,11 & 73,68 & 331,53 & 280,89 & 90,92 & 107,44 & 459,50 \\
\hline & GO & 206,81 & 80,70 & 57,35 & 332,60 & 279,44 & 113,77 & 78,36 & 490,35 \\
\hline & DF & 460,83 & - & 460,83 & 460,83 & 595,31 & - & 595,31 & 595,31 \\
\hline Brasil & & 225,13 & 144,17 & 19,10 & 614,50 & 293,81 & 172,90 & 34,82 & 890,72 \\
\hline
\end{tabular}

Obs.: $\quad$ Renda familiar per capita em Reais (R\$) de julho de 2000. 
Tabela 3.D - Estatísticas Básicas do Número de Pobres

\begin{tabular}{|c|c|c|c|c|c|c|c|c|c|c|c|}
\hline \multirow{2}{*}{$\begin{array}{c}\text { Região } \\
\text { Geográfica }\end{array}$} & \multirow[b]{2}{*}{ Estado } & \multicolumn{5}{|c|}{1991} & \multicolumn{5}{|c|}{2000} \\
\hline & & População & $\mathrm{n}^{\circ}$ de pobres & $\begin{array}{l}\text { Desvio- } \\
\text { Padrão }\end{array}$ & Mínimo & Máximo & População & $\mathrm{n}^{\circ}$ de pobres & $\begin{array}{l}\text { Desvio- } \\
\text { Padrão }\end{array}$ & Mínimo & Máximo \\
\hline \multirow{7}{*}{ Norte } & $\mathrm{RO}$ & 1.125 .046 & 592.474 & 25.989 & 4.285 & 100.479 & 1.369 .444 & 413.956 & 24.457 & 4.330 & 109.731 \\
\hline & $A C$ & 414.102 & 236.376 & 34.844 & 1.405 & 106.141 & 555.471 & 248.706 & 36.534 & 1.904 & 113.250 \\
\hline & AM & 2.087.753 & 1.071 .908 & 41.175 & 2.292 & 328.598 & 2.807.323 & 1.464 .688 & 67.142 & 3.889 & 536.882 \\
\hline & $\mathrm{RR}$ & 211.419 & 87.094 & 21.350 & 5.823 & 53.134 & 322.523 & 117.861 & 25.344 & 12.516 & 67.128 \\
\hline & PA & 4.905 .433 & 2.924 .886 & 63.118 & 3.262 & 553.307 & 6.166 .634 & 3.043 .942 & 58.892 & 3.074 & 488.560 \\
\hline & AP & 286.673 & 130.648 & 23.272 & 3.055 & 69.578 & 474.658 & 210.767 & 41.312 & 3.913 & 123.149 \\
\hline & TO & 910.157 & 569.515 & 8.910 & 1.506 & 54.818 & 1.150 .882 & 549.217 & 9.635 & 1.032 & 53.119 \\
\hline \multirow{9}{*}{ Nordeste } & $\overline{M A}$ & 4.902 .860 & 3.667 .799 & 44.580 & 4.072 & 316.484 & 5.634 .915 & 3.489 .450 & 46.271 & 2.781 & 362.365 \\
\hline & PI & 2.558 .077 & 1.982 .934 & 45.829 & 1.142 & 372.593 & 2.826 .459 & 1.614 .816 & 37.999 & 672 & 306.213 \\
\hline & CE & 6.305 .476 & 4.704 .922 & 75.164 & 3.625 & 988.145 & 7.371 .074 & 4.120 .592 & 64.846 & 3.142 & 844.290 \\
\hline & RN & 2.392.757 & 1.619 .406 & 23.971 & 973 & 267.617 & 2.766 .106 & 1.314 .127 & 20.005 & 946 & 226.116 \\
\hline & PB & 3.175 .867 & 2.380 .405 & 24.909 & 1.548 & 233.126 & 3.414 .992 & 1.759 .576 & 19.229 & 659 & 184.562 \\
\hline & PE & 7.077.995 & 5.158 .807 & 70.795 & 242 & 806.941 & 7.895 .020 & 4.467.386 & 63.319 & 112 & 706.375 \\
\hline & $\mathrm{AL}$ & 2.491.971 & 1.754 .907 & 31.991 & 2.875 & 293.910 & 2.817 .468 & 1.647 .160 & 34.831 & 1.976 & 330.192 \\
\hline & SE & 1.478 .474 & 976.286 & 22.064 & 1.532 & 179.716 & 1.776 .661 & 901.104 & 19.317 & 1.281 & 148.996 \\
\hline & BA & 11.753 .125 & 8.587 .033 & 59.139 & 2.287 & 1.154 .932 & 13.018 .111 & 7.019 .497 & 56.564 & 1.586 & 1.117 .500 \\
\hline \multirow{4}{*}{ Sudeste } & MG & 15.542 .085 & 7.186 .046 & 30.466 & 274 & 720.423 & 17.555 .247 & 5.344 .092 & 24.364 & 77 & 547.940 \\
\hline & ES & 2.580 .027 & 1.057 .540 & 20.299 & 2.291 & 107.255 & 3.084 .122 & 754.579 & 17.817 & 966 & 90.200 \\
\hline & RJ & 12.679 .997 & 5.931 .173 & 275.802 & 3.948 & 2.071 .107 & 14.303 .997 & 4.621 .398 & 216.426 & 2.829 & 1.575 .441 \\
\hline & SP & 31.200 .800 & 9.956 .227 & 126.838 & 129 & 2.973 .435 & 36.758 .099 & 10.941 .701 & 144.732 & 233 & 3.372 .853 \\
\hline \multirow{3}{*}{ Sul } & PR & 8.370 .891 & 3.216 .316 & 20.383 & 562 & 315.402 & 9.510 .719 & 2.348 .006 & 17.789 & 331 & 268.979 \\
\hline & SC & 4.497 .033 & 1.222 .821 & 8.549 & 466 & 54.479 & 5.323 .622 & 781.310 & 6.168 & 184 & 49.295 \\
\hline & $\mathrm{RS}$ & 9.041 .154 & 2.777 .048 & 19.302 & 304 & 207.809 & 10.114 .344 & 1.972 .804 & 16.227 & 18 & 190.673 \\
\hline \multirow{4}{*}{$\begin{array}{l}\text { Centro- } \\
\text { Oeste }\end{array}$} & MS & 1.762 .655 & 982.122 & 27.563 & 1.916 & 221.386 & 2.065 .883 & 804.638 & 24.879 & 1.372 & 201.464 \\
\hline & MT & 2.002 .481 & 1.132 .757 & 26.440 & 975 & 181.769 & 2.492.199 & 928.331 & 21.401 & 784 & 146.765 \\
\hline & GO & 3.976 .645 & 2.230 .962 & 30.348 & 618 & 387.855 & 4.978 .472 & 1.879 .287 & 25.526 & 311 & 284.139 \\
\hline & $\mathrm{DF}$ & 1.565 .191 & 744.411 & - & 744.411 & 744.411 & 2.022 .513 & 746.364 & - & 746.364 & 746.364 \\
\hline \multicolumn{2}{|c|}{ Brasil } & 145.296 .144 & 72.882 .823 & 58.231 & 129 & 2.973 .435 & 168.576 .958 & 63.505 .355 & 55.168 & 18 & 3.372 .853 \\
\hline
\end{tabular}

Tabela 4.D - Estatísticas Básicas do Índice de Gini

\begin{tabular}{|c|c|c|c|c|c|c|c|c|c|}
\hline \multirow{2}{*}{$\begin{array}{c}\text { Região } \\
\text { Geográfica }\end{array}$} & \multirow[b]{2}{*}{ Estado } & \multicolumn{4}{|c|}{1991} & \multicolumn{4}{|c|}{2000} \\
\hline & & Gini & $\begin{array}{l}\text { Desvio- } \\
\text { Padrão }\end{array}$ & Mínimo & Máximo & Gini & $\begin{array}{l}\text { Desvio- } \\
\text { Padrão }\end{array}$ & Mínimo & Máximo \\
\hline \multirow{7}{*}{ Norte } & $\overline{R O}$ & 0,628 & 0,032 & 0,510 & 0,686 & 0,615 & 0,022 & 0,495 & 0,675 \\
\hline & $A C$ & 0,638 & 0,024 & 0,476 & 0,675 & 0,658 & 0,022 & 0,585 & 0,700 \\
\hline & AM & 0,640 & 0,055 & 0,428 & 0,780 & 0,694 & 0,039 & 0,547 & 0,815 \\
\hline & $\mathrm{RR}$ & 0,668 & 0,049 & 0,632 & 0,763 & 0,632 & 0,021 & 0,600 & 0,675 \\
\hline & PA & 0,632 & 0,051 & 0,394 & 0,715 & 0,656 & 0,039 & 0,471 & 0,764 \\
\hline & AP & 0,600 & 0,024 & 0,537 & 0,719 & 0,648 & 0,011 & 0,616 & 0,681 \\
\hline & TO & 0,631 & 0,049 & 0,413 & 0,715 & 0,657 & 0,040 & 0,473 & 0,760 \\
\hline \multirow{9}{*}{ Nordeste } & $\overline{M A}$ & 0,612 & 0,059 & 0,397 & 0,686 & 0,666 & 0,042 & 0,456 & 0,747 \\
\hline & PI & 0,650 & 0,054 & 0,408 & 0,778 & 0,667 & 0,044 & 0,427 & 0,694 \\
\hline & CE & 0,659 & 0,066 & 0,381 & 0,686 & 0,682 & 0,044 & 0,497 & 0,722 \\
\hline & RN & 0,644 & 0,054 & 0,407 & 0,726 & 0,663 & 0,045 & 0,426 & 0,780 \\
\hline & PB & 0,646 & 0,063 & 0,345 & 0,761 & 0,653 & 0,049 & 0,437 & 0,714 \\
\hline & PE & 0,663 & 0,063 & 0,399 & 0,693 & 0,674 & 0,051 & 0,458 & 0,732 \\
\hline & $\mathrm{AL}$ & 0,638 & 0,072 & 0,372 & 0,666 & 0,691 & 0,055 & 0,444 & 0,786 \\
\hline & SE & 0,634 & 0,058 & 0,405 & 0,623 & 0,662 & 0,054 & 0,432 & 0,693 \\
\hline & BA & 0,667 & 0,068 & 0,384 & 0,766 & 0,672 & 0,053 & 0,374 & 0,815 \\
\hline \multirow{4}{*}{ Sudeste } & $M G$ & 0,619 & 0,047 & 0,374 & 0,741 & 0,616 & 0,049 & 0,361 & 0,761 \\
\hline & ES & 0,606 & 0,046 & 0,434 & 0,712 & 0,612 & 0,036 & 0,401 & 0,694 \\
\hline & RJ & 0,616 & 0,056 & 0,459 & 0,714 & 0,616 & 0,045 & 0,485 & 0,637 \\
\hline & SP & 0,559 & 0,047 & 0,333 & 0,731 & 0,592 & 0,046 & 0,387 & 0,723 \\
\hline \multirow{3}{*}{ Sul } & PR & 0,603 & 0,050 & 0,366 & 0,723 & 0,607 & 0,045 & 0,392 & 0,730 \\
\hline & SC & 0,554 & 0,055 & 0,357 & 0,685 & 0,561 & 0,049 & 0,371 & 0,720 \\
\hline & $\mathrm{RS}$ & 0,590 & 0,056 & 0,414 & 0,745 & 0,589 & 0,050 & 0,356 & 0,727 \\
\hline \multirow{4}{*}{ Centro-Oeste } & MS & 0,607 & 0,036 & 0,442 & 0,689 & 0,625 & 0,037 & 0,470 & 0,727 \\
\hline & MT & 0,607 & 0,044 & 0,456 & 0,722 & 0,624 & 0,034 & 0,396 & 0,715 \\
\hline & GO & 0,590 & 0,046 & 0,402 & 0,748 & 0,608 & 0,050 & 0,422 & 0,784 \\
\hline & DF & 0,619 & - & 0,619 & 0,619 & 0,641 & - & 0,641 & 0,641 \\
\hline Brasil & & 0,640 & 0,058 & 0,333 & 0,780 & 0,647 & 0,054 & 0,356 & 0,815 \\
\hline
\end{tabular}

Obs.: $\quad$ Os valores da coluna Gini correspondem aos índices de Gini estaduais e nacional, enquanto que as colunas Desvio-Padrão, Mínimo e Máximo são referentes aos municípios. 
Tabela 5.D - Estatísticas Básicas do Índice de Theil

\begin{tabular}{|c|c|c|c|c|c|c|c|c|c|}
\hline \multirow{2}{*}{$\begin{array}{c}\text { Região } \\
\text { Geográfica }\end{array}$} & \multirow[b]{2}{*}{ Estado } & \multicolumn{4}{|c|}{1991} & \multicolumn{4}{|c|}{2000} \\
\hline & & Theil & $\begin{array}{l}\text { Desvio- } \\
\text { Padrão }\end{array}$ & Mínimo & Máximo & Theil & $\begin{array}{l}\text { Desvio- } \\
\text { Padrão }\end{array}$ & Mínimo & Máximo \\
\hline \multirow{7}{*}{ Norte } & $\mathrm{RO}$ & 0,798 & 0,128 & 0,467 & 1,081 & 0,743 & 0,093 & 0,372 & 0,980 \\
\hline & $A C$ & 0,829 & 0,051 & 0,385 & 0,847 & 0,887 & 0,075 & 0,560 & 0,862 \\
\hline & AM & 0,789 & 0,169 & 0,327 & 1,390 & 0,911 & 0,166 & 0,386 & 2,190 \\
\hline & $\mathrm{RR}$ & 0,731 & 0,138 & 0,654 & 1,051 & 0,715 & 0,082 & 0,425 & 0,846 \\
\hline & PA & 0,842 & 0,134 & 0,293 & 1,011 & 0,879 & 0,167 & 0,312 & 2,390 \\
\hline & AP & 0,681 & 0,116 & 0,476 & 1,117 & 0,810 & 0,106 & 0,618 & 1,010 \\
\hline & TO & 0,884 & 0,152 & 0,324 & 1,115 & 0,898 & 0,166 & 0,372 & 1,552 \\
\hline \multirow{9}{*}{ Nordeste } & MA & 0,835 & 0,174 & 0,256 & 1,387 & 0,939 & 0,170 & 0,361 & 1,742 \\
\hline & PI & 0,944 & 0,202 & 0,284 & 2,041 & 0,952 & 0,176 & 0,297 & 1,151 \\
\hline & CE & 0,985 & 0,188 & 0,243 & 1,533 & 0,971 & 0,154 & 0,391 & 1,312 \\
\hline & $\mathrm{RN}$ & 0,863 & 0,162 & 0,264 & 1,467 & 0,864 & 0,173 & 0,248 & 1,900 \\
\hline & PB & 0,914 & 0,172 & 0,213 & 1,131 & 0,870 & 0,164 & 0,249 & 1,246 \\
\hline & PE & 0,946 & 0,175 & 0,276 & 1,301 & 0,922 & 0,173 & 0,368 & 2,008 \\
\hline & $A L$ & 0,894 & 0,181 & 0,234 & 1,142 & 0,976 & 0,192 & 0,338 & 1,882 \\
\hline & SE & 0,859 & 0,144 & 0,295 & 1,159 & 0,883 & 0,146 & 0,313 & 1,072 \\
\hline & BA & 0,987 & 0,197 & 0,263 & 1,959 & 0,933 & 0,195 & 0,214 & 2,184 \\
\hline \multirow{4}{*}{ Sudeste } & MG & 0,799 & 0,147 & 0,218 & 1,706 & 0,775 & 0,161 & 0,172 & 2,395 \\
\hline & ES & 0,737 & 0,155 & 0,305 & 1,323 & 0,746 & 0,124 & 0,256 & 1,363 \\
\hline & RJ & 0,757 & 0,137 & 0,377 & 1,340 & 0,732 & 0,116 & 0,385 & 1,157 \\
\hline & SP & 0,611 & 0,111 & 0,182 & 1,346 & 0,682 & 0,118 & 0,251 & 1,253 \\
\hline \multirow{3}{*}{ Sul } & PR & 0,738 & 0,170 & 0,229 & 1,500 & 0,751 & 0,148 & 0,270 & 1,889 \\
\hline & SC & 0,602 & 0,148 & 0,232 & 1,361 & 0,637 & 0,149 & 0,246 & 1,686 \\
\hline & $\mathrm{RS}$ & 0,687 & 0,159 & 0,305 & 1,403 & 0,684 & 0,126 & 0,218 & 1,458 \\
\hline \multirow{4}{*}{ Centro-Oeste } & MS & 0,787 & 0,145 & 0,345 & 1,304 & 0,828 & 0,161 & 0,405 & 1,782 \\
\hline & MT & 0,777 & 0,156 & 0,364 & 1,321 & 0,837 & 0,129 & 0,210 & 1,510 \\
\hline & $\mathrm{GO}$ & 0,725 & 0,150 & 0,281 & 1,586 & 0,784 & 0,180 & 0,300 & 1,986 \\
\hline & DF & 0,724 & - & 0,724 & 0,724 & 0,763 & - & 0,763 & 0,763 \\
\hline Brasil & & 0,826 & 0,156 & 0,182 & 2,041 & 0,828 & 0,164 & 0,172 & 2,395 \\
\hline
\end{tabular}

Obs.: $\quad$ Os valores da coluna Theil correspondem aos índices de Theil estaduais e nacional, enquanto que as colunas Desvio-Padrão, Mínimo e Máximo são referentes aos municípios.

\section{b) Resultados para o Capítulo 3}

Tabela 6.D - Regressão em Logaritmo da Linha de Pobreza na Renda

\begin{tabular}{|c|c|c|c|c|}
\hline \multirow{2}{*}{ Variável } & \multicolumn{2}{|c|}{1991} & \multicolumn{2}{|c|}{2000} \\
\hline & Coeficiente & Desvio-Padrão & Coeficiente & Desvio-Padrão \\
\hline constante & 1,0992 & 0,3344 & 0,6019 & 0,4675 \\
\hline $\log ($ renda $)$ & 0,6284 & 0,0656 & 0,6875 & 0,0839 \\
\hline número de observações & \multicolumn{2}{|c|}{26} & \multicolumn{2}{|c|}{26} \\
\hline $\mathrm{R}^{2}$ & \multicolumn{2}{|c|}{0,8162} & \multicolumn{2}{|c|}{0,7818} \\
\hline
\end{tabular}

Tabela 7.D - Regressão em Logaritmo da Linha de Pobreza com os Anos de 1991 e 2000

\begin{tabular}{ccc}
\hline Variável & Coeficiente & Desvio-Padrão \\
\hline constante & 0,6019 & 0,4675 \\
log (renda) & 0,6875 & 0,0839 \\
dummy 91 & 0,4973 & 0,5748 \\
dummy 91 * log (renda) & $-0,0591$ & 0,1065 \\
\hline número de observações & \multicolumn{2}{c}{26} \\
\hline $\mathrm{R}^{2}$ & \multicolumn{2}{c}{0,7997} \\
\hline
\end{tabular}

Obs.: Todas as estimações usam White robusto para heterocedasticidade. 
Tabela 8.D - Linha Híbrida de Pobreza com Renda Média por Estrato e Nacional

\begin{tabular}{|c|c|c|c|c|c|c|c|c|c|c|c|}
\hline \multirow{4}{*}{ Regiões } & \multirow{4}{*}{ Estratos } & \multicolumn{5}{|c|}{1991} & \multicolumn{5}{|c|}{2000} \\
\hline & & \multirow{3}{*}{$\begin{array}{c}\text { Renda } \\
\text { Média } \\
\text { (RM) }\end{array}$} & \multicolumn{4}{|c|}{ Linha Híbrida (Zh) } & \multirow{3}{*}{$\begin{array}{c}\text { Renda } \\
\text { Média } \\
(\mathrm{RM})\end{array}$} & \multicolumn{4}{|c|}{ Linha Híbrida (Zh) } \\
\hline & & & \multicolumn{2}{|c|}{ RM por Estrato } & \multicolumn{2}{|c|}{ RM Nacional } & & \multicolumn{2}{|c|}{ RM por Estrato } & \multicolumn{2}{|c|}{ RM Nacional } \\
\hline & & & Zh30 & Zh50 & Zh30 & Zh50 & & Zh30 & Zh50 & Zh30 & Zh50 \\
\hline \multirow{3}{*}{ Norte } & Belém & 252,10 & 81,34 & 112,13 & 75,76 & 104,44 & 262,30 & 83,47 & 118,59 & 90,24 & 128,21 \\
\hline & Urbano & 179,53 & 62,98 & 86,81 & 72,60 & 100,08 & 206,56 & 67,85 & 96,40 & 86,45 & 122,82 \\
\hline & Rural & 79,36 & 31,73 & 43,75 & 61,11 & 84,24 & 85,08 & 31,37 & 44,57 & 73,54 & 104,49 \\
\hline \multirow{5}{*}{ Nordeste } & Fortaleza & 193,93 & 70,40 & 97,05 & 77,32 & 106,58 & 251,72 & 80,38 & 114,21 & 89,40 & 127,01 \\
\hline & Recife & 223,14 & 89,30 & 123,11 & 89,80 & 123,80 & 276,00 & 96,23 & 136,72 & 100,46 & 142,73 \\
\hline & Salvador & 255,40 & 90,74 & 125,09 & 83,83 & 115,56 & 308,36 & 100,83 & 143,26 & 97,54 & 138,58 \\
\hline & Urbano & 122,20 & 50,21 & 69,22 & 73,71 & 101,62 & 163,66 & 57,60 & 81,84 & 86,13 & 122,37 \\
\hline & Rural & 48,37 & 23,25 & 32,05 & 61,11 & 84,24 & 57,71 & 24,02 & 34,13 & 73,54 & 104,49 \\
\hline \multirow{15}{*}{ Sudeste } & Minas Gerais & & & & & & & & & & \\
\hline & Belo Horizonte & 304,96 & 97,01 & 133,74 & 80,17 & 110,51 & 374,37 & 113,33 & 161,01 & 95,94 & 136,31 \\
\hline & Urbano & 193,54 & 62,90 & 86,71 & 69,17 & 95,36 & 272,32 & 80,43 & 114,27 & 84,74 & 120,40 \\
\hline & Rural & 77,53 & 29,13 & 40,16 & 56,93 & 78,48 & 120,22 & 38,92 & 55,29 & 71,94 & 102,21 \\
\hline & Espírito Santo & & & & & & & & & & \\
\hline & Urbano & 231,44 & 70,38 & 97,03 & 69,17 & 95,36 & 324,58 & 90,75 & 128,93 & 84,74 & 120,40 \\
\hline & Rural & 83,27 & 30,47 & 42,00 & 56,93 & 78,48 & 146,17 & 44,51 & 63,25 & 71,94 & 102,21 \\
\hline & Rio de Janeiro & & & & & & & & & & \\
\hline & Metrópole & 336,41 & 110,36 & 152,14 & 85,74 & 118,20 & 447,16 & 135,41 & 192,39 & 101,45 & 144,14 \\
\hline & Urbano & 220,38 & 70,93 & 97,78 & 71,88 & 99,09 & 315,45 & 91,85 & 130,50 & 87,47 & 124,28 \\
\hline & Rural & 100,55 & 38,54 & 53,12 & 63,95 & 88,16 & 161,20 & 52,47 & 74,55 & 79,28 & 112,64 \\
\hline & São Paulo & & & & & & & & & & \\
\hline & Metrópole & 448,28 & 141,37 & 194,88 & 91,70 & 126,42 & 500,07 & 156,68 & 222,60 & 108,70 & 154,43 \\
\hline & Urbano & 321,12 & 97,06 & 133,80 & 77,64 & 107,04 & 393,35 & 115,49 & 164,09 & 94,50 & 134,27 \\
\hline & Rural & 152,37 & 51,14 & 70,50 & 65,36 & 90,10 & 209,03 & 64,70 & 91,92 & 81,76 & 116,16 \\
\hline \multirow{4}{*}{ Sul } & Curitiba & 354,31 & 106,62 & 146,97 & 80,18 & 110,53 & 452,90 & 128,55 & 182,64 & 95,47 & 135,64 \\
\hline & Porto Alegre & 353,05 & 97,07 & 133,81 & 73,16 & 100,86 & 457,89 & 119,60 & 169,93 & 88,16 & 125,25 \\
\hline & Urbano & 249,09 & 73,58 & 101,44 & 69,05 & 95,19 & 336,14 & 92,25 & 131,07 & 84,10 & 119,49 \\
\hline & Rural & 111,03 & 38,25 & 52,73 & 59,64 & 82,22 & 179,53 & 52,99 & 75,29 & 74,35 & 105,64 \\
\hline \multirow{4}{*}{$\begin{array}{c}\text { Centro- } \\
\text { Oeste }\end{array}$} & Brasília & 460,83 & 146,81 & 202,38 & 93,59 & 129,02 & 595,31 & 171,60 & 243,80 & 105,60 & 150,04 \\
\hline & Urbano & 233,75 & 84,40 & 116,35 & 82,43 & 113,64 & 301,71 & 96,59 & 137,23 & 94,84 & 134,75 \\
\hline & Rural & 112,89 & 43,47 & 59,93 & 67,08 & 92,47 & 161,17 & 52,78 & 74,98 & 79,75 & 113,31 \\
\hline & BRASIL & 225,13 & \multicolumn{4}{|c|}{$(*)$} & 293,81 & \multicolumn{4}{|c|}{$(*)$} \\
\hline
\end{tabular}

Obs.: (1) Valores em Reais (R $\$$ ) de julho de 2000.

(2) As colunas Zh30 e Zh50 indicam as linhas híbridas considerando linhas relativas de $30 \%$ e $50 \%$ da renda média, respectivamente.

(*) As linhas híbridas nacionais são a ponderação das linhas absolutas por estrato com a linha relativa considerando renda média nacional, e estão apresentadas nas colunas de RM Nacional. 
Tabela 9.D - Incidência da Pobreza com Renda Média por Estrato

\begin{tabular}{|c|c|c|c|c|c|c|c|c|c|c|c|c|c|c|c|}
\hline \multirow{4}{*}{ Regiões } & \multirow{4}{*}{ Estratos } & \multicolumn{7}{|c|}{1991} & \multicolumn{7}{|c|}{2000} \\
\hline & & \multirow{2}{*}{\multicolumn{2}{|c|}{$\begin{array}{c}\text { Linha Absoluta } \\
\text { de Pobreza }\end{array}$}} & \multicolumn{4}{|c|}{ Linha Híbrida de Pobreza } & \multirow{3}{*}{$\begin{array}{l}\text { População } \\
\text { Total }\end{array}$} & \multirow{2}{*}{\multicolumn{2}{|c|}{$\begin{array}{c}\text { Linha Absoluta } \\
\text { de Pobreza }\end{array}$}} & \multicolumn{4}{|c|}{ Linha Híbrida de Pobreza } & \multirow{3}{*}{$\begin{array}{c}\text { População } \\
\text { Total }\end{array}$} \\
\hline & & & & \multicolumn{2}{|c|}{ Zh30 } & \multicolumn{2}{|l|}{ Zh50 } & & & & Zh30 & & Zh50 & & \\
\hline & & $n^{0}$ de pobres & $\%$ & $\mathrm{n}^{\circ}$ de pobres & $\%$ & $n^{\circ}$ de pobres & $\%$ & & $n^{\circ}$ de pobres & $\%$ & $n^{\circ}$ de pobres & $\%$ & $n^{0}$ de pobres & $\%$ & \\
\hline \multirow{3}{*}{ Norte } & Belém & 606 & 46,0 & 485 & 36,8 & 651 & 49,4 & 1.318 & 732 & 41,1 & 663 & 37,2 & 890 & 49,9 & 1.783 \\
\hline & Urbano & 2.617 & 52,8 & 1.681 & 33,9 & 2.307 & 46,5 & 4.958 & 3.292 & 45,5 & 2.734 & 37,8 & 3.644 & 50,4 & 7.237 \\
\hline & Rural & 2.390 & 65,2 & 1.623 & 44,3 & 2.148 & 58,6 & 3.665 & 2.025 & 52,9 & 1.525 & 39,8 & 1.956 & 51,1 & 3.827 \\
\hline \multirow{5}{*}{ Nordeste } & Fortaleza & 1.420 & 62,7 & 1.003 & 44,3 & 1.290 & 56,9 & 2.265 & 1.371 & 46,4 & 1.251 & 42,3 & 1.623 & 54,9 & 2.954 \\
\hline & Recife & 1.998 & 70,2 & 1.397 & 49,1 & 1.707 & 60,0 & 2.845 & 1.896 & 57,2 & 1.486 & 44,8 & 1.912 & 57,6 & 3.317 \\
\hline & Salvador & 1.467 & 60,0 & 1.124 & 45,9 & 1.395 & 57,0 & 2.447 & 1.477 & 49,4 & 1.311 & 43,9 & 1.634 & 54,7 & 989 \\
\hline & Urbano & 12.899 & 71,0 & 6.966 & 38,3 & 9.398 & 51,7 & 18.167 & 12.689 & 53,5 & 9.340 & 39,4 & 12.689 & 53,5 & 23.724 \\
\hline & Rural & 13.050 & 79,5 & 7.889 & 48,1 & 10.397 & 63,3 & 16.413 & 8.900 & 61,2 & 5.403 & 37,2 & 7.210 & 49,6 & 14.537 \\
\hline \multirow{16}{*}{ Sudeste } & M & & & & & & & & & & & & & & \\
\hline & Belo & 1.542 & 45,5 & 1.164 & 34,4 & 1.577 & 46,5 & 3.388 & 1.608 & 33,7 & 1.582 & 33,1 & 2.265 & 47,4 & 4.777 \\
\hline & Urbano & 3.544 & 42,2 & 2.353 & 28,0 & 3.475 & 41,4 & 8.392 & 2.696 & 27,6 & 2.801 & 28,6 & 3.999 & 40,9 & 9.779 \\
\hline & Rural & 2.100 & 55,8 & 1.558 & 41,4 & 2.131 & 56,6 & 3.762 & 1.040 & 34,7 & 911 & 30,4 & 1.264 & 42,1 & 3.000 \\
\hline & Espírito & & & & & & & & & & & & & & \\
\hline & Urban & 695 & 36,5 & 501 & 26,3 & 740 & 38,8 & 1.906 & 598 & 24,4 & 706 & 28,8 & 1.023 & 41,7 & 2.450 \\
\hline & Rural & 363 & 53,8 & 303 & 44,9 & 404 & 60,0 & 674 & 156 & 24,7 & 152 & 23,9 & 237 & 37,4 & 634 \\
\hline & Rio de Jane & & & & & & & & & & & & & & \\
\hline & Metr & 4.660 & 48,0 & 3.322 & 34,2 & 4.496 & 46,3 & 9.711 & 3.755 & 34,7 & 3.692 & 34,1 & 5.067 & 46,8 & 10.821 \\
\hline & Urba & 966 & 39,5 & 711 & 29,1 & 1.017 & 41,6 & 2.446 & 710 & 23,7 & 765 & 25,6 & 1.140 & 38,1 & 2.995 \\
\hline & Rural & 305 & 58,3 & 261 & 49,8 & 337 & 64,3 & 523 & 157 & 32,0 & 126 & 25,7 & 179 & 36,7 & 489 \\
\hline & São Paulo & & & & & & & & & & & & & & \\
\hline & Metrópo & 5.395 & 35,5 & 4.209 & 27,7 & 6.081 & 40,0 & 66 & 6.550 & 36,9 & 5.954 & 33,6 & 8.220 & 46,3 & 17.744 \\
\hline & Urbano & 3.784 & 26,9 & 2.846 & 20,2 & 4.648 & 33,0 & 14.076 & 3.956 & 22,8 & 4.164 & 24,0 & 6.587 & 38,0 & 17.356 \\
\hline & Rural & 777 & 40,5 & 733 & 38,2 & 1.033 & 53,8 & & 436 & 26,3 & 403 & 24,3 & 649 & 39,1 & 1.658 \\
\hline & Curitiba & 652 & 33,1 & 508 & 25,8 & 757 & 38,4 & 1.972 & 681 & 25,2 & 794 & 29,4 & 1.159 & 42,9 & 2.704 \\
\hline \multirow{3}{*}{ Sul } & Porto Alegre & 692 & 23,1 & 689 & 23,0 & 1.028 & 34,4 & 2.992 & 634 & 17,5 & 913 & 25,2 & 1.402 & 38,6 & 3.628 \\
\hline & Urbano & 3.401 & 29,6 & 2.565 & 22,4 & 3.949 & 34,4 & 11.475 & 2.680 & 18,9 & 3.292 & 23,2 & 5.029 & 35,4 & 14.214 \\
\hline & Rural & 2.472 & 45,2 & 2.189 & 40,0 & 2.960 & 54,1 & 5.471 & 1.108 & 25,2 & 1.122 & 25,5 & 1.597 & 36,3 & 4.403 \\
\hline \multirow{4}{*}{$\begin{array}{l}\text { Centro- } \\
\text { Oeste }\end{array}$} & Brasília & 744 & 47,6 & 643 & 41,1 & 816 & 52,1 & 1.565 & 746 & 36,9 & 800 & 39,5 & 1.005 & 49,7 & 2.023 \\
\hline & Urbano & 3.359 & 55,2 & 2.072 & 34,1 & 2.939 & 48,3 & 6.082 & 3.078 & 38,1 & 2.576 & 31,9 & 3.779 & 46,7 & 8.087 \\
\hline & Rural & 987 & 59,5 & 738 & 44,5 & 985 & 59,3 & 1.660 & 534 & 36,9 & 443 & 30,6 & 595 & 41,0 & 1.450 \\
\hline & BRASIL & 72.883 & 50,2 & 49.530 & 34,1 & 68.666 & 47,3 & 145.296 & 63.505 & 37,7 & 54.910 & 32,6 & 76.752 & 45,5 & 168.577 \\
\hline
\end{tabular}

Obs.: (1) $n^{o}$ de pobres e População Total em milhares de habitantes.

(2) Os valores das colunas $n^{o}$ de pobres correspondem ao número de pessoas com renda familiar per capita abaixo da linha de pobreza considerada e os valores das colunas \% são o percentual de pessoas pobres em relação ao total populacional de habitantes de cada estrato.

(3) As colunas Zh30 e Zh50 indicam os valores correspondentes às linhas híbridas considerando linhas relativas de $30 \%$ e $50 \%$ da renda média, respectivamente. 
Tabela 10.D - Incidência da Pobreza com Renda Média Nacional

\begin{tabular}{|c|c|c|c|c|c|c|c|c|c|c|c|c|c|c|c|}
\hline \multirow{4}{*}{ Regiões } & \multirow{4}{*}{ Estratos } & \multicolumn{7}{|c|}{1991} & \multicolumn{7}{|c|}{2000} \\
\hline & & \multirow{2}{*}{\multicolumn{2}{|c|}{$\begin{array}{c}\text { Linha Absoluta } \\
\text { de Pobreza } \\
\end{array}$}} & \multicolumn{4}{|c|}{ Linha Híbrida de Pobreza } & \multirow{3}{*}{$\begin{array}{l}\text { População } \\
\text { Total }\end{array}$} & \multirow{2}{*}{\multicolumn{2}{|c|}{$\begin{array}{c}\text { Linha Absoluta } \\
\text { de Pobreza } \\
\end{array}$}} & \multicolumn{4}{|c|}{ Linha Híbrida de Pobreza } & \multirow{3}{*}{$\begin{array}{l}\text { População } \\
\text { Total }\end{array}$} \\
\hline & & & & \multicolumn{2}{|c|}{ Zh30 } & \multicolumn{2}{|l|}{ Zh50 } & & & & Zh30 & & Zh50 & & \\
\hline & & $\mathrm{n}^{\circ}$ de pobres & $\%$ & $\mathrm{n}^{\circ}$ de pobres & $\%$ & $\mathrm{n}^{\circ}$ de pobres & $\%$ & & $\mathrm{n}^{0}$ de pobres & $\%$ & $\mathrm{n}^{0}$ de pobres & $\%$ & $\mathrm{n}^{0}$ de pobres & $\%$ & \\
\hline \multirow{3}{*}{ Norte } & Belém & 606 & 46,0 & 455 & 34,5 & 622 & 47,2 & 1.318 & 732 & 41,1 & 707 & 39,7 & 944 & 53,0 & 1.783 \\
\hline & Urbano & 2.617 & 52,8 & 2.252 & 45,4 & 2.871 & 57,9 & 4.958 & 3.292 & 45,5 & 3.405 & 47,0 & 4.327 & 59,8 & 7.237 \\
\hline & Rural & 2.390 & 65,2 & 2.487 & 67,9 & 2.895 & 79,0 & 3.665 & 2.025 & 52,9 & 2.602 & 68,0 & 3.063 & 80,0 & 3.827 \\
\hline \multirow{5}{*}{ Nordeste } & Fortaleza & 1.420 & 62,7 & 1.152 & 50,8 & 1.420 & 62,7 & 2.265 & 1.371 & 46,4 & 1.333 & 45,1 & 1.742 & 59,0 & 2.954 \\
\hline & Recife & 1.998 & 70,2 & 1.455 & 51,2 & 1.791 & 63,0 & 2.845 & 1.896 & 57,2 & 1.576 & 47,5 & 1.952 & 58,9 & 3.317 \\
\hline & Salvador & 1.467 & 60,0 & 1.089 & 44,5 & 1.374 & 56,1 & 2.447 & 1.477 & 49,4 & 1.223 & 40,9 & 1.607 & 53,8 & 2.989 \\
\hline & Urbano & 12.899 & 71,0 & 11.337 & 62,4 & 13.302 & 73,2 & 18.167 & 12.689 & 53,5 & 13.045 & 55,0 & 15.965 & 67,3 & 23.724 \\
\hline & Rural & 13.050 & 79,5 & 13.394 & 81,6 & 14.674 & 89,4 & 16.413 & 8.900 & 61,2 & 10.963 & 75,4 & 12.632 & 86,9 & 14.537 \\
\hline \multirow{16}{*}{ Sudeste } & Minas Gerais & & & & & & & & & & & & & & \\
\hline & Belo Horizonte & 1.542 & 45,5 & 1.046 & 30,9 & 1.447 & 42,7 & 3.388 & 1.608 & 33,7 & 1.277 & 26,7 & 1.909 & 40,0 & 4.777 \\
\hline & Urbano & 3.544 & 42,2 & 3.121 & 37,2 & 4.241 & 50,5 & 8.392 & 2.696 & 27,6 & 2.909 & 29,7 & 4.201 & 43,0 & 9.779 \\
\hline & Rural & 2.100 & 55,8 & 2.388 & 63,5 & 2.859 & 76,0 & 3.762 & 1.040 & 34,7 & 1.529 & 51,0 & 2.036 & 67,9 & 3.000 \\
\hline & Espirito Santo & & & & & & & & & & & & & & \\
\hline & Urbano & 695 & 36,5 & 607 & 31,8 & 847 & 44,4 & 1.906 & 598 & 24,4 & 655 & 26,7 & 963 & 39,3 & 2.450 \\
\hline & Rural & 363 & 53,8 & 409 & 60,7 & 499 & 74,0 & 674 & 156 & 24,7 & 266 & 42,0 & 375 & 59,1 & 634 \\
\hline & Rio de Janeiro & & & & & & & & & & & & & & \\
\hline & Metrópole & 4.660 & 48,0 & 2.851 & 29,4 & 4.016 & 41,4 & 9.711 & 3.755 & 34,7 & 2.838 & 26,2 & 3.869 & 35,8 & 10.821 \\
\hline & Urbano & 966 & 39,5 & 786 & 32,1 & 1.105 & 45,2 & 2.446 & 710 & 23,7 & 717 & 23,9 & 1.073 & 35,8 & 2.995 \\
\hline & Rural & 305 & 58,3 & 305 & 58,3 & 376 & 71,9 & 523 & 157 & 32,0 & 212 & 43,3 & 286 & 58,5 & 489 \\
\hline & São Paulo & & & & & & & & & & & & & & \\
\hline & Metrópole & 5.395 & 35,5 & 2.306 & 15,2 & 3.832 & 25,2 & 15.206 & 6.550 & 36,9 & 3.917 & 22,1 & 5.908 & 33,3 & 17.744 \\
\hline & Urbano & 3.784 & 26,9 & 2.290 & 16,3 & 3.719 & 26,4 & 14.076 & 3.956 & 22,8 & 3.135 & 18,1 & 5.115 & 29,5 & 17.356 \\
\hline & Rural & 777 & 40,5 & 759 & 39,5 & 1.019 & 53,1 & 1.919 & 436 & 26,3 & 570 & 34,4 & 830 & 50,1 & 1.658 \\
\hline & Curitiba & 652 & 33,1 & 384 & 19,5 & 591 & 30,0 & 1.972 & 681 & 25,2 & 533 & 19,7 & 841 & 31,1 & 2.704 \\
\hline \multirow{3}{*}{ Sul } & Porto Alegre & 692 & 23,1 & 515 & 17,2 & 819 & 27,4 & 2.992 & 634 & 17,5 & 634 & 17,5 & 992 & 27,3 & 3.628 \\
\hline & Urbano & 3.401 & 29,6 & 2.788 & 24,3 & 4.291 & 37,4 & 11.475 & 2.680 & 18,9 & 2.994 & 21,1 & 4.511 & 31,7 & 14.214 \\
\hline & Rural & 2.472 & 45,2 & 2.770 & 50,6 & 3.482 & 63,6 & 5.471 & 1.108 & 25,2 & 1.505 & 34,2 & 2.213 & 50,3 & 4.403 \\
\hline \multirow{4}{*}{$\begin{array}{l}\text { Centro- } \\
\text { Oeste }\end{array}$} & Brasília & 744 & 47,6 & 407 & 26,0 & 574 & 36,7 & 1.565 & 746 & 36,9 & 507 & 25,1 & 718 & 35,5 & 2.023 \\
\hline & Urbano & 3.359 & 55,2 & 2.229 & 36,7 & 3.071 & 50,5 & 6.082 & 3.078 & 38,1 & 2.533 & 31,3 & 3.738 & 46,2 & 8.087 \\
\hline & Rural & 987 & 59,5 & 929 & 56,0 & 1.171 & 70,5 & 1.660 & 534 & 36,9 & 683 & 47,1 & 911 & 62,8 & 1.450 \\
\hline & BRASIL & 72.883 & 50,2 & 60.513 & 41,6 & 76.906 & 52,9 & 145.296 & 63.505 & 37,7 & 62.268 & 36,9 & 82.722 & 49,1 & 168.577 \\
\hline \multicolumn{16}{|c|}{$\begin{array}{l}\text { Obs.: (1) } n^{o} \text { de pobres e População Total em milhares de habitantes. } \\
\text { (2) Os valores das colunas } n^{\circ} \text { de pobres correspondem ao número de pessoas com renda familiar per } \\
\text { capita abaixo da linha de pobreza considerada e os valores das colunas \% são o percentual de pessoas pobres em } \\
\text { relação ao total populacional de habitantes de cada estrato. } \\
\text { (3) As colunas } Z h 30 \text { e } Z h 50 \text { indicam os valores correspondentes às linhas híbridas considerando linhas }\end{array}$} \\
\hline
\end{tabular}


Tabela 11.D - Variação da Incidência da Pobreza entre os Anos de 1991 e 2000

\begin{tabular}{|c|c|c|c|c|c|c|c|c|c|c|c|}
\hline \multirow{3}{*}{ Regiões } & \multirow{3}{*}{ Estratos } & \multicolumn{5}{|c|}{ Diferença em Pontos Percentuais } & \multicolumn{5}{|c|}{ Variação Percentual para 1991} \\
\hline & & \multirow{2}{*}{$\mathrm{Za}$} & \multicolumn{2}{|c|}{ Zh com RM por Estrato } & \multicolumn{2}{|c|}{ Zh com RM Nacional } & \multirow{2}{*}{$\mathrm{Za}$} & \multicolumn{2}{|c|}{ Zh com RM por Estrato } & \multicolumn{2}{|c|}{ Zh com RM Nacional } \\
\hline & & & Zh30 & Zh50 & Zh30 & Zh50 & & Zh30 & Zh50 & Zh30 & Zh50 \\
\hline \multirow{3}{*}{ Norte } & Belém & $-4,9$ & $\overline{0,4}$ & 0,5 & 5,1 & 5,8 & $-10,7$ & $\overline{1,0}$ & $\overline{1,0}$ & 14,8 & 12,2 \\
\hline & Urbano & $-7,3$ & 3,9 & 3,8 & 1,6 & 1,9 & $-13,8$ & 11,4 & 8,2 & 3,6 & 3,3 \\
\hline & Rural & $-12,3$ & $-4,4$ & $-7,5$ & 0,2 & 1,0 & $-18,9$ & $-10,0$ & $-12,8$ & 0,2 & 1,3 \\
\hline \multirow{5}{*}{ Nordeste } & Fortaleza & $-16,3$ & $-1,9$ & $-2,0$ & $-5,7$ & $-3,7$ & $-26,0$ & $-4,4$ & $-3,5$ & $-11,3$ & $-5,9$ \\
\hline & Recife & $-13,1$ & $-4,3$ & $-2,3$ & $-3,6$ & $-4,1$ & $-18,6$ & $-8,7$ & $-3,9$ & $-7,1$ & $-6,5$ \\
\hline & Salvador & $-10,5$ & $-2,1$ & $-2,4$ & $-3,6$ & $-2,4$ & $-17,6$ & $-4,5$ & $-4,1$ & $-8,0$ & $-4,2$ \\
\hline & Urbano & $-17,5$ & 1,0 & 1,8 & $-7,4$ & $-5,9$ & $-24,7$ & 2,7 & 3,4 & $-11,9$ & $-8,1$ \\
\hline & Rural & $-18,3$ & $-10,9$ & $-13,7$ & $-6,2$ & $-2,5$ & $-23,0$ & $-22,7$ & $-21,7$ & $-7,6$ & $-2,8$ \\
\hline \multirow{15}{*}{ Sudeste } & Minas Gerais & & & & & & & & & & \\
\hline & Belo Horizonte & $-11,9$ & $-1,2$ & 0,9 & $-4,2$ & $-2,7$ & $-26,1$ & $-3,6$ & 1,9 & $-13,4$ & $-6,4$ \\
\hline & Urbano & $-14,7$ & 0,6 & $-0,5$ & $-7,4$ & $-7,6$ & $-34,7$ & 2,2 & $-1,3$ & $-20,0$ & $-15,0$ \\
\hline & Rural & $-21,1$ & $-11,0$ & $-14,5$ & $-12,5$ & $-8,1$ & $-37,9$ & $-26,6$ & $-25,6$ & $-19,7$ & $-10,7$ \\
\hline & Espirito Santo & & & & & & & & & & \\
\hline & Urbano & $-12,0$ & 2,5 & 2,9 & $-5,1$ & $-5,1$ & $-33,0$ & 9,7 & 7,5 & $-16,0$ & $-11,6$ \\
\hline & Rural & $-29,2$ & $-21,0$ & $-22,6$ & $-18,7$ & $-14,9$ & $-54,2$ & $-46,8$ & $-37,6$ & $-30,9$ & $-20,1$ \\
\hline & Rio de Janeiro & & & & & & & & & & \\
\hline & Metrópole & $-13,3$ & $-0,1$ & 0,5 & $-3,1$ & $-5,6$ & $-27,7$ & $-0,3$ & 1,1 & $-10,7$ & $-13,5$ \\
\hline & Urbano & $-15,8$ & $-3,5$ & $-3,5$ & $-8,2$ & $-9,3$ & $-40,0$ & $-12,1$ & $-8,5$ & $-25,5$ & $-20,7$ \\
\hline & Rural & $-26,2$ & $-24,1$ & $-27,6$ & $-15,0$ & $-13,4$ & $-45,0$ & $-48,4$ & $-42,9$ & $-25,7$ & $-18,6$ \\
\hline & São Paulo & & & & & & & & & & \\
\hline & Metrópole & 1,4 & 5,9 & 6,3 & 6,9 & 8,1 & 4,0 & 21,2 & 15,8 & 45,5 & 32,1 \\
\hline & Urbano & $-4,1$ & 3,8 & 4,9 & 1,8 & 3,1 & $-15,2$ & 18,7 & 14,9 & 11,0 & 11,6 \\
\hline & Rural & $-14,2$ & $-13,9$ & $-14,7$ & $-5,1$ & $-3,0$ & $-35,1$ & $-36,4$ & $-27,3$ & $-13,0$ & $-5,6$ \\
\hline \multirow{4}{*}{ Sul } & Curitiba & $-7,9$ & 3,6 & 4,5 & 0,2 & 1,1 & $-23,8$ & 14,1 & 11,7 & 1,1 & 3,8 \\
\hline & Porto Alegre & $-5,7$ & 2,2 & 4,3 & 0,3 & 0,0 & $-24,5$ & 9,4 & 12,4 & 1,5 & $-0,1$ \\
\hline & Urbano & $-10,8$ & 0,8 & 1,0 & $-3,2$ & $-5,7$ & $-36,4$ & 3,6 & 2,8 & $-13,3$ & $-15,1$ \\
\hline & Rural & $-20,0$ & $-14,5$ & $-17,9$ & $-16,5$ & $-13,4$ & $-44,3$ & $-36,3$ & $-33,0$ & $-32,5$ & $-21,0$ \\
\hline \multirow{4}{*}{$\begin{array}{c}\text { Centro- } \\
\text { Oeste }\end{array}$} & Brasília & $-10,7$ & $-1,5$ & $-2,4$ & $-1,0$ & $-1,2$ & $-22,4$ & $-3,7$ & $-4,6$ & $-3,7$ & $-3,2$ \\
\hline & Urbano & $-17,2$ & $-2,2$ & $-1,6$ & $-5,3$ & $-4,3$ & $-31,1$ & $-6,5$ & $-3,3$ & $-14,5$ & $-8,4$ \\
\hline & Rural & $-22,6$ & $-13,9$ & $-18,3$ & $-8,9$ & $-7,7$ & $-38,0$ & $-31,2$ & $-30,9$ & $-15,8$ & $-10,9$ \\
\hline & BRASIL & $-12,5$ & $-1,5$ & $-1,7$ & $-4,7$ & $-3,9$ & $-24,9$ & $-4,4$ & $-3,7$ & $-11,3$ & $-7,3$ \\
\hline
\end{tabular}

Obs.: (1) As colunas referentes à Diferença em Pontos Percentuais indicam a diferença da incidência da pobreza entre os anos de 1991 e 2000. Já as colunas da Variação Percentual para 1991, correspondem a relação entre esta diferença e a incidência da pobreza em 1991.

(2) As colunas Za correspondem aos valores considerando as linhas absolutas de pobreza.

(3) As colunas Zh com RM por Estrato correspondem aos valores utilizando linhas híbridas construídas a partir de linhas relativas por estrato, enquanto que as colunas Zh com RM Nacional correspondem aos valores utilizando linhas híbridas construídas a partir da linha relativa nacional.

(4) As colunas Zh30 e Zh50 indicam os valores correspondentes às linhas híbridas considerando linhas relativas de $30 \%$ e $50 \%$ da renda média, respectivamente. 
Tabela 12.D -Regressões do Modelo Probit para 1991 e 2000

\begin{tabular}{|c|c|c|c|c|c|c|c|c|c|c|c|c|}
\hline \multirow{3}{*}{$\begin{array}{l}\text { Variável } \\
\text { Dependente: }\end{array}$} & \multicolumn{6}{|c|}{1991} & \multicolumn{6}{|c|}{2000} \\
\hline & \multicolumn{2}{|c|}{ pobre } & \multicolumn{2}{|c|}{ pobre30 } & \multicolumn{2}{|c|}{ pobre50 } & \multicolumn{2}{|c|}{ pobre } & \multicolumn{2}{|c|}{ pobre 30} & \multicolumn{2}{|c|}{ pobre50 } \\
\hline & Coeficiente & $\begin{array}{l}\text { desvio- } \\
\text { padrão }\end{array}$ & Coeficiente & $\begin{array}{l}\text { desvio- } \\
\text { padrão }\end{array}$ & Coeficiente & $\begin{array}{l}\text { desvio- } \\
\text { padrão }\end{array}$ & Coeficiente & $\begin{array}{l}\text { desvio- } \\
\text { padrão }\end{array}$ & Coeficiente & $\begin{array}{l}\text { desvio- } \\
\text { padrão }\end{array}$ & Coeficiente & $\begin{array}{l}\text { desvio- } \\
\text { padrão }\end{array}$ \\
\hline \multicolumn{13}{|l|}{ Variáveis } \\
\hline \multicolumn{13}{|l|}{ Independente: } \\
\hline Intercepto & $-0,1582$ & 0,0004 & $-0,3555$ & 0,0004 & 0,0767 & 0,0004 & $-0,0062$ & 0,0004 & 0,0144 & 0,0004 & 0,4386 & 0,0004 \\
\hline Mulher & 0,0754 & 0,0002 & 0,0763 & 0,0002 & 0,0760 & 0,0002 & 0,0693 & 0,0002 & 0,0695 & 0,0002 & 0,0707 & 0,0002 \\
\hline Não-Branco & 0,3566 & 0,0002 & 0,2935 & 0,0003 & 0,3291 & 0,0002 & 0,3740 & 0,0002 & 0,3282 & 0,0002 & 0,3581 & 0,0002 \\
\hline Idade & $-0,0065$ & 0,00001 & $-0,0070$ & 0,00001 & $-0,0068$ & 0,00001 & $-0,0116$ & 0,00001 & $-0,0114$ & 0,00001 & $-0,0118$ & 0,00001 \\
\hline Escolaridade & $-0,0840$ & 0,0000 & $-0,0742$ & 0,0000 & $-0,0785$ & 0,0000 & $-0,0757$ & 0,0000 & $-0,0678$ & 0,0000 & $-0,0728$ & 0,0000 \\
\hline Reg.Metropolitana & 0,0404 & 0,0001 & 0,0412 & 0,0001 & 0,0407 & 0,0001 & 0,2101 & 0,0003 & 0,2628 & 0,0003 & 0,2385 & 0,0003 \\
\hline Urbano & $-0,1567$ & 0,0003 & $-0,1177$ & 0,0003 & $-0,1418$ & 0,0003 & $-0,0575$ & 0,0003 & $-0,2272$ & 0,0003 & $-0,2092$ & 0,0003 \\
\hline Dummy RO & 0,3432 & 0,0013 & 0,2138 & 0,0013 & 0,1270 & 0,0012 & $-0,1706$ & 0,0012 & $-0,0722$ & 0,0012 & $-0,1383$ & 0,0012 \\
\hline Dummy AC & 0,3447 & 0,0020 & 0,1725 & 0,0021 & 0,0808 & 0,0020 & 0,1480 & 0,0018 & 0,0088 & 0,0018 & $-0,0307$ & 0,0018 \\
\hline Dummy AM & 0,2432 & 0,0010 & 0,0777 & 0,0010 & 0,0009 & 0,0010 & 0,3518 & 0,0008 & 0,1342 & 0,0008 & 0,0433 & 0,0008 \\
\hline Dummy RR & 0,0394 & 0,0029 & 0,2904 & 0,0028 & 0,1077 & 0,0028 & $-0,0457$ & 0,0024 & $-0,0058$ & 0,0024 & $-0,1183$ & 0,0023 \\
\hline Dummy PA & 0,4464 & 0,0007 & 0,1544 & 0,0007 & 0,0986 & 0,0007 & 0,2166 & 0,0006 & $-0,0669$ & 0,0006 & $-0,1274$ & 0,0006 \\
\hline Dummy AP & 0,1171 & 0,0025 & 0,0967 & 0,0025 & 0,0227 & 0,0024 & 0,1882 & 0,0020 & 0,1797 & 0,0020 & 0,0638 & 0,0019 \\
\hline Dummy TO & 0,4958 & 0,0014 & 0,1901 & 0,0014 & 0,1228 & 0,0014 & 0,2750 & 0,0012 & 0,0451 & 0,0013 & 0,0020 & 0,0012 \\
\hline Dummy MA & 0,7909 & 0,0007 & 0,1464 & 0,0007 & 0,1058 & 0,0007 & 0,5995 & 0,0006 & 0,0829 & 0,0006 & 0,0009 & 0,0006 \\
\hline Dummy PI & 0,9389 & 0,0009 & 0,3512 & 0,0009 & 0,2712 & 0,0009 & 0,5013 & 0,0008 & 0,0923 & 0,0008 & 0,0264 & 0,0008 \\
\hline Dummy CE & 0,9551 & 0,0006 & 0,3616 & 0,0006 & 0,3177 & 0,0006 & 0,4773 & 0,0005 & 0,0951 & 0,0005 & 0,0366 & 0,0005 \\
\hline Dummy RN & 0,7486 & 0,0009 & 0,2925 & 0,0009 & 0,2374 & 0,0009 & 0,3640 & 0,0008 & 0,1096 & 0,0009 & 0,0456 & 0,0008 \\
\hline Dummy PB & 0,9381 & 0,0008 & 0,3129 & 0,0008 & 0,2681 & 0,0008 & 0,4454 & 0,0008 & 0,0644 & 0,0008 & 0,0084 & 0,0008 \\
\hline Dummy PE & 0,9337 & 0,0006 & 0,4104 & 0,0006 & 0,3516 & 0,0006 & 0,5243 & 0,0005 & 0,1199 & 0,0005 & 0,0514 & 0,0005 \\
\hline Dummy AL & 0,7243 & 0,0009 & 0,1616 & 0,0009 & 0,1240 & 0,0009 & 0,5420 & 0,0008 & 0,1331 & 0,0008 & 0,0496 & 0,0008 \\
\hline Dummy SE & 0,6257 & 0,0011 & 0,1696 & 0,0011 & 0,1250 & 0,0011 & 0,3636 & 0,0010 & 0,0158 & 0,0010 & $-0,0503$ & 0,0010 \\
\hline Dummy BA & 0,8034 & 0,0005 & 0,2745 & 0,0005 & 0,2151 & 0,0005 & 0,3909 & 0,0004 & 0,0315 & 0,0005 & $-0,0320$ & 0,0004 \\
\hline Dummy MG & 0,2468 & 0,0004 & 0,1461 & 0,0004 & 0,1124 & 0,0004 & $-0,0820$ & 0,0004 & $-0,1066$ & 0,0004 & $-0,1075$ & 0,0004 \\
\hline Dummy ES & 0,0985 & 0,0009 & 0,1164 & 0,0009 & 0,0682 & 0,0009 & $-0,2348$ & 0,0009 & $-0,0901$ & 0,0008 & $-0,1067$ & 0,0008 \\
\hline Dummy RJ & 0,4000 & 0,0005 & 0,2596 & 0,0005 & 0,2149 & 0,0004 & $-0,0233$ & 0,0004 & $-0,0280$ & 0,0004 & $-0,0668$ & 0,0004 \\
\hline Dummy PR & 0,0961 & 0,0005 & 0,1053 & 0,0005 & 0,0815 & 0,0005 & $-0,1554$ & 0,0005 & $-0,0779$ & 0,0005 & $-0,0702$ & 0,0005 \\
\hline Dummy SC & $-0,1221$ & 0,0007 & 0,0156 & 0,0007 & $-0,0316$ & 0,0007 & $-0,4373$ & 0,0008 & $-0,1818$ & 0,0007 & $-0,1863$ & 0,0006 \\
\hline Dummy RS & $-0,0215$ & 0,0005 & 0,1204 & 0,0005 & 0,0707 & 0,0005 & $-0,2842$ & 0,0005 & $-0,0875$ & 0,0005 & $-0,1177$ & 0,0005 \\
\hline Dummy MS & 0,5292 & 0,0010 & 0,3178 & 0,0010 & 0,2862 & 0,0010 & 0,2199 & 0,0010 & 0,1230 & 0,0010 & 0,1302 & 0,0009 \\
\hline Dummy MT & 0,4649 & 0,0010 & 0,2395 & 0,0010 & 0,1817 & 0,0010 & 0,0976 & 0,0009 & 0,0173 & 0,0009 & 0,0083 & 0,0009 \\
\hline Dummy GO & 0,5214 & 0,0007 & 0,2307 & 0,0007 & 0,2044 & 0,0007 & 0,1684 & 0,0007 & 0,0155 & 0,0007 & 0,0295 & 0,0006 \\
\hline Dummy DF & 0,6470 & 0,0011 & 0,6663 & 0,0011 & 0,5910 & 0,0011 & 0,2430 & 0,0010 & 0,4453 & 0,0010 & 0,3176 & 0,0010 \\
\hline Pseudo- $\mathrm{R}^{2}$ & \multicolumn{2}{|c|}{0,1671} & \multicolumn{2}{|c|}{0,0852} & \multicolumn{2}{|c|}{0,0945} & \multicolumn{2}{|c|}{0,1509} & \multicolumn{2}{|c|}{0,1032} & \multicolumn{2}{|c|}{0,1098} \\
\hline $\begin{array}{l}\text { número de } \\
\text { observações }\end{array}$ & \multicolumn{6}{|c|}{145.303 .385} & \multicolumn{6}{|c|}{168.584 .058} \\
\hline
\end{tabular}

Obs.: (1) A Dummy SP (Estado de São Paulo) foi retirada da regressão para evitar o problema de multicolinearidade perfeita. Portanto, é a variável de estado referência.

(2) As variáveis dependentes são dummies que recebem o valor 1 (um) quando o individuo é pobre, considerando certa linha de pobreza: pobre (dummy considerando linha absoluta de pobreza); pobre30 (dummy considerando linha híbrida com linha relativa de 30\%); e pobre50 (dummy considerando linha híbrida com linha relativa de $50 \%$ ).

(3) Todas as estimações usam White robusto para heterocedasticidade. 


\section{c) Resultados para o Capítulo 4}

Tabela 14.D - Estimações de Logaritmo da Incidência da Pobreza em Logaritmos da Renda e Desigualdade

\begin{tabular}{|c|c|c|c|c|c|c|c|c|c|}
\hline \multirow{2}{*}{$\begin{array}{l}\text { Variável dependente: } \\
\text { Proporção de Pobres }\end{array}$} & \multicolumn{3}{|c|}{ MQO } & \multicolumn{3}{|c|}{ Efeitos Fixos } & \multicolumn{3}{|c|}{ Efeitos Aleatórios } \\
\hline & sem indice & com Gini & com Theil & sem índice & com Gini & com Theil & sem índice & com Gini & com Theil \\
\hline Intercepto & $\begin{array}{l}2,7606 \\
(0,051)\end{array}$ & $\begin{array}{l}3,3763 \\
(0,064)\end{array}$ & $\begin{array}{l}3,1998 \\
(0,057)\end{array}$ & $\begin{array}{l}2,2199 \\
(0,092)\end{array}$ & $\begin{array}{l}3,4648 \\
(0,095)\end{array}$ & $\begin{array}{l}3,4422 \\
(0,098)\end{array}$ & $\begin{array}{l}2,4848 \\
(0,035)\end{array}$ & $\begin{array}{l}3,1819 \\
(0,042)\end{array}$ & $\begin{array}{l}2,9203 \\
(0,038)\end{array}$ \\
\hline Renc & $\begin{array}{l}-0,7605 \\
(0,011) \\
\end{array}$ & $\begin{array}{l}-0,7428 \\
(0,010) \\
\end{array}$ & $\begin{array}{l}-0,8007 \\
(0,011)\end{array}$ & $\begin{array}{l}-0,6397 \\
(0,018)\end{array}$ & $\begin{array}{l}-0,7591 \\
(0,017) \\
\end{array}$ & $\begin{array}{l}-0,8494 \\
(0,019)\end{array}$ & $\begin{array}{l}-0,6926 \\
(0,008)\end{array}$ & $\begin{array}{l}-0,6984 \\
(0,007)\end{array}$ & $\begin{array}{l}-0,7433 \\
(0,008) \\
\end{array}$ \\
\hline $\begin{array}{c}\text { Indice de Desigualdade de } \\
\text { Renda }\end{array}$ & & $\begin{array}{l}1,1508 \\
(0,057) \\
\end{array}$ & $\begin{array}{l}0,4015 \\
(0,019) \\
\end{array}$ & & $\begin{array}{l}1,1227 \\
(0,031)\end{array}$ & $\begin{array}{l}0,3388 \\
(0,011) \\
\end{array}$ & & $\begin{array}{l}1,1592 \\
(0,027) \\
\end{array}$ & $\begin{array}{l}0,3562 \\
(0,009) \\
\end{array}$ \\
\hline Dummy do ano de 1991 & $\begin{array}{l}0,1580 \\
(0,010)\end{array}$ & $\begin{array}{l}0,2000 \\
(0,009) \\
\end{array}$ & $\begin{array}{l}0,1494 \\
(0,009) \\
\end{array}$ & $\begin{array}{l}0,1651 \\
(0,007)\end{array}$ & $\begin{array}{l}0,1753 \\
(0,005) \\
\end{array}$ & $\begin{array}{l}0,1052 \\
(0,006) \\
\end{array}$ & $\begin{array}{l}0,1467 \\
(0,004)\end{array}$ & $\begin{array}{l}0,1980 \\
(0,003)\end{array}$ & $\begin{array}{l}0,1426 \\
(0,003) \\
\end{array}$ \\
\hline $\mathrm{R}^{2}$ & 0,6742 & 0,7438 & 0,7369 & 0,7505 & 0,8403 & 0,8080 & 0,7500 & 0,8394 & 0,8049 \\
\hline $\mathrm{n}^{\circ}$ de observações & & 8576 & & & 8576 & & & 8576 & \\
\hline
\end{tabular}

Obs.: (1) MQO corresponde ao método de Mínimos Quadrados Ordinários com os dois anos (1991 e 2000).

(2) Os valores entre parênteses abaixo de cada coeficiente correspondem ao respectivo desvio-padrão.

(3) Todas as estimações usam White robusto para heterocedasticidade.

Tabela 15.D - Testes de Verificação dos Métodos Aplicados

\begin{tabular}{ccccccc}
\hline Testes & \multicolumn{2}{c}{ sem índice } & \multicolumn{2}{c}{ com Gini } & \multicolumn{2}{c}{ com Theil } \\
\cline { 2 - 7 } & Qui-Quadrado & p-valor & Qui-Quadrado & p-valor & Qui-Quadrado & p-valor \\
\hline $\begin{array}{c}\text { Wald modificado para } \\
\text { heterocedasticidade em Efeitos Fixos }\end{array}$ & $1,1 \mathrm{E}+31$ & 0,000 & $0,0 \mathrm{E}+00$ & 1,000 & $0,0 \mathrm{E}+00$ & 1,000 \\
\hline $\begin{array}{c}\text { Breuch Pagan - existência de efeito } \\
\text { individual não observado }\end{array}$ & 1908 & 0,000 & 2190 & 0,000 & 1915 & 0,000 \\
\hline Hausman & 13 & 0,002 & 54 & 0,000 & 147 & 0,000 \\
\hline
\end{tabular}

Tabela 16.D - Estimações em Logaritmo da Incidência da Pobreza em Renda e Desigualdade por MQVD com Peso

\begin{tabular}{cccc}
\hline Variável dependente: & \multicolumn{3}{c}{ MQVD } \\
\cline { 2 - 4 } Proporção de Pobres & sem índice & com Gini & com Theil \\
\hline Intercepto & 1,9103 & 3,7050 & 3,5710 \\
& $(0,165)$ & $(0,153)$ & $(0,162)$ \\
\hline \multirow{2}{*}{ Renda Familiar per Capita } & $-0,5905$ & $-0,8036$ & $-0,8781$ \\
& $(0,033)$ & $(0,028)$ & $(0,031)$ \\
\hline Índice de Desigualdade de Renda & & 1,1883 & 0,3710 \\
& & $(0,057)$ & $(0,021)$ \\
\hline Dummy do ano de 1991 & 0,2200 & 0,1754 & 0,1163 \\
& $(0,012)$ & $(0,010)$ & $(0,010)$ \\
\hline $\mathrm{R}^{2}$ Ajustado & 0,8667 & 0,9147 & 0,8981 \\
\hline $\mathrm{n}^{\circ}$ de observações & \multicolumn{3}{c}{8576} \\
\hline
\end{tabular}

Obs.: (1) MQVD corresponde ao método de Mínimos Quadrados com Variáveis Dummy considerando os dois anos (1991 e 2000).

(2) Os valores entre parênteses abaixo de cada coeficiente correspondem ao respectivo desvio-padrão.

(3) Todas as estimações usam White robusto para heterocedasticidade. 
Tabela 17.D - Estimações da Diferença dos Logaritmos da Incidência da Pobreza nas Variáveis de Renda e Desigualdade

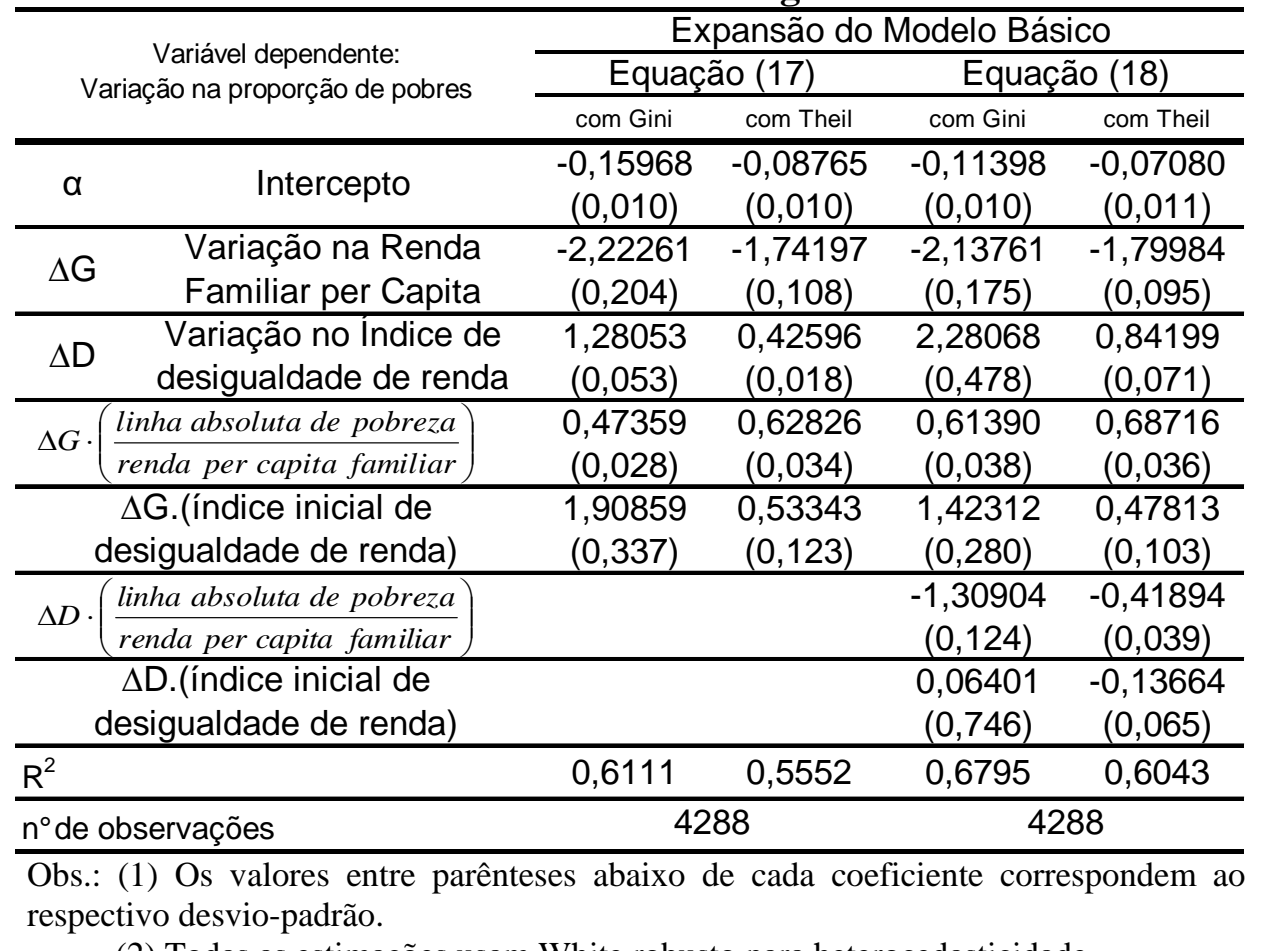

(2) Todas as estimações usam White robusto para heterocedasticidade.

Tabela 18.D - Comparativo entre as Elasticidades-Renda $\left(\varepsilon_{\mathrm{y}}\right.$ e $\left.\varepsilon_{\mathrm{m}}\right)$ e ElasticidadesDesigualdade $\left(\varepsilon_{\mathrm{G}}\right)$

\begin{tabular}{|c|c|c|c|c|c|c|c|c|c|c|c|c|c|c|c|c|c|c|c|c|}
\hline \multirow{3}{*}{ Estado } & \multicolumn{7}{|c|}{1991} & \multicolumn{7}{|c|}{2000} & \multicolumn{6}{|c|}{ Hoffmann (2004) } \\
\hline & \multirow{2}{*}{$\begin{array}{l}\text { Linha de } \\
\text { Pobreza }\end{array}$} & \multicolumn{3}{|c|}{ Gini } & \multicolumn{3}{|c|}{ Theil } & \multirow[t]{2}{*}{ ha de } & \multicolumn{3}{|c|}{ Gini } & \multicolumn{3}{|c|}{ Theil } & \multicolumn{2}{|c|}{1999} & \multicolumn{2}{|c|}{2001} & \multicolumn{2}{|c|}{2002} \\
\hline & & $\sigma$ & $\varepsilon_{y}$ & $\varepsilon_{G}$ & $\sigma$ & $\varepsilon_{y}$ & $G$ & & $\sigma$ & $\varepsilon_{y}$ & $\varepsilon_{G}$ & $\sigma$ & $\varepsilon_{y}$ & $\varepsilon_{G}$ & $\varepsilon_{m}$ & $\mathcal{E}_{G}$ & $\varepsilon_{m}$ & $\mathcal{E}_{G}$ & $\varepsilon_{m}$ & $G$ \\
\hline 10 & 6926 & 1,26 & $-0,63$ & 1,32 & 1,26 & $-0,63$ & $\overline{0,50}$ & 081 & 23 & $-0,84$ & 2,12 & 1,22 & $-0,86$ & 0,83 &, 01 & 2,05 & $-0,92$ & 1,60 & 1,00 & \\
\hline & & & & & & & & & & & 50 & & & & & & & & & \\
\hline AN & & & 63 & 1,41 & & 66 & & & & & & & & & & & & & & \\
\hline $\mathrm{RF}$ & & 37 & $-0,73$ & 2,32 & 1,21 & $-0,96$ & 1,0 & & 1,27 & $-0,76$ & 1,93 & 20 & $-0,86$ & & $-1,22$ & 2,18 & $-0,90$ & 1,44 & 0,76 & \\
\hline $\mathrm{P}$ & & & & & & & & & & & 1,26 & & $-0,57$ & & 77 & 15 & $-0,78$ & 1,16 & 0,78 & 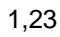 \\
\hline $\mathrm{AF}$ & & & & & & 0 & & & & & & & & & & 1,24 & , 28 & $1,9 /$ & & 1,3 \\
\hline 15 & & & 54 & 99 & & & & & & $-0,57$ & 35 & & $-0,57$ & & & 8 & $-0,64$ & 1,10 & & 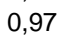 \\
\hline MA & & 22 & $-0,44$ & 0,53 & 29 & 0 & & & & & 84 & & & & & & 52 & & $T$ & \\
\hline $\mathrm{P}$ & & & & & & & & & & & & & & & & & 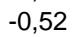 & 88 & & 0,7 \\
\hline $\mathrm{CE}$ & & & 41 & 0, & & 8 & & & & -0 & 1,14 & & & & & 0,72 & 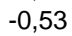 & 1 & & 0, \\
\hline$n$ & & & 49 & 0,00 & & 48 & & & & & & & & & &, 98 & $-0,64$ & 0,97 &, 0 & 0,9 \\
\hline$D P$ & & & & & & & & & & & & & & & & & & & & \\
\hline $\mathrm{PE}$ & & & & & & & & & & & & & & & & 0 & $-0,56$ & 3 & & $0, \mathrm{~S}$ \\
\hline AL & & & 47 & 0,77 & & 4 & 0,2 & & & & 1,07 & & -0 & & & 0 & 0,4 & 55 & & 0,6 \\
\hline $\mathrm{S}$ & & & 52 & 0, & & 9 & & & & & & & & & & &, 64 & & & $0, \mathrm{C}$ \\
\hline & & & & & & & & & & & & & & & & & & & & 0,8 \\
\hline$M C$ & & & & & & & & & & & 14 & & & & & & -0 & 8 & & 1,7 \\
\hline$E \subseteq$ & & & 83 & & & ,82 & & & & & 64 & & & & & & 0,82 & 69 & & 1,8 \\
\hline R & & & 74 & 1 , & & 4 & & & & & & & & & & & ,13 & 2,73 & & 2,8 \\
\hline & & & & & & & & & & & & & & & & & & & & $<, 9$ \\
\hline & & & & & & & & & & & & & & & & & & & & \\
\hline & & & & & & & & & & & & & & & & & & & & 2,9 \\
\hline $\mathrm{R}$ & & & & 2 & & & & & & & & & & & & & & 11 & & 2,4 \\
\hline & & & & & & & & & & & & & & & & & & & & 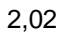 \\
\hline & & & & & & & & & & & & & & & & & & & & \\
\hline $\mathrm{GC}$ & & & & & & & & & & & & & & & & & & & & \\
\hline & & & & & & & 0,1 & & 1,00 & & & $1, L$ & & & & & & & 1,04 & \\
\hline & & & 04 & & $\therefore \mathrm{S}$ &, 00 & 0,00 & & 101, & $-0, \pi 0$ & & $1, \angle \mathrm{J}$ & 0,10 & & U, & זור, & ד, & 1,04 & 0,01 & \\
\hline
\end{tabular}

Obs.: (1) Os valores da coluna Linha de Pobreza correspondem às linhas da Tabela 2 abertas por estado e ponderadas pela população de cada estrato. 
(2) $\sigma$ é o desvio-padrão do logaritmo da renda, calculado a partir do índice de Gini, para a elasticidaderenda e elasticidade-desigualdade de Gini. Já para as elasticidades de Theil, $\sigma$ é calculado a partir do índice de desigualdade de Theil.

(3) Os valores $\varepsilon_{\mathrm{y}}$ e $\varepsilon_{\mathrm{G}}$ correspondem às elasticidades pela metodologia descrita no Apêndice F, usando os Censos de 1991 e 2000.

(4) Os valores $\varepsilon_{\mathrm{m}}$ e $\varepsilon_{\mathrm{G}}$ de Hoffmann (2004) correspondem às elasticidades com relação à renda e desigualdade, respectivamente, usando o índice de Gini, a partir das PNAD's de 1999, 2001 e 2002.

Tabela 19.D - Resultados do Teste Log-Normal com base em Bourguignon (2002)

\begin{tabular}{|c|c|c|c|c|c|}
\hline \multirow{3}{*}{\multicolumn{2}{|c|}{$\begin{array}{l}\text { Variável dependente: } \\
\text { Variação na proporção de pobres }\end{array}$}} & \multicolumn{4}{|c|}{ Teste - Modelo Lognormal } \\
\hline & & \multicolumn{2}{|c|}{ Equação (19) } & \multicolumn{2}{|c|}{ Equação (21) } \\
\hline & & com Gini & com Theil & com Gini & com Theil \\
\hline \multicolumn{2}{|r|}{ Intercepto } & $\begin{array}{c}-0,22169 \\
(0,015)\end{array}$ & $\begin{array}{c}-0,17535 \\
(0,021)\end{array}$ & $\begin{array}{c}-0,12900 \\
(0,012)\end{array}$ & $\begin{array}{c}-0,13171 \\
(0,017)\end{array}$ \\
\hline \multirow[t]{3}{*}{$\Delta \mathrm{D}$} & $\begin{array}{l}\text { Variação no Índice de } \\
\text { desigualdade de renda }\end{array}$ & $\begin{array}{l}1,17628 \\
(0,058) \\
\end{array}$ & $\begin{array}{c}0,38886 \\
(0,019) \\
\end{array}$ & & \\
\hline & $\Delta \mathrm{G} . \mathrm{E}_{\mathrm{G}}$ & $\begin{array}{c}-0,89069 \\
(0,058) \\
\end{array}$ & $\begin{array}{c}-0,97234 \\
(0,088) \\
\end{array}$ & $\begin{array}{c}-1,06016 \\
(0,051) \\
\end{array}$ & $\begin{array}{c}-1,09812 \\
(0,074) \\
\end{array}$ \\
\hline & $\Delta \mathrm{D} . \mathrm{E}_{\mathrm{D}}$ & & & $\begin{array}{c}0,56962 \\
(0,028) \\
\end{array}$ & $\begin{array}{c}0,95479 \\
(0,048) \\
\end{array}$ \\
\hline & 0,5638 & 0,4689 & 0,6816 & 0,5662 \\
\hline \multicolumn{2}{|c|}{$\mathrm{n}^{\circ}$ de observações } & \multicolumn{2}{|c|}{4288} & \multicolumn{2}{|c|}{428} \\
\hline
\end{tabular}

Obs.: (1) Os valores entre parênteses abaixo de cada coeficiente correspondem ao respectivo desvio-padrão.

(2) Todas as estimações usam White robusto para heterocedasticidade.

Tabela 20.D - Teste dos Coeficientes dos Termos das Elasticidades

\begin{tabular}{ccccc}
\hline \multirow{2}{*}{ Variável } & \multicolumn{4}{c}{$\mathrm{p}$-valor } \\
\cline { 2 - 5 } & \multicolumn{2}{c}{ Equação (19) } & \multicolumn{2}{c}{ Equação (21) } \\
\cline { 2 - 5 } & com Gini & com Theil & com Gini & com Theil \\
\hline$\Delta$ G.E $_{\mathrm{G}}$ & 0,0616 & 0,7544 & 0,2417 & 0,1846 \\
\hline$\Delta$ D.E & & & 0,0000 & 0,3429 \\
\hline
\end{tabular}

Obs.: (1) Hipóteses Nulas: Coeficiente da Elasticidade-Renda $=-1$

e Coeficiente da Elasticidade-Desigualdade $=1$.

Tabela 21.D - Estimações em Logaritmo da Incidência da Pobreza em Renda, Desigualdade e Linha Híbrida

\begin{tabular}{|c|c|c|c|c|c|c|c|c|}
\hline \multirow{3}{*}{$\begin{array}{l}\text { Variável dependente: } \\
\text { Proporção de Pobres }\end{array}$} & \multicolumn{4}{|c|}{ Efeitos Fixos } & \multicolumn{4}{|c|}{ Efeitos Aleatórios } \\
\hline & \multicolumn{2}{|c|}{ Zh30 } & \multicolumn{2}{|c|}{ Zh50 } & \multicolumn{2}{|c|}{ Zh30 } & \multicolumn{2}{|c|}{ Zh50 } \\
\hline & com Gini & com Theil & com Gini & com Theil & com Gini & com Theil & com Gini & com Theil \\
\hline Intercepto & $\begin{array}{l}1,0333 \\
(0,060)\end{array}$ & $\begin{array}{l}1,6560 \\
(0,083)\end{array}$ & $\begin{array}{l}0,0152 \\
(0,047)\end{array}$ & $\begin{array}{l}0,7826 \\
(0,059)\end{array}$ & $\begin{array}{l}1,2155 \\
(0,016)\end{array}$ & $\begin{array}{l}0,8249 \\
(0,022)\end{array}$ & $\begin{array}{l}0,3891 \\
(0,013)\end{array}$ & $\begin{array}{l}0,2074 \\
(0,015)\end{array}$ \\
\hline - Capita & $\begin{array}{l}-0,9883 \\
(0,037)\end{array}$ & $\begin{array}{l}-0,3476 \\
(0,047)\end{array}$ & $\begin{array}{l}-0,8913 \\
(0,025)\end{array}$ & $\begin{array}{r}-0,5059 \\
(0,029)\end{array}$ & $\begin{array}{l}-1,2162 \\
(0,016)\end{array}$ & $\begin{array}{r}-1,0940 \\
(0,022)\end{array}$ & $\begin{array}{r}-0,9732 \\
(0,011)\end{array}$ & $\begin{array}{r}-0,9163 \\
(0,013)\end{array}$ \\
\hline $\begin{array}{c}\text { İndice de Desigualdade de } \\
\text { Renda }\end{array}$ & $\begin{array}{l}1,8002 \\
(0,024)\end{array}$ & $\begin{array}{l}0,5387 \\
(0,009)\end{array}$ & $\begin{array}{l}1,1824 \\
(0,017)\end{array}$ & $\begin{array}{l}0,3851 \\
(0,006)\end{array}$ & $\begin{array}{l}2,0126 \\
(0,016)\end{array}$ & $\begin{array}{l}0,6220 \\
(0,007)\end{array}$ & $\begin{array}{l}1,3171 \\
(0,012)\end{array}$ & $\begin{array}{l}0,4416 \\
(0,005)\end{array}$ \\
\hline Linha Híbrida & $\begin{array}{l}0,9326 \\
(0,049)\end{array}$ & $\begin{array}{l}-0,2287 \\
(0,065)\end{array}$ & $\begin{array}{l}0,9896 \\
(0,033)\end{array}$ & $\begin{array}{l}0,2507 \\
(0,039)\end{array}$ & $\begin{array}{l}1,2058 \\
(0,020)\end{array}$ & $\begin{array}{l}0,9367 \\
(0,030)\end{array}$ & $\begin{array}{l}1,0160 \\
(0,014)\end{array}$ & $\begin{array}{l}0,8680 \\
(0,017)\end{array}$ \\
\hline Dummy do a & $\begin{array}{l}0,1195 \\
(0,004)\end{array}$ & $\begin{array}{l}0,0331 \\
(0,006)\end{array}$ & $\begin{array}{l}0,1303 \\
(0,003)\end{array}$ & $\begin{array}{l}0,0452 \\
(0,004)\end{array}$ & $\begin{array}{l}0,1082 \\
(0,002)\end{array}$ & $\begin{array}{l}0,0246 \\
(0,003)\end{array}$ & $\begin{array}{l}0,1145 \\
(0,001)\end{array}$ & $\begin{array}{l}0,0545 \\
(0,002)\end{array}$ \\
\hline $\mathrm{R}^{2}$ & 0,8350 & 0,6944 & 0,8442 & 0,7761 & 0,8321 & 0,6574 & 0,8397 & 0,7560 \\
\hline $\mathrm{n}^{\circ}$ de observações & & & & & & & & \\
\hline
\end{tabular}

Obs.: (1) Os valores entre parênteses abaixo de cada coeficiente correspondem ao respectivo desvio-padrão.

(2) Todas as estimações usam White robusto para heterocedasticidade.

(3) As colunas Zh30 e Zh50 indicam os valores correspondentes às linhas híbridas considerando linhas relativas de $30 \%$ e $50 \%$ da renda média, respectivamente. 
Tabela 22.D - Testes de Verificação dos Métodos Aplicados

\begin{tabular}{|c|c|c|c|c|c|c|c|c|}
\hline \multirow{3}{*}{ Testes } & \multicolumn{4}{|c|}{ Zh30 } & \multicolumn{4}{|c|}{ Zh50 } \\
\hline & \multicolumn{2}{|c|}{ com Gini } & \multicolumn{2}{|c|}{ com Theil } & \multicolumn{2}{|c|}{ com Gini } & \multicolumn{2}{|c|}{ com Theil } \\
\hline & Qui-Quadrado & p-valor & Qui-Quadrado & p-valor & Qui-Quadrado & p-valor & Qui-Quadrado & p-valor \\
\hline $\begin{array}{c}\text { Wald modificado para } \\
\text { heterocedasticidade em Efeitos Fixos }\end{array}$ & $1,8 E+35$ & 0,000 & $1,5 E+29$ & 0,000 & $8,6 E+35$ & 0,000 & $6,4 \mathrm{E}+33$ & 0,000 \\
\hline $\begin{array}{c}\text { Breuch Pagan - existência de efeito } \\
\text { individual não observado }\end{array}$ & 264 & 0,000 & 341 & 0,000 & 346 & 0,000 & 341 & 0,000 \\
\hline Hausman & 146 & 0,000 & 369 & 0,000 & 156 & 0,000 & 276 & 0,000 \\
\hline
\end{tabular}

Obs.: (1) Os valores entre parênteses abaixo de cada coeficiente correspondem ao respectivo desvio-padrão.

(2) Todas as estimações usam White robusto para heterocedasticidade.

(3) As colunas Zh30 e Zh50 indicam os valores correspondentes às linhas híbridas considerando linhas relativas de $30 \%$ e $50 \%$ da renda média, respectivamente.

Tabela 23.D - Estimações em Logaritmo da Incidência da Pobreza em Renda, Desigualdade e Linha Híbrida por MQVD com Peso

\begin{tabular}{ccccc}
\hline \multirow{2}{*}{$\begin{array}{c}\text { Variável dependente: } \\
\text { Proporção de Pobres }\end{array}$} & \multicolumn{3}{c}{ Zh30 } & \multicolumn{2}{c}{ Zh50 } \\
\cline { 2 - 5 } Intercepto & 1,1070 & 1,5809 & 0,1420 & 0,8563 \\
& $(0,116)$ & $(0,169)$ & $(0,102)$ & $(0,132)$ \\
\hline \multirow{2}{*}{ Renda Familiar per Capita } & $-0,9095$ & $-0,2260$ & $-0,8357$ & $-0,4158$ \\
& $(0,078)$ & $(0,095)$ & $(0,055)$ & $(0,061)$ \\
\hline \multirow{2}{*}{ Índice de Desigualdade de Renda } & 1,8866 & 0,5894 & 1,2622 & 0,4249 \\
& $(0,049)$ & $(0,018)$ & $(0,034)$ & $(0,012)$ \\
\hline \multirow{2}{*}{ Linha Híbrida de Pobreza } & 0,8226 & $-0,3670$ & 0,9052 & 0,1297 \\
& $(0,114)$ & $(0,141)$ & $(0,083)$ & $(0,093)$ \\
\hline \multirow{2}{*}{ Dummy do ano de 1991 } & 0,1381 & 0,0643 & 0,1431 & 0,0614 \\
& $(0,008)$ & $(0,011)$ & $(0,005)$ & $(0,006)$ \\
\hline $\mathrm{R}^{2}$ Ajustado & 0,9116 & 0,8437 & 0,9184 & 0,8789 \\
\hline $\mathrm{n}^{\circ}$ de observações & \multicolumn{3}{c}{8576} & \multicolumn{3}{c}{8576} \\
\hline
\end{tabular}

Obs.: (1) MQVD corresponde ao método de Mínimos Quadrados com Variáveis Dummy considerando os dois anos (1991 e 2000).

(2) Os valores entre parênteses abaixo de cada coeficiente correspondem ao respectivo desvio-padrão.

(3) Todas as estimações usam White robusto para heterocedasticidade.

(4) As colunas Zh30 e Zh50 indicam os valores correspondentes às linhas híbridas considerando linhas relativas de $30 \%$ e $50 \%$ da renda média, respectivamente.

Tabela 24.D - Cálculo da Elasticidade-Renda da Pobreza $\left(\varepsilon_{r}\right)$

\begin{tabular}{|c|c|c|c|c|c|c|c|}
\hline \multirow{2}{*}{$\begin{array}{l}\text { Linha } \\
\text { Híbrida }\end{array}$} & \multirow{2}{*}{$\begin{array}{c}\text { Índice de } \\
\text { Desigualdade }\end{array}$} & \multirow{2}{*}{$\beta_{1}$} & \multirow{2}{*}{$\beta_{3}$} & \multicolumn{2}{|c|}{1991} & \multicolumn{2}{|c|}{2000} \\
\hline & & & & $\rho_{t}$ & $\varepsilon_{\mathrm{r}}$ & $\rho_{t}$ & $\varepsilon_{r}$ \\
\hline $\begin{array}{l}\text { Zh30 } \\
\text { Zh50 }\end{array}$ & Gini & $\begin{array}{l}-0,90947 \\
-0,83571 \\
\end{array}$ & $\begin{array}{l}0,82263 \\
0,90524 \\
\end{array}$ & 0,62844 & $\begin{array}{l}-0,39250 \\
-0,26682\end{array}$ & 0,68752 & $\begin{array}{l}-0,34389 \\
-0,21333\end{array}$ \\
\hline $\begin{array}{l}\text { Zh30 } \\
\text { Zh50 }\end{array}$ & Theil & $\begin{array}{l}-0,22598 \\
-0,41581 \\
\end{array}$ & $\begin{array}{c}-0,36696 \\
0,12971 \\
\end{array}$ & 0,62844 & $\begin{array}{l}-0,45659 \\
-0,33430 \\
\end{array}$ & 0,68752 & $\begin{array}{l}-0,47827 \\
-0,32663\end{array}$ \\
\hline
\end{tabular}

Obs.: (1) As linhas Zh30 e Zh50 indicam os valores correspondentes às linhas híbridas considerando linhas relativas de $30 \%$ e $50 \%$ da renda média, respectivamente.

(2) As colunas $\beta_{1}$ e $\beta_{3}$ correspondem aos coeficientes da Renda Familiar per Capita e Linha Híbrida de Pobreza da Tabela 23, respectivamente.

(3) As colunas $\rho_{t}$ correspondem aos valores da elasticidade-renda da linha de pobreza calculados no capítulo anterior e apresentados na Tabela 6 . 


\section{d) Resultados para o Apêndice C}

Tabela C1.D - Estatísticas Descritivas das Principais Variáveis

\begin{tabular}{|c|c|c|c|c|c|c|c|c|}
\hline \multirow[b]{2}{*}{ Variável } & \multicolumn{4}{|c|}{1991} & \multicolumn{4}{|c|}{2000} \\
\hline & Média & $\begin{array}{l}\text { Desvio- } \\
\text { Padrão }\end{array}$ & Mínimo & Máximo & Média & $\begin{array}{l}\text { Desvio- } \\
\text { Padrão }\end{array}$ & Mínimo & Máximo \\
\hline Renda Familiar per Capita & 225.17 & 144.16 & 19.10 & 614.50 & 293.81 & 172.90 & 34.82 & 890.72 \\
\hline Índice de Desigualdade de Gini & 0.557 & 0.058 & 0.333 & 0.780 & 0.584 & 0.054 & 0.356 & 0.815 \\
\hline Índice de Desigualdade de Theil & 0.628 & 0.165 & 0.182 & 2.041 & 0.664 & 0.161 & 0.172 & 2.395 \\
\hline Linha Absoluta de Pobreza Za & 91.08 & 31.79 & 44.45 & 162.51 & 97.32 & 35.10 & 49.94 & 172.38 \\
\hline Linha Híbrida de Pobreza Zh30 & 73.56 & 38.21 & 13.32 & 163.06 & 89.03 & 44.27 & 17.64 & 220.99 \\
\hline Linha Híbrida de Pobreza Zh50 & 101.41 & 52.67 & 18.36 & 224.79 & 126.49 & 62.89 & 25.06 & 313.98 \\
\hline Número de Pobres considerando Za & 16,985 & 70,086 & 129 & $2,973,435$ & 14,810 & 69,712 & 18 & $3,372,853$ \\
\hline Número de Pobres considerando Zh30 & 11,543 & 61,257 & 111 & $2,751,290$ & 12,147 & 71,344 & 86 & $3,493,206$ \\
\hline Número de Pobres considerando Zh50 & 16,002 & 82,849 & 201 & $3,864,834$ & 17,200 & 97,666 & 252 & $4,832,802$ \\
\hline Incidência da Pobreza considerando Za & 0.448 & 0.209 & 0.039 & 0.957 & 0.377 & 0.170 & 0.005 & 0.860 \\
\hline Incidência da Pobreza considerando Zh30 & 0.320 & 0.093 & 0.066 & 0.670 & 0.309 & 0.081 & 0.024 & 0.602 \\
\hline Incidência da Pobreza considerando Zh50 & 0.450 & 0.100 & 0.112 & 0.758 & 0.438 & 0.080 & 0.104 & 0.721 \\
\hline Elasticidade-Renda da Pobreza com Gini & $(0.852)$ & 0.360 & $(0.088)$ & (3.078) & $(0.882)$ & 0.338 & $(0.155)$ & (3.574) \\
\hline Elasticidade-Renda da Pobreza com Theil & $(0.793)$ & 0.340 & $(0.088)$ & $(2.723)$ & $(0.825)$ & 0.318 & $(0.143)$ & $(3.448)$ \\
\hline Elasticidade-Desigualdade da Pobreza com Gini & 3.103 & 2.054 & $(0.265)$ & 11.022 & 3.874 & 2.177 & 0.063 & 14.599 \\
\hline Elasticidade-Desigualdade da Pobreza com Theil & 0.610 & 0.409 & $(0.057)$ & 2.385 & 0.744 & 0.430 & 0.015 & 2.963 \\
\hline População & 33,877 & 189,012 & 715 & $9,452,474$ & 39,314 & 210,811 & 499 & $10,338,500$ \\
\hline População Feminina & 17,103 & 98,094 & 364 & $4,886,388$ & 19,952 & 110,322 & 215 & $5,400,929$ \\
\hline População sem Raça Branca & 16,392 & 75,868 & - & $2,896,545$ & 18,172 & 86,494 & - & $3,403,414$ \\
\hline Idade & 25.97 & 2.48 & 17.32 & 34.49 & 28.22 & 2.55 & 18.08 & 38.26 \\
\hline Anos de Estudo & 3.79 & 1.40 & 0.35 & 7.02 & 4.95 & 1.35 & 1.11 & 7.99 \\
\hline
\end{tabular}

Obs.: (1) A renda familiar per capita e as linhas de pobreza estão em Reais (R\$) de julho de 2000.

(2) As colunas Za correspondem aos valores considerando as linhas absolutas de pobreza.

(3) As colunas Zh30 e Zh50 indicam os valores correspondentes às linhas híbridas considerando linhas relativas de $30 \%$ e $50 \%$ da renda média dos estratos, respectivamente.

\section{D.3 - Considerações sobre os Resultados Apresentados}

De maneira geral, não observamos diferenças significativas entre os resultados apresentados das quatro possibilidades. A última possibilidade apresentada, em que não há a estimação do aluguel implícito, mostra uma renda familiar per capita da ordem de $10 \%$ inferior do que as demais possibilidades. Além disso, nesta possibilidade, observamos um aumento da desigualdade de renda no Brasil tanto no ano de 1991 quanto em 2000. Enquanto nas demais possibilidades o índice de Gini é próximo de 0,62, na possibilidade sem estimação do aluguel implícito, este índice é de 0,64. O mesmo ocorre com o índice de desigualdade de Theil, apresentando um aumento de 0,79 para 0,83 em 1991 e de 0,80 para 0,83 em 2000 . Com isso, concluímos que a imputação do aluguel implícito na renda familiar per capita contribui para melhorar a distribuição de renda. Como este valor representa um rendimento 
em termos de consumo, que seria equivalente a um aluguel implícito pelo fato do indivíduo possuir casa própria, a utilização desta estimação no cálculo da renda familiar per capita é uma forma de aproximarmos a distribuição de renda com a distribuição de riqueza no Brasil.

Apesar desta diferença na renda e sua distribuição, os resultados entre as possibilidades foram bastante semelhantes, sem alterar a análise feita ao longo deste trabalho. 
APÊNDICE E -

COMPATIBILIZAÇÃO ENTRE

MUNICÍPIOS DE 1991 E 2000

Este trabalho utiliza um Painel balanceado para a análise econométrica.

Assim, é necessário estudar a evolução dos municípios ao longo do período de 1991 a 2000, considerando eventuais fusões e emancipações de municípios. A relação, a seguir, mostra a correlação dos municípios entre os períodos. $^{21}$ São apresentados apenas os municípios que sofreram algum tipo de fusão ou emancipação e aqueles criados entre 1991 e 2000.

\section{Tabela E1 - Listagem de Municípios}

\begin{tabular}{ll}
$\begin{array}{c}\text { Código } \\
\mathbf{1 9 9 1}\end{array}$ Nome do Município em $\mathbf{1 9 9 1} \begin{array}{c}\text { Código } \\
\mathbf{2 0 0 0}\end{array}$ & Nome do Município em $\mathbf{2 0 0 0}$ \\
\hline 110001 Alta Floresta d'Oeste & 1100015 ALTA FLORESTA D'OESTE \\
110001 Alta Floresta d'Oeste & 1100031 CABIXI \\
110001 Alta Floresta d'Oeste & 1100056 CEREJEIRAS \\
110001 Alta Floresta d'Oeste & 1100379 ALTO ALEGRE DOS \\
110001 Alta Floresta d'Oeste & 1101468 PIMENTE \\
110002 Ariquemes & 1100023 ARIQUEMES DO OESTE \\
110002 Ariquemes & 1100403 ALTO PARAISO \\
110002 Ariquemes & 1100601 CACAULANDIA \\
110002 Ariquemes & 1101401 MONTE NEGRO \\
110004 Cacoal & 1100049 CACOAL \\
110004 Cacoal & 1101203 MINISTRO ANDREAZZA \\
110006 Colorado do Oeste & 1100064 COLORADO DO OESTE \\
110006 Colorado do Oeste & 1100072 CORUMBIARA \\
110006 Colorado do Oeste & 1100189 PIMENTA BUENO \\
110006 Colorado do Oeste & 1100304 VILHENA \\
110006 Colorado do Oeste & 1100924 CHUPINGUAIA \\
110006 Colorado do Oeste & 1101450 PARECIS \\
110006 Colorado do Oeste & 1101476 PRIMAVERA DE RONDONIA \\
\hline
\end{tabular}

\footnotetext{
${ }^{21}$ Agradecimentos a Carla Rossi pelo trabalho de conciliação entre os municípios dos Censos Demográficos de 1991 e 2000, utilizado neste trabalho.
}

\begin{tabular}{|c|c|}
\hline${ }_{1991}^{\text {Código }}$ Nome do Município em 1991 & ${ }_{2000}^{\text {Código Nome do Município em } 2000}$ \\
\hline 110006 Colorado do Oeste & 1101484 SAO FELIPE D'OESTE \\
\hline 110008 Costa Marques & 1100080 COSTA MARQUES \\
\hline 110008 Costa Marques & 1100320 SAO MIGUEL DO GUAPORE \\
\hline 110008 Costa Marques & $\begin{array}{l}1101492 \text { SAO FRANCISCO DO } \\
\text { GUAPORE }\end{array}$ \\
\hline 110008 Costa Marques & 1101500 SERINGUEIRAS \\
\hline 110011 Jaru & 1100114 JARU \\
\hline 110011 Jaru & $\begin{array}{l}1101005 \text { GOVERNADOR JORGE } \\
\text { TEIXEIRA }\end{array}$ \\
\hline 110011 Jaru & 1101609 THEOBROMA \\
\hline 110013 Machadinho d'Oeste & 1100130 MACHADINHO D'OESTE \\
\hline 110013 Machadinho d'Oeste & 1100262 RIO CRESPO \\
\hline 110013 Machadinho d'Oeste & 1100940 CUJUBIM \\
\hline 110013 Machadinho d'Oeste & 1101757 VALE DO ANARI \\
\hline 110015 Ouro Preto do Oeste & 1100155 OURO PRETO DO OESTE \\
\hline 110015 Ouro Preto do Oeste & 1100346 ALVORADA D'OESTE \\
\hline 110015 Ouro Preto do Oeste & 1101302 MIRANTE DA SERRA \\
\hline 110015 Ouro Preto do Oeste & 1101435 NOVA UNIAO \\
\hline 110015 Ouro Preto do Oeste & 1101559 TEIXEIROPOLIS \\
\hline 110015 Ouro Preto do Oeste & 1101708 URUPA \\
\hline 110015 Ouro Preto do Oeste & 1101807 VALE DO PARAISO \\
\hline 110020 Porto Velho & 1100205 PORTO VELHO \\
\hline 110020 Porto Velho & 1100452 BURITIS \\
\hline 110020 Porto Velho & $\begin{array}{l}1100700 \text { CAMPO NOVO DE } \\
\text { RONDONIA }\end{array}$ \\
\hline 110020 Porto Velho & 1100809 CANDEIAS DO JAMARI \\
\hline 110028 Rolim de Moura & 1100288 ROLIM DE MOURA \\
\hline 110028 Rolim de Moura & $\begin{array}{l}1100502 \text { NOVO HORIZONTE DO } \\
\text { OESTE }\end{array}$ \\
\hline 110028 Rolim de Moura & 1100908 CASTANHEIRAS \\
\hline 120010 Brasiléia & 1200104 BRASILEIA \\
\hline 120010 Brasiléia & 1200138 BUJARI \\
\hline 120010 Brasiléia & 1200179 CAPIXABA \\
\hline 120010 Brasiléia & 1200252 EPITACIOLANDIA \\
\hline 120010 Brasiléia & 1200401 RIO BRANCO \\
\hline 120010 Brasiléia & 1200708 XAPURI \\
\hline 120010 Brasiléia & 1200807 PORTO ACRE \\
\hline 120020 Cruzeiro do Sul & 1200203 CRUZEIRO DO SUL \\
\hline 120020 Cruzeiro do Sul & 1200336 MANCIO LIMA \\
\hline 120020 Cruzeiro do Sul & $\begin{array}{l}1200351 \text { MARECHAL } \\
\text { THAUMATURGO }\end{array}$ \\
\hline 120020 Cruzeiro do Sul & 1200393 PORTO WALTER \\
\hline 120020 Cruzeiro do Sul & 1200427 RODRIGUES ALVES \\
\hline 120034 Manoel Urbano & 1200344 MANOEL URBANO \\
\hline 120034 Manoel Urbano & 1200435 SANTA ROSA DO PURUS \\
\hline 120038 Plácido de Castro & 1200013 ACRELANDIA \\
\hline 120038 Plácido de Castro & 1200385 PLACIDO DE CASTRO \\
\hline 120038 Plácido de Castro & 1200450 SENADOR GUIOMARD \\
\hline 120060 Tarauacá & 1200328 JORDAO \\
\hline 120060 Tarauacá & 1200609 TARAUACA \\
\hline 140005 Alto Alegre & 1400027 AMAJARI \\
\hline 140005 Alto Alegre & 1400050 ALTO ALEGRE \\
\hline 140010 Boa Vista & 1400100 BOA VISTA \\
\hline 140010 Boa Vista & 1400407 NORMANDIA \\
\hline 140010 Boa Vista & 1400456 PACARAIMA \\
\hline 140010 Boa Vista & 1400704 UIRAMUTA \\
\hline 140015 Bonfim & 1400159 BONFIM \\
\hline 140015 Bonfim & 1400175 CANTA \\
\hline 140015 Bonfim & 1400209 CARACARAI \\
\hline 140015 Bonfim & 1400282 IRACEMA \\
\hline 140015 Bonfim & 1400308 MUCAJAI \\
\hline 140050 São João da Baliza & 1400233 CAROEBE \\
\hline 140050 São João da Baliza & 1400472 RORAINOPOLIS \\
\hline 140050 São João da Baliza & 1400506 SAO JOAO DA BALIZA \\
\hline 140050 São João da Baliza & 1400605 SAO LUIZ \\
\hline 150040 Alenquer & 1500404 ALENQUER \\
\hline 150040 Alenquer & 1502855 CURUA \\
\hline 150060 Altamira & 1500602 ALTAMIRA \\
\hline 150060 Altamira & 1500859 ANAPU \\
\hline 150060 Altamira & 1501725 BRASIL NOVO \\
\hline 150060 Altamira & 1501782 BREU BRANCO \\
\hline 150060 Altamira & 1503705 ITUPIRANGA \\
\hline 150060 Altamira & 1503804 JACUNDA \\
\hline 150060 Altamira & 1504455 MEDICILANDIA \\
\hline 150060 Altamira & 1504703 MOJU \\
\hline 150060 Altamira & 1504976 NOVA IPIXUNA \\
\hline 150060 Altamira & 1505064 NOVO REPARTIMENTO \\
\hline 150060 Altamira & 1505486 PACAJA \\
\hline 150060 Altamira & 1505908 PORTO DE MOZ \\
\hline 150060 Altamira & 1507805 SENADOR JOSE PORFIRIO \\
\hline 150060 Altamira & 1508100 TUCURUI \\
\hline 150060 Altamira & 1508357 VITORIA DO XINGU \\
\hline 150150 Benevides & 1501501 BENEVIDES \\
\hline 150150 Benevides & 1504422 MARITUBA \\
\hline 150150 Benevides & 1506351 SANTA BARBARA DO PARA \\
\hline 150157 Bom Jesus do Tocantins & 1500131 ABEL FIGUEIREDO \\
\hline
\end{tabular}


Código Nome do Município em 1991 Código Nome do Município em 2000 1991 Nome do Município em $1991 \underset{2000}{200}$ Nome do Município em 2000

150157 Bom Jesus do Tocantins

150170 Bragança

150170 Bragança

150175 Brejo Grande do Araguaia

150175 Brejo Grande do Araguaia

150270 Conceiço do Araguaia

150270 Conceiço do Araguaia

150277 Curionópolis

150277 Curionópolis

150290 Curuçá

150290 Curuçá

150300 Faro

150300 Faro

150300 Faro

150360 Itaituba

150360 Itaituba

150360 Itaituba

150360 Itaituba

150540 Ourém

150540 Ourém

150540 Ourém

150540 Ourém

150540 Ourém

150543 Ourilândia do Norte

150543 Ourilândia do Norte

150543 Ourilândia do Norte

150550 Paragominas

150550 Paragominas

150553 Parauapebas

150553 Parauapebas

150553 Parauapebas

150610 Primavera

150610 Primavera

150613 Redenção

150613 Redenção

150618 Rondon do Pará

150618 Rondon do Pará

150680 Santarém

150680 Santarém

150680 Santarém

150710 São Caetano de Odivelas

150710 São Caetano de Odivelas 150720 São Domingos do Capim 150720 São Domingos do Capim 150720 São Domingos do Capim 150745 São Geraldo do Araguaia 150745 São Geraldo do Araguaia

150750 São João do Araguaia

150750 São João do Araguaia 150840 Xinguara

150840 Xinguara

160010 Amapá

160010 Amapá

160023 Ferreira Gomes

160023 Ferreira Gomes

160023 Ferreira Gomes

160023 Ferreira Gomes

160023 Ferreira Gomes

160023 Ferreira Gomes

160023 Ferreira Gomes

160027 Laranjal do Jari

160027 Laranjal do Jari

170035 Aliança do Tocantins

170035 Aliança do Tocantins

170100 Ananás

170100 Ananás

170100 Ananás

170190 Araguacema

170190 Araguacema

170210 Araguaína

170210 Araguaína

170210 Araguaína

170210 Araguaína

170210 Araguaína

170230 Arapoema

170230 Arapoema

170230 Arapoema

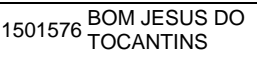

1501709 BRAGANCA

1508035 TRACUATEUA

1501758 BREJO GRANDE DO

505494 PALESTINA DO PARA

1502707 CONCEICAO DO ARAGUAIA

1503044 FLORESTA DO ARAGUAIA

1502772 CURIONOPOLIS

1502954 ELDORADO DOS CARAJAS

1502905 CURUCA

1507961 TERRA ALTA

1503002 FARO

1505304 ORIXIMINA

1507979 TERRA SANTA

1503606 ITAITUBA

1503754 JACAREACANGA

1505031 NOVO PROGRESSO

1508050 TRAIRAO

1501956 CACHOEIRA DO PIRIA

1504950 NOVA ESPERANCA DO

1504950 PIRIA

1505403 OUREM

1506559 SANTA LUZIA DO PARA

1508308 VISEU

1501253 BANNACH

1502764 CUMARU DO NORTE

1505437 OURILANDIA DO NORTE

1505502 PARAGOMINAS

1508126 ULIANOPOLIS

1500347 AGUA AZUL DO NORTE

1502152 CANAA DOS CARAJAS

1505536 PARAUAPEBAS

1506104 PRIMAVERA

1506112 QUATIPURU

1505551 PAU D'ARCO

1506138 REDENCAO

1503093 GOIANESIA DO PARA

1506187 RONDON DO PARA

1501451 BELTERRA

1505650 PLACAS

1507102 SAO CAETANO DE

1507466 SAO JOAO DA PONTA

1500958 AURORA DO PARA

1503457 IPIXUNA DO PARA

1507201 SAO DOMINGOS DO CAPIM

1505635 PICARRA

1507458 SAO GERALDO DO

ARAGUAIA

1507151 SAO DOMINGOS DO

1507508 SAO JOAO DO ARAGUAIA

1507755 SAPUCAIA

1508407 XINGUARA

1600105 AMAPA

1600550 PRACUUBA

1600055 SERRA DO NAVIO

1600154 PEDRA BRANCA DO

1600212 CUTIAS

1600238 FERREIRA GOMES

1600253 ITAUBAL

1600303 MACAPA

1600535 PORTO GRANDE

1600279 LARANJAL DO JAR

1600808 VITORIA DO JARI

1700350 ALIANCA DO TOCANTINS

1706258 CRIXAS DO TOCANTINS

1701002 ANANAS

1718550 RIACHINHO

1700251 ABREULANDIA

1701903 ARAGUACEMA

1701309 ARAGOMINAS

1702109 ARAGUAINA

1702158 ARAGUANA

1703883 CARMOLANDIA

1713957 MURICILANDIA

1702307 ARAPOEMA

1703057 BANDEIRANTES DO
1506807 SANTAREM

1507102 ODIVELAS

1718899 SANTA RITA DO

\begin{tabular}{|c|c|}
\hline${ }_{1991}^{\text {Código }}$ Nome do Município em 1991 & Código Nome do Município em 2000 \\
\hline 170240 Arraias & 1702406 ARRAIAS \\
\hline 170240 Arraias & 1715150 NOVO ALEGRE \\
\hline 170270 Aurora do Tocantins & 1702703 AURORA DO TOCANTINS \\
\hline 170270 Aurora do Tocantins & 1712157 LAVANDEIRA \\
\hline 170310 Barrolândia & 1703107 BARROLANDIA \\
\hline 170310 Barrolândia & $\begin{array}{l}1707108 \text { DIVINOPOLIS DO } \\
\text { TOCANTINS }\end{array}$ \\
\hline 170310 Barrolândia & $\begin{array}{l}1713700 \text { MONTE SANTO DO } \\
\text { TOCANTINS }\end{array}$ \\
\hline 170380 Buriti do Tocantins & 1703800 BURITI DO TOCANTINS \\
\hline 170380 Buriti do Tocantins & 1703891 CARRASCO BONITO \\
\hline 170380 Buriti do Tocantins & 1718808 SAMPAIO \\
\hline 170560 Conceição do Tocantins & $\begin{array}{l}1705607 \text { CONCEICAO DO } \\
\text { TOCANTINS }\end{array}$ \\
\hline 170560 Conceição do Tocantins & 1707009 DIANOPOLIS \\
\hline 170560 Conceição do Tocantins & 1718659 RIO DA CONCEICAO \\
\hline 170560 Conceição do Tocantins & $\begin{array}{l}1720002 \text { SANTA TEREZINHA DO } \\
\text { TOCANTINS }\end{array}$ \\
\hline 170560 Conceição do Tocantins & 1720937 TAIPAS DO TOCANTINS \\
\hline 170600 Couto de Magalhães & 1706001 COUTO DE MAGALHAES \\
\hline 170600 Couto de Magalhães & 1711803 JUARINA \\
\hline 170610 Cristalândia & 1706100 CRISTALANDIA \\
\hline 170610 Cristalândia & 1711902 LAGOA DA CONFUSAO \\
\hline 170730 Dueré & 1703867 CARIRI DO TOCANTINS \\
\hline 170730 Dueré & 1707306 DUERE \\
\hline 170730 Dueré & 1708205 FORMOSO DO ARAGUAIA \\
\hline 170730 Dueré & 1709500 GURUPI \\
\hline 170755 Fátima & 1707553 FATIMA \\
\hline 170755 Fátima & 1715507 OLIVEIRA DE FATIMA \\
\hline 170765 Figueirópolis & 1700707 ALVORADA \\
\hline 170765 Figueirópolis & 1707652 FIGUEIROPOLIS \\
\hline 170765 Figueirópolis & 1711506 JAU DO TOCANTINS \\
\hline 170765 Figueirópolis & 1716604 PEIXE \\
\hline 170765 Figueirópolis & 1720853 SUCUPIRA \\
\hline 170765 Figueirópolis & 1720978 TALISMA \\
\hline 170770 Filadélfia & 1707702 FILADELFIA \\
\hline 170770 Filadélfia & 1715705 PALMEIRANTE \\
\hline 170900 Goiatins & 1703073 BARRA DO OURO \\
\hline 170900 Goiatins & 1703842 CAMPOS LINDOS \\
\hline 170900 Goiatins & 1704105 CENTENARIO \\
\hline 170900 Goiatins & 1709005 GOIATINS \\
\hline 170900 Goiatins & 1710508 ITACAJA \\
\hline 170900 Goiatins & 1710904 ITAPIRATINS \\
\hline 170900 Goiatins & 1718501 RECURSOLANDIA \\
\hline 170900 Goiatins & $\begin{array}{l}1718881 \text { SANTA MARIA DO } \\
\text { TOCANTINS }\end{array}$ \\
\hline 170930 Guaraí & 1708254 FORTALEZA DO TABOCAO \\
\hline 170930 Guaraí & 1709302 GUARAI \\
\hline 170930 Guaraí & 1721257 TUPIRAMA \\
\hline 171070 Itaguatins & 1710706 ITAGUATINS \\
\hline 171070 Itaguatins & 1718303 PRAIA NORTE \\
\hline 171070 Itaguatins & $\begin{array}{l}1720200 \text { SAO MIGUEL DO } \\
\text { TOCANTINS }\end{array}$ \\
\hline 171070 Itaguatins & $\begin{array}{l}1720804 \text { SITIO NOVO DO } \\
\text { TOCANTINS }\end{array}$ \\
\hline 171320 Miracema do Tocantins & 1713205 MIRACEMA DO TOCANTINS \\
\hline 171320 Miracema do Tocantins & 1718709 RIO DOS BOIS \\
\hline 171320 Miracema do Tocantins & $\begin{array}{l}1720101 \text { SAO BENTO DO } \\
\text { TOCANTINS }\end{array}$ \\
\hline 171420 Natividade & 1705102 CHAPADA DA NATIVIDADE \\
\hline 171420 Natividade & 1714203 NATIVIDADE \\
\hline 171430 Nazaré & 1700301 AGUIARNOPOLIS \\
\hline 171430 Nazaré & 1701051 ANGICO \\
\hline 171430 Nazaré & 1703826 CACHOEIRINHA \\
\hline 171430 Nazaré & 1706506 DARCINOPOLIS \\
\hline 171430 Nazaré & 1712454 LUZINOPOLIS \\
\hline 171430 Nazaré & $\begin{array}{l}1712801 \text { MAURILANDIA DO } \\
\text { TOCANTINS }\end{array}$ \\
\hline 171430 Nazaré & $\begin{array}{l}\text { PALMEIRAS DO } \\
\text { TOCANTINS }\end{array}$ \\
\hline 171430 Nazaré & 1714302 NAZARE \\
\hline 171430 Nazaré & 1721208 TOCANTINOPOLIS \\
\hline 171510 Novo Acordo & 1711951 LAGOA DO TOCANTINS \\
\hline 171510 Novo Acordo & 1715101 NOVO ACORDO \\
\hline 171510 Novo Acordo & $\begin{array}{l}1719004 \text { SANTA TEREZA DO } \\
\text { TOCANTINS }\end{array}$ \\
\hline $\begin{array}{l}171510 \text { Novo Acordo } \\
171575 \text { Palmeirópolis }\end{array}$ & $\begin{array}{l}1720150 \text { SAO FELIX DO TOCANTINS } \\
1715754 \text { PALMEIROPOLIS }\end{array}$ \\
\hline 171575 Palmeirópolis & $\begin{array}{l}1720259 \text { SAO SALVADOR DO } \\
\text { TOCANTINS }\end{array}$ \\
\hline 171610 Paraíso do Tocantins & 1716109 PARAISO DO TOCANTINS \\
\hline 171610 Paraíso do Tocantins & 1718451 PUGMIL \\
\hline 171610 Paraíso do Tocantins & 1718865 SANTA FE DO ARAGUAIA \\
\hline 171650 Pedro Afonso & $\begin{array}{l}1703305 \text { BOM JESUS DO } \\
\text { TOCANTINS }\end{array}$ \\
\hline 171650 Pedro Afonso & 1716505 PEDRO AFONSO \\
\hline 171750 Pium & 1704600 CHAPADA DE AREIA \\
\hline
\end{tabular}


Código Nome do Município em 1991 Código Nome do Município em 2000 1991 Nome do Município em 19912000 Nome do Município em 2000

171750 Pium 1717503 PIUM

171780 Ponte Alta do Bom Jesus 171780 Ponte Alta do Bom Jesus 171790 Ponte Alta do Tocantins 171790 Ponte Alta do Tocantins

171820 Porto Nacional 171820 Porto Nacional 171840 Presidente Kennedy 171840 Presidente Kennedy 171840 Presidente Kennedy 172030 São Sebastião do Tocantins 172030 São Sebastião do Tocantins 172030 São Sebastião do Tocantins 172110 Tocantínia 172110 Tocantínia 172210 Xambioá 172210 Xambioá 172210 Xambioá 210005 Açailândia 210005 Açailândia 210005 Açailândia 210005 Açailândia 210005 Açailândia 210005 Açailândia

210005 Açailândia

210005 Açailândia

210005 Açailândia

210040 Altamira do Maranhão 210040 Altamira do Maranhão

210090 Araioses

210090 Araioses

210120 Bacabal

210120 Bacabal

210120 Bacabal

210120 Bacabal

210120 Bacabal

210120 Bacabal

210120 Bacabal

210120 Bacabal

210120 Bacabal

210120 Bacabal

210120 Bacabal

210120 Bacabal

210120 Bacabal

210130 Bacuri

210130 Bacuri

210160 Barra do Corda

210160 Barra do Corda

210160 Barra do Corda

210180 Benedito Leite

210180 Benedito Leite

210180 Benedito Leite

210180 Benedito Leite

210200 Bom Jardim

210200 Bom Jardim

210210 Brejo

210210 Brejo

210210 Brejo

210240 Cajapió

210240 Cajapió

210260 Cândido Mendes

210260 Cândido Mendes

210260 Cândido Mendes

210300 Caxias

210300 Caxias

210310 Cedral

210310 Cedral

210350 Colinas

210350 Colinas

210370 Cururupu

210370 Cururupu
1715259 NOVO JARDIM

1717800 PONTE ALTA DO BOM

1712702 MATEIROS

1717909 PONTE ALTA DO

1709807 IPUEIRAS

1718204 PORTO NACIONAL

1703602 BRASILANDIA DO

1703602 TOCANTINS

1718402 PRESIDENTE KENNEDY

1721307 TUPIRATINS

1702208 ARAGUATINS

1707405 ESPERANTINA

1720309 SAO SEBASTIAO DO

TOCANTINS

1712009 LAJEADO

1721109 TOCANTINIA

1717206 PIRAQUE

1718840 SANDOLANDIA

1722107 XAMBIOA

2100055 ACAILANDIA

2103257 CIDELANDIA

2103752 DAVINOPOLIS

2104552 GOVERNADOR EDISON

RATRIZ

2105427 ITINGA DO MARANHAO

2110856 SAO FRANCISCO DO

2110856 BREJAO

2111532 SAO PEDRO DA AGUA BRANCA

2112852 VILA NOVA DOS

2100402 ALTAMIRA DO MARANHAO

2102150 BREJO DE AREIA

2100154 AGUA DOCE DO

2100907 ARAIOSES 2100436 ALTO ALEGRE DO

2101202 BACABAL

2102077 BOM LUGAR

2102705 CANTANHEDE

2102754 CAPINZAL DO NORTE

2103307 CODO

2103604 COROATA

2106003 LIMA CAMPOS

2106631 MATOES DO NORTE

2108454 PERITORO

2110302 SANTO ANTONIO DOS

2111409 SAO LUIS GONZAGA DO

2111508 SAO MATEUS DO

2100832 APICUM-ACU

2101301 BACURI

2101608 BARRA DO CORDA

2104081 FERNANDO FALCAO

2105476 JENIPAPO DOS VIEIRAS

2101806 BENEDITO LEITE

2108009 PASTOS BONS

2110658 SAO DOMINGOS DO

2111904 SUCUPIRA DO NORTE

2102002 BOM JARDIM

2111029 SAO JOAO DO CARU

2102101 BREJO

2106672 MILAGRES DO MARANHAO

2110104 SANTA QUITERIA DO

MARANHAO

2102408 CAJAPIO

2102606 CANDIDO MENDES

2104677 GOVERNADOR NUNES

2106375 MARANHAOZINHO

2103000 CAXIAS

2111078 SAO JOAO DO SOTER

2103109 CEDRAL

2109056 PORTO RICO DO

2103505 COLINAS

2105450 JATOBA

2103703 CURURUPU

2111789 SERRANO DO MARANHAO
2101350 BACURITUBA

\begin{tabular}{|c|c|}
\hline${ }_{1991}^{\text {Código }}$ Nome do Município em 1991 & Código Nome do Município em 2000 \\
\hline 210400 Esperantinópolis & 2104008 ESPERANTINOPOLIS \\
\hline 210400 Esperantinópolis & $\begin{array}{l}2111631 \text { SAO RAIMUNDO DO DOCA } \\
\text { BEZERRA }\end{array}$ \\
\hline 210400 Esperantinópolis & 2111672 SAO ROBERTO \\
\hline 210405 Estreito & 2104057 ESTREITO \\
\hline 210405 Estreito & 2111573 SAO PEDRO DOS CRENTES \\
\hline 210410 Fortaleza dos Nogueiras & $\begin{array}{l}2104107 \text { FORTALEZA DOS } \\
\text { NOGUEIRAS }\end{array}$ \\
\hline 210410 Fortaleza dos Nogueiras & 2107258 NOVA COLINAS \\
\hline 210460 Governador Eugênio Barros & $\begin{array}{l}2104602 \text { GOVERNADOR EUGENIO } \\
\text { BARROS }\end{array}$ \\
\hline 210460 Governador Eugênio Barros & $\begin{array}{l}2111748 \text { SENADOR ALEXANDRE } \\
\text { COSTA }\end{array}$ \\
\hline 210480 Grajaú & 2104099 FORMOSA DA SERRA \\
\hline 210480 Grajaú & 2104800 GRAJAU \\
\hline 210480 Grajaú & 2105351 ITAIPAVA DO GRAJAU \\
\hline 210520 Igarapé Grande & 2101939 BERNARDO DO MEARIM \\
\hline 210520 Igarapé Grande & 2105203 IGARAPE GRANDE \\
\hline 210550 João Lisboa & 2102358 BURITIRANA \\
\hline 210550 João Lisboa & 2105500 JOAO LISBOA \\
\hline 210550 João Lisboa & 2111763 SENADOR LA ROCQUE \\
\hline 210570 Lago da Pedra & 2105708 LAGO DA PEDRA \\
\hline 210570 Lago da Pedra & $\begin{array}{l}2105963 \text { LAGOA GRANDE DO } \\
\text { MARANHAO }\end{array}$ \\
\hline 210580 Lago do Junco & 2105807 LAGO DO JUNCO \\
\hline 210580 Lago do Junco & 2105948 LAGO DOS RODRIGUES \\
\hline 210620 Luís Domingues & 2100550 AMAPA DO MARANHAO \\
\hline 210620 Luís Domingues & 2101970 BOA VISTA DO GURUPI \\
\hline 210620 Luís Domingues & 2102903 CARUTAPERA \\
\hline 210620 Luís Domingues & 2103158 CENTRO DO GUILHERME \\
\hline 210620 Luís Domingues & $\begin{array}{l}2103174 \text { CENTRO NOVO DO } \\
\text { MARANHAO }\end{array}$ \\
\hline 210620 Luís Domingues & 2104305 GODOFREDO VIANA \\
\hline 210620 Luís Domingues & 2105658 JUNCO DO MARANHAO \\
\hline 210620 Luís Domingues & 2106201 LUIS DOMINGUES \\
\hline 210620 Luís Domingues & 2106326 MARACACUME \\
\hline 210650 Matinha & 2106508 MATINHA \\
\hline 210650 Matinha & $\begin{array}{l}2107456 \text { OLINDA NOVA DO } \\
\text { MARANHAO }\end{array}$ \\
\hline 210650 Matinha & 2111003 SAO JOAO BATISTA \\
\hline 210650 Matinha & 2111706 SAO VICENTE FERRER \\
\hline 210680 Mirinzal & 2103125 CENTRAL DO MARANHAO \\
\hline 210680 Mirinzal & 2106805 MIRINZAL \\
\hline 210700 Montes Altos & 2105989 LAJEADO NOVO \\
\hline 210700 Montes Altos & 2107001 MONTES ALTOS \\
\hline 210700 Montes Altos & 2109551 RIBAMAR FIQUENE \\
\hline 210710 Morros & 2102374 CACHOEIRA GRANDE \\
\hline 210710 Morros & 2107100 MORROS \\
\hline 210750 Paço do Lumiar & 2107506 PACO DO LUMIAR \\
\hline 210750 Paço do Lumiar & 2109452 RAPOSA \\
\hline 210790 Passagem Franca & 2105922 LAGOA DO MATO \\
\hline 210790 Passagem Franca & 2107902 PASSAGEM FRANCA \\
\hline 210810 Paulo Ramos & 2106359 MARAJA DO SENA \\
\hline 210810 Paulo Ramos & 2108108 PAULO RAMOS \\
\hline 210820 Pedreiras & 2108207 PEDREIRAS \\
\hline 210820 Pedreiras & 2112233 TRIZIDELA DO VALE \\
\hline 210850 Pindaré Mirim & 2108504 PINDARE-MIRIM \\
\hline 210850 Pindaré Mirim & 2112274 TUFILANDIA \\
\hline 210860 Pinheiro & 2108256 PEDRO DO ROSARIO \\
\hline 210860 Pinheiro & 2108603 PINHEIRO \\
\hline 210860 Pinheiro & 2109270 PRESIDENTE SARNEY \\
\hline 210870 Pio XII & 2108702 PIO XII \\
\hline 210870 Pio XII & 2111722 SATUBINHA \\
\hline 210900 Porto Franco & $\begin{array}{l}2102556 \text { CAMPESTRE DO } \\
\text { MARANHAO }\end{array}$ \\
\hline 210900 Porto Franco & 2109007 PORTO FRANCO \\
\hline 210900 Porto Franco & 2111052 SAO JOAO DO PARAISO \\
\hline 210910 Presidente Dutra & 2109106 PRESIDENTE DUTRA \\
\hline 210910 Presidente Dutra & 2111250 SAO JOSE DOS BASILIOS \\
\hline 210940 Primeira Cruz & 2109403 PRIMEIRA CRUZ \\
\hline 210940 Primeira Cruz & $\begin{array}{l}2110278 \text { SANTO AMARO DO } \\
\text { MARANHAO }\end{array}$ \\
\hline 210950 Riachão & $\begin{array}{l}2104073 \text { FEIRA NOVA DO } \\
\text { MARANHAO }\end{array}$ \\
\hline 210950 Riachão & 2109502 RIACHAO \\
\hline 210960 Rosário & 2101251 BACABEIRA \\
\hline 210960 Rosário & 2109601 ROSARIO \\
\hline 211000 Santa Luzia & 2100477 ALTO ALEGRE DO PINDARE \\
\hline 211000 Santa Luzia & 2102036 BOM JESUS DAS SELVAS \\
\hline 211000 Santa Luzia & 2102325 BURITICUPU \\
\hline 211000 Santa Luzia & 2110005 SANTA LUZIA \\
\hline 211003 Santa Lu & 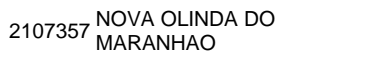 \\
\hline 211003 Santa Luzia do Paruá & 2109239 PRESIDENTE MEDICI \\
\hline 211003 Santa Luzia do Paruá & 2110039 SANTA LUZIA DO PARUA \\
\hline 211003 Santa Luzia do Paruá & 2112407 TURIACU \\
\hline
\end{tabular}


Código Nome do Município em 1991 Código Nome do Município em 2000 1991 Nome do Município em $1991 \underset{2000}{\text { Codigo }}$ Nome do Município em 2000 \begin{tabular}{ll}
\hline 211003 Santa Luzia do Paruá & 2112456 TURILANDIA \\
211060 São Bernardo & 2110237 SANTANA DO MARANHAO
\end{tabular} 211060 São Bernardo 2110609 SAO BERNARDO 211070 Sao Domingos do Maranhão 2104628 GOVERNADOR LUIZ 211070 Sao Domingos do Maranhão 2110708 SAO DOMINGOS DO 211110 São João dos Patos 211110 São João dos Patos 211230 Tuntum 211230 Tuntum 211250 Tutóia 211250 Tutóia 211260 Urbano Santos 211260 Urbano Santos 211290 Vitória do Mearim 211290 Vitória do Mearim 211290 Vitória do Mearim 211290 Vitória do Mearim 211400 Zé Doca

211400 Zé Doca

211400 Zé Doca 220010 Agricolãndia 220010 Agricolãndia 220010 Agricolãndia 220010 Agricolãndia 220010 Agricolãndia 220010 Agricolãndia 220010 Agricolãndia 220010 Agricolãndia 220010 Agricolãndia 220010 Agricolãndia 220010 Agricolãndia 220010 Agricolãndia 220010 Agricolãndia 220030 Alto Longá 220030 Alto Longá 220040 Altos

\section{Altos}

220070 Anísio de Abreu 220070 Anísio de Abreu 220070 Anísio de Abreu 220070 Anísio de Abreu 220070 Anísio de Abreu 220070 Anísio de Abreu 220070 Anísio de Abreu 220070 Anísio de Abreu 220080 Antônio Almeida 220080 Antônio Almeida 220080 Antônio Almeida 220080 Antônio Almeida 220090 Aroazes

220090 Aroazes

220100 Arraial

220100 Arraial

220100 Arraial

220100 Arraia

220100 Arraial

220100 Arraial

220100 Arraial

220110 Avelino Lopes

220110 Avelino Lopes

220110 Avelino Lopes

220110 Avelino Lopes

220120 Barras

220120 Barras

220120 Barras

220120 Barras

220150 Batalha

220150 Batalha

220150 Batalha

220150 Batalha

220150 Batalha

220150 Batalha

220150 Batalha

220150 Batalha

220150 Batalha

220170 Bertolínia

220170 Bertolínia
2111102 SAO JOAO DOS PATOS 2111953 SUCUPIRA DO RIACHAO 2109759 SANTA FILOMENA DO MARANHAO

2112308 TUNTUM

2108058 PAULINO NEVES

2112506 TUTOIA

2112605 URBANO SANTOS

2101772 BELA VISTA DO

2103554 CONCEICAO DO LAGO-ACU

2105153 IGARAPE DO MEIO

2112902 VITORIA DO MEARIM

2100873 ARAGUANA

2104651 GOVERNADOR NEWTON

$2114007 Z E$

2200202 AGUA BRANCA

2201176 BARRA D'ALCANTARA

2201408 BARRO DURO

2201606 BENEDITINOS

2203305 DEMERVAL LOBAO

2203503 ELESBAO VELOSO

2205540 LAGOINHA DO PIAUI

2205581 LAGOA DO PIAUI

2206902 NOVO ORIENTE DO PIAUI

2207108 OLHO D'AGUA DO PIAUI

2211407 VARZEA GRANDE

2200301 ALTO LONGA

2206951 NOVO SANTO ANTONIO

2200400 ALTOS

2202737 COIVARAS

2200707 ANISIO DE ABREU

2201929 BONFIM DO PIAUI

2205532 JUREMA

2209559 SAO BRAZ DO PIAUI

2210359 SAO LOURENCO DO PIAUI

2210607 SAO RAIMUNDO NONATO

2200806 ANTONIO ALMEIDA

2204501 GUADALUPE

2206001 MARCOS PARENTE

2208551 PORTO ALEGRE DO PIAUI

2200905 AROAZES

2209153 SANTA CRUZ DOS

2201002 ARRAIAL

2202075 CAJAZEIRAS DO PIAUI

2202778 COLONIA DO PIAUI

2207009 OEIRAS

2209377 SANTA ROSA DO PIAUI

2209955 SAO JOAO DA VARJOTA

2210979 TANQUE DO PIAUI

2201101 AVELINO LOPES

2203206 CURIMATA

2205524 JULIO BORGES

2201200 BARR

2201770 BOA HORA

2202059 CABECEIRAS DO PIAUI

2205557 LAGOA ALEGRE

2201507 BATALHA

2201960 BRASILEIRA

2205573 LAGOA DE SAO

2206357 MILTON BRANDAO

2207900 PEDRO II

2208304 PIRACURUCA

2208403 PIRIPIRI

2209872 SAO JOAO DA FRONTEIRA

2210052 SAO JOSE DO DIVINO

2201705 BERTOLINIA

2210631 SEBASTIAO LEAL
2101731 BELAGUA

2200103 AGRICOLANDIA

2207751 PASSAGEM FRANCA DO

2202851 CORONEL JOSE DIAS

2211357 VARZEA BRANCA

2206654 MORRO CABECA NO
${ }_{1991}^{\text {Código }}$ Nome do Município em $1991 \stackrel{\text { Código }}{2000}$ Nome do Município em 2000

220170 Bertolínia 2211209 URUCUI

220190 Bom Jesus 2201903 BOM JESUS

220190 Bom Jesus

220200 Buriti dos Lopes

220200 Buriti dos Lopes

220200 Buriti dos Lopes

220200 Buriti dos Lopes

220200 Buriti dos Lopes

220200 Buriti dos Lopes

220200 Buriti dos Lopes

220200 Buriti dos Lopes

220200 Buriti dos Lopes

220200 Buriti dos Lopes

220200 Buriti dos Lopes

220200 Buriti dos Lopes

220220 Campo Maior

220220 Campo Maior

220220 Campo Maior

220220 Campo Maior

220220 Campo Maior

220220 Campo Maior

220230 Canto do Buriti

220230 Canto do Buriti

220230 Canto do Buriti

220230 Canto do Buriti

220230 Canto do Buriti

220230 Canto do Buriti

220230 Canto do Buriti

220230 Canto do Buriti

220230 Canto do Buriti

220230 Canto do Buriti

220230 Canto do Buriti

220230 Canto do Buriti

220230 Canto do Buriti

220230 Canto do Buriti

220250 Caracol

220250 Caracol

220260 Castelo do Piaú

220260 Castelo do Piaú

220260 Castelo do Piauí

220270 Cocal

220270 Cocal

220280 Conceição do Canindé

220280 Conceição do Canindé

220290 Corrente

220290 Corrente

220310 Cristino Castro

220310 Cristino Castro

220310 Cristino Castro

220335 Dirceu Arcoverde

220335 Dirceu Arcoverde

220360 Eliseu Martins

220360 Eliseu Martins

220430 Fronteiras

220430 Fronteiras

220440 Gilbués

220440 Gilbués

220500 Itainópolis

220500 Itainópolis

220520 Jaicós

220520 Jaicós

220520 Jaicós

220520 Jaicós

220530 Jerumenha

220530 Jerumenha

220580 Luzilândia

220580 Luzilândia

220580 Luzilândia

220580 Luzilândia

220580 Luzilândia

220640 Monsenhor Gil

220640 Monsenhor Gil

220640 Monsenhor Gil

220640 Monsenhor Gil

220720 Padre Marcos

220720 Padre Marcos

220720 Padre Marcos

220720 Padre Marcos

2203230 CURRAIS

2201919 BOM PRINCIPIO DO PIAUI

2202000 BURITI DOS LOPES

2202083 CAJUEIRO DA PRAIA

2202539 CARAUBAS DO PIAUI

2202653 CAXINGO

2203701 ESPERANTINA

2204659 ILHA GRANDE

2205409 JOAQUIM PIRES

2205706 LUIS CORREIA

2206670 MORRO DO CHAPEU DO

2206696 MURICI DOS PORTELAS

2207702 PARNAIBA

2201945 BOQUEIRAO DO PIAUI

2202208 CAMPO MAIOR

2202711 COCAL DE TELHA

2205276 JATOBA DO PIAUI

2206753 NOSSA SENHORA DE

2206753 NAZARE

2210656 SIGEFREDO PACHECO

2201988 BREJO DO PIAUI

2202117 CAMPO ALEGRE DO

2202307 CANTO DO BURITI

2202455 CAPITAO GERVASIO

22025 OLIVEIRA

2203453 DOM INOCENCIO

2205359 JOAO COSTA

2205565 LAGOA DO BARRO DO

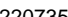

2207934 PEDRO LAURENTINO

2207959 NOVA SANTA RITA

2208874 RIBEIRA DO PIAUI

2210003 SAO JOAO DO PIAUI

2210904 SOCORRO DO PIAUI

2210953 TAMBORIL DO PIAUI

2202505 CARACOL

2204550 GUARIBAS

2202026 BURITI DOS MONTES

2202604 CASTELO DO PIAUI

2205516 JUAZEIRO DO PIAUI

2202703 COCAL

2202729 COCAL DOS ALVES

2202802 CONCEICAO DO CANINDE

2209658 SAO FRANCISCO DE ASSIS

DOPIAUI

PRENTE

2210623 SEBASTIAO BARROS

2200459 ALVORADA DO GURGUEIA

2203107 CRISTINO CASTRO

2205904 MANOEL EMIDIO

2203354 DIRCEU ARCOVERDE

2203750 FARTURA DO PIAUI

2202752 COLONIA DO GURGUEIA

2203602 ELISEU MARTINS

2202091 CALDEIRAO GRANDE DO 
Código Nome do Município em 1991 Código Nome do Município em 2000 1991 Nome do Município em 19912000 Nome do Município em 2000 220720 Padre Marcos 220730 Paes Landim 220730 Paes Landim 220760 Parnaguá 220760 Parnaguá 220780 Paulistana 220780 Paulistana 220780 Paulistana 220780 Paulistana 220780 Paulistana 220800 Picos 220800 Picos 220800 Picos 220800 Picos 220800 Picos 220810 Pimenteiras 220810 Pimenteiras 220810 Pimenteiras 220850 Porto 220850 Porto 220880 Regeneração 220880 Regeneração 220890 Ribeiro Gonçalves 220890 Ribeiro Gonçalves 220900 Rio Grande do Piauí 220900 Rio Grande do Piauí 220910 Santa Cruz do Piaui 220910 Santa Cruz do Piaú 220950 Santo Inácio do Piauí 220950 Santo Inácio do Piauí 220960 São Félix do Piauí

220960 São Félix do Piauí

220980 São Gonçalo do Piauí 220980 São Gonçalo do Piauí 220985 São João da Canabrava 220985 São João da Canabrava 221030 São Julião 221030 São Julião 221040 São Miguel do Tapuio 221040 São Miguel do Tapuio 221070 Simões

221070 Simões 221070 Simões

221080 Simplício Mendes 221080 Simplício Mendes 230110 Aracati

230110 Aracati

230425 Cruz

230425 Cruz 230930 Nova Russas 230930 Nova Russas 230970 Pacatuba 230970 Pacatuba 231130 Quixadá 231130 Quixadá 231220 Santa Quitéria 231220 Santa Quitéria 240080 Angicos 240080 Angicos 240130 Augusto Severo 240130 Augusto Severo 240250 Carnaubais 240250 Carnaubais 240380 Florânia 240380 Florânia 240440 Grossos 240440 Grossos 240470 Ipanguaçu 240470 Ipanguaçu 240700 Luís Gomes 240700 Luís Gomes 240740 Martins 240740 Martins 240750 Maxaranguape 240750 Maxaranguape 241140 Santana do Matos 241140 Santana do Matos 241160 São Bento do Norte 241160 São Bento do Norte 241250 São Miguel 241250 São Miguel

2211605 VILA NOVA DO PIAUI
2207306 PAES LANDIM

2210391 SAO MIGUEL DO FIDALGO

2207603 PARNAGUA

2208858 RIACHO FRIO

2200053 ACAUA

2201739 BETANIA DO PIAUI

2205151 JACOBINA DO PIAUI

2207801 PAULISTANA

2208650 QUEIMADA NOVA

2204352 GEMINIANO

2207553 PAQUETA

2208007 PICOS

2209351 SANTANA DO PIAUI

2210938 SUSSUAPARA

2205599 LAGOA DO SITIO

2208106 PIMENTEIRAS

2211308 VALENCA DO PIAUI

2202174 CAMPO LARGO DO PIAUI

2208502 PORTO

2205250 JARDIM DO MULATO

2208809 REGENERACAO

2201150 BAIXA GRANDE DO

2209005 RIO GRANDE DO PIAUI

2209104 SANTA CRUZ DO PIAUI

2211704 WALL FERRAZ

2203859 FLORESTA DO PIAUI

2209500 SANTO INACIO DO PIAUI

2209609 SAO FELIX DO PIAUI

2210383 SAO MIGUEL DA BAIXA

GRANDE

2209807 SAO GONCALO DO PIAUI

2209856 SAO JOAO DA CANABRAVA

2210375 SAO LUIS DO PIAUI

2200277 ALEGRETE DO PIAUI

2210300 SAO JULIAO

2201051 ASSUNCAO DO PIAUI

2210409 SAO MIGUEL DO TAPUIO

2202554 CARIDADE DO PIAUI

2203271 CURRAL NOVO DO PIAUI

2210706 SIMOES

2201556 BELA VISTA DO PIAU

2210805 SIMPLICIO MENDES

2301109 ARACATI

2304459 FORTIM

2304251 CRUZ

2307254 JIJOCA DE JERICOACOARA

2301257 ARARENDA

2309300 NOVA RUSSAS

2306256 ITAITINGA

2309706 PACATUBA

2303931 CHORO

2311306 QUIXADA

2303659 CATUNDA

2312205 SANTA QUITERIA

2400802 ANGICOS

2403756 FERNANDO PEDROZA

2401305 AUGUSTO SEVERO

2414456 TRIUNFO POTIGUAR

2402501 CARNAUBAIS

2410256 PORTO DO MANGUE

2403806 FLORANIA

2414159 TENENTE LAURENTINO

2404408 GROSSOS

2411056 TIBAU

2404705 IPANGUACU

2404853 ITAJA

2407005 LUIS GOMES

2407252 MAJOR SALES

2407401 MARTINS

2413557 SERRINHA DOS PINTOS

2407500 MAXARANGUAPE

2408953 RIO DO FOGO

2401651 BODO

2411403 SANTANA DO MATOS

2411601 SAO BENTO DO NORTE

2412500 SAO MIGUEL

2414753 VENHA-VER
2207850 PAVUSSU

2209450 SANTO ANTONIO DOS

2401859 CAICARA DO NORTE

\begin{tabular}{|c|c|}
\hline${ }_{1991}^{\text {Código }}$ Nome do Município em 1991 & Código Nome do Município em 2000 \\
\hline 241260 São Paulo do Potengi & 2409332 SANTA MARIA \\
\hline 241260 São Paulo do Potengi & 2412609 SAO PAULO DO POTENGI \\
\hline 241440 Touros & 2412559 SAO MIGUEL DE TOUROS \\
\hline 241440 Touros & 2414407 TOUROS \\
\hline 250040 Alagoa Nova & 2500403 ALAGOA NOVA \\
\hline 250040 Alagoa Nova & 2509339 MATINHAS \\
\hline 250070 São João do Rio do Peixe & $\begin{array}{l}2500700 \text { SAO JOAO DO RIO DO } \\
\text { PEIXE }\end{array}$ \\
\hline 250070 São João do Rio do Peixe & 2512077 POCO DE JOSE DE MOURA \\
\hline 250100 Araruna & 2501005 ARARUNA \\
\hline 250100 Araruna & 2512747 RIACHAO \\
\hline 250130 Aroeiras & 2501302 AROEIRAS \\
\hline 250130 Aroeiras & 2506251 GADO BRAVO \\
\hline 250160 Barra de Santa Rosa & 2501609 BARRA DE SANTA ROSA \\
\hline 250160 Barra de Santa Rosa & 2505352 DAMIAO \\
\hline 250250 Boqueirão & 2500536 ALCANTIL \\
\hline 250250 Boqueirão & 2501575 BARRA DE SANTANA \\
\hline 250250 Boqueirão & 2502508 BOQUEIRAO \\
\hline 250250 Boqueirão & 2504355 CATURITE \\
\hline 250250 Boqueirão & $2512788 \begin{array}{l}\text { RIACHO DE SANTO } \\
\text { ANTONIO }\end{array}$ \\
\hline 250280 Brejo do Cruz & 2502805 BREJO DO CRUZ \\
\hline 250280 Brejo do Cruz & $\begin{array}{l}2514651 \text { SAO JOSE DO BREJO DO } \\
\text { CRUZ }\end{array}$ \\
\hline 250310 Cabaceiras & 2503100 CABACEIRAS \\
\hline 250310 Cabaceiras & 2513943 SAO DOMINGOS DO CARIRI \\
\hline 250360 Caiçara & 2503605 CAICARA \\
\hline 250360 Caiçara & 2508554 LOGRADOURO \\
\hline 250400 Campina Grande & 2502151 BOA VISTA \\
\hline 250400 Campina Grande & 2504009 CAMPINA GRANDE \\
\hline 250440 Conceição & 2504405 CONCEICAO \\
\hline 250440 Conceição & 2513356 SANTA INES \\
\hline 250510 Cuité & 2505105 CUITE \\
\hline 250510 Cuité & 2516151 SOSSEGO \\
\hline 250540 Desterro & 2503555 CACIMBAS \\
\hline 250540 Desterro & 2505402 DESTERRO \\
\hline 250580 Duas Estradas & 2505808 DUAS ESTRADAS \\
\hline 250580 Duas Estradas & 2515930 SERTAOZINHO \\
\hline 250650 Gurjão & 2506509 GURJAO \\
\hline 250650 Gurjão & 2513851 SANTO ANDRE \\
\hline 250730 Jacaraú & 2507309 JACARAU \\
\hline 250730 Jacaraú & 2512721 PEDRO REGIS \\
\hline 250740 Jericó & 2507408 JERICO \\
\hline 250740 Jericó & 2509370 MATO GROSSO \\
\hline 250770 Juazeirinho & 2501351 ASSUNCAO \\
\hline 250770 Juazeirinho & 2507705 JUAZEIRINHO \\
\hline 250770 Juazeirinho & 2516755 TENORIO \\
\hline 250890 Mamanguape & 2504033 CAPIM \\
\hline 250890 Mamanguape & 2505238 CUITE DE MAMANGUAPE \\
\hline 250890 Mamanguape & 2505279 CURRAL DE CIMA \\
\hline 250890 Mamanguape & 2508901 MAMANGUAPE \\
\hline 251070 Passagem & 2501153 AREIA DE BARAUNAS \\
\hline 251070 Passagem & 2510709 PASSAGEM \\
\hline 251140 Picuí & 2501534 BARAUNA \\
\hline 251140 Picuí & 2511400 PICUI \\
\hline 251150 Pilar & 2511509 PILAR \\
\hline 251150 Pilar & 2514453 SAO JOSE DOS RAMOS \\
\hline 251210 Pombal & 2503753 CAJAZEIRINHAS \\
\hline 251210 Pombal & 2512101 POMBAL \\
\hline 251210 Pombal & 2513927 SAO BENTINHO \\
\hline 251210 Pombal & $\begin{array}{l}2513968 \text { SAO DOMINGOS DE } \\
\text { POMBAL }\end{array}$ \\
\hline 251230 Princesa Isabel & 2512309 PRINCESA ISABEL \\
\hline 251230 Princesa Isabel & 2514552 SAO JOSE DE PRINCESA \\
\hline 251270 Remígio & 2500577 ALGODAO DE JANDAIRA \\
\hline 251270 Remígio & 2512705 REMIGIO \\
\hline 251290 Rio Tinto & 2509057 MARCACAO \\
\hline 251290 Rio Tinto & 2512903 RIO TINTO \\
\hline 251400 São João do Cariri & 2504074 CARAUBAS \\
\hline 251400 São João do Cariri & 2514008 SAO JOAO DO CARIRI \\
\hline 251480 São José dos Cordeiros & 2510659 PARARI \\
\hline 251480 São José dos Cordeiros & $\begin{array}{l}2514800 \text { SAO JOSE DOS } \\
\text { CORDEIROS }\end{array}$ \\
\hline 251520 São Sebastião do Umbuzeiro & $\begin{array}{l}2515203 \text { SAO SEBASTIAO DO } \\
\text { UMBUZEIRO }\end{array}$ \\
\hline 251520 São Sebastião do Umbuzeiro & 2517407 ZABELE \\
\hline 251530 Sapé & 2512762 RIACHAO DO POCO \\
\hline 251530 Sapé & 2515302 SAPE \\
\hline 251530 Sapé & 2515971 SOBRADO \\
\hline 251550 Serra Branca & 2504850 COXIXOLA \\
\hline 251550 Serra Branca & 2515500 SERRA BRANCA \\
\hline 251600 Solânea & 2504157 CASSERENGUE \\
\hline 251600 Solânea & 2516003 SOLANEA \\
\hline 251620 Sousa & 2500775 APARECIDA \\
\hline 251620 Sousa & 2509156 MARIZOPOLIS \\
\hline 251620 Sousa & 2513984 SAO FRANCISCO \\
\hline
\end{tabular}


Código Nome do Município em 1991 Código Nome do Município em 2000 1991 Nome do Município em 19912000 Nome do Município em 2000 251620 Sousa 251620 Sousa 251630 Sumé 251630 Sumé 251670 Teixeira 251670 Teixeira 251680 Triunfo 251680 Triunfo 251690 Uiraúna 251690 Uiraúna 251690 Uiraúna 251700 Umbuzeiro 251700 Umbuzeiro 260040 Àgua Preta 260040 Àgua Preta 260390 Carnaíba 260390 Carnaíba 260400 Carpina 260400 Carpina 260570 Floresta 260570 Floresta 260680 Igarassu 260680 Igarassu 260700 Inajá 260700 Inajá 260830 Jupi 260830 Jupi 260920 Maraial 260920 Maraial 260990 Ouricuri 260990 Ouricuri 260990 Ouricuri 261100 Petrolândia 261100 Petrolândia 261110 Petrolina 261110 Petrolina

261190 Rio Formoso 261190 Rio Formoso 261260 Santa Maria da Boa Vista 261260 Santa Maria da Boa Vista 261450 Surubim 261450 Surubim 261450 Surubim

261570 Triunfo

261570 Triunfo 270010 Água Branca 270010 Água Branca

270050 Barra de Santo Antônio

270050 Barra de Santo Antônio 270120 Cacimbinhas 270120 Cacimbinhas 270120 Cacimbinhas 270120 Cacimbinhas 270390 Jundiá 270390 Jundiá 280440 Neópolis 280440 Neópolis 310030 Abre Campo 310030 Abre Campo 310050 Açucena 310050 Açucena 310050 Açucena 310090 Águas Formosas 310090 Águas Formosas 310100 Águas Vermelhas 310100 Águas Vermelhas 310100 Águas Vermelhas 310170 Almenara 310170 Almenara 310170 Almenara 310170 Almenara 310190 Alpinópolis 310190 Alpinópolis 310650 Berilo

310650 Berilo

310660 Bertópolis 310660 Bertópolis 310730 Bocaiúva 310730 Bocaiúva 310730 Bocaiúva 310820 Bonfinópolis de Minas
2516201 SOUSA 2517209 VIEIROPOLIS 2500734 AMPARO

2516300 SUME 2509396 MATUREIA 2516706 TEIXEIRA 2502052 BERNARDINO BATISTA 2516805 TRIUNFO 2512036 POCO DANTAS 2513653 SANTAREM 2516904 UIRAUNA 2513158 SANTA CECILIA 2517001 UMBUZEIRO 2600401 AGUA PRETA 2616506 XEXEU 2603900 CARNAIBA 2604007 CARPINA 2608453 LAGOA DO CARRO 2603926 CARNAUBEIRA DA PENHA 2605707 FLORESTA

2601052 ARACOIABA

2606804 IGARASSU

2607000 INAJA

2609154 MANARI

2608255 JUCATI

2608305 JUPI

2607950 JAQUEIRA

2609204 MARAIAL

2609907 OURICURI

2612455 SANTA CRUZ

2612554 SANTA FILOMENA

2608057 JATOBA

2611002 PETROLANDIA

2605152 DORMENTES

2611903 RIO FORMOSO

2614857 TAMANDARE

2608750 LAGOA GRANDE

2612604 SANTA MARIA DA BOA

2604155 CASINHAS

2614501 SURUBIM

2616183 VERTENTE DO LERIO

2612471 SANTA CRUZ DA BAIXA

2612471 VERDE

2615706 TRIUNFO

2700102 AGUA BRANCA

2706422 PARICONHA

2700508 BARRA DE SANTO

2706448 PARIPUEIRA

2701209 CACIMBINHAS

2702553 ESTRELA DE ALAGOAS

2705309 MINADOR DO NEGRAO

2706307 PALMEIRA DOS INDIOS

2701357 CAMPESTRE

2703908 JUNDIA

2804409 NEOPOLIS

3100302 ABRE CAMPO

3148756 PEDRA BONITA

3100500 ACUCENA

3144359 NAQUE

3149952 PERIQUITO

3100906 AGUAS FORMOSAS

3120151 CRISOLITA

3101003 AGUAS VERMELHAS

3120870 CURRAL DE DENTRO

3122355 DIVISA ALEGRE

3101706 ALMENARA

3122454 DIVISOPOLIS

3140530 MARTINS SOARES

3140555 MATA VERDE

3101904 ALPINOPOLIS

3162948 SAO JOSE DA BARRA

3106507 BERILO

106606 BERTOPOLIS

3157658 SANTA HELENA DE MINAS

3107307 BOCAIUVA

3128253 GUARACIAMA

3145455 OLHOS-D'AGUA

3108206 BONFINOPOLIS DE MINAS 2611533 QUIXABA

2611101 PETROLINA

2806404 SANTANA DO SAO

3136520 JOSE GONCALVES DE

\begin{tabular}{|c|c|}
\hline $\begin{array}{l}\text { Código } \\
1991\end{array}$ & ${ }_{2000}^{\text {Código Nome do Município em } 2000}$ \\
\hline 310820 Bonfinópolis de Minas & 3122470 DOM BOSCO \\
\hline 310820 Bonfinópolis de Minas & 3144375 NATALANDIA \\
\hline 310830 Borda da Mata & 3108305 BORDA DA MATA \\
\hline 310830 Borda da Mata & 3169059 TOCOS DO MOJI \\
\hline 310860 Brasília de Minas & 3108602 BRASILIA DE MINAS \\
\hline 310860 Brasília de Minas & 3111150 CAMPO AZUL \\
\hline 310860 Brasília de Minas & 3135357 JAPONVAR \\
\hline 310860 Brasília de Minas & 3138682 LUISLANDIA \\
\hline 311060 Cambuí & 3110608 CAMBUI \\
\hline 311060 Cambuí & 3165578 SENADOR AMARAL \\
\hline 311080 Campanário & 3110806 CAMPANARIO \\
\hline 311080 Campanário & 3135076 JAMPRUCA \\
\hline 311210 Caparaó & 3102050 ALTO CAPARAO \\
\hline 311210 Caparaó & 3112109 CAPARAO \\
\hline 311230 Capelinha & 3102852 ANGELANDIA \\
\hline 311230 Capelinha & 3112307 CAPELINHA \\
\hline 311330 Carangola & 3113305 CARANGOLA \\
\hline 311330 Carangola & 3125952 FERVEDOURO \\
\hline 311340 Caratinga & 3113404 CARATINGA \\
\hline 311340 Caratinga & 3123858 ENTRE FOLHAS \\
\hline 311340 Caratinga & 3130556 IMBE DE MINAS \\
\hline 311340 Caratinga & 3131158 IPABA \\
\hline 311340 Caratinga & 3150158 PIEDADE DE CARATINGA \\
\hline 311340 Caratinga & $\begin{array}{l}3157252 \text { SANTA BARBARA DO } \\
\text { LESTE }\end{array}$ \\
\hline 311340 Caratinga & 3159357 SANTA RITA DE MINAS \\
\hline 311340 Caratinga & 3170057 UBAPORANGA \\
\hline 311340 Caratinga & 3170578 VARGEM ALEGRE \\
\hline 311840 Conselheiro Pena & 3118403 CONSELHEIRO PENA \\
\hline 311840 Conselheiro Pena & 3120839 CUPARAQUE \\
\hline 311840 Conselheiro Pena & 3127370 GOIABEIRA \\
\hline 311880 Coração de Jesus & 3118809 CORACAO DE JESUS \\
\hline 311880 Coração de Jesus & 3162252 SAO JOAO DA LAGOA \\
\hline 311880 Coração de Jesus & 3162658 SAO JOAO DO PACUI \\
\hline 312000 Córrego Novo & 3120003 CORREGO NOVO \\
\hline 312000 Córrego Novo & 3150539 PINGO-D'AGUA \\
\hline 312200 Divino & 3122009 DIVINO \\
\hline 312200 Divino & 3145877 ORIZANIA \\
\hline 312270 Dom Silvério & 3122702 DOM SILVERIO \\
\hline 312270 Dom Silvério & 3165560 SEM-PEIXE \\
\hline 312430 Espinosa & 3124302 ESPINOSA \\
\hline 312430 Espinosa & 3139250 MAMONAS \\
\hline 312610 Formiga & 3119955 CORREGO FUNDO \\
\hline 312610 Formiga & 3126109 FORMIGA \\
\hline 312650 Francisco Badaró & 3126505 FRANCISCO BADARO \\
\hline 312650 Francisco Badaró & 3135456 JENIPAPO DE MINAS \\
\hline 312730 Galiléia & 3127305 GALILEIA \\
\hline 312730 Galiléia & 3161650 SAO GERALDO DO BAIXIO \\
\hline 312780 Grão Mogol & 3127800 GRAO MOGOL \\
\hline 312780 Grão Mogol & 3136579 JOSENOPOLIS \\
\hline 312780 Grão Mogol & 3146255 PADRE CARVALHO \\
\hline 312930 lapu & 3109253 BUGRE \\
\hline 312930 lарu & 3129301 IAPU \\
\hline 312980 Ibirité & 3129806 IBIRITE \\
\hline 312980 Ibirité & 3140159 MARIO CAMPOS \\
\hline 312980 Ibirité & 3165537 SARZEDO \\
\hline 313010 Igarapé & 3130101 IGARAPE \\
\hline 313010 Igarapé & 3162922 SAO JOAQUIM DE BICAS \\
\hline 313090 Inhapim & 3130903 INHAPIM \\
\hline 313090 Inhapim & $\begin{array}{l}3160959 \text { SAO DOMINGOS DAS } \\
\text { DORES }\end{array}$ \\
\hline 313090 Inhapim & 3164472 SAO SEBASTIAO DO ANTA \\
\hline 313120 Ipanema & 3131208 IPANEMA \\
\hline 313120 Ipanema & 3168051 TAPARUBA \\
\hline 313210 Itacarambi & 3132107 ITACARAMBI \\
\hline 313210 Itacarambi & 3162450 SAO JOAO DAS MISSOES \\
\hline 313230 Itaipé & 3115458 CATUJI \\
\hline 313230 Itaipé & 3132305 ITAIPE \\
\hline 313250 Itamarandiba & 3104452 ARICANDUVA \\
\hline 313250 Itamarandiba & 3132503 ITAMARANDIBA \\
\hline 313320 Itanhomi & 3112653 CAPITAO ANDRADE \\
\hline 313320 Itanhomi & 3133204 ITANHOMI \\
\hline 313400 Itinga & 3134004 ITINGA \\
\hline 313400 Itinga & 3152170 PONTO DOS VOLANTES \\
\hline 313440 Iturama & 3114550 CARNEIRINHO \\
\hline 313440 Iturama & 3134400 ITURAMA \\
\hline 313440 Iturama & 3138625 LIMEIRA DO OESTE \\
\hline 313440 Iturama & 3170438 UNIAO DE MINAS \\
\hline 313510 Janaúba & 3129657 IBIRACATU \\
\hline 313510 Janaúba & 3135100 JANAUBA \\
\hline 313510 Janaúba & 3170909 VARZELANDIA \\
\hline 313510 Janaúba & 3171030 VERDELANDIA \\
\hline 313520 Januária & 3108255 BONITO DE MINAS \\
\hline 313520 Januária & 3117836 CONEGO MARINHO \\
\hline 313520 Januária & 3135209 JANUARIA \\
\hline
\end{tabular}


Código Nome do Município em 1991 Código Nome do Município em 2000 1991 Nome do Município em 19912000 Nome do Município em 2000

313520 Januária 3149150 PEDRAS DE MARIA DA 313600 Joaíma 313600 Joaíma 313630 João Pinheiro 313630 João Pinheiro 313680 Juramento 313680 Juramento 313760 Lagoa Santa 313760 Lagoa Santa 313920 Malacacheta 313920 Malacacheta 313920 Malacacheta 313930 Manga 313930 Manga 313930 Manga 313930 Manga 313930 Manga 313930 Manga 313930 Manga 313940 Manhuaçu 313940 Manhuaçu 313940 Manhuaçu 313940 Manhuaçu 313950 Manhumirim 313950 Manhumirim 313960 Mantena 313960 Mantena 313960 Mantena 314070 Mateus Leme 314070 Mateus Leme 314100 Mato Verde 314100 Mato Verde 314150 Mendes Pimentel 314150 Mendes Pimentel 314170 Mesquita 314170 Mesquita 314180 Minas Novas 314180 Minas Novas 314200 Mirabela 314200 Mirabela 314220 Miraí

314220 Miraí

314390 Muriaé 314390 Muriaé 314860 Peçanha 314860 Peçanha 315210 Ponte Nova 315210 Ponte Nova 315220 Porteirinha 315220 Porteirinha 315220 Porteirinha 315220 Porteirinha 315340 Presidente Olegário 315340 Presidente Olegário 315400 Raul Soares 315400 Raul Soares 315440 Ressaquinha 315440 Ressaquinha 315510 Rio do Prado 315510 Rio do Prado 315540 Rio Novo 315540 Rio Novo 315560 Rio Pardo de Minas 315560 Rio Pardo de Minas 315560 Rio Pardo de Minas 315560 Rio Pardo de Minas 315560 Rio Pardo de Minas 315590 Rio Preto 315590 Rio Preto

315700 Salinas 315700 Salinas 315700 Salinas 315700 Salinas 315720 Santa Bárbara 315720 Santa Bárbara 315820 Santa Maria do Suaçuí 315820 Santa Maria do Suaçuí 316110 São Francisco 316110 São Francisco 316110 São Francisco
3136009 JOAIMA

3143153 MONTE FORMOSO

3108552 BRASILANDIA DE MINAS

3136306 JOAO PINHEIRO

3127354 GLAUCILANDIA

3136801 JURAMENTO

3117876 CONFINS

3137601 LAGOA SANTA

3126752 FRANCISCOPOLIS

3139201 MALACACHETA

3165552 SETUBINHA

3127339 GAMELEIRAS

3135050 JAIBA

3136959 JUVENILIA

3139300 MANGA

3140852 MATIAS CARDOSO

3142254 MIRAVANIA

3142908 MONTE AZUL

3138674 LUISBURGO

3139409 MANHUACU

3154150 REDUTO

3162559 SAO JOAO DO MANHUACU

3123528 DURANDE

3139508 MANHUMIRIM

3139607 MANTENA

3144672 NOVA BELEM

3162575 SAO JOAO DO

3136652 JUATUBA

3115474 CATUTI

3141009 MATO VERDE

3141504 MENDES PIMENTEL

3161056 SAO FELIX DE MINAS

3141702 MESQUITA

3158953 SANTANA DO PARAISO

3138351 LEME DO PRADO

3141801 MINAS NOVAS

3142007 MIRABELA

3147956 PATIS

3142205 MIRAI

3164431 SAO SEBASTIAO DA

VARGEM ALEGRE

3143906 MURIAE

3156452 ROSARIO DA LIMEIRA

3112059 CANTAGALO

3148608 PECANHA

3145851 ORATORIOS

3152105 PONTE NOVA

3145059 NOVA PORTEIRINHA

3146552 PAI PEDRO

3152204 PORTEIRINHA

3166956 SERRANOPOLIS DE MINAS

3137536 LAGOA GRANDE

3153400 PRESIDENTE OLEGARIO

3154002 RAUL SOARES

3171154 VERMELHO NOVO

3101631 ALFREDO VASCONCELOS

3154408 RESSAQUINHA

3146750 PALMOPOLIS

3155108 RIO DO PRADO

3127388 GOIANA

3155405 RIO NOVO

3130655 INDAIABIRA

3143450 MONTEZUMA

3155603 RIO PARDO DE MINAS

3160454 SANTO

3170651 VARGEM GRANDE DO RIO

3155900 RIO PRETO

3157278 SANTA BARBARA DO

3127073 FRUTA DE LEITE

3145372 NOVORIZONTE

3157005 SALINAS

3157377 SANTA CRUZ DE SALINAS

3115359 CATAS ALTAS

3157203 SANTA BARBARA

3136553 JOSE RAYDAN

3158201 SANTA MARIA DO SUACUI

3116159 CHAPADA GAUCHA

3130051 ICARAI DE MINAS

3150570 PINTOPOLIS
3140704 MATEUS LEME

\begin{tabular}{|c|c|}
\hline $\begin{array}{l}\text { Código } \\
1991\end{array}$ & Código Nome do Município em 2000 \\
\hline 316110 São Francisco & 3161106 SAO FRANCISCO \\
\hline 316110 São Francisco & 3170529 URUCUIA \\
\hline 316170 São Gonçalo do Abaeté & 3161700 SAO GONCALO DO ABAETE \\
\hline 316170 São Gonçalo do Abaeté & 3170750 VARJAO DE MINAS \\
\hline 316240 São João da Ponte & 3138658 LONTRA \\
\hline 316240 São João da Ponte & 3162401 SAO JOAO DA PONTE \\
\hline 316270 São João do Paraíso & 3144656 NINHEIRA \\
\hline 316270 São João do Paraíso & 3162708 SAO JOAO DO PARAISO \\
\hline 316350 São José do Jacuri & 3126950 FREI LAGONEGRO \\
\hline 316350 São José do Jacuri & 3163508 SAO JOSE DO JACURI \\
\hline 316420 São Romão & 3154457 RIACHINHO \\
\hline 316420 São Romão & 3164209 SAO ROMAO \\
\hline 316800 Taiobeiras & 3106655 BERIZAL \\
\hline 316800 Taiobeiras & 3168002 TAIOBEIRAS \\
\hline 316860 Teófilo Otoni & 3145356 NOVO ORIENTE DE MINAS \\
\hline 316860 Teófilo Otoni & 3168606 TEOFILO OTONI \\
\hline 316880 Tiradentes & 3157336 SANTA CRUZ DE MINAS \\
\hline 316880 Tiradentes & 3168804 TIRADENTES \\
\hline 316960 Tupaciguara & 3103751 ARAPORA \\
\hline 316960 Tupaciguara & 3169604 TUPACIGUARA \\
\hline 316970 Turmalina & 3169703 TURMALINA \\
\hline 316970 Turmalina & 3171071 VEREDINHA \\
\hline 317000 Ubaí & 3152131 PONTO CHIQUE \\
\hline 317000 Ubaí & 3170008 UBAI \\
\hline 317010 Uberaba & 3121258 DELTA \\
\hline 317010 Uberaba & 3170107 UBERABA \\
\hline 317040 Unaí & 3109451 CABECEIRA GRANDE \\
\hline 317040 Unaí & 3170404 UNAI \\
\hline 317040 Unaí & 3170479 URUANA DE MINAS \\
\hline 317120 Vespasiano & 3162955 SAO JOSE DA LAPA \\
\hline 317120 Vespasiano & 3171204 VESPASIANO \\
\hline 320010 Afonso Cláudio & 3200102 AFONSO CLAUDIO \\
\hline 320010 Afonso Cláudio & 3201159 BREJETUBA \\
\hline 320150 Colatina & 3201506 COLATINA \\
\hline 320150 Colatina & $\begin{array}{l}3204658 \text { SAO DOMINGOS DO } \\
\text { NORTE }\end{array}$ \\
\hline 320190 Domingos Martins & 3201902 DOMINGOS MARTINS \\
\hline 320190 Domingos Martins & 3203346 MARECHAL FLORIANO \\
\hline 320280 Itapemirim & 3202801 ITAPEMIRIM \\
\hline 320280 Itapemirim & 3203320 MARATAIZES \\
\hline 320300 lúna & 3202652 IRUPI \\
\hline 320300 lúna & 3203007 IUNA \\
\hline 320320 Linhares & 3203205 LINHARES \\
\hline 320320 Linhares & 3204708 SAO GABRIEL DA PALHA \\
\hline 320320 Linhares & 3205010 SOORETAMA \\
\hline 320320 Linhares & 3205176 VILA VALERIO \\
\hline 320360 Mucurici & $3203601 \mathrm{MUCURICI}$ \\
\hline 320360 Mucurici & 3204252 PONTO BELO \\
\hline 320390 Nova Venécia & 3203908 NOVA VENECIA \\
\hline 320390 Nova Venécia & 3205150 VILA PAVAO \\
\hline 320460 Santa Teresa & 3204609 SANTA TERESA \\
\hline 320460 Santa Teresa & 3204955 SAO ROQUE DO CANAA \\
\hline 330040 Barra Mansa & 3300407 BARRA MANSA \\
\hline 330040 Barra Mansa & 3304128 QUATIS \\
\hline 330070 Cabo Frio & 3300233 ARMACAO DOS BUZIOS \\
\hline 330070 Cabo Frio & 3300704 CABO FRIO \\
\hline 330090 Cambuci & 3300902 CAMBUCl \\
\hline 330090 Cambuci & 3305133 SAO JOSE DE UBA \\
\hline 330100 Campos dos Goytacazes & 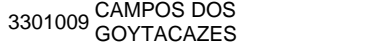 \\
\hline 330100 Campos dos Goytacazes & 3301157 CARDOSO MOREIRA \\
\hline 330110 Cantagalo & 3301108 CANTAGALO \\
\hline 330110 Cantagalo & 3301504 CORDEIRO \\
\hline 330110 Cantagalo & 3302452 MACUCO \\
\hline 330110 Cantagalo & 3305307 SAO SEBASTIAO DO ALTO \\
\hline 330130 Casimiro de Abreu & 3301306 CASIMIRO DE ABREU \\
\hline 330130 Casimiro de Abreu & 3304524 RIO DAS OSTRAS \\
\hline 330190 Itaboraí & 3301900 ITABORAI \\
\hline 330190 Itaboraí & 3305752 TANGUA \\
\hline 330200 Itaguaí & 3302007 ITAGUAI \\
\hline 330200 Itaguaí & 3305554 SEROPEDICA \\
\hline 330240 Macaé & 3300936 CARAPEBUS \\
\hline 330240 Macaé & 3302403 MACAE \\
\hline 330250 Magé & 3301850 GUAPIMIRIM \\
\hline 330250 Magé & 3302502 MAGE \\
\hline 330310 Natividade & 3303104 NATIVIDADE \\
\hline 330310 Natividade & 3306156 VARRE-SAI \\
\hline 330350 Nova Iguaçu & 3300456 BELFORD ROXO \\
\hline 330350 Nova Iguaçu & 3302270 JAPERI \\
\hline 330350 Nova Iguaçu & 3303500 NOVA IGUACU \\
\hline 330350 Nova Iguaçu & 3304144 QUEIMADOS \\
\hline 330400 Piraí & 3303955 PINHEIRAL \\
\hline 330400 Piraí & 3304003 PIRAI \\
\hline 330420 Resende & 3304110 PORTO REAL \\
\hline 330420 Resende & 3304201 RESENDE \\
\hline
\end{tabular}


Código Nome do Município em 1991 Código Nome do Município em 2000 1991 Nome do Município em 19912000 Nome do Município em 2000 330470 Santo Antônio de Pádua 330470 Santo Antônio de Pádua

330500 São João da Barra

330500 São João da Barra 330520 São Pedro da Aldeia 330520 São Pedro da Aldeia 330600 Três Rios

330600 Três Rios

330600 Três Rios

350055 Águas de Santa Bárbara

350055 Águas de Santa Bárbara 350070 Agudos

350070 Agudos

350220 Angatuba

350220 Angatuba

350270 Apiaí

350270 Apiaí

350270 Apiaí

350280 Araçatuba

350280 Araçatuba

350320 Araraquara

350320 Araraquara

350320 Araraquara

350380 Artur Nogueira

350380 Artur Nogueira

350380 Artur Nogueira

350380 Artur Nogueira

350380 Artur Nogueira

350380 Artur Nogueira

350400 Assis

350400 Assis

350490 Bananal

350490 Bananal

350670 Boa Esperança do Su

350670 Boa Esperança do Su

350760 Bragança Paulista

350760 Bragança Paulista

350760 Bragança Paulista

350930 Cajobi

350930 Cajobi

350940 Cajuru

350940 Cajuru

350990 Cananéia

350990 Cananéia

350990 Cananéia

351020 Capão Bonito

351020 Capão Bonito

351110 Catanduva

351110 Catanduva

351250 Coroados

351250 Coroados

351330 Cruzália

351330 Cruzália

351660 Gália

351660 Gália

351690 General Salgado

351690 General Salgado

351690 General Salgado

351800 Guarani d'Oeste

351800 Guarani d'Oeste

351840 Guaratinguetá

351840 Guaratinguetá

351990 lepé

351990 lepé

352190 Itajobi

52190 ltajobi

352220 Itapecerica da Serra

352220 Itapecerica da Serra

352230 Itapetininga

352230 Itapetininga

352240 Itapeva

352240 Itapeva

352240 Itapeva

352320 Itararé

352320 Itararé

352460 Jacupiranga

352460 Jacupiranga
3300159 APERIBE

3304706 SANTO ANTONIO DE

3304755 SAO FRANCISCO DE

3305000 SAO JOAO DA BARRA

3301876 IGUABA GRANDE

3305208 SAO PEDRO DA ALDEIA

3300225 AREAL

3306008 TRES

3500550 AGUAS DE SANTA

3519253 IARAS

3500709 AGUDOS

3536570 PAULISTANIA

3502200 ANGATUBA

3509452 CAMPINA DO MONTE

3509452 ALEGR

3502705 APIAI

3505351 BARRA DO CHAPEU

3522158 ITAOCA

3502804 ARACATUBA

3548054 SANTO ANTONIO DO

3503208 ARARAQUARA

3516853 GAVIAO PEIXOTO

3532058 MOTUCA

3503802 ARTUR NOGUEIRA

3512803 COSMOPOLIS

3515152 ENGENHEIRO COELHO

3519055 HOLAMBRA

3524709 JAGUARIUNA

3504008 ASSIS

3553955 TARUMA

3503158 ARAPEI

3504909 BANANAL

3506706 BOA ESPERANCA DO SUL

3554755 TRABIJU

3507605 BRAGANCA PAULISTA

3554953 TUIUTI

3556354 VARGEM

3509304 CAJOBI

3514957 EMBAUBA

3509403 CAJURU

3546256 SANTA CRUZ DA

3509908 CANANEIA

3520301 IGUAPE

3520426 ILHA COMPRIDA

3510203 CAPAO BONITO

3543253 RIBEIRAO GRANDE

3511102 CATANDUVA

3514924 ELISIARIO

3507753 BREJO ALEGRE

3512506 COROADOS

3513306 CRUZALIA

3537156 PEDRINHAS PAULISTA

3515657 FERNAO

3516606 GALIA

3516903 GENERAL SALGADO

3532868 NOVA CASTILHO

3549250 SAO JOAO DE IRACEMA

3518008 GUARANI D'OESTE

3534757 OUROESTE

3518404 GUARATINGUETA

3540754 POTIM

3519907 IEPE

3532157 NANTES

3521903 ITAJOB

3528858 MARAPOAMA

3522208 ITAPECERICA DA SERRA

3549953 SAO LOURENCO DA SERRA

3500758 ALAMBARI

3522307 ITAPETININGA

3522406 ITAPEVA

3553856 TAQUARIVA

3507159 BOM SUCESSO DE

3523206 ITARARE

3509254 CAJATI

3524600 JACUPIRANGA
3300951 COMENDADOR LEVY

3548005 SANTO ANTONIO DE

3532827 NOVA CAMPINA

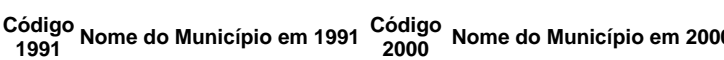

352480 Jales

352480 Jales

352480 Jales

352570 José Bonifácio

352570 José Bonifácio

352680 Lençóis Paulista

352680 Lençóis Paulista

352720 Lorena

352720 Lorena

352740 Lucélia

352740 Lucélia

352840 Mairinque

352840 Mairinque

353070 Mogi-Guaçu

353070 Mogi-Guaçu

353590 Paranapuã

353590 Paranapuã

353740 Pereira Barreto

353740 Pereira Barreto

353740 Pereira Barreto

353870 Piracicaba

353870 Piracicaba

353950 Pitangueiras

353950 Pitangueiras

353960 Planalto

353960 Planalto

354050 Porangaba

354050 Porangaba

354120 Presidente Bernardes

354120 Presidente Bernardes

354280 Ribeira

354280 Ribeira

354340 Ribeirão Preto

354340 Ribeirão Preto

354640 Santa Cruz do Rio Pardo

354640 Santa Cruz do Rio Pardo

354770 Santo Anastácio

354770 Santo Anastácio

354850 Santos

354850 Santos

354900 São Francisco

354900 São Francisco

354980 São José do Rio Preto

354980 São José do Rio Preto

355010 São Manuel

355010 São Manuel

355060 São Roque

355060 São Roque

355240 Sumaré

355240 Sumaré

355260 Tabapuã

355260 Tabapuã

355400 Tatuí

355400 Tatuí

355430 Teodoro Sampaio

355430 Teodoro Sampaio

355430 Teodoro Sampaio

355450 Tietê

355450 Tietê

355490 Três Fronteiras

355490 Três Fronteiras

355500 Tupã

355500 Tupã

355520 Turiúba

355520 Turiúba

355580 Urânia

355580 Urânia

355580 Urânia

355710 Votuporanga

355710 Votuporanga

355720 Chavantes

355720 Chavantes

410040 Almirante Tamandaré

410040 Almirante Tamandaré

410070 Alto Piquiri

410070 Alto Piquir

410260 Barracão

410260 Barracão

410260 Barracão

410260 Barracão

410260 Barracão

410260 Barracão

3524808 JALES

3540259 PONTALINDA

3556958 VITORIA BRASIL

3525706 JOSE BONIFACIO

3555356 UBARANA

3507456 BOREB

3526803 LENCOIS PAULISTA

3509957 CANAS

3527207 LORENA

3527405 LUCELIA

3540853 PRACINHA

3501152 ALUMINIO

3528403 MAIRINQUE

3530706 MOGI GUACU

3557303 ESTIVA GERB

3529658 MESOPOLIS

3535903 PARANAPUA

3520442 ILHA SOLTEIRA

3537404 PEREIRA BARRETO

3552551 SUZANAPOLIS

3538709 PIRACICABA

3545159 SALTINHO

3539509 PITANGUEIRAS

3553658 TAQUARAL

3539608 PLANALTO

3557154 ZACARIAS

3540507 PORANGABA

3554656 TORRE DE PEDRA

3515129 EMILIANOPOLIS

3541208 PRESIDENTE BERNARDES

3522653 ITAPIRAPUA PAULISTA

3542800 RIBEIRA

3518859 GUATAPARA

3543402 RIBEIRAO PRETO

3515194 ESPIRITO SANTO DO

3546405 SANTA

3543238 RIBEIRAO DOS INDIOS

3547700 SANTO ANASTACIO

3506359 BERTIOGA

3548500 SANTOS

3513850 DIRCE REIS

3549003 SAO FRANCISCO

3521150 IPIGUA

3549805 SAO JOSE DO RIO PRETO

3541059 PRATANIA

3550100 SAO MANUEL 
Código Nome do Município em 1991 Código Nome do Município em 2000 1991 Nome do Município em 19912000 Nome do Município em 2000

410310 Bocaiúva do Sul 410310 Bocaiúva do Sul 410380 Cambira 410380 Cambira 410430 Campo Mourão 410430 Campo Mourão 410445 Cantagalo 410445 Cantagalo 410445 Cantagalo

410460 Capitão Leônidas Marques 410460 Capitão Leônidas Marques 410490 Castro

410490 Castro

410520 Cerro Azul

410520 Cerro Azul

410540 Chopinzinho

410540 Chopinzinho

410630 Corbélia

410630 Corbélia

410630 Corbélia

410720 Dois Vizinhos

410720 Dois Vizinhos

410720 Dois Vizinhos

410740 Enéas Marques

410740 Enéas Marques

410740 Enéas Marques

410760 Faxinal

410760 Faxinal

410820 Formosa do Oeste

410820 Formosa do Oeste

410860 Goio-Erê

410860 Goio-Erê

410860 Goio-Erê

410870 Grandes Rios

410870 Grandes Rios

410870 Grandes Rios

410930 Guaraniaçu

410930 Guaraniaçu

410940 Guarapuava

410940 Guarapuava

410940 Guarapuava

410940 Guarapuava

411000 Iguaraçu

411000 Iguaraçu

411010 Imbituva

411010 Imbituva

411040 Indianópolis

411040 Indianópolis

411060 Iporã

411060 Iporã

411150 Ivaiporã

411150 Ivaiporã

411150 Ivaiporã

411250 Jardim Alegre

411250 Jardim Alegre

411330 Laranjeiras do Sul

411330 Laranjeiras do Sul

411330 Laranjeiras do Sul

411330 Laranjeiras do Sul

411330 Laranjeiras do Sul

411370 Londrina

411370 Londrina

411430 Mandirituba

411430 Mandirituba

411440 Mangueirinha

411440 Mangueirinha

411460 Marechal Cândido Rondon

411460 Marechal Cândido Rondon

411460 Marechal Cândido Rondon

411460 Marechal Cândido Rondon

411460 Marechal Cândido Rondon

411490 Marilândia do Sul

411490 Marilândia do Sul

411560 Mateâfndia

411560 Mateâfndia

411580 Medianeira

411580 Medianeira

411600 Miraselva

411600 Miraselva

411760 Palmas
4103107 BOCAIUVA DO SUL

4127882 TUNAS DO PARANA

4103800 CAMBIRA

4117297 NOVO ITACOLOMI

4104303 CAMPO MOURAO

4107553 FAROL

4104451 CANTAGALO

4108650 GOIOXIM

4115457 MARQUINHO

4104600 CAPITAO LEONIDAS

MARQUES

4123824 SANTA LUCIA

4104659 CARAMBEI

4104907 CASTRO

4105201 CERRO AZUL

4128633 DOUTOR ULYSSES

4105409 CHOPINZINHO

4126272 SAUDADE DO IGUACU

4101051 ANAHY

4106308 CORBELIA

4110052 IGUATU

4103024 BOA ESPERANCA DO

4106571 CRUZEIRO DO IGUACU

4107207 DOIS VIZINHOS

4107405 ENEAS MARQUES

4116950 NOVA ESPERANCA DO

SUDOESTE

4123006 SALTO DO LONTRA

4106852 CRUZMALTINA

4107603 FAXINAL

4108205 FORMOSA DO OESTE

4110656 IRACEMA DO OESTE

4108601 GOIOERE

4120655 QUARTO CENTENARIO

4121356 RANCHO ALEGRE D'OESTE

4108700 GRANDES RIOS

4122172 RIO BRANCO DO IVAI

4122651 ROSARIO DO IVAI

4107124 DIAMANTE DO SUL

4109302 GUARANIACU

4103958 CAMPINA DO SIMAO

4104428 CANDOI

4108452 FOZ DO JORDAO

4109401 GUARAPUAVA

4101150 ANGULO

4110003 IGUARACU

4108957 GUAMIRANGA

4110102 IMBITUVA

4110409 INDIANOPOLIS

4125555 SAO MANOEL DO PARANA

4103479 CAFEZAL DO SUL

4110607 IPORA

4101655 ARAPUA

4101853 ARIRANHA DO IVAI

4111506 IVAIPORA

4112504 JARDIM ALEGRE

4113429 LIDIANOPOLIS

4113304 LARANJEIRAS DO SUL

4117057 NOVA LARANJEIRAS

4120150 PORTO BARREIRO

4122156 RIO BONITO DO IGUACU

4128658 VIRMOND

4113700 LONDRINA

4126678 TAMARANA

4107652 FAZENDA RIO GRANDE

4114302 MANDIRITUBA

4109658 HONORIO SERPA

4114401 MANGUEIRINHA

4107538 ENTRE RIOS DO OESTE

4114609 MARECHAL CANDIDO

4115853 MERCEDES

4118451 PATO BRAGADO

4120853 QUATRO PONTES

4114906 MARILANDIA DO SUL

4115754 MAUA DA SERRA

4115606 MATELANDIA

4121257 RAMILANDIA

4115804 MEDIANEIRA

4126355 SERRANOPOLIS DO

4116000 MIRASELVA

4120333 PRADO FERREIRA
4106456 CORONEL DOMINGOS
${ }_{1991}^{\text {Código }}$ Nome do Município em 1991 Código 2000 Nome do Município em 2000

411760 Palmas

411780 Palmital

411780 Palmital

411790 Palotina

411790 Palotina

411820 Paranaguá

411820 Paranaguá

411850 Pato Branco

411850 Pato Branco

411890 Pérola

411890 Pérola

411900 Pérola d'Oeste

411900 Pérola d'Oeste

411900 Pérola d'Oeste

411930 Pinhão

411930 Pinhão

411950 Piraquara

411950 Piraquara

411960 Pitanga

411960 Pitanga

411960 Pitanga

411960 Pitanga

412090 Quedas do Iguaçu

412090 Quedas do Iguaçu

412170 Reserva

412170 Reserva

412170 Reserva

412220 Rio Branco do Sul

412220 Rio Branco do Sul

412240 Rolândia

412240 Rolândia

412320 Santa Cecília do Pavão

412320 Santa Cecília do Pavão

412370 Santa Isabel do Ivaí

412370 Santa Isabel do Ivaí

412440 Santo Antônio do Sudoeste

412440 Santo Antônio do Sudoeste

412570 São Miguel do Iguaçu

412570 São Miguel do Iguaçu

412700 Teixeira Soares

412700 Teixeira Soares

412750 Tibagi

412750 Tibagi

412770 Toledo

412770 Toledo

412810 Umuarama

412810 Umuarama

412810 Umuarama

412810 Umuarama

420010 Abelardo Luz

420010 Abelardo Luz

420010 Abelardo Luz

420010 Abelardo Luz

420010 Abelardo Luz

420010 Abelardo Luz

420010 Abelardo Luz

420080 Anchieta

420080 Anchieta

420080 Anchieta

420080 Anchieta

420080 Anchieta

420080 Anchieta

420080 Anchieta

420080 Anchieta

420080 Anchieta

420080 Anchieta

420100 Anita Garibaldi

420100 Anita Garibaldi

420100 Anita Garibaldi

420130 Araquari

420130 Araquari

420130 Araquari

420140 Araranguá

420140 Araranguá

420210 Barra Velha

420210 Barra Velha

420300 Caçador

420300 Caçador

420360 Campos Novos

420360 Campos Novos

420360 Campos Novos

420360 Campos Novos

4117602 PALMAS

4113254 LARANJAL

4117800 PALMITAL

4115358 MARIPA

4117909 PALOTINA

4118204 PARANAGUA

4119954 PONTAL DO PARANA

4103222 BOM SUCESSO DO SUL

4118501 PATO BRANCO

4107520 ESPERANCA NOVA

4118907 PEROLA

4102752 BELA VISTA DA CAROBA

4119004 PEROLA D'OESTE

4120358 PRANCHITA

4119301 PINHAO

4121752 RESERVA DO IGUACU

4119152 PINHAIS

4119509 PIRAQUARA

4103040 BOA VENTURA DE SAO

4115739 MATO RICO

4119608 PITANGA

4123857 SANTA MARIA DO OESTE

4107546 ESPIGAO ALTO DO IGUACU

4120903 QUEDAS DO IGUACU

4110078 IMBAU

4121703 RESERVA

4127106 TELEMACO BORBA

4111258 ITAPERUCU

4122206 RIO BRANCO DO SUL

4119657 PITANGUEIRAS

4122404 ROLANDIA

4117214 NOVA SANTA BARBARA

4123204 SANTA CECILIA DO PAVAO

4123709 SANTA ISABEL DO IVAI

4123956 SANTA MONICA

4119251 PINHAL DE SAO BENTO

4124400 SANTO ANTONIO DO

2110953 ITAIPULANDIA

4125704 SAO MIGUEL DO IGUACU

4107736 FERNANDES PINHEIRO 
Código Nome do Município em 1991 Código Nome do Município em 2000 1991 Nome do Município em 19912000 Nome do Município em 2000 420360 Campos Novos 420380 Canoinhas 420380 Canoinhas 420400 Catanduvas 420400 Catanduvas 420410 Caxambu do Sul 420410 Caxambu do Sul 420420 Chapecó 420420 Chapecó 420420 Chapecó 420420 Chapecó 420430 Concórdia 420430 Concórdia 420430 Concórdia 420440 Coronel Freitas 420440 Coronel Freitas 420440 Coronel Freitas 420440 Coronel Freitas 420480 Curitibanos 420480 Curitibanos 420480 Curitibanos 420480 Curitibanos 420560 Galvão 420560 Galvão 420810 Itaiópolis 420810 Itaiópolis 420840 Itapiranga 420840 Itapiranga 420840 Itapiranga 420840 Itapiranga 420840 Itapiranga 420850 Ituporanga 420850 Ituporanga 420880 Jaguaruna 420880 Jaguaruna 420900 Joaçaba 420900 Joaçaba 420930 Lages 420930 Lages 420930 Lages 420930 Lages 421050 Maravilha 421050 Maravilha 421050 Maravilha 421050 Maravilha 421050 Maravilha 421050 Maravilha 421050 Maravilha 421050 Maravilha 421050 Maravilha 421050 Maravilha 421050 Maravilha 421050 Maravilha 421050 Maravilha 421070 Matos Costa 421070 Matos Costa 421080 Meleiro 421080 Meleiro 421175 Otacílio Costa 421175 Otacílio Costa 421340 Ponte Serrada 421340 Ponte Serrada 421350 Porto Belo 421350 Porto Belo 421420 Quilombo 421420 Quilombo 421420 Quilombo 421420 Quilombo 421600 São Carlos 421600 São Carlos 421600 São Carlos 421610 São Domingos 421610 São Domingos 421640 São João do Sul 421640 São João do Sul 421660 São José

421660 São José

421670 São José do Cedro 421670 São José do Cedro 421750 Seara 421750 Seara 421750 Seara
4219853 ZORTEA
4202131 BELA VISTA DO TOLDO 4203808 CANOINHAS

4204004 CATANDUVAS

4219176 VARGEM BONITA

4204103 CAXAMBU DO SUL 4213153 PLANALTO ALEGRE 4204202 CHAPECO

4204350 CORDILHEIRA ALTA

4206652 GUATAMBU

4211454 NOVA ITABERABA

4200754 ALTO BELA VISTA

4201273 ARABUTA

4204301 CONCORDIA

4200556 AGUAS FRIAS

4204400 CORONEL FREITAS

4208955 JARDINOPOLIS

4218855 UNIAO DO OESTE

4204806 CURITIBANOS

4205555 FREI ROGERIO

4213351 PONTE ALTA DO NORTE

4216057 SAO CRISTOVAO DO SUL

4205605 GALVAO

4209177 JUPIA

4208104 ITAIOPOLIS

4215679 SANTA TEREZINHA

4208401 ITAPIRANGA

4211009 MONDAI

4215075 RIQUEZA

4216255 SAO JOAO DO OESTE

4218756 TUNAPOLIS

4204194 CHAPADAO DO LAGEADO

4208500 ITUPORANGA

4208807 JAGUARUNA

4215455 SANGAO

4209003 JOACABA

4210035 LUZERNA

4202438 BOCAINA DO SUL

4203253 CAPAO ALTO

4209300 LAGES

4211892 PAINEL

4202578 BOM JESUS DO OESTE

4203501 CAMPO ERE

4205357 FLOR DO SERTAO

4210506 MARAVILHA

4210902 MODELO

4211652 NOVO HORIZONTE

4215356 SALTINHO

4215687 SANTA TEREZINHA DO

4215752 SAO BERNARDINO

4216909 SAO LOURENCO DO

4217154 SAO MIGUEL DA BOA VISTA

4217758 SUL BRASIL

4217956 TIGRINHOS

4203154 CALMON

4210704 MATOS COSTA

4210803 MELEIRO

4211256 MORRO GRANDE

4212056 PALMEIRA

4212270 PASSOS MAIA

4213401 PONTE SERRADA

4202453 BOMBINHAS

4213500 PORTO BELO

4205431 FORMOSA DO SUL

4207858 IRATI

4214201 QUILOMBO

4215695 SANTIAGO DO SUL

4204756 CUNHATAI

4216008 SAO CARLOS

4217303 SAUDADES

4204459 CORONEL MARTINS

4216107 SAO DOMINGOS

4212254 PASSO DE TORRES

4216404 SAO JOAO DO SUL

4216602 SAO JOSE

4217253 SAO PEDRO DE

4214151 PRINCESA

4216701 SAO JOSE DO CEDRO

4201653 ARVOREDO

4208005 ITA

4211876 PAIAL
4211751 OTACILIO COSTA
${ }_{1991}^{\text {Código }}$ Nome do Município em 1991 Código 2000 Nome do Município em 2000

421750 Seara

421760 Siderópolis

421760 Siderópolis

421770 Sombrio

421770 Sombrio

421780 Taió

421780 Taió

421790 Tangará

421790 Tangará

421860 Trombudo Central

421860 Trombudo Central

421870 Tubarão

421870 Tubarão

421880 Turvo

421880 Turvo

421890 Urubici

421890 Urubici

421900 Urussanga

421900 Urussanga

421930 Videira

421930 Videira

421970 Xaxim

421970 Xaxim

430005 Água Santa

430005 Água Santa

430005 Água Santa

430005 Água Santa

430005 Água Santa

430005 Água Santa

430005 Água Santa

430005 Água Santa

430005 Água Santa

430005 Água Santa

430005 Água Santa

430005 Água Santa

430005 Água Santa

430005 Água Santa

430005 Água Santa

430005 Água Santa

430005 Água Santa

430005 Água Santa

430005 Água Santa

430005 Água Santa

430005 Água Santa

430005 Água Santa

430005 Água Santa

430005 Água Santa

430020 Ajuricaba

430020 Ajuricaba

430030 Alecrim

430030 Alecrim

430030 Alecrim

430030 Alecrim

430040 Alegrete

430040 Alegrete

430040 Alegrete

430070 Anta Gorda

430070 Anta Gorda

430070 Anta Gorda

430090 Aratiba

430090 Aratiba

430100 Arroio do Meio

430100 Arroio do Meio

430100 Arroio do Meio

430100 Arroio do Meio

430120 Arroio do Tigre

430120 Arroio do Tigre

430140 Arvorezinha

430140 Arvorezinha

430150 Augusto Pestana

430150 Augusto Pestana

430150 Augusto Pestana

430155 Áurea

430155 Áurea

430160 Bagé

430160 Bagé

430160 Bagé

430160 Bagé

430165 Barão

430165 Barão

430165 Barão

430165 Barão

430165 Barão

430165 Barão

4217501 SEARA

4217600 SIDEROPOLIS

4218350 TREVISO

4202073 BALNEARIO GAIVOTA

4217709 SOMBRIO

4210852 MIRIM DOCE

4217808 TAIO

4206751 IBIAM

4217907 TANGARA

4202859 BRACO DO TROMBUDO

4218608 TROMBUDO CENTRAL

4203956 CAPIVARI DE BAIXO

4218707 TUBARAO

4205191 ERMO

4218806 TURVO

4215059 RIO RUFINO

4218905 URUBICI

4204251 COCAL DO SUL

4219002 URUSSANGA

4207577 IOMERE

4219309 VIDEIRA

4209458 LAJEADO GRANDE

4219705 XAXIM

4300059 AGUA SANTA

4301958 BARRA FUNDA

4304705 CARAZINHO

4305306 CHAPADA

4305504 CIRIACO

4305850 COQUEIROS DO SUL

4305975 COXILHA

4306304 DAVID CANABARRO

4308854 GENTIL

4309902 IBIRAIARAS

4311270 LAGOA DOS TRES CANTOS

4311809 MARAU

4312138 MATO CASTELHANO

4312625 MULITERNO

4312658 NAO-ME-TOQUE

4312674 NICOLAU VERGUEIRO 

Código
1991 430165 Barão 430165 Barão 430165 Barão

430170 Barão de Cotegipe 430170 Barão de Cotegipe 430170 Barão de Cotegipe 430190 Barra do Ribeiro 430190 Barra do Ribeiro 430190 Barra do Ribeiro 430190 Barra do Ribeiro 430190 Barra do Ribeiro 430190 Barra do Ribeiro 430190 Barra do Ribeiro 430190 Barra do Ribeiro 430190 Barra do Ribeiro 430190 Barra do Ribeiro 430190 Barra do Ribeiro 430190 Barra do Ribeiro 430190 Barra do Ribeiro 430200 Barros Cassal 430200 Barros Cassal 430200 Barros Cassal 430200 Barros Cassal 430200 Barros Cassal 430200 Barros Cassal 430200 Barros Cassa 430220 Boa Vista do Buricá 430220 Boa Vista do Buricá 430220 Boa Vista do Buricá 430230 Bom Jesus 430230 Bom Jesus 430240 Bom Retiro do Sul 430240 Bom Retiro do Sul 430270 Butiá 430270 Butiá 430300 Cachoeira do Sul 430300 Cachoeira do Sul 430300 Cachoeira do Sul 430320 Cacique Doble 430320 Cacique Doble 430320 Cacique Doble 430320 Cacique Doble 430370 Campina das Missões 430370 Campina das Missões 430370 Campina das Missõe 430370 Campina das Missões 430370 Campina das Missões 430370 Campina das Missões 430400 Campo Novo 430400 Campo Novo 430400 Campo Novo 430400 Campo Novo 430400 Campo Novo 430400 Campo Novo 430460 Canoas 430460 Canoas 430463 Capão da Canoa 430463 Capão da Canoa 430490 Casca

430490 Casca

430500 Catuípe 430500 Catuípe 430500 Catuípe 430510 Caxias do Sul 430510 Caxias do Sul 430510 Caxias do Sul 430510 Caxias do Sul 430510 Caxias do Sul 430510 Caxias do Sul 430510 Caxias do Sul 430510 Caxias do Sul 430510 Caxias do Sul 430510 Caxias do Sul 430510 Caxias do Sul 430510 Caxias do Sul 430510 Caxias do Sul 430510 Caxias do Sul 430515 Cerro Grande 430515 Cerro Grande 430515 Cerro Grande 430515 Cerro Grande 430515 Cerro Grande 430515 Cerro Grande 430515 Cerro Grande
4312385 MONTE BELO DO SUL 4315800 ROCA SALES

4317251 SANTA TEREZA

4301701 BARAO DE COTEGIPE

4310900 JACUTINGA

4300851 ARAMBARE

4301750 BARAO DO TRIUNFO

4301909 BARRA DO RIBEIRO

4303509 CAMAQUA

4305173 CERRO GRANDE DO SUL

4305447 CHUVISCA

4306502 DOM FELICIANO

4309308 GUAIBA

4311981 MARIANA PIMENTEL

4318408 SAO JERONIMO

4320354 SENTINELA DO SUL

4320552 SERTAO SANTANA

4321105 TAPES

4302006 BARROS CASSAL

4304200 CANDELARIA

4309159 GRAMADO XAVIER

4309571 HERVEIRAS

4316808 SANTA CRUZ DO SUL

4320677 SINIMBU

4322533 VALE DO SOL

4302204 BOA VISTA DO BURICA

4306007 CRISSIUMAL

4313011 NOVA CANDELARIA

4302303 BOM JESUS

4302402 BOM RETIRO DO SUL

4308078 FAZENDA VILANOVA

4302709 BUTIA

4312252 MINAS DO LEAO

4303004 CACHOEIRA DO SUL

4305132 CERRO BRANCO

4313391 NOVO CABRAIS

4303202 CACIQUE DOBLE

4317954 SANTO EXPEDITO DO SUL

4318606 SAO JOSE DO OURO

4322186 TUPANCI DO SUL

4303707 CAMPINA DAS MISSOES

4309001 GIRUA

4309506 GUARANI DAS MISSOES

4320321 SENADOR SALGADO FILHO

4320578 SETE DE SETEMBRO

4322343 UBIRETAMA

4302378 BOM PROGRESSO

4304002 CAMPO NOVO

4307450 ESPERANCA DO SUL

4309704 HUMAITA

4321477 TIRADENTES DO SUL

4321907 TRES PASSOS

4304606 CANOAS

4313375 NOVA SANTA RITA

4304630 CAPAO DA CANOA

4323804 XANGRI-LA

4304903 CASCA

4317558 SANTO ANTONIO DO

4305009 CATUIPE

4305405 CHIAPETA

4310413 INHACORA

4300570 ALTO FELIZ

4305108 CAXIAS DO SUL

4306403 DOIS IRMAOS

4308102 FELIZ

4310801 IVOT

4311627 LINDOLFO COLLOR

4311643 LINHA NOVA

4312476 MORRO REUTER

4313201 NOVA PETROPOLIS

4314423 PICADA CAFE

4315149 PRESIDENTE LUCENA

4316956 SANTA MARIA DO HERVAL

4318481 SAO JOSE DO HORTENCIO 4322541 VALE REAL

4302154 BOA VISTA DAS MISSOES

4305157 CERRO GRANDE

4310850 JABOTICABA

4311429 LAJEADO DO BUGRE

4313490 NOVO BARREIRO

4313706 PALMEIRA DAS MISSOES

4316428 SAGRADA FAMILIA
4314787 PONTE PRETA

4318622 SAO JOSE DOS AUSENTES
${ }_{1991}^{\text {Código Nome do Município em } 1991 \text { Código }} 2000$ Nome do Município em 2000

430515 Cerro Grande

430520 Cerro Largo

430520 Cerro Largo

430520 Cerro Largo

430545 Cidreira

430545 Cidreira

430580 Constantina

430580 Constantina

430620 Cruzeiro do Sul

430620 Cruzeiro do Sul

430620 Cruzeiro do Sul

430620 Cruzeiro do Sul

430620 Cruzeiro do Sul

430620 Cruzeiro do Sul

430620 Cruzeiro do Sul

430645 Dois Lajeados

430645 Dois Lajeados

430730 Erval Seco

430730 Erval Seco

430740 Esmeralda

430740 Esmeralda

430740 Esmeralda

430740 Esmeralda

430740 Esmeralda

430740 Esmeralda

430800 Faxinal do Soturno

430800 Faxinal do Soturno

430820 Flores da Cunha

430820 Flores da Cunha

430880 General Câmara

430880 General Câmara

430890 Getúlio Vargas

430890 Getúlio Vargas

430890 Getúlio Vargas

430890 Getúlio Vargas

430890 Getúlio Vargas

430940 Guaporé

430940 Guaporé

431050 Iraí

431050 Iraí

431050 Iraí

431050 Iraí

431050 Iraí

431050 Iraí

431050 Iraí

431060 Itaqui

431060 Itaqui

431120 Júlio de Castilhos

431120 Júlio de Castilhos

431120 Júlio de Castilhos

431120 Júlio de Castilhos

431240 Montenegro

431240 Montenegro

431240 Montenegro

431260 Muçum

431260 Muçum

431270 Nonoai

431270 Nonoai

431270 Nonoai

431306 Nova Hartz

431306 Nova Hartz

431306 Nova Hartz

431350 Osório

431350 Osório

431365 Palmares do Sul

431365 Palmares do Sul

431380 Palmitinho

431380 Palmitinho

431420 Pedro Osório

431420 Pedro Osório

431440 Pelotas

431440 Pelotas

431440 Pelotas

431570 Rio Pardo

431570 Rio Pardo

431650 Salvador do Sul

431650 Salvador do Sul

431690 Santa Maria

431690 Santa Maria

431690 Santa Maria

431690 Santa Maria

431730 Santa Vitória do Palmar

4318457 SAO JOSE DAS MISSOES 4305207 CERRO LARGO

4316477 SALVADOR DAS MISSOES

4319372 SAO PEDRO DO BUTIA

4301636 BALNEARIO PINHAL

4305454 CIDREIRA

4305801 CONSTANTINA

4306924 ENGENHO VELHO

4306205 CRUZEIRO DO SUL

4311403 LAJEADO

4312054 MARQUES DE SOUZA

4312153 MATO LEITAO

4316758 SANTA CLARA DO SUL

4320453 SERIO

4322608 VENANCIO AIRES

4306452 DOIS LAJEADOS

4319711 SAO VALENTIM DO SUL

4306429 DOIS IRMAOS DAS

DSOES

4307302 ERVAL SECO

4303673 CAMPESTRE DA SERRA

4307401 ESMERALDA

4311304 LAGOA VERMELHA

4312377 MONTE ALEGRE DOS

CAMPOS

4312617 MUITOS CAPOES

4322509 VACARIA

4308003 FAXINAL DO SOTURNO

4318432 SAO JOAO DO POLESINE

4308201 FLORES DA CUNHA

4313086 NOVA PADUA

4308805 GENERAL CAMARA

4322525 VALE VERDE

4305371 CHARRUA

4308250 FLORIANO PEIXOTO

4308904 GETULIO VARGAS

4320909 TAPEJARA

4323358 VILA LANGARO 

Código
1991 Nome do Município em $1991 \stackrel{\text { Código }}{2000}$ Nome do Município em 2000

431730 Santa Vitória do Palmar 4317301 SANTA VITORIA DO
PALMAR 431740 Santiago

431740 Santiago

431750 Santo Ângelo

431750 Santo Ângelo

431760 Santo Antônio da Patrulha

431760 Santo Antônio da Patrulha

431770 Santo Antônio das Missões

431770 Santo Antônio das Missões

431770 Santo Antônio das Missões

431780 Santo Augusto

431780 Santo Augusto

431780 Santo Augusto

431830 São Gabriel

431830 São Gabriel

431830 São Gabriel

431940 São Pedro do Sul

431940 São Pedro do Sul

431970 São Valentim

431970 São Valentim

432070 Sobradinho

432070 Sobradinho

432080 Soledade

432080 Soledade

432130 Taquar

432130 Taquar

432140 Tenente Portela

432140 Tenente Portela

432140 Tenente Portela

432150 Torres

432150 Torres

432150 Torres

432150 Torres

432150 Torres

432180 Três de Maio

432180 Três de Maio

432210 Tucunduva

432210 Tucunduva

432210 Tucunduva

432210 Tucunduva

432220 Tupanciretã

432220 Tupanciretã

432240 Uruguaiana

432240 Uruguaiana

432290 Viadutos

432290 Viadutos

500330 Coxim

500330 Coxim

500470 Ivinhema

500470 Ivinhema

500568 Mundo Novo

500568 Mundo Novo

500660 Ponta Porã

500660 Ponta Porã

500720 Rio Brilhante

500720 Rio Brilhante

500720 Rio Brilhante

510025 Alta Floresta

510025 Alta Floresta

510025 Alta Floresta

510025 Alta Floresta

510025 Alta Floresta

510025 Alta Floresta

510025 Alta Floresta

510025 Alta Floresta

510130 Arenápolis

510130 Arenápolis

510130 Arenápolis

510170 Barra do Bugres

510170 Barra do Bugres

510170 Barra do Bugres

510170 Barra do Bugres

510170 Barra do Bugres

510170 Barra do Bugres

510170 Barra do Bugres

510263 Campo Novo do Parecis

510263 Campo Novo do Parecis

510270 Canarana

510270 Canarana

510270 Canarana

510270 Canarana
4317400 SANTIAGO

4322376 UNISTALDA

4317509 SANTO ANGELO

4323754 VITORIA DAS MISSOES

4304713 CARAA

4308656 GARRUCHOS

4317707 SANTO ANTONIO DAS

4318002 SAO BORJA

4317806 SANTO AUGUSTO

4319109 SAO MARTINHO

4319737 SAO VALERIO DO SUL

4318309 SAO GABRIEL

4319604 SAO SEPE

4319406 SAO PEDRO DO SUL

4321493 TOROPI

4319703 SAO VALENTIM

4314068 PASSA SETE

4320701 SOBRADINHO

4312427 MORMACO

4320800 SOLEDADE

4320859 TABAI

4321303 TAQUARI

4301859 BARRA DO GUARITA

4306320 DERRUBADAS

4321402 TENENTE PORTELA

4306551 DOM PEDRO DE

4311734 MAMPITUBA

4312443 MORRINHOS DO SUL

4321501 TORRES

4321832 TRES FORQUILHAS

4318499 SAO JOSE DO INHACORA

4321808 TRES DE MAIO

4313425 NOVO MACHADO

4315057 PORTO MAUA

4322103 TUCUNDUVA

4322301 TUPARENDI

4311130 JARI

4322202 TUPANCIRETA

4301875 BARRA DO QUARA

4322400 URUGUAIANA

4304853 CARLOS GOMES

4322905 VIADUTOS

5000252 ALCINOPOLIS

5003306 COXIM

5004700 IVINHEMA

5006259 NOVO HORIZONTE DO SUL

5004809 JAPORA

5005681 MUNDO NOVO

5005251 LAGUNA CARAPA

5006002 NOVA ALVORADA DO SUL

5007208 RIO BRILHANTE

5007901 SIDROLANDIA

5100250 ALTA FLORESTA

5100805 APIACAS

5102793 CARLINDA

5105101 JUARA

5106158 NOVA BANDEIRANTES

5106802 PORTO DOS GAUCHOS

5107941 TABAPORA

5108956 NOVA MONTE VERDE

5101308 ARENAPOLIS

5107263 SANTO AFONSO

5108857 NOVA MARILANDIA

5101704 BARRA DO BUGRES

5102504 CACERES

5103957 GLORIA D'OESTE

5105234 LAMBARI D'OESTE

5105622 MIRASSOL D'OESTE

5106851 PORTO ESTRELA

5107206 RIO BRANCO

5102637 CAMPO NOVO DO PARECIS

5107875 SAPEZAL

5100359 ALTO BOA VISTA

5102694 CANABRAVA DO NORTE

5102702 CANARANA

5106778 PORTO ALEGRE DO NORTE
4317608 SANTO ANTONIO DA

4323457 VILA NOVA DO SUL

4302055 BENJAMIN CONSTANT DO

5006606 PONTA PORA
${ }_{1991}^{\text {Código }}$ Nome do Município em $1991 \underset{2000}{\text { Código }}$ Nome do Município em 2000

510270 Canarana 5107065 QUERENCIA

510270 Canarana 5107180 RIBEIRAO CASCALHEIRA

510270 Canarana

510305 Cláudia

510305 Cláudia

510305 Cláudia

510305 Cláudia

510305 Cláudia

510320 Colíder

510320 Colíder

510320 Colíder

510320 Colíder

510330 Comodoro

510330 Comodoro

510330 Comodoro

510330 Comodoro

510360 Dom Aquino

510360 Dom Aquino

510360 Dom Aquino

510410 Guarantã do Norte

510410 Guarantã do Norte

510420 Guiratinga

510420 Guiratinga

510420 Guiratinga

510517 Juruena

510517 Juruena

510530 Luciara

510530 Luciara

510620 Nova Brasilândia

510620 Nova Brasilândia

510620 Nova Brasilândia

510620 Nova Brasilândia

510670 Ponte Branca

510670 Ponte Branca

510730 São José do Rio Claro

510730 São José do Rio Claro

510777 Santa Terezinha

510777 Santa Terezinha

510820 Torixoreu

510820 Torixoreu

510850 Vera

510850 Vera

510850 Vera

520150 Aporé

520150 Aporé

520180 Aragoiânia

520180 Aragoiânia

520180 Aragoiânia

520180 Aragoiânia

520180 Aragoiânia

520320 Barro Alto

520320 Barro Alto

520320 Barro Alto

520330 Bela Vista de Goiás

520330 Bela Vista de Goiás

520500 Carmo do Rio Verde

520500 Carmo do Rio Verde

520580 Corumbá de Goiás

520580 Corumbá de Goiás

520640 Crixás

520640 Crixás

520800 Formosa

520800 Formosa

520840 Goinápolis

520840 Goinápolis

520880 Goianira

520880 Goianira

520910 Goiatuba

520910 Goiatuba

521120 Itapuranga

521120 Itapuranga

521150 Itumbiara

521150 Itumbiara

521190 Jataí

521190 Jataí

521190 Jataí

521250 Luziânia

521250 Luziânia

521250 Luziânia

521250 Luziânia

521270 Mambaí

521270 Mambaí

521280 Mara Rosa

5103056 CLAUDIA

5105580 MARCELANDIA

5107248 SANTA CARMEM

5107909 SINOP

5108303 UNIAO DO SUL

5103205 COLIDER

5106422 PEIXOTO DE AZEVEDO

5108055 TERRA NOVA DO NORTE

5108808 NOVA GUARITA

5102686 CAMPOS DE JULIO

5103304 COMODORO

5105507 VILA BELA DA SANTISSIMA

5106182 NOVA LACERDA

5103601 DOM AQUINO

5104807 JACIARA

5107404 SAO PEDRO DA CIPA

5104104 GUARANTA DO NORTE

5106265 NOVO MUNDO

5104203 GUIRATINGA

5107297 SAO JOSE DO POVO

5107602 RONDONOPOLIS

5103379 COTRIGUACU

5105176 JURUENA

5105309 LUCIARA

5107354 SAO JOSE DO XINGU

5103858 GAUCHA DO NORTE

5106208 NOVA BRASILANDIA

5106307 PARANATINGA

5106455 PLANALTO DA SERRA

5106703 PONTE BRANCA

5107198 RIBEIRAOZINHO

5107305 SAO JOSE DO RIO CLARO

5108907 NOVA MARINGA

5103353 CONFRESA

5107776 SANTA TEREZINHA

5106653 PONTAL DO ARAGUAIA

5108204 TORIXOREU

5103700 FELIZ NATAL

5106240 NOVA UBIRATA

5108501 VERA 


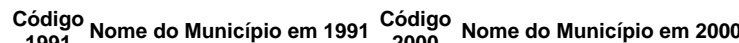
1991 Nome do Município em 19912000 Nome do Município em 2000

521280 Mara Rosa 5200829 AMARALINA

521280 Mara Rosa

5212808 MARA ROSA

521280 Mara Rosa

5214879 NOVA IGUACU DE GOIAS

521390 Mossâmedes

5203939 BURITI DE GOIAS

521390 Mossâmedes

521710 Piracanjuba

5213905 MOSSAMEDES

521710 Piracanjuba $\quad 5218391$ PROFESSOR JAMIL

521730 Pirenópolis 5217302 PIRENOPOLIS

521730 Pirenópolis 5222302 VILA PROPICIO

521800 Porangatu 5203575 BONOPOLIS

521800 Porangatu 5218003 PORANGATU

521880 Rio Verde 5205059 CASTELANDIA

521880 Rio Verde 5218805 RIO VERDE

521880 Rio Verde 5219712 SANTO ANT

521975 Santo Antônio do Descoberto 5200258 AGUAS LINDAS DE GOIAS

521975 Santo Antônio do Descoberto 5219753 SANTO ANTONIO DO

521990 São Francisco de Goiás

5212055 JESUPOLIS

521990 São Francisco de Goiás

5219902 SAO FRANCISCO DE GOIAS

522145 Trombas

5213772 MONTIVIDIU DO NORTE

522145 Trombas 5221452 TROMBAS 


\section{APÊNDICE F - DEDUÇÃO DAS ELASTICIDADES}

Este apêndice apresenta em detalhes a dedução das fórmulas de elasticidade da pobreza utilizadas neste trabalho.

\section{F.1 - Elasticidades para Linha Absoluta de Pobreza}

Considerando a hipótese de que a distribuição da renda $y$ é log-normal, ou seja, $x=\ln$ (y) segue uma distribuição normal com média $\mu$ e variância $\sigma^{2}$, a média de $y$ é:

$$
\bar{y}=\exp \left(\mu+\frac{1}{2} \sigma^{2}\right)
$$

Com isso, podemos definir a medida de pobreza através da incidência de pobreza. Sendo a proporção da população com renda abaixo da linha absoluta de pobreza $z_{a}$, esta medida corresponde à probabilidade da renda $Y$ ser menor do que a linha de pobreza, conforme a seguir:

$H=\operatorname{Pr}\left(Y<z_{a}\right) \equiv \mathrm{F}\left(z_{a}\right)$,

onde $\mathrm{F}($.$) pode ser definida de acordo com a equação a seguir, em que Hoffmann (2004)$ apresenta a proporção de pobres $(H)$, para uma dada linha de pobreza $z_{a}$, como:

$H=\Phi\left(\frac{\ln z_{a}-\mu}{\sigma}\right)$

onde $\Phi($.$) é a função de distribuição acumulada da normal-padrão.$

Assim, isolando $\mu$ na equação (F1) e substituindo em (F3), segue-se que:

$H=\Phi\left(\frac{1}{2} \sigma+\frac{\ln \left(z_{a} / \bar{y}\right)}{\sigma}\right)$

que é a proporção de pobres, assumindo que a distribuição de renda é log-normal, de acordo com Bourguignon (2002) e Epaulard (2003). 


\section{F.1.1- Elasticidades a partir do Índice de Gini}

As elasticidades da pobreza com relação à renda e desigualdade, a partir da proporção de pobres $(H)$ e da fórmula do índice de Gini para a distribuição log-normal, seguem Hoffmann (2004).

Considerando que o índice de Gini para a distribuição log-normal é:

$$
G=2 \Phi\left(\frac{\sigma}{\sqrt{2}}\right)-1
$$

é possível estabelecer a proporção de pobres $(H)$ como função da renda média $(\bar{y})$ e do índice de Gini $(G)$.

Para a dedução da elasticidade-renda da pobreza, ou seja, da elasticidade de $\mathrm{H}$ com relação à $\bar{y}$, derivemos a equação $(\mathrm{F} 4)$ :

$$
\frac{\partial H}{\partial \bar{y}}=-\frac{1}{\sigma \cdot \bar{y}} \cdot \phi\left(\frac{1}{2} \sigma+\frac{\ln \left(z_{a} / \bar{y}\right)}{\sigma}\right) \text {. }
$$

Sendo a elasticidade-renda da pobreza:

$$
\varepsilon_{y}=\frac{\partial H}{\partial \bar{y}} \cdot \frac{\bar{y}}{H}
$$

e substituindo $\mathrm{H}$ pela equação (F4), temos:

$$
\varepsilon_{y}=-\frac{1}{\sigma} \cdot \frac{\phi\left(\frac{1}{2} \sigma+\frac{\ln \left(z_{a} / \bar{y}\right)}{\sigma}\right)}{\Phi\left(\frac{1}{2} \sigma+\frac{\ln \left(z_{a} / \bar{y}\right)}{\sigma}\right)},
$$

que é apresentada em Bourguignon (2002) através da função de taxa de risco $\lambda($.) que é a razão da função de densidade pela função de distribuição acumulada. ${ }^{22}$

Já a elasticidade de H com relação ao índice de Gini é obtida a partir da derivação da equação (F4) com relação a $\mathrm{G}$, da seguinte forma:

$$
\frac{\partial H}{\partial G}=\frac{\partial H}{\partial \sigma} \frac{\partial \sigma}{\partial G}=\left(\frac{1}{2}-\frac{\ln \left(z_{a} / \bar{y}\right)}{\sigma^{2}}\right) \cdot \phi\left(\frac{1}{2} \sigma+\frac{\ln \left(z_{a} / \bar{y}\right)}{\sigma}\right) \cdot \frac{\partial \sigma}{\partial G} \text {. }
$$

Como o cálculo do termo $\frac{\partial \sigma}{\partial G}$ não é trivial, utilizamos uma regra de diferenciação válida quando a função é inversível:

\footnotetext{
${ }^{22}$ Bourguignon (2002) mostra esta elasticidade em módulo como sendo $\varepsilon_{y}=\frac{1}{\sigma} \cdot \lambda\left(\frac{\ln \left(z_{a} / \bar{y}\right)}{\sigma}+\frac{1}{2} \sigma\right)$.
} 
$\frac{\partial \sigma}{\partial G}=\frac{1}{\frac{\partial G}{\partial \sigma}}$

Para tanto, precisamos provar que $\mathrm{G}(\sigma)$, dado pela equação (F5), é uma função inversível. Inicialmente, derivemos $\mathrm{G}$ com relação a $\sigma$ :

$$
\frac{\partial G}{\partial \sigma}=\sqrt{2} \cdot \phi\left(\frac{\sigma}{\sqrt{2}}\right)>0 \text {. }
$$

Qualquer que seja o valor de $\sigma$, a função de densidade da distribuição normal-padrão é maior do que zero e, conseqüentemente, $G$ é uma função monotonamente crescente. Geometricamente, isto significa que a inclinação da função $\mathrm{G}(\sigma)$ é sempre positiva. Logo, G é uma função inversível e vale a relação (F10).

Utilizando (F9), (F10) e (F11), na equação da elasticidade-desigualdade da pobreza, temos:

$\varepsilon_{G}=\frac{\partial H}{\partial G} \cdot \frac{G}{H}=\frac{G \cdot\left(\frac{1}{2}-\frac{\ln \left(z_{a} / \bar{y}\right)}{\sigma^{2}}\right)}{H \cdot \sqrt{2} \cdot \phi\left(\frac{\sigma}{\sqrt{2}}\right)} \cdot \phi\left(\frac{1}{2} \sigma+\frac{\ln \left(z_{a} / \bar{y}\right)}{\sigma}\right)$.

Substituindo H pela equação (F4), temos:

$$
\varepsilon_{G}=\frac{G \cdot\left(\frac{1}{2}-\frac{\ln \left(z_{a} / \bar{y}\right)}{\sigma^{2}}\right)}{\sqrt{2} \cdot \phi\left(\frac{\sigma}{\sqrt{2}}\right)} \cdot \frac{\phi\left(\frac{1}{2} \sigma+\frac{\ln \left(z_{a} / \bar{y}\right)}{\sigma}\right)}{\Phi\left(\frac{1}{2} \sigma+\frac{\ln \left(z_{a} / \bar{y}\right)}{\sigma}\right)},
$$

que é a elasticidade-desigualdade com o índice de Gini usada neste trabalho.

\section{F.1.2- Elasticidades a partir do Índice de Theil}

A análise da variação de $H$ com relação à desigualdade por ser feita adotando o índice de Theil como medida de desigualdade. Hoffmann (2004) cita que o próprio Theil (1967) definiu o índice de Theil para a distribuição log-normal como:

$$
T=\frac{\sigma^{2}}{2}
$$


Utilizando este índice, a equação da elasticidade-renda da pobreza é a igual à deduzida no sub-item anterior, porém o desvio-padrão $\sigma$ passa a ser função de $T$, de acordo com a equação (F14).

Para a dedução da elasticidade-desigualdade da pobreza utilizando o índice de Theil, partimos da derivação da equação (F4) com relação a $T$, conforme a seguir:

$$
\frac{\partial H}{\partial T}=\frac{\partial}{\partial T}\left[\Phi\left(\frac{1}{2} \sqrt{2 T}+\frac{\ln \left(z_{a} / \bar{y}\right)}{\sqrt{2 T}}\right)\right] .
$$

Desenvolvendo esta derivada parcial, chegamos a:

$$
\frac{\partial H}{\partial T}=\left[\frac{1}{2 \sigma}-\frac{\ln \left(z_{a} / \bar{y}\right)}{\sigma^{3}}\right] \cdot \phi\left(\frac{1}{2} \sigma+\frac{\ln \left(z_{a} / \bar{y}\right)}{\sigma}\right) .
$$

Pela fórmula da elasticidade-desigualdade da pobreza, temos:

$$
\varepsilon_{G}=\frac{\partial H}{\partial T} \cdot \frac{T}{H}=\frac{\sigma^{2}}{2 H}\left[\frac{1}{2 \sigma}-\frac{\ln \left(z_{a} / \bar{y}\right)}{\sigma^{3}}\right] \cdot \phi\left(\frac{1}{2} \sigma+\frac{\ln \left(z_{a} / \bar{y}\right)}{\sigma}\right) .
$$

Substituindo $H$ pela equação (F4), temos:

$$
\varepsilon_{G}=\left[\frac{\sigma}{4}-\frac{\ln \left(z_{a} / \bar{y}\right)}{2 \sigma}\right] \cdot \frac{\phi\left(\frac{1}{2} \sigma+\frac{\ln \left(z_{a} / \bar{y}\right)}{\sigma}\right)}{\Phi\left(\frac{1}{2} \sigma+\frac{\ln \left(z_{a} / \bar{y}\right)}{\sigma}\right)},
$$

que é a elasticidade-desigualdade com o índice de Theil usada neste trabalho.

Todas as elasticidades deduzidas neste item são iguais às utilizadas em Hoffmann (2004). Vale destacar apenas que este trabalha com a relação $m=\bar{y} / z_{a}$, o que inverte os sinais dos termos com logaritmo natural. Já com relação a Bourguignon (2002), apenas é possível observar que a elasticidade-renda é igual a deduzida neste trabalho, porém não é possível comparar a elasticidade-desigualdade uma vez que não é explicitada.

\section{F.2 - Estimação da Elasticidade-Renda com Linha Híbrida de Pobreza}

As elasticidades deduzidas no item anterior consideram a variação sobre a pobreza medida a partir de uma linha absoluta, ou seja, captam os efeitos crescimento e distribuição sobre uma dada linha de pobreza. Contudo, utilizando uma linha híbrida de pobreza, incluí-se 
um efeito da mudança da linha em consequiência de uma variação da renda relativa. Este efeito, é na verdade uma consequiência do efeito crescimento. Assim, o efeito crescimento econômico influência não somente a pobreza como também sua medida de mensuração.

A partir da especificação da equação (27), temos:

$\ln p_{i t}=\alpha_{i}+\alpha_{t}+\beta_{1} \ln r_{i t}+\beta_{2} \ln d_{i t}+\beta_{3} \ln Z h_{i t}+\varepsilon_{i t}$

onde $p_{i t}$ é a proporção de pobres medida por uma linha híbrida de pobreza; $\alpha_{i}$ é o efeito individual não observado do município $i ; \alpha_{t}$ é o termo constante em cada período; $r_{i t}$ é a renda familiar per capita do município $i$ no período $t ; d_{i t}$ é o índice de desigualdade de renda do município $i$ em $t ; Z h_{i t}$ é a linha híbrida de pobreza segundo a especificação da equação (4), e $\varepsilon_{i t}$ é o resíduo da regressão.

Com isso, podemos calcular a elasticidade-renda da pobreza com linha híbrida $\left(\varepsilon_{\mathrm{r}}\right)$, da seguinte forma:

$$
\begin{aligned}
& \varepsilon_{\mathrm{r}}=\frac{\partial \ln p_{i t}}{\partial \ln r_{i t}}= \\
& =\frac{\partial \ln p_{i t}(r, \bar{z})}{\partial \ln r_{i t}}+\frac{\partial \ln p_{i t}(\bar{r}, z)}{\partial \ln r_{i t}}=23 \\
& =\frac{\partial \ln p_{i t}(r, \bar{z})}{\partial \ln r_{i t}}+\frac{\partial \ln p_{i t}(\bar{r}, z)}{\partial \ln Z h_{i t}} \cdot \frac{\partial \ln Z h_{i t}}{\partial \ln r_{i t}}= \\
& =\beta_{1}+\beta_{3} \cdot \frac{\partial \ln Z h_{i t}}{\partial \ln r_{i t}}= \\
& =\beta_{1}+\beta_{3} \cdot \frac{\partial \ln \left(Z a_{i t}^{1-\rho_{t}} \cdot Z r_{i t}^{\rho_{t}}\right)}{\partial \ln r_{i t}}= \\
& =\beta_{1}+\beta_{3} \cdot\left[\frac{\partial \ln \left(Z a_{i t}^{1-\rho_{t}}\right)}{\partial \ln r_{i t}}+\frac{\partial \ln \left(Z r_{i t}^{\rho_{t}}\right)}{\partial \ln r_{i t}}\right]= \\
& =\beta_{1}+\beta_{3} \cdot\left\{\frac{\partial\left[\left(1-\rho_{t}\right) \cdot \ln Z a_{i t}\right]}{\partial \ln r_{i t}}+\frac{\partial\left(\rho_{t} \cdot \ln Z r_{i t}\right)}{\partial \ln r_{i t}}\right\}= \\
& =\beta_{1}+\beta_{3} \cdot\left[\left(1-\rho_{t}\right) \cdot \frac{\partial \ln Z a_{i t}}{\partial \ln r_{i t}}+\rho_{t} \cdot \frac{\partial \ln Z r_{i t}}{\partial \ln r_{i t}}\right]={ }^{24}
\end{aligned}
$$

\footnotetext{
${ }^{23} \mathrm{O}$ termo da derivação para $p_{i t}(\bar{r}, \bar{z}, d)$ é zero.

${ }^{24}$ Como $\rho_{t}$ é único para o País em cada período de tempo, consideramos que não é função de ln $r_{i t}$ que varia no tempo e entre municípios. Além disso, na diferenciação da linha absoluta de pobreza $\mathrm{Za}_{\mathrm{it}}$, assumimos que esta linha não varia devido à ln $r_{i t}$ no tempo, apesar de sofrer alteração pela renda para um dado período de tempo (ver estimação de $\rho_{t}$ ).
} 
$=\beta_{1}+\beta_{3} \cdot\left[\rho_{t} \cdot \frac{\partial \ln \left(\alpha \bar{r}_{i t}\right)}{\partial \ln r_{i t}}\right]=25$

$=\beta_{1}+\beta_{3} \cdot \rho_{t} \cdot\left[\frac{\partial \ln \alpha}{\partial \ln r_{i t}}+\frac{\partial \ln \bar{r}_{i t}}{\partial \ln r_{i t}}\right]=$

$=\beta_{1}+\beta_{3} \cdot \rho_{t} \cdot\left[\frac{\partial \ln \bar{r}_{i t}}{\partial \ln r_{i t}}\right]=$

$\varepsilon_{\mathrm{r}}=\beta_{1}+\beta_{3} \cdot \rho_{t}$

${ }^{25}$ Consideramos que a linha relativa de pobreza $\left(Z r_{i t}\right)$ é função da renda média $\left(\bar{r}_{i t}\right)$, sendo representada por $Z r_{i t}$ $=\alpha \overline{r_{i t}}$ onde $\alpha$ é um percentual da renda média. 